\title{
Neuroimmune and molecular aspects of antidepressants
}

Citation for published version (APA):

Kenis, G. R. L. (2004). Neuroimmune and molecular aspects of antidepressants. [Doctoral Thesis, Maastricht University]. Datawyse / Universitaire Pers Maastricht. https://doi.org/10.26481/dis.20041111gk

Document status and date:

Published: 01/01/2004

DOI:

10.26481/dis.20041111gk

Document Version:

Publisher's PDF, also known as Version of record

\section{Please check the document version of this publication:}

- A submitted manuscript is the version of the article upon submission and before peer-review. There can be important differences between the submitted version and the official published version of record.

People interested in the research are advised to contact the author for the final version of the publication, or visit the DOI to the publisher's website.

- The final author version and the galley proof are versions of the publication after peer review.

- The final published version features the final layout of the paper including the volume, issue and page numbers.

Link to publication

\footnotetext{
General rights rights.

- You may freely distribute the URL identifying the publication in the public portal. please follow below link for the End User Agreement:

www.umlib.nl/taverne-license

Take down policy

If you believe that this document breaches copyright please contact us at:

repository@maastrichtuniversity.nl

providing details and we will investigate your claim.
}

Copyright and moral rights for the publications made accessible in the public portal are retained by the authors and/or other copyright owners and it is a condition of accessing publications that users recognise and abide by the legal requirements associated with these

- Users may download and print one copy of any publication from the public portal for the purpose of private study or research.

- You may not further distribute the material or use it for any profit-making activity or commercial gain

If the publication is distributed under the terms of Article $25 \mathrm{fa}$ of the Dutch Copyright Act, indicated by the "Taverne" license above, 
Neuroimmune and molecular aspects of antidepressants

Gunter Kenis 
(C) G.R.L. Kenis, Maastricht 2004

Neuroimmune and molecular aspects of antidepressants.

ISBN: $90-5278-440-X$

Universitaire Pers Maastricht

Production: Datawyse 


\title{
Neuroimmune and molecular aspects of antidepressants
}

\author{
PROEFSCHRIFT
}

ter verkrijging van de graad van doctor aan de Universiteit Maastricht op gezag van de Rector Magnificus, Prof. mr. G. P. M. F. Mols, volgens het besluit van het College van Decanen in het openbaar te verdedigen op donderdag 11 november 2004 om 16.00 uur

door

\section{Gunter Robert Leo Kenis}

geboren op 8 maart 1972 te Diest (België)

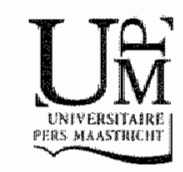




\section{Promotores}

Prof. dr. M. Maes

Prof. dr. H.W.M. Steinbusch

\section{Co-promotor}

Dr. M. De Baets

\section{Beoordelingscommissie}

Prof. dr. E.J.L. Griez (voorzitter)

Prof. dr. J. Korf (Rijksuniversiteit Groningen)

Prof. dr. B.E. Leonard (National University of Ireland, Galway)

Dr. N. Nicolson

Prof. dr. F.C.S. Ramaekers

The publication of this thesis was financially supported by 'Het Van Leersumfonds' of the Royal Dutch Academy of Sciences (KNAW). 


\title{
Contents
}

\author{
Chapter 1
}

General introduction

Chapter 2

Effects of antidepressants on the production of cytokines

\section{Chapter 3}

Stability of interleukin-6, soluble interleukin-6 receptor, interleukin- 10 and $\mathrm{CC} 16$ in human serum

Chapter 4

Anti-inflammatory effects of antidepressants through suppression of the interferon- $\gamma /$ interleukin- 10 production ratio

\section{Chapter 5}

Effects of serotonin and serotonergic agonists and antagonists on the production of interferon- $\gamma$ and interleukin-10

\section{Chapter 6}

Cytokine production in stimulated whole blood after modulation of the cAMP/PKA-pathway

\section{Chapter 7}

Role of the CAMP/PKA-pathway in the anti-inflammatory effects of paroxetine and imipramine in human whole blood and peripheral blood mononuclear cells

Influence of antidepressants on intracellular levels of cyclic adenosine monophosphate in human peripheral blood mononuclear cells 
Imipramine inhibits interleukin-6 and tumor necrosis factor- $\alpha$ production in primary rat whole brain cell cultures

Chapter 10

General discussion

Summary

Samenvating

Curriculum vitae 


Cllingrer

General introduction 


\section{MAJOR DEPRESSION}

\subsection{General}

Everyone now and then feels unhappy or sad, or experiences feelings of depressed mood. However, this everyday sadness does not resemble the clinical features of major depression. The latter is characterized by persistent depressed mood, lack of enjoyment or inability to experience pleasure (anhedonia), reduced energy, pessimistic thoughts, feelings of worthlessness and inappropriate guilt, anxiety and slowness (psychomotor retardation). In addition, the patient may display vegetative symptoms such as reduced appetite, weight loss and sleep disturbances. Depressed patients are often not able to work or to perform normal daily activities. Furthermore, a great deal of patients suffers from suicidal ideation and a number of them actually commit suicide. Thus, major depression is a highly disabling and life-threatening disease that affects both the patient and the persons in his/her environment.

According to the Global Burden of Disease study, conducted by the World Health Organization, the World Bank and Harvard University in the early 1990's, major depression is the leading cause of disability world-wide, and second to ischaemic heart disease in the Western world. The study predicted that by the year 2020 unipolar major depression is the major cause of years lost due to disability throughout the developing regions of the world (Murray and Lopez, 1996). In addition, mental illnesses in general outrank all other causes of disability in the United States, Canada and Western Europe (Iglehart, 2004).

The life-time prevalence of major depression is estimated as high as $16.1 \%$, and affects twice as many women as men (Doris et al., 1999). The "burden" of this disease is further highlighted by its chronic course. A Dutch study pointed out that newly originated episodes of major depression had a median duration of 3 months. Twenty percent of the patients did not recover within 24 months (Spijker et al., 2002).

Despite the development of new antidepressants, about $30 \%$ of patients do not respond to the first treatment. Eventually, about $10 \%$ of patients stay refractory to antidepressant treatment. Although the side effect profile of the second generation antidepressants has markedly improved, they still display uncomfortable side effects. Moreover, there is a delay in the onset of clinical improvement of depressive symptoms after starting antidepressant therapy.

The above indicates that the search for better antidepressants, with an improved side effect profile, a faster onset of action, and which are useful in treatment resistant patients, remains open. The major obstacles for designing and developing better antidepressants is the lack of reliable animal models of 
depression, and the fact that the exact pathophysiology of major depression has not been resolved.

Several hypothesis concerning the aetiopathogenesis of major depression have been formulated, but so far, no conclusive evidence for one of them has emerged. A summary of the most important biological disturbances that could be relevant for the pathophysiology of major depression is given below.

\subsection{Biological findings in major depression}

The first biological systems proposed to underlie major depression were the monoamines. This hypothesis was primarily based on the fact that the first discovered antidepressants (mono-amine oxidase inhibitors and tricyclic antidepressants) increased brain concentrations of monoamines, especially those of serotonin and noradrenaline. Moreover, all parts of the limbic system, which is implicated in the control of emotions, mood, anxiety and cognition, are strongly innervated and regulated by both the serotonergic and noradrenergic system (Ressler and Nemeroff, 2000).

There is no conclusive direct evidence for a deficiency in either serotonin or noradrenaline in depressed patients. However some findings strongly suggest a role of serotonin in major depression (Maes and Meltzer, 1995; Smith and Cowen, 1997), namely: 1) the availability of L-tryptophan (the precursor of serotonin) to the brain is lower in depressed patients, and 2) remitted patients treated with antidepressants that primarily target the serotonergic system show a relapse of depressive symptoms after taking a tryptophan-free diet. Further, evidence from challenge studies indicate that $5 \mathrm{HT}_{2}$-receptors may be upregulated (i.e. supersensitive), whereas 5-HT1A-receptors may be downregulated (in number or density) in depressed patients. Moreover, treatment with antidepressants may restore these abnormalities in 5-HT-receptor function (Smith and Cowen, 1997).

Evidence for a role of noradrenaline in major depression comes from the observation that chemical depletion of catecholamines may induce depressivelike symptoms, which can be reversed by several antidepressants that target the noradrenergic system (Anand and Channey, 1997). Although some studies suggest that both $\alpha_{2}$-adrenergic and $\beta$-adrenergic receptors may be downregulated in depressed patients, these findings are still a matter of debate (Schatzberg and Schildkraut, 1995; Anand and Charney, 1997). However, down-regulation of both receptors is the most consistent effect of antidepressant treatment in clinical and pre-clinical studies (Anand and Charney, 1997).

Despite the useful information that emerged from the intensive research on the role of monoaminergic neurotransmitter systems in major depression, it is of limited value in elucidating the exact pathophysiology of the disease. Major 
depression arises from the complex interaction of multiple susceptibility genes and environmental factors. Moreover, although most antidepressants exert their initial effect by increasing intrasynaptic monoamine concentrations, their clinical antidepressant effects occurs only after chronic treatment (2-8 weeks). This indicates that downstream adaptational mechanisms are necessary for the therapeutic effect.

One of the most consistent biological findings in major depression is the hyperactivity of the hypothalamic-pituitary-adrenal (HPA)-axis. This neuroendocrine system regulates physiological responses to stress by controlling the release of corticosteroids. Hypothalamic secretion of corticotropin releasing hormone (CRH) stimulates the pituitary to release adrenocorticotropic hormone (ACTH) which is released in the blood stream. ACTH triggers the secretion of glucocorticoids (i.e. cortisol in humans) by the adrenal cortex. Cortisol ultimately inhibits its own secretion through a negative feedback mechanism by binding with glucocorticoid receptors (GRs) in the hypothalamus and pituitary, thereby inhibiting the release of CRH and ACTH respectively. Hyperactivity of the HPA-axis in major depression is characterized by: 1) increased concentrations of cortisol in plasma, urine, saliva and cerebrospinal fluid of depressed patients, 2) an enhanced cortisol response to ACTH, and 3) increased concentrations of CRH in cerebrospinal fluid. Dysfunction of the glucocorticoid receptor in the hypothalamus has been implicated in HPA-axis hyperactivity in major depression. This is supported by the notion that administration of the synthetic glucocorticoid dexamethasone fails to suppress cortisol secretion in depressed patients. Some studies suggest that antidepressants enhance glucocorticoid receptor function and may thus restore this "glucocorticoid resistance" (Pariante and Miller, 2001).

It has long been recognized that major depression shows a high co-morbidity with other physical diseases such as cardiovascular disease, auto-immune disorders (e.g. rheumatoid arthritis, multiple sclerosis) and chronic infectious diseases (Irwin, 2002). Therefore, the status of immune function in depressed patients has been subject of intense investigation. Changes in several aspects of the immune system have been described. Early reports described that major depression is associated with a decrease in Natural Killer Cell activity and a lowered proliferative response of lymphocytes to mitogen stimulation (Herbert and Cohen, 1993; Zorrilla et al., 2001). Depressed patients also had lower numbers of circulating lymphocytes. Although these findings point to a state of immunosuppression in depressed patients, other immune variables show an activation of certain aspects of the immune system. Indeed, it is now clear that major depression is accompanied by an activation of the inflammatory response system (Maes, 1999). Evidence for this includes: 1) increased numbers of circulating monocytes and neutrophils; 2) increased numbers of circulating 
activated lymphocytes; 3 ) the presence of an acute phase response, with positive acute phase proteins (such as haptoglobin) being upregulated (for review see Maes, 1999; Zorrilla et al., 2001). Furthermore, several studies found that major depressed patients had higher levels of pro-inflammatory cytokines in their serum or plasma. The ex-vivo production of these molecules is also enhanced. Pro-inflammatory cytokines have dramatic effects on brain function and neuroendocrine homeostasis, and profoundly affect behaviour in animals and humans. It has therefore been proposed that pro-inflammatory cytokines play an important role in the pathophysiology of major depression. This will be dealt with in detail below, but first an introduction to the nature and physiology of the cytokine network is presented.

\section{CYTOKINES AND MAJOR DEPRESSION}

\subsection{General features of cytokines}

Cytokines are small $(15-44 \mathrm{kD})$ glycoproteins, primarily secreted by immune cells, but also endothelial, epithelial, and neuronal cells can produce them. They interact with a specific membrane-bound receptor on target cells. Given the large number of known cytokines (probably many more to be discovered) and the diverse functions attributed to each of them, classification of cytokines is still obscure. Nevertheless, when examining systemic activity of the immune system in depressed patients, differentiation in 2 major groups is justified, namely pro-inflammatory and anti-inflammatory cytokines. Pro-inflammatory cytokines are mainly produced by activated immune cells and stimulate others, and, thereby, enhance inflammatory reactions. Anti-inflammatory cytokines on the other hand, tend to inhibit activated cells and temper inflammatory responses.

Monocytes and macrophages, activated by the recognition of pathogens, produce a diverse array of pro-inflammatory cytokines such as interleukin-1 (IL-1), tumor necrosis factor- $\alpha$ (TNF- $\alpha$ ), IL-6 and IL-12, IL-1 and TNF- $\alpha$ promote inflammatory reactions, i.e. they stimulate other monocytes/macrophages and neutrophils to migrate to the site of infection and to phagocytosis. IL-6 activates lymphocytes and induces B-cells to differentiate to antibody producing plasma cells. After the initial activation, monocytes/macrophages also produce anti-inflammatory cytokines or proteins such as IL-10 and IL-1 Receptor antagonist (IL-IRA). IL-10 is a major deactivator of activated monocytes/macrophages, lymphocytes and neutrophils, and directly inhibits pro-inflammatory cytokine production. IL-1 RA binds the IL-1 receptor and blocks the action of IL- 1 . Thus, the major monocytic pro- 
inflammatory cytokines are IL-1, TNF-o and IL-6 and are as such indicative for an activation of the monocytic arm of the immune system.

Activated T-lymphocytes can be divided in two major groups according the cytokines they produce, namely $\mathrm{T}$-helper-1 (Th1) and Th2-cells. Th1-cells mainly produce interferon- $\gamma$ (IFN- $\gamma$ ), IL-2 and TNF- $\beta$; Th2-cells produce IL-4, IL-5, and IL-10. These cytokines have differential functions, i.e. Thl cytokines stimulate cell-mediated immunity (CMI) whereas Th2 cytokines promote humoral immunity. CMI is characterized by the activation of monocytes/macrophages, neutrophils, cytotoxic T-cells (Tc-cells) and the stimulation of $\mathrm{B}$-cells to produce opsonizing antibodies (and thus facilitating phagocytic activity). For example, IFN- $\gamma$ (produced by Thl-cells) stimulates macrophages to phagocytosis; IL-2 further stimulates Th1-cells and induces Tccells to cytotoxic activity. On the other hand, IL-4 and IL-5 from Th2-cells mainly stimulate $B$-cells to produce non-opsonizing antibodies like $\operatorname{lgE}$, and activate eosinophils, basophils and mast cells, which release several allergic mediators. In addition, Thl and Th2 responses are mutually exclusive, i.e. IFN$\gamma$ inhibits Th2-cells, whereas IL-4 and IL-10 inhibit Th1-cells. This results in a polarization of the phenotype of the immune response. This phenotype is determined by the kind of microbial antigen and the micro-environment at the time of immune activation. For more information on Th1/Th2-responses and the accompanying cytokines, see Abbas et al. (1996).

It is clear that the concepts pro/anti-inflammatory and Th1/Th2-cytokines are more or less overlapping. Pro-inflammatory cytokines induce the production of Th1 cytokines, which have by themselves pro-inflammatory capacities; Th2 cytokines are anti-inflammatory and inhibit Th1 and/or pro-inflammatory cytokine production. One exception in this respect is IL-6. It has many proinflammatory properties, but is, besides monocytes/macrophages, produced by Th2-celis. Nevertheless, IL-6 is an important activator of the inflammatory response system. A major aspect of IRS is the acute phase response, which is predominantly induced by IL-6.

As mentioned before, cytokines act through specific membrane bound receptors. Some of these receptors can be released in a soluble form in the circulation. In most cases, they are shed from the cell membrane of activated leukocytes. For example, the soluble IL-2 receptor (sIL-2R) is shed from activated T-cells. As such, increased levels of sIL-2R indicates ongoing T-cell activation. Soluble cytokine receptors usually act as antagonists, since they prevent the respective cytokine from binding with its receptor on the target cell. Again, IL-6 is an exception to this rule. The IL-6/sIL-6R complex in serum can bind to gp 130 , a membrane-bound molecule that mediates IL-6 signaling. Therefore, sIL-6R can enhance the biological activity of circulating IL-6. 


\subsection{Neuroimmunology: cytokine-brain interaction}

Although cytokines have long been implicated in the regulation of the immune response, it is now clear that they play (together with other aspects of the immune system) a central role in homeostasis of the whole body. Nowadays, the immune system is regarded as a sense organ that, through the release of cytokines, communicates the status of peripheral infection and injury to the brain. As such, cytokines perform important regulatory functions, not only on the immune system, but for example also on brain function, endocrine and neuro-endocrine regulation, cardiovascular functioning and the reproductive system.

Concerning the central nervous system, all brain cells (both glial and neuronal cells) express various cytokine receptors and are capable of producing cytokines (Vitkovic et al., 2000; Szelenyi, 2001). There is a specific bi-directional communication between the immune system and the brain. Cytokines produced by peripheral immune cells affect brain neurotransmission and neurotransmitter turn-over (Linthorst and Reul, 1998). Various pro-inflammatory cytokines also increase HPA-axis activity at all levels (Dunn, 2000).

Several possible pathways by which peripherally produced cytokines influence brain function have been described (Connor and Leonard, 1998; Maier and Watkins, 1998). First, although the size of the cytokines prevents diffusion through the blood-brain-barrier (BBB), passive transport across the BBB is possible at locations where a functional $B B B$ is absent (i.e. the circumventricular organs). This mechanism could be particularly relevant when high concentrations of circulating cytokines are involved (e.g. in the case of cytokine therapy). In addition, active transport mechanism for some cytokines have been described, but their exact physiological role remains elusive. Second, circulating cytokines can induce cytokine production within the brain by interacting with receptors on vascular endothelial cells, that respond with de novo production of cytokines or other inflammatory intermediates, such as prostaglandin $\mathrm{E}_{2}\left(\mathrm{PGE}_{2}\right)$, that can enter the brain. In this way, cytokine production can spread through the brain parenchyma. Third, it has been shown that i) cytokines can trigger the afferent fibres of the vagus nerve; ii) stimulation of the vagus nerve induces cytokine production in several brain areas; iii) sectioning of the vagus nerve abrogates behavioural and neurochemical responses to peripheral administration of cytokines or endotoxin (for review see Maier et all, 1998). Thus, the effects of peripheral cytokines on the central nervous system are, at least in part, mediated by afferent neuronal pathways.

On the other hand, peripheral immune responses are controlled by the central nervous system. Immune cells express a broad array of neurotransmitter receptors and transporters (Gordon and Barnes, 2003). Lymphoid organs and 
the spleen (which are important centers for immune regulation) are strongly innervated by efferent nerves of the sympathetic nervous system. These nerve terminals release noradrenaline and neuropeptides that strongly influence the nature of the ongoing immune response. For example, noradrenaline produces a shift in the Th1/Th2-balance, by inhibiting Th1- and promoting Th2-responses (Elenkov et al., 2000). Recently, it has been reported that the efferent vagus nerve, through the release of acetylcholine, influences the release of cytokines by activated macrophages (Pavlov et al., 2003; Wang et al., 2003).

\subsection{The cytokine hypothesis of major depression}

The notion that pro-inflammatory cytokines may underlie psychiatric disorders, especially major depression, comes from both human studies and animal experiments. As mentioned before, there is evidence that depressed patients suffer from an ongoing inflammatory reaction. One aspect of this is that higher concentrations of circulating pro-inflammatory cytokines such as IL-6, IL-1 $\beta$ and TNF- $\alpha$ are found in depressed patients (Maes et al., 1997; Lanquillon et al., 2000; Mikova et al., 2001; Owen et al., 2001). Also ex-vivo production of these cytokines is increased (Seidel et al., 1995, 1996). Whether these proinflammatory cytokines contribute to the pathophysiology of major depression has long been (and still is) a matter of debate, but strong evidence favours this hypothesis. Indeed, administration of pro-inflammatory cytokines to humans (e.g. in the treatment of persistent viral infections or malignancies) induces depressive symptoms and even clinical major depression in previously psychiatrically healthy patients (Capuron et al., 2000). Also a moderate activation of the cytokine system induces cognitive and mood disturbances in healthy volunteers, even in the absence of physiological signs of sickness (Reichenberg et al, 2001). Many diseases that are associated with a hypersecretion of pro-inflammatory cytokines (e.g. cancer, chronic infections, atherosclerosis, auto-immune disorders) have a high co-morbidity with major depression (Pollak and Yirmiya, 2002). In animals, pro-inflammatory cytokines provoke "sickness-behaviour", a syndrome that resembles many clinical. features of major depression, such as anhedonia, psychomotor retardation, reduced social exploration, decreased appetite, anorexia and sleep disturbances (Dantzer, 2001). Moreover, antidepressants and anti-inflammatory cytokines (such as IL-10 and IL-1RA) efficiently attenuate or completely prevent these cytokine-induced depressive symptoms (Dantzer, 2001; Musselman et al., 2001).

Several mechanisms that may underlie cytokine-induced depression have been proposed. First, virtually all pro-inflammatory cytokines are known activators of the HPA-axis (Dunn, 2000; Haddad et al, 2002), resulting in adrenal 
hypersecretion of corticosteroids. As mentioned above, hyperactivity of the HPA-axis is implicated in the aetiology of major depression. On the other hand, corticosteroids are known to inhibit cytokine production and temper several facets of immune activation. Thus, sustained increases in circulating corticosteroids should reduce cytokine secretion. However, it has recently been shown that pro-inflammatory cytokines decrease glucocorticoid receptor function, and may induce glucocorticoid resistance (Pariante et al., 1999; Pariante and Miller, 2001). Thus, pro-inflammatory cytokines disturb the negative feed-back mechanism of glucocorticoids. This results in a sustained HPA-axis hyperactivity and a continuous secretion of pro-inflammatory cytokines.

Secondly, cytokines have dramatic effects on brain neurotransmission and neurotransmitter turn-over. Regarding this subject, most studies report that acute administration of cytokines or inflammatory stimuli (i.e. LPS) increase serotonin and noradrenaline secretion and turn-over, thereby facilitating serotonergic and noradrenergic neurotransmission (Linthorst and Reul, 1998; Dunn et al., 1999). Although these data seem less compatible with the monoamine hypothesis of depression, it has been proposed that chronic administration will result in mono-amine depletion and, hence, in a disturbance of monoaminergic neurotransmission (Pollak and Yirmiya, 2002). Another, indirect mechanism of cytokine effects on serotonergic neurotransmission, implicates the enzyme indoleamine 2,3 dioxygenase (IDO), which catalyses the breakdown of tryptophan through the kynurenine pathway. Pro-inflammatory cytokines (especially $\mathbb{I F N}-\gamma$, TNF- $\alpha$ ) up-regulate both the transcription and activity of IDO, leading to depletion of circulating tryptophan, and thus to decreased serotonin synthesis. In addition, it has been proposed that (neuro-)toxic metabolites of kynurenine contribute to neurodegeneration, hippocampal atrophy and neuropsychiatric disorders (for review see Wichers and Maes, 2004).

Although further investigations are required, the cytokine hypothesis of major depression offers an alternative explanation for the multi-factorial pathophysiology of the disease. It states that a moderate, but chronic hypersecretion of pro-inflammatory cytokines induces alterations in both neurological and neuro-endocrine networks, resulting in depressed mood and in several depression-related vegetative and somatic disturbances. 


\section{ANTIDEPRESSANTS}

\subsection{Different classes of antidepressants}

Although the nature of major depression has been described for many centuries (starting by the Greek philosopher Hippocrates), an efficient and biological directed treatment for the disease was only introduced in 1938, when patients were treated with electroconvulsive therapy. Pharmacological treatment became available when antidepressants were serendipitously discovered in the 1950's. The first antidepressants were clearly effective in reducing the depressive symptomatology, but displayed a broad range of (sometimes dangerous) side effects. With the introduction of fluoxetine (Prozac ${ }^{3}$ ), a number of other socalled "second generation" antidepressants became available. The major advantage of these drugs over the first generation antidepressants was their better side effect profile. However, as mentioned before, clinical efficiency has only slightly improved. This despite the fact that psychiatrists now have of a number of antidepressants, with different proposed mechanisms of action, at their disposal.

Classification of antidepressants is based on their primary mechanism of action, except for the group of tricyclic antidepressants (TCAs), which are classified according their chemical structure. Table 1 presents the major classes of antidepressants with the most important substances of each class and their primary mechanism of action. Most antidepressants increase the availability of neurotransmitters (usually serotonin and/or noradrenaline) in the synaptic cleft, either by blocking the reuptake of the neurotransmitter in the presynaptic neuron, or by inhibiting the enzymes responsible for the neurotransmitter breakdown in the synaptic cleft. Selective Serotonin Reuptake Inhibitors (SSRIs) block the reuptake of serotonin, while Selective Noradrenaline Reuptake Inhibitors (NRIs) inhibit that of noradrenaline. Antidepressants that block the reuptake of both serotonin and noradrenaline belong to the SerotoninNoradrenaline Reuptake Inhibitors (SNRIs). TCAs also block the reuptake of both neurotransmitters, but the ratio between serotonin and noradrenaline reuptake inhibition differs for each. For example, desipramine primarily blocks noradrenaline reuptake, whereas clomipramine selectively inhibits that of serotonin. Apart from reuptake inhibition, TCAs also interact with various receptor types, an effect that is associated with side effects. Another way of increasing neurotransmitter concentration in the synaptic cleft is by inhibition of their breakdown by the enzyme Monoamine Oxidase (MAO). Inhibitors of MAO (MAOIs) were, together with the TCAs, the first antidepressants in clinical practice, but they are no longer used due to dangerous side effect. This was partly because MAOIs interacted in an irreversible manner with the 
enzyme. There is however currently one antidepressant available (i.e. moclobemide) that is a reversible inhibitor of MAO-A (RIMA) and displays fewer side effects than the MAOIs.

The above-described antidepressants are by far the most used, but recently a group of atypical antidepressants has emerged. Their primary mechanism of action is not limited to increases in synaptic concentrations of serotonin or noradrenaline, and may in fact be completely unrelated to these increases. For example, nefazodone and trazodone, which is sometimes described as a heterocyclic antidepressant according its chemical structure, are antagonists of the 5-HT2A-receptor. Mirtazapine blocks $\alpha_{2}$-adrenergic receptors, and thereby increases the activity of noradrenergic (and partly serotonergic) neurons. Some atypical antidepressants do not seem to have a primary effect on neurotransmitters. Rolipram, for instance, is an inhibitor of phosphodiesterase type 4 (PDE4), an enzyme that catalyses the breakdown of the second messenger cyclic Adenosine Monphosphate (cAMP). Although the clinical efficacy of rolipram proved to be equal to that of TCAs, it is not on the market any more due to severe side effects. However, several pharmaceutical companies are still trying to develop new PDE4-inhibitors as potential antidepressants. A remarkable substance that recently came available as an antidepressant on the European market is tianeptine. It appears to have the opposite effect as SSRIs, namely it enhances the reuptake of serotonin and thereby decreases serotonin availability in the synaptic cleft.

From the above, it is clear that substances with different biochemical and pharmacological effects can display antidepressant properties. The viewpoint that the working mechanism of antidepressants is to increase neurotransmitter availability has therefore recently been questioned. It is more likely that the primary effects of SSRIs, TCAs, NRIs and SNRIs on reuptake inhibition of either serotonin or noradrenaline is not directly related to their antidepressant effect. Rather, it appears that these effects induce adaptational changes in neuronal functioning which eventually translate into antidepressant effects. This phenomenon would also explain the fact that no currently available antidepressant can significantly reduce the delay in therapeutic effect. Indeed, all antidepressants have to be taken for several weeks before clinical improvement emerges. The biochemical and pharmacological effects on the other hand, are seen only a few minutes to hours after administration of the antidepressant. There is now more and more evidence that antidepressant effects are associated with (molecular) neurobiological changes, such as increases in synaptic plasticity and/or neurogenesis, and changes in the activity of intracellular signalling cascades (Manji et al, 2003). 
Trable 1

Classes of antidepressants with different biochenical effects

\begin{tabular}{|c|c|c|}
\hline Clates & Antideptessants & Primary biochenical effect \\
\hline $\begin{array}{l}\text { Tricycilic antidepressints } \\
\text { (TCAs) }\end{array}$ & $\begin{array}{l}\text { imipramine, desipramine: } \\
\text { amiripty line, nortriptyline, } \\
\text { clomipramine }\end{array}$ & $\begin{array}{l}\text { Reuptake inhibition of serotonin, and for } \\
\text { noradremahe, interaction with various } \\
\text { feceptor types }\end{array}$ \\
\hline $\begin{array}{l}\text { Selecine Serotonin Reuptake } \\
\text { Inhibitors (SSRIs) }\end{array}$ & $\begin{array}{l}\text { Puwetine, paroxctine, } \\
\text { cilalopran, sertraline, } \\
\text { fuvoxamine }\end{array}$ & $\begin{array}{l}\text { Selective inhibition of the reuplake of } \\
\text { serotonin }\end{array}$ \\
\hline $\begin{array}{l}\text { Selective Noradranaline } \\
\text { Reuptake Inwibitors (NRIs) }\end{array}$ & rebuketine, mianserine & $\begin{array}{l}\text { Selective inhibition of the reuptake of } \\
\text { noradrenaline }\end{array}$ \\
\hline $\begin{array}{l}\text { Seroton in and Noradrenaline } \\
\text { Retuptake Inlwibitors (SNRIS) }\end{array}$ & venlafaxine, duloxedine & $\begin{array}{l}\text { Inhibition of the resptake of both serotonin } \\
\text { and noradrenaline }\end{array}$ \\
\hline $\begin{array}{l}\text { Monoamine Oxidase Inhibirors } \\
\text { (MAOHs) }\end{array}$ & phenelzine, tranylcipromine & Blockade of monamine breatkdown \\
\hline $\begin{array}{l}\text { Reversible inhibilors of } \\
\text { MAOA }\end{array}$ & moclobemide & $\begin{array}{l}\text { Reversible indubition of the breakdown of } \\
\text { monoamines }\end{array}$ \\
\hline Abypical antidepressants & $\begin{array}{l}\text { nefacodone, trazodone } \\
\text { mirtazapine } \\
\text { rolipran } \\
\text { tiancptine }\end{array}$ & $\begin{array}{l}\text { Antagonism of } 5-\mathrm{HT}_{2} \text {-receptors } \\
\text { Antegonism of } \alpha_{2} \text {-adrenergic receptors } \\
\text { Inhibition of PDE } 4 \\
\text { Enhancement of serotonim reuptake }\end{array}$ \\
\hline
\end{tabular}

\subsection{Antidepressants and cytokines}

As stated previously, the working mechanism(s) of antidepressants are generally thought to be mediated by their effects on central neurotransmission. Since the emerging evidence of the possible role of cytokines in major depression, the influence of antidepressants on cytokine production has been subject of several studies. Indeed, the cytokine-hypothesis of major depression implies that antidepressants should interfere in cytokine production. Several studies that addressed this issue are reviewed in Chapter 2. The overall conclusion is that antidepressants have anti-inflammatory effects in-vitro and in several animal models of depression. Thus, antidepressants seem to inhibit pro-inflammatory cytokines, and enhance the production of $1 \mathrm{~L}-10$. The effect of antidepressant treatment on cytokine production in depressed patients has also been examined, but the results are inconclusive. Several methodological issues may underlie this inconsistency (see Chapter 2). 


\section{THE CAMP/PKA-PATHWAY}

\subsection{General}

Cells are dynamic entities that respond to physiological alterations in their immediate environment and to molecules secreted by neighbouring or distant cells. These chemical messages interact with specific receptors at the cell membrane, which subsequently generate an intracellular signal.

Cyclic adenosine monophosphate (CAMP) is one of the best characterized second messenger molecules. It is produced by the enzyme adenylate cyclase that is coupled to certain G-protein coupled receptors (GPCRs). Activation of such receptors leads to rapid stimulation of adenylate cyclase and subsequent cAMP-production. Receptors that are linked to adenylate cyclase include receptors for hormones, neurotransmitters, purines and prostaglandines. Among the cAMP-coupled neurotransmitter receptors are serotonergic 5-HT4, 5-HT5 and 5-HT7 receptors, $\beta_{2}$-adrenergic receptors and histaminergic $\mathrm{H} 2$-receptors. The binding of a ligand with these receptors causes conformational changes and reorganization of receptor associated G-protein subunits. This results in activation of the membrane-bound adenylate cyclase and a subsequent rise in intracellular cAMP-concentrations. The major effect of $\mathrm{cAMP}$ is the activation of protein kinase A (PKA, see Figure 1). Inactive PKA consists of two catalytic subunits (PKA-c) that are held together by two regulatory subunits (PKA-r). Cyclic AMP binds with the regulatory subunits causing the release of the catalytic units. The active PKA-subunits are then able to activate other kinases, enzymes and transcription factors by phosphorylation. One of the best known targets of PKA is the CAMP responsive element binding protein (CREB), a transcription factor that binds to a cAMP responsive element (CRE) in the DNA, which is found in the promotor region of many genes. Binding of CREB to the CRE can have either stimulatory or inhibitory effects on gene transcription.

Intracellular homeostasis of CAMP is predominantly controlled by phosphodiesterase type 4 (PDE4) that hydrolyses CAMP to AMP. PDEs are a group of enzymes that are responsible for the breakdown of cyclic nucleotides such as cAMP and cyclic guanosine monophosphate (cGMP). They differ in the specificity and affinity for the respective cyclic nucleotides. PDE4 is highly specific for the breakdown of $\mathrm{CAMP}$. Inhibition of PDE4 consequently results in the rapid and sustained accumulation of intracellular $C A M P$. 
Thus, modulation of the CAMP/PKA-pathway can be achieved by:

- stimulation of receptors that are positively coupled to adenylate cyclase (by natural ligands or artificial agonists)

- direct stimulation or inhibition of adenylate cyclase.

- inhibition of PDE4

- stimulation or inhubition of PKA

These strategies have been employed to study the role of the CAMP/PKApathway on the production of cytokines by immunocompetent cells.

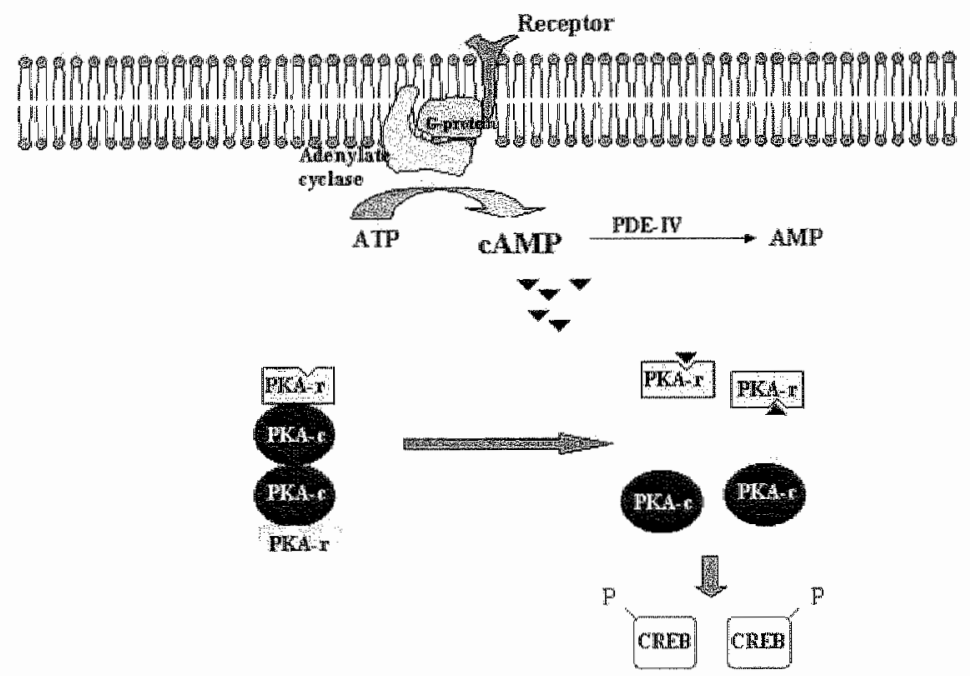

Figure 1

Schematic presentation of intracellular CAMPJKA-signalling.

\subsection{Cyclic-AMP/PKA and cytokine production}

Cytokine production is controlled by many different processes. As mentioned previously, cytokine production is induced by immunological activation of immune cells (e.g. by antigens) and/or by cytokines secreted from neighbouring cells. The binding of a cytokine with its receptor activates receptor associated protein kinases (usually tyrosine kinases), which in turn activate other kinases 
and transcription factors. In this way, the cells respond rapidly to cytokine stimulation, resulting in certain immunological activities, such as induction or enhanced production of other cytokines. Stimulation of the CAMP/PKA-cascade does not directly induce cytokine production, but this signalling pathway strongly modulates cytokine expression induced by other stimuli such as antigens, lipopolysaccharidles and mitogens (for review see Zidek, 1999). The influence of CAMP-signalling on cytokine production has been examined on several cell types, mainly T-lymphocytes, monocytes, macrophages, lymphoid or myeloid cell lines and peripheral blood mononuclear cells (PBMCs). The latter is the purified fraction of lymphocytes and monocytes from whole blood. Also microglia (the macrophage-like cells in the brain) have been used to study the role of $\mathrm{CAMP} / \mathrm{PKA}$ in cytokine production. In most studies, modulation of the cAMP/PKA-activity was achieved by agonists of adenylate cyclase coupled receptors ( $\beta_{2}$-adrenergic receptors, $H_{2}$-histaminergic receptors and $E P_{2^{-}}$ prostaglandin receptors), PDE4-inhibition or stimulation with CAMP-analogues such as dibutyryl-cAMP. Chapter 6 provides a summary of the most important findings on this subject. In general, stimulation of the cAMP/PKA-pathway decreases the stimulated production of IFN- $\gamma, T N F-\alpha$ and IL-12, while it enhances that of the IL-10. Thus, increased CAMP/PKA-activity provokes antiinflammatory effects in-vitro. The effects of CAMP/PKA-signalling on other cytokines is not yet clear and presumably depends on the cell type, stimulus and micro-environment.

\section{GENERAL HYPOTHESIS}

If pro-inflammatory cytokines play a role in the pathophysiology of major depression, then antidepressants should interfere with production and/or action of these cytokines. Therefore, the effects of antidepressants on the production of various cytokines in either human whole blood or in primary rat brain cells are explored. Further, if antidepressants of different classes decrease proinflammatory and/or increase anti-inflammatory cytokine production, then this effect resembles that of substances that up-regulate the activity of the CAMP/PKA-pathway. Therefore, it is hypothesized that: a) antidepressants enhance CAMP/PKA-signalling either by increasing intracellular cAMP-levels or by augmenting PKA-activity; b) this antidepressant-induced increase in cAMP/PKA-activity changes the pattern of cytokine production. 


\section{CHAPTER OVERVIEW}

This introductory chapter provides a concise background on the field of "psychoneuroimmunology", specifically in relation to the pathophysiology of major depression. It contains an introduction to the biology of major depression, the immune system and cytokines, brain-cytokine interactions, the different classes of antidepressants, and the CAMP/PKA signalling cascade.

In Chapter 2, an overview of the current knowledge about the influence of antidepressants on cytokine production is presented. Human studies, animal models of depression and in-vitro culture models, have all been used to examine the effects of antidepressants on the immune system in general and on cytokines in particular. The respective literature is critically reviewed with respect to methodology and the type of model used.

The reliable measurement of cytokines is a crucial aspect of most experiments presented throughout this thesis. Handling and storage of samples is an important aspect of pre-analytical variability. The study in Chapter 3 provides evidence that long-term storage of samples has no influence on the correct measurement of cytokines.

Stimulated human whole blood is a reproducible and robust method to study the influence of chemical therapeutics on cytokine production. Although this model has been used previously to study the effects of some antidepressants (Maes et al., 1999), the effects of different classes of antidepressants are further explored in Chapter 4 . One of the possible mechanisms by which antidepressants can influence cytokine production is by their serotonergic action, i.e. either by interacting with serotonergic receptors on peripheral immune cells, or by blocking serotonin reuptake and thereby increasing extracellular serotonin concentrations. Therefore, the direct effects of serotonin, serotonergic receptor agonists and antagonists, and the effect of serotonin depletion are examined in Chapter 5, using the same whole blood stimulation model. Another possible mediator is the CAMP/PKA-pathway. Although there are numerous reports about the role of CAMP and PKA on cytokine production, none of them have employed stimulated whole blood. In addition, most of these studies only examine a single aspect of cAMP/PKA signalling (mainly enhancing or inhibiting PKA-activity, or blocking PDE4), or they present data about a limited number of cytokines. The study in Chapter 6 examines the influence of CAMP/PKA-signalling on stimulated cytokine production (in human whole blood) by modulating the cascade at all levels, i.e. at the level of cAMPformation by adenylate cyclase, at the level of cAMP-degradation by PDE4, and at the level of PKA-activity.

To test the hypothesis that the effects of antidepressants on cytokine production are mediated by an increase in CAMP/PKA-activity, whole blood was 
stimulated in the presence or absence of inhibitors of adenylate cyclase (SQ22536) or PKA (Rp-8-Br-cAMPS). If the hypothesis is correct, then these inhibitors should reverse the effects of the antidepressants on cytokine production. The data of these experiments are presented in Chapter 7. Further, the effect of antidepressants on intracellular cAMP-concentrations in human peripheral blood mononuclear cells is explored in Chapter 8.

As explained elsewhere in this chapter, it is likely that the effects of peripheral cytokines on brain function are mediated by cytokines produced within the central nervous system. However, the effects of antidepressants on cytokine production by brain cells has never been examined before. Chapter 9 presents data on the production of cytokines by re-aggregating whole brain cell cultures ("spheroid" cultures), and the influence of the antidepressant imipramine hereon.

Finally, the results of the experiments are critically reviewed in Chapter 10 . Directions for future research are discussed.

\section{REFERENCES}

Abbas AK, Murphy KM, Sher A, (1996) Functional diversity of helper T lymphocytes. Noture 383: 787-793.

Anand A, Charney DS (1997) Catecholamines in Depression. In: Honig, A. and van Pratag, H. M. (Eds.), Depression: Newobiological, Psychopathological and Therapewic Advances. (pp. 147-178) Chichester: John Wiley \& Sons.

Capuron L, Ravaud A, Dantzer R, (2000) Early depressive symptoms in cancer patients receiving interleukin 2 and/or interferon alfa-2b therapy. J Chin Oncol $18: 2143-2151$.

Connor TJ, Leonard BE, (1998) Depression, stress and immunological activation: the role of cytokines in depressive disorders. Life Sci 62: 583-606.

Dantzer R, (2001) Cytokine-induced sickness behavior: where do we stand? Brain Behos lmmum 1.5:7-24.

Doris A, Ebmeier K, Shajahan P, (1999) Depressive illness. Lancer 354: 1369-1375.

Dunn AJ, (2000) Cytokine activation of the HPA axis, Amn N Y Acad Sci 917: 608-617.

Dunn AJ, Wang J, Ando T, (1999) Effects of cylokines on cerbbral neurotransmission. Comparison with the effects of stress. Adv Exp Med Bio 461: 117-127.

Elenkov U, Wilder RL, Chrousos GP, Vizi ES, (2000) The sympathetic nerve--an integrative interface between two supersystems: the brain and the immune systen. Pharmacol Rev 52: $595-638$.

Gordon J, Bames NM, (2003) Lymphocyles transport serotonin and dopamine: agony or ecstasy? Trends lmmunol $24: 438-443$.

Haddad J), Sade NE, Safieh-Garabedian B, (2002) Cytokines and neuro-immune-endocrine interactions: a role for the hypothalamic-pituitary-adrenal revolving axis. J Nowrommunal 133: $1-19$.

Herbert TB, Cohen S, (1993) Depression and immunity: a meta-analytic review. Psychol Bull $113: 472-486$ 
Iglehart $J K,(2004)$ The mental health maze and the call for ransformation. $N$ Engl I Med 350 : $507-514$.

Irwin $M_{3},(2002)$ Psychoneuroimmunology of depression: clinical implications. Brain Behan Immun 16: 1-16.

Lanquillon S, Krieg JC, Bening-Abu-Sach U H V, (2000) Cytokine production and treatment response in major depressive disorder. Neuropsychopharmacology 22: $370-379$.

Linthorst AC, Reul JM, (1998) Brain neurotransmission during peripheral inflammation. Anm $N Y$ Acad Sci $840: 139-152$.

Maes M, (1999) Major depression and activation of the inflammatory response system. Adv Exp Med Biol $461: 25.46$.

Maes M, Bosmans $E$, De Jongh $R$, Kenis $G$, Vandoolaeghe $E$, Neels $H$, (1997) lncreased serum IL-6 and $L_{L} \mid 1$ receptor antagonist concentrations in major depression and treatment resistant depression. Cylokine 9:853-858.

Maes M, Meltzer HYM (1995) The serotonin Hypothesis of Major Depression. In: Bloon, F. E. and Kupfer, D. J. (Eds.), Psychophamacology. The Fourth Generation of Progress (pp. 933944) New York: Raven Press, Lid.

Maes M, Song C, Jin A-h, Bonaccorso S, Kenis G, De Jongh R, Bosmans E, Scharpe S, (1999) Negative immunoregulatory effects of antidepressants: inhibition of interferon- $\gamma$ and stimulation of interleukin 10 secretion. Newropsychopharmacology $20: 370-379$.

Maier SF, Goehler LE, Fleshner M, Watkins LR, (1998) The role of the vagus nerve in cytokineto-brain communication. Am N Y Acad Sci 840:289-300.

Maier SF, Watkins LR, (1998) Cytokines for psychologists: implications of bidirectional immune-to- brain communication for understanding behavior, mood, and cognition. Psychol Rev 105: 83-107.

Manji HK, Quiroz JA, Sporn I, Payne JL, Denicoff K, A Gray N, Zarate CA, Chamey, DS, (2003) Enhancing neuronal plasticity and cellular resilience to develop novel, improved therapeutics for difficult-to-treat depression. Biol Psychiatry 53: 707-742.

Mikova $O$, Yakinova $R_{s}$ Bosmans $E$, Kenis $G$, Maes M, (2001) Increased tumor necrosis factor alpha concentrations in major depression and multiple sclerosis. Eu Neuropsychopharmacol 11:203-208.

Murray CJL, Lopez AD (1996) The Global Burden of Disease. A comprehensive assessment of mortality and disability from diseases. winries, and risk factors in 1000 and projected to 2020., Harvard Universtiy Press, Camebridge MA.

Musselinan DL, Lawson DH, Gumnick JF, Manatunga AK, Penna S, Goodkin RS, Greiner K, Nemeroff $C B$, Miller AH, (2001) Paroxetine for the prevention of depression induced by high-dose interferon alla. N Engl J Med 344: $961-966$.

Owen BM, Eccleston D, Ferrier IN. Young AH, (2001) Raised levels of plasma interleukin-lbeta in major and postviral depression. Acta Psychatr Scand 103: 226-228.

Pariante CM. Miller AH, (2001) Glucocorticoid receptors in major depression: relevance to pathophysiology and treatment. Biol Psychiatry 49: 391-404.

Pariante CM, Pearce BD, Pisell TL, Sanchez Cl, Po C, Sil C, Miller AH, (1999) The proinflammatory cylokine, interleukin-latpha, reduces gucocorticoid receptor transhocation and function. Endocrinology 140: 4359-4366.

Pavlov VA. Wang $H_{2}$ Caura CJ, Friedman SG, Tracey KJ, (2003) The cholinergic antiinflammatory pathway: a missing link in neuroimmunomodulation. Mol Med 9: 125-134.

Pollak $Y$, Yirmiya $\mathbb{R},(2002)$ Cytokine-induced changes in mood and behaviour: implications for "depression due to a general medical condition", immunotherapy and antidepressive treament. Int J Newropsychopharmacol $5: 389-399$. 
Reichenberg A, Yirmiya R, Schuld A, Kraus T, Haack M, Morag A, Pollmacher T, (2001) Cytokine-associated emotional and cognitive disturbances in humans. Aroh Gen Psychiatry 58: $445-452$.

Ressler KJ, Nemeroff CB, (2000) Role of serotonergic and nonadrenergic systems in the pathophysiology of depression and anxiety disorders. Depress Antiety 12 Suppl 1:2-19.

Schatzberg AF, Schildkraut JJ (1995) Recent Studies on Norepinephrine Systems in Mood Disorders. In: Bloom, F. E. and Kupter, D. J. (Eds.), Psychophamacology: The Fouth Generation of Progress. (pp. $911-920$ ) New York: Raven Press.

Seidel A, Arolt V, Hunstiger M, Rink L, Behnisch A, Kirchner H, (1995) Cylokine production and serum proteins in depression. Scand J Immunol $41: 534-538$.

Seidel A, Arolt V. Huntstiger M, Rink L, Behnisch A, Kirchner H, (1996) Increased CD56* natural killer cells and related cytokines in major depression. Clin Immonol Immumopathof 78: 83-85.

Smith KA, Cowen PJ (1997) Serotonin and Depression. In: Honig, A. and van Praag, H. M. (Eds.), Depression: Netrobiological, Psychopathological and Therapeutic Advances. (pp. 129-146) Chichester: John Wiley \& Sons.

Spijker J, de Graaf R, Bijl RV, Beekman AT, Ormel J, Nolen WA, (2002) Duration of major depressive episodes in the general population: results from The Netherlands Mental Health Survey and Incidence Study (NEMESIS). Br J Psychiatry 18 1: 208-213.

Szelenyi J, (2001) Cytokines and the central nervous system. Brain Res Bull 54: 329-338.

Vitkovic L, Bockaert J, Jacque C, (2000) "Inflammatory" cytokines: neuromodulators in normal brain? INeurochem 74: 457-471.

Wang H, Yu M, Ochani M, Amella CA, Tanovic M, Susarla S, Li JH, Yang H, Ulloa L, Al-Abed Y, Czura CJ, Tracey KJ, (2003) Nicotinic acetylcholine receptor allpha7 subunit is an essential regulator of inflammation. Narwe $421: 384-388$.

Wichers $\mathrm{MC}$. Maes $\mathrm{M}$, (2004) The role of indoleamine 2,3-dioxygenase (IDO) in the pathophysiology of interferon-alpha-induced depression. I Psychiatry Newrosci 29: 11-17.

Zidek Z, (1999) Adenosine-cyclic AMP pathways and cytokine expression. Eur Cytokine Netw 10: $319-328$.

Zorrilla EP, Luborsky L, McKay JR, Rosenthal R, Houldin A, Tax A, McCorkle R, Seligman DA, Schmidt $K_{,},(2001)$ The relationship of depression and stressops to immunological assays: a meta-analytic review. Brain Behav Inmm 15: 199-226. 


\section{Chapter}

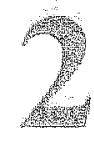

\section{Effects of antidepressants on the production of cytokines}

Gunter Kenis, Michael Maes

International Journal of Neuropsychopharmacology (2002), 5, pp. $40 I-412$ 


\section{ABSTRACT}

There is now evidence that major depression is associated with an upregulation of the inflammatory response system (IRS). One of the major factors in this IRS activation is the hyperproduction of pro-inflammatory cytokines. Recently, a number of studies examined whether there is a causative role of these inflammatory mediators in the aetiology of major depression. Studies with animal models and cytokine immune therapy in humans suggest that proinflammatory cytokines induce depressive symptomatology. Moreover, these depressive symptoms can be effectively reversed by antidepressant treatment. Thus, it may be suggested that antidepressants suppress pro-inflammatory cytokine production and/or action, resulting in improvement of depressive symptoms. The influence of antidepressants on cytokine production has been examined in culture systems in-vitro, and in animal models of depression - in which cytokine production is induced by endotoxin administration. Results suggest that antidepressants of several classes decrease the production of proinflammatory cytokines like interferon- $\gamma$ and tumor necrosis factor- $\alpha$, and increase that of interleukin-10, an anti-inflammatory cytokine. Further, the effect of antidepressive treatment on cytokine secretion and on plasma levels of cytokines in depressed patients has been studied. Unfortunately, different approaches to examine cytokine production and different techniques to measure cytokines in plasma are used in these studies. Despite this, current data point to a normalization of cytokine plasma levels and cytokine production after antidepressant treatment. It is clear, however, that more research is warranted and we strongly argue the need for higher standardization in the methodology used to examine the cytokine network in depressed patients. 


\section{INTRODUCTION}

In the past decade, it has become clear that there is a strong interaction between the peripheral immune system and the central nervous system (CNS). Immune activation influences brain functioning and the CNS modulates the immune response. Moreover, immune activation can lead to profound alterations in psychological status (e.g. mood and behaviour). Therefore, alterations of the immune system have been intensively investigated in psychiatric disorders like major depression, dysthymia and schizophrenia (for review see: Maes, 1999; Kronfol and Remick, 2000; Muller et al., 2000).

The most important link whereby the immune system influences the brain is established by the cytokine network. Initially, cytokines were discovered and described as proteins that were produced by immunocompetent cells to stimulate or inhibit the function of other immune cells. Now it is clear that these molecules do much more than solely participating in the regulation of the immune response and that various cell types, including cells of the CNS (astrocytes, microglia and even neurons) can produce cytokines. However, classification of cytokines is still based on their role in immune homeostasis. Two classification systems can be distinguished. One of them denotes cytokines as pro-inflammatory or anti-inflammatory, whereas the other uses the terms Thelper1(Th1)-like or Th2-like cytokines. These terms are not exactly the same, although there is an overlap. Pro-inflammatory cytokines promote inflammatory reactions and, as such, they tend to stimulate or activate immunocompetent cells. In contrast, anti-inflammatory cytokines inhibit inflammation and deactivate immune cells. The most important pro-inflammatory cytokines are interleukin-1 (IL-1), IL-6, IL-8, tumor necrosis factor (TNF) and interferon- $\gamma$ $($ IFN- $\gamma)$. The prototypical anti-inflammatory cytokine is IL-10, which is a major deactivator of monocytes, macrophages and lymphocytes. Interleukin-1 receptor antagonist (IL-1RA) is another anti-inflammatory protein that specifically antagonizes the activities of IL-1. The distinction between ThI- and Th2-like cytokines is based on the respective lymphocyte subset that secretes them. Thelper I (Th1) Iymphocytes produce IL-2, IFN- $\gamma$ and TNF- $\beta$, whereas Th/2 lymphocytes mainly produce IL-4, IL-5 and IL-10 (Abbas e1 al., 1996).

Cytokines act through specific membrane bound receptors. Binding of a cytokine with its receptor induces activation of several intracellular pathways, eventually leading to changes in gene expression. Interestingly, some cytokine receptors can be cleaved from the plasma membrane by proteases. Furthermore, alternatively spliced mRNA, coding only the extracellular part of receptors, has been described. These "soluble receptors" enter the circulation in concentrations that often exceed that of their ligand. Soluble cytokine receptors usually act as antagonists because they compete with the membrane bound receptor for 
binding. One important exception is the soluble IL-6 Receptor (sIL-6R), since the IL-6/sIL-6R-complex in serum can bind with gp130 (the final signal transduction molecule for $(\mathrm{L}-6)$ on the cell membrane, thereby augmenting the biological activity of 11 - 6 (Peters et al., 1998).

The pro-inflammatory cytokines have profound effects on CNS and endocrine functioning. They increase central monoamine metabolism and are potent activators of the hypothalamic-pituitary-adrenal axis (HPA-axis). Both systems are disturbed in major depression.

Much attention has focused on the role of cytokines in the aetiology and pathophysiology of mood disorders, especially major depression. A complete overview of these studies is far beyond the scope of this review. The topic has been excellently reviewed in recent publications (Connor and Leonard, 1998; Dantzer et al., 1999; Licinio and Wong, 1999; Maes, 1999).

If pro-inflammatory cytokines play a causative role in major depressive disorders, then antidepressants should downregulate these cytokines or interfere with their actions. Accumulating evidence has been published that antidepressants modulate cytokine production. This paper reviews studies concerning the influence of antidepressants on cytokines in depressed patients and experimental animals, and on in-vitro cytokine production.

\section{INFLUENCE OF ANTIDEPRESSANT TREATMENT ON CYTOKINES IN DEPRESSED PATIENTS}

\subsection{Methods to study cytokine production in humans}

One approach to study the influence of antidepressants on cytokine production in humans is to look at differences in cytokine patterns before and after antidepressant therapy. Indeed, several investigators addressed this issue. However, the methods employed to investigate changes in the cytokine homeostasis differ greatly among the reported studies. Circulating cytokine levels are very low in healthy subjects and in patients with psychiatric disorders, and, hence, are very difficult to detect in serum or plasma of these subjects. Therefore, the production of cytokines is often examined ex-vivo, e.g. in the supernatant of cultured white blood cells or cultured whole blood. In both cases, cytokine production is induced by the addition of lipopolysaccharides (LPS) and/or mitogens, like phytohaemagglutinin (PHA) or Concanavalin A (Con A). In the first case, leukocytes are purified from blood to obtain a mixture of predominantly lymphocytes and monocytes, usually referred to as Peripheral Blood Mononuclear Cells (PBMCs). In the latter case, whole blood form the patient (sometimes diluted in culture medium) is directly cultured, without 
purification of specific cell types. Thus, besides lymphocytes and monocytes, all other cell types capable of producing cytokines (including neutrophils, granulocytes and platelets) are present in the culture. It has been shown that diluted, stimulated whole blood is a good and reliable method to study cytokine production ex-vivo or in-vitro. Compared to PBMC-cultures, whole blood cultures reflect better the in-vivo conditions and are more reproducible in terms of cytokine production (De Groote et al., 1992, 1993; Zangerle et al., 1992; Yaqoob et al., 1999). First, natural cell-to-cell interactions are preserved in whole blood cultures, including endogenous immunoregulatory mediators present in the plasma. Second, purification of white blood cells modifies the lymphocyte/monocyte ratio, leading to reduced monocyte concentrations (De Groote et al., 1992). Since some cytokines are secreted by one cell type, whereas others can be produced by several cell types, and sinee the production of cytokines is influenced by other cytokines, it is better to measure cytokines in cultures with a preserved lymphocyte/monocyte ratio.

Nowadays, cytokines are mostly determined by means of enzyme-linked immunosorbent assays (ELISA) or radio-immunoassays (RIA). These methods use specific mono- or polyclonal antibodies to detect the respective cytokine in biological fluids or culture medium. Earlier, cytokines were measured using certain cell-lines that displayed a dose-dependent biological response to the cytokine. This response could be proliferation, growth inhibition or the secretion of certain proteins. However, these bio-assays only measure biological active cytokines. This biological activity can be influenced by the presence of soluble receptors or by degradation of the cytokine in the sample (through the action of endogenous proteases or by freezing and thawing of the samples). Moreover, cell lines might not solely respond to one cytokine, but also to other proteins (including cytokines), hormones or other factors present in the sample, leading to non-specific responses. This phenomenon can be checked using neutralizing antibodies added to the sample (in which case the biological activity of the cytokine is blocked). Overall, bio-assays have the advantage of measuring biological active cytokines, but immuno-assays perform much better in terms of sensitivity, specificity, reliability and reproducibility. It should also be noted that there are now numerous commercial immuno-assays (e.g. ELISAs) available. Over the last years they have been significantly improved in terms of sensitivity. Moreover, specific assays for cytokine detection in serum or plasma have been developed. We strongly recommend to use these ultrasensitive ELISAs when measuring cytokine levels in serum or plasma.

All methods mentioned above have been employed by investigators to study cytokine patterns in psychiatric patients. It is therefore difficult to interpret and to compare divergent (and sometimes conflicting) results obtained by different laboratories. One should always keep in mind the differences between the 
methods used: e.g. cytokine levels in plasma versus ex-vivo cytokine production - stimulated PBMCs versus whole blood cultures - cytokine measurement by immunoassays versus bio-assays.

\subsection{Ex-vivo cytokine production in depressed patients before and after pharmacotherapy}

Table 1 gives an overview of studies that examined ex-vivo cytokine production before and after antidepressant treatment. In an early study, Weizman et al. reported that the stimulated production of $I L-1 \beta$ by PBMCs was significantly enhanced after a 4 week treatment with clomipramine compared with that before the start of the treatment (Weizman et al., 1994). In this study, stimulated production of $I L-1 \beta$ and $I L-2$ in major depressed patients before treatment was significantly lower compared to matched healthy controls. It should be noted that indomethacin was added to these cultures to inhibit prostaglandin formation, which affects cytokine production. However, indomethacin may change cytokine patterns as well. So it is difficult to compare this study with later reports that examined cytokine production without indomethacin. Recently, it was found that the production of $1 \mathrm{~L}-1 \beta$ in stimulated whole blood is not different in patients with melancholic and non-melancholic depression and healthy controls, although higher monocyte counts were found in patients with non-melancholic depression (Rothermundt et al., 2001b). Antidepressive treatment did not affect the production of IL-1 $\beta$. It is noteworthy that the aim of this study was to investigate differences in immune parameters between melancholic and non-melancholic major depressed patients. The majority of these patients were already on different types of antidepressants at baseline. Thus, conclusions regarding the influence of antidepressant treatment on IL-1 $\beta$ production are not reliable. Anisman et al. found increased production of IL-1 $\beta$ in dysthymic patients, which persisted despite successful antidepressant treatment (Anisman et al., 1999).

Seidel et al. (1995) examined the stimulated production of IL-1 $\beta$, IL-2, IL-6, IL10, sIL-2R and IFN- $y$ in whole blood of healthy controls and major depressed patients before and after therapy. The production of IFN-y and SIL-2R was significantly higher in patients as compared to controls. After six weeks of treatment, IFN- $\gamma$, sIL-2R, IL-2 and IL-10 production was significantly reduced compared to pre-treatment values (Seidel et al., 1995, 1996). Unfortunately, the type of treatment was not specified in these papers. Recently, Rothermundt et al. (2001a) reported that the stimulated production of IFN- $\gamma$, IL-2 and IL-10 was significantly lower in patients suffering from melancholic depression compared to healthy controls, but not in non-melancholic depressed patients. The 
production of these cytokines normalized after two weeks of treatment, but patients were not free of antidepressants at the start of the study.

Others reported no effect of four and twelve weeks of moclobemide treatment on the stimulated production of TNF- $\alpha$ in PBMCs of major depressed patients (Landmann et al., 1997). It is noteworthy that the TNF- $\alpha$ production did not differ between patients before therapy and healthy controls. In contrast, Lanquillon and colleagues reported an increase in the unstimulated TNF- $\alpha$ secretion in whole blood from depressed patients (Lanquillon et al., 2000). Moreover, this secretion was significantly reduced in patients who responded to a six-week treatment with amitryptiline. TNF- $\alpha$ secretion in non-responders decreased not significantly. Interestingly, in the same study, it was shown that the secretion of IL-6 was significantly normalized in both responders and nonresponders, where responders had significantly lower and non-responders significantly higher IL-6 levels before treatment-start as compared to healthy controls (Lanquillon et al., 2000).

\section{Table 1}

Summary of studies that examined ex-wo cytokine production in depressed patients before and after antidepressant treatment.

\begin{tabular}{|c|c|c|c|}
\hline Study & Antidepressant & $\begin{array}{l}\text { Cytokines } \\
\text { examined }\end{array}$ & Outcome \\
\hline Weizman et al., 1994 & Clomipramine & $\mathrm{IL}-1 \beta$ & Increase \\
\hline Rothermundt et al., $200 \mathrm{db}$ & Not specified & $I L-1 \beta$ & No effect \\
\hline Anisman et al., 1999 & Sertraline & IL- $1 \beta$ & No effect \\
\hline Seidel et al. 1995, 1996 & Not specified & $\begin{array}{l}\text { IFN-y } \\
s I L-2 R \\
11-2 \\
\| L-10\end{array}$ & $\begin{array}{l}\text { Decrase } \\
\text { Decranse } \\
\text { Decrease } \\
\text { Decrouse }\end{array}$ \\
\hline Rothermundt et al., $2001 \mathrm{a}$ & Not specified & $\begin{array}{l}\text { IFN- } \\
\text { IL-2 } \\
\text { IL }-10\end{array}$ & $\begin{array}{l}\text { Increase } \\
\text { Increase } \\
\text { Increase }\end{array}$ \\
\hline Landmann et al., 1997 & Moclobemide & $T N F=\alpha$ & No effect \\
\hline Lanquillon et al., 2000 & Amitryptilyne & $\begin{array}{l}T N F \sim \alpha \\
I L-6\end{array}$ & $\begin{array}{l}\text { Decrease } \\
\text { Increase in treatment responders } \\
\text { Decrease in treatment non- } \\
\text { responders }\end{array}$ \\
\hline
\end{tabular}




\subsection{Cytokine levels in serum or plasma}

Other investigators examined plasma levels of cytokines in major depressed patients before and after antidepressant therapy (see Table 2). Maes et al. reported that subchronic (five weeks) treatment with fluoxetine or various tricyclic antidepressants (TCAs) had no effect on increased IL-6, sIL-6R and sIL-2R levels (Maes et al., 1995). Additionally, there was no influence of antidepressant treatment on serum IL-6 and IL-IRA levels, which were increased in major depressed patients, inchuding treatment-resistant depressed patients (Maes et al., 1997). The plasma level of IFN- $\gamma$ was reported not to be different between healthy controls and depressed patients, and treatment with moclobemide for up to three months did not affect the IFN- $\gamma$ concentration (Landmann et al., 1997). In contrast, two other studies found that antidepressant treatment significantly lowered the initially increased serum IL-6 concentrations in depressed patients (Sluzewska et al., 1995; Frommberger et al., 1997). Sluzewska et al. (1995) reported that only 6 out of 22 patients had increased IL6 levels. Treatment with fluoxetine for eight weeks reduced IL 6 levels in these patients to those of healthy controls and patients with non-elevated IL-6 levels. This may indicate that circulating levels of pro-inflammatory cytokines are not increased in all depressed patients, and that increased cytokine production may be related to certain subtypes of depressive disorders and/or the state of the patient. However, in patients where increased cytokine levels are apparent, antidepressant treatment may normalize this increase. Finally, in a recent study it was found that treatment with TCAs significantly increased the plasma level of the TNF-receptor type II (Hinze-Selch et al., 2000). This effect was not seen after treatment with paroxetine. The authors suggest that activation of the TNFa system might precede the induction of weight gain by TCAs. However, it is well known that soluble TNF-receptors may antagonize the effects of TNF- $\alpha$, indicating that TCAs may display anti-inflammatory effects regarding the TNF$\alpha$ system.

It is clear that divergent and contradictory results regarding the influence of antidepressant treatment on cytokine production are reported. Discrepancies in study results may be related to differences in methodology, the heterogeneity of the study population and the patient status regarding the use of antidepressants. Obviously, more studies are needed to fully clarify the influence of antidepressant treatment on cytokines in depressed patients. 
Table 2

Summary of studies that examined serum or plasma cytokine levels in depressed patients before ard after antidepressant treatment.

\begin{tabular}{|c|c|c|c|}
\hline Study & Antidepressant & $\begin{array}{l}\text { Cytokines } \\
\text { examined }\end{array}$ & Outcome \\
\hline Maes et all., 1995 & Flouxeline/TCAs & $\begin{array}{l}I L-6 \\
\text { SIL-2R } \\
\text { SIL-6R }\end{array}$ & $\begin{array}{l}\text { Wo effect } \\
\text { No effect } \\
\text { No efled }\end{array}$ \\
\hline Maes et all., 1997 & Fluoxetine/Trazodone & $\begin{array}{l}1 L-6 \\
\mathbb{L}-1 \mathbb{R A}\end{array}$ & $\begin{array}{l}\text { No effect } \\
\text { No effect }\end{array}$ \\
\hline Landmann et al., 1997 & Moclobemide & IFN-y & No affed \\
\hline Frommberger et al., 1997 & Various types & IL-6 & Decrease \\
\hline Sluzewska et al., 1995 & Fluoxetine & IL-6 & Dectease \\
\hline Hinze-Selch et al., 2000 & $\begin{array}{l}\text { TCAs } \\
\text { Paroxetine }\end{array}$ & $\begin{array}{l}\text { STWF-RII } \\
\text { STNF-RII }\end{array}$ & $\begin{array}{l}\text { Increase } \\
\text { Noeffeel }\end{array}$ \\
\hline
\end{tabular}

\section{EFFECTS OF ANTIDEPRESSANTS ON CYTOKINE PRODUCTION IN-VITRO}

The effects of antidepressants have also been examined in several in-vitro culture systems. Xia et al. (1996) reported on the effects of imipramine, clomipramine and citalopram on cytokine secretion in isolated monocytes and T-lymphocytes. They found that a 24 hour pre-incubation with all antidepressants examined, significantly decreased the stimulated production of IL-1 3, IL- 6 and TNF- $\alpha$ by monocytes. The same effect was seen on the production of IL-2 and IFN- $\gamma$ from stimulated T-lymphocytes. In the latter case, the inhibition was more pronounced with imipramine and clomipramine in comparison to citalopram. Maes and co-workers examined the effects of antidepressants on cytokine production in stimulated, diluted whole blood cultures. In these studies, several classes of antidepressants were compared in view of their effect on the IFN- $\gamma / \mathrm{IL}-10$ production ratio. IFN- $\gamma$ is predominantly produced by regulatory Th1-lymphocytes and promotes the production of other pro-inflammatory cytokines. On the contrary, IL-10 is the major antiinflammatory cytokine and downregulates pro-inflammatory cytokine production. Therefore, the balance between IFN- $\gamma$ and IL-10 production is critical in determining the pro- or anti-inflammatory capacities of the culture supernatant (Katsikis et al., 1995). 
The authors showed that clomipramine reduces the secretion of IFN- $\gamma$ (Maes et al., 1999a), and that imipramine enhances the production of IL-10 (Kubera et al., 2001a). Both TCAs significantly reduced the IFN- $\gamma /$ IL-10 production ratio. Sertraline and fluoxetine significantly reduced IFN- $\gamma$ and increased IL-10 production. Hence, both SSRIs significantly decreased the IFN- $\gamma /$ IL-10 ratio (Maes et al., 1999a; Kubera et al., 2001a). Venlafaxine, a serotonin noradrenaline reuptake inhibitor (SNRI), significantly enhanced the production of IL-10 (Kubera et al., 2001a), whereas the heterocyclic antidepressant (HCA) trazodone decreased the secretion of IFN- $\gamma$ (Maes et al., 1999a). Most important, both antidepressants reduced the IFN-y/IL-10 ratio. In summary, TCAs, SSRIs, SNRIs and HCAs have negative immunoregulatory effects by decreasing the production of IFN- $\gamma$ relative to that of IL-10. Another study examined the influence of moclobemicle on cytokine production in whole blood cultures (Lin et al., 2000). It was found that moclobemide enhanced the stimulated production of IL-10, but did not affect that of IFN- $\gamma$. Interestingly, moclobemide suppressed the spontaneous (unstimulated) release of the proinflammatory cytokines TNF- $\alpha$ and IL-8. These data indicate that moclobemide may have anti-inflammatory capacities, by inhibiting pro- and stimulating antiinflammatory cytokine production.

The effect of the mood stabilizer lithium on in-vitro cytokine production was subject of several studies. Early studies reported that lithium increases the production of IL-2 in PBMCs and T-cells (Wilson et al., 1989; Wu and Yang, 1991; Kucharz et al., 1993), and stimulated monocytic TNF-a secretion (Kleinerman et al., 1989). A recent study showed that lithium reduced the spontaneous and the LPS-induced IL-8 production by monocytes (Merendino et al., 2000). Maes et al. reported that in stimulated whole blood, lithium increased the production of the pro-inflammatory cytokines TNF- $\alpha$ and IL-8, but not IL-6 and IFN- $\gamma$ (Maes et al., 1999b). Also the production of the anti-inflammatory cytokines $\mathbb{L}-10$ and IL-IRA was significantly enhanced in lithium treated cultures. However, lithium did not influence the IFN- $\gamma / \mathrm{IL}-10$ production ratio (Maes et al., 1999b). In a recent study, lithium produced a shift in the Th1/Th2balance by enhancing IL-4 and IL-10 production and decreasing that of IL-2 and IFN- $\gamma$ in stimulated whole blood (Rapaport and Manji, 2001). To summarize, lithium may influence both pro- and anti-inflammatory cytokine production. It has been suggested that lithium can restore mild immune activation and disequilibria in cytokine production (Sluzewska et al., 1997; Maes et al., 1999b; Rapaport et al., 1999).

Overall, it is concluded that antidepressants of different classes have, at least invitro, negative inmunoregulatory effects in terms of cytokine secretion. 


\section{ANTIDEPRESSANTS AND CYTOKINES IN ANIMAL MODELS OF DEPRESSION}

Several animal models have been developed to study the pathophysiology of major depression. Commonly studied models of depression are submission to chronic mild stress, lesion of the olfactory bulb and injection of lipopolysaccharides (LPS). These models have been evaluated on the basis of the induction of depressive like symptoms also seen in major depressed patients, like anhedonia, reduced social activity, sleep disturbances, alterations in food consumption, and on the basis of the reversal of these symptoms by antidepressant treatment. Only recently, few studies have been undertaken to assess immune parameters and cytokine secretion in these animals.

Administration of lipopolysaccharides to animals induces an array of symptoms commonly referred to as sickness behaviour (Dantzer et al., 1998b). Reduced food intake, weight loss, decreased social and locomotor activity, and anhedonia (mostly measured as a decrease in the consumption and preference for saccharine solution) are part of the behavioural symptoms (Yirmiya, 1996). The symptoms of sickness behaviour can be effectively attenuated by pretreatment with antidepressants (Yirmiya, 1996; Shen et al., 1999; Yirmiya et al., 2001). It is thought that the LPS-induced production of pro-inflammatory cytokines forms the basis for this phenomenon (Dantzer et al., 1998a). Therefore, the effect of antidepressant treatment on cytokine production in endotoxaemic animals has been investigated. Shen et al. reported that chronic treatment with the TCA desipramine inhibits the LPS-induced TNF- $\alpha$ production and potentiates the secretion of $I L-10$ in response to LPS administration (Shen et al., 1999). The desipramine pretreatment also attenuated the LPS-induced behavioural response. However, neither the SSRI paroxetine, nor the SNRI venlafaxine had any effect on the behavioural response or on the secretion of TNF $\alpha \alpha$ and IL-10. In contrast, chronic treatment with imipramine or fluoxetine had no effect on the LPS-induced splenic TNF- $\alpha$ and IL-1 $\beta$ mRNA expression, although fluoxetine was effective in attenuating some of the effects on behaviour and also on the LPS-induced activation of the hypothalamo-pituitaryadrenal axis (HPA-axis) (Yirmiya et al., 2001). In a recent study, it was found that the atypical antidepressant tianeptine effectively reduced symptoms of sickness behaviour induced by peripheral administration of either LPS or IL-1 $\beta$ (Castanon et al., 2001). This effect was not seen when LPS or IL-1 $\beta$ was administered by intracerebroventricular injection, suggesting that tianeptine attenuated peripheral rather than central cytokine actions on behaviour. Additionally, only chronic, but not acute, tianeptine pretreatment attenuated the LPS-induced sickness-behaviour. 
Connor et al. (2000) examined the production of IL-1 $\beta$ and TNF- $\alpha$ after an LPS-challenge in olfactory bulbectomized rats. This animal model of depression exhibits many behavioural, neurochemical, endocrine and immune alterations that are qualitatively observed in clinically depressed patients. Furthermore, chronic antidepressant treatment is able to reverse these effects (Kelly et al., 1997). Olfactory bulbectomized rats displayed decreased IL- $1 \beta$ and TNF- $\alpha$ levels after LPS injection compared to sham-operated control rats. Chronic pretreatment with desipramine decreased the production of IL-1 $\beta$ and TNF- $\alpha$ in control rats and further reduced the production of these cytokines in olfactory bulbectomized rats (Connor et al., 2000).

It has been shown that chronic imipramine treatment in animals subjected to chronic mild stress (CMS) effectively reverses the reduced sucrose intake (a measure for anhedonia) in the stressed animals (Kubera et al., 1995). This reversal is accompanied by a reduced proliferation of splenocytes in response to mitogen, only in the stressed animals. Moreover, in these stressed animals (and not in control animals), the production of IL-1 and IL-2 by splenocytes was significantly reduced after chronic imipramine administration (Kubera et al.., 1996). In another study, it was shown that chronic desipramine treatment significantly increases the capacity of splenocytes to produce IL-10, from both control and CMS-subjected animals. The capacity of splenocytes to produce IL-2, IL-4 and IFN- $\gamma$ was unaffected (Kubera et al., 2001b). In addition, acute administration of desipramine in mice, caused an increase in the stimulated production of IL-10 from splenocytes, an effect that was completely reversed by an acute stressor (Kubera et al., 1998). In the same splenocytes, the production of IFN- $\gamma$, IL-2 and IL- 4 were unaltered following desipramine treatment. The secretion of IFN- $\gamma$ however, was severely inhibited by the acute stressor, regardless of desipramine treatment. Recent studies from Kubera et al., showed that prolonged ( 28 day) administration of the TCAs amitriptyline and desipramine and the SSRIs fluoxetine and citalopram, increases the stimulated production of IL- 10 by splenocytes from normal (not subjected to chronic mild stress) mice (Kubera et al., 2000a, c).

It is concluded that the production of the pro-inflammatory cytokines TNF- $\alpha$ and $I L-J \beta$ is reduced after chronic (pre-)treatment with TCAs like imipramine and desipramine. In addition, both antidepressants seem to upregulate the production of IL-10. Hence, especially TCAs have anti-inflammatory effects invivo and could contribute to successful antidepressant therapy in depressed patients that display hypersecretion of cytokines (Shen et al., 1999). The influence of SSRIs on cytokine production in these animal models remains unclear. 


\section{EFFECTS OF ANTIDEPRESSANTS ON CYTOKINES IN THE BRAIN}

Only few studies report on the effects of antidepressants on cytokine expression in the brain. Suzuki et al. found that imipramine, fluvoxamine and maprotiline increase mRNA levels of IL-1 $\beta$ and IL-1RA in several regions of the rat brain (Suzuki et al., 1996). The expression of IL-1RA mRNA was much more increased than that of $I L-1 \beta$, suggesting that chronic exposure to the antidepressants induces an IL-1 antagonistic activity in the brain. Interestingly, the maximal increase in IL-IRA mRNA was observed after 28 days of treatment, which parallels that of the clinical onset of antidepressants. However, the effects of the antidepressants was not specific, since also several neuroleptics were found to increase the mRNA of these cytokines (Suzuki et al., 1996).

It has been shown that some cytokines, including TNF- $\alpha$, may play a physiological role in neurotransmission (Vitkovic et al., 2000). Thus, low levels of TNF- $\alpha$ are found within neurons of the hippocampus, locus coeruleus (LC) and hypothalamus of normal rats (Ignatowski and Spengler, 1994). Acute desipramine administration induces an accumulation of TNF- $\alpha$ mRNA in the LC and increases TNF- $\alpha$ protein levels in the hippocampus (Ignatowski and Spengler, 1994). Chronic desipramine administration also increases total hippocampal TNF- $\alpha$ content but decreases neuronal associated TNF- $\alpha$ in hippocampus and LC (Ignatowski et al., 1997), although no differences were found in the accumulation of TNF- $\alpha$ mRNA (Nickola et al., 2001). Whether this points to an increased release or degradation of TNF- $\alpha$ protein is not clear, just as is the role of this phenomenon in antidepressant drug action. It is suggested that TCAs as well as SSRIs may alter the regulatory effect of TNF- $\alpha$ on noradrenaline release in conjunction with $\alpha_{2}$-adrenergic receptors (Nickola ef al., 2001).

\section{POSSIBLE MECHANISMS OF ANTIDEPRESSANT ALTERED CYTOKINE PRODUCTION}

Only few studies have addressed the issue of how antidepressants may modulate cytokine secretion. Nevertheless, several possible mechanisms can be suggested from the present data. It should be noted that one must distinguish the different approaches used to examine the effects of antidepressants on cytokine secretion. Thus, the mechanism underlying the effects of antidepressants on ex-vivo cytokine production by lymphocytes may be different from that underlying the decrease in plasma levels of pro-inflammatory cytokines in depressed patients. 
Moreover, different mechanisms may be involved in the modulation of cytokine production in humans versus laboratory animals.

A furst possible mechanism may be related to the effect of antidepressants on the serotonergic system. The presence of receptors for serotonin on immune cells has been demonstrated, both in humans and in animals (Aune et al., 1993, 1994; Stefulj et al., 2000). Further, serotonin may influence cytokine production. Arzt et al, showed that serotonin inhibits the stimulated production of IFN- $\gamma$ by human PBMCs and of TNF- $\alpha$ in human monocytes (Arzt et al., 1988, 1991). In a recent study it was shown that serotonin, in supraphysiological concentrations $(1.5$ and $15 \mu \mathrm{g} / \mathrm{ml})$, decreased the IFN- $\gamma$ production in stimulated whole blood (Kubera et al., 2000b). These findings are similar to those found with antidepressant drugs. There are, however, numerous reports which show immune-enhancing effects of serotonin. This discrepancy may be explained by the following. Experiments with para-chlorophenylalanine (PCPA: an inhibitor of serotonin synthesis that depletes intracellular serotonin) indicate that endogenous serotonin is necessary for optimal immune function. PCPA inhibits T-cell proliferation and activation (Young et al., 1993; Aune et al., 1994; Young and Matthews, 1995), effects that can be reversed by the addition of serotonin to the culture medium. Kubera et al. (2000b) found that PCPA inhibits the production of both IFN- $\gamma$ and IL-10. Further, low doses of serotonin (in the range of physiological concentrations) promote the production of IFN- $\gamma$ and IL-2 (Hellstrand et al., 1993; Young et al., 1993). Taken together, these data suggest that intracellular serotonin and low concentrations extracellular serotonin are necessary for optimal production of cytokines and normal immune functions, whereas higher concentrations of serotonin (e.g. supra-physiological) are immunosuppressive and inhibit cytokine production. Lymphocytes and monocytes are able to synthesize and secrete serotonin upon stimulation with mitogens (Finocchiaro et al., 1988; Aune et al., 1994). Therefore, in in-vitro studies with immune cells, stimulation with LPS or mitogens results in increased concentrations of extracellular serotonin. Antidepressants (especially SSRIs) that inhibit the reuptake of serotonin may further increase serotonin concentrations in culture medium (Ferjan and Erjavec, 1996). This may resuit in high extracellular serotonin concentrations and the subsequent inhibition of cytokine production. As such, this may explain the inhibitory effect of antidepressants on cytokine secretion when added invitro. In Section 2, it was mentioned that treatment with antidepressants might normalize elevated cytokine levels in depressed patients. It has been shown that prolonged pharmacotherapy can result in a depletion of serotonin from platelets and blood cells, and in a decrease of serotonin plasma levels (Karage et al., 1994; Fekkes et al., 1997; Alvarez et al., 1999). Therefore, since physiological serotonin levels are indispensable for cytokine production, it is suggested that 
reduction of these concentrations and/or depletion of intracellular serotonin might result in a down-regulation of cytokine production and in the subsequent decrease of cytokine plasma levels.

A second possible mechanism of antidepressant altered cytokine production revolves around the capacity of antidepressants to increase intraceliular concentrations of cyclic adenosine monophosphate (cAMP). Indeed, it has been shown that antidepressants of several classes may increase cAMP levels in immune cells. Xia et al. (1996) found that a 24h. pre-incubation with imipramine, clomipramine or citalopram enhances CAMP concentrations after stimulation in both monocytes and lymphocytes. Others found that fluoxetine at pharmacological concentrations increases cAMP formation in T-lymphocytes when optimal stimulation conditions were employed (Edgar et al., 1999). cAMP is formed from ATP by the enzyme adenylate cyclase. The activity of this enzyme is modulated by several G-protein coupled receptors. For example, $\beta_{2}$ adrenergic receptors are positively coupled to adenylate cyclase and stimulate CAMP formation after ligand binding. Some serotonergic receptors $(5-\mathrm{HT}$ receptors) are also positively coupled to adenylate cyclase (5HT-4, 5HT-6 and 5HT-7 receptors), whereas others are negatively coupled and will downregulate adenylate cyclase activity ( $5 \mathrm{HT}-1 \mathrm{~A}$ receptor). It is thought that cAMP activates Protein Kinase A (PKA), a kinase that in turn stimulates other downstream enzymes, including transcription factors like cAMP responsive element binding protein (CREB). Activation of the cAMP/PKA cascade results in altered cytokine expression (for review see Zidek, 1999). It is generally believed that pharmacological augmentation of cAMP down-regulates the expression of proinflammatory cytokines like IFN- $\gamma$ and TNF- $\alpha$ (Benbernou et al., 1997; Eigler et al., 1998; Brideau et al., 1999) and increases that of IL-10 (Platzer et al., 1995, 1999; Benbernou et al., 1997; Eigler et al., 1998). Thus, antidepressant induced increases in CAMP levels, may result in a decreased production of IFN$\gamma$ and in an enhanced IL-10 secretion. However, we should mention that in our laboratory, we were not able to confirm that antidepressants (imipramine and paroxetine) increased cAMP levels in human PBMCs after stimulation with LPS and PHA (Kenis et al., 2003). Moreover, in stimulated whole blood, the antidepressant induced decrease in IFN- $\gamma$ and TNF- $\alpha$ production, could only partially be reversed by pre-incubation with antagonists of adenylate cyclase (which reduces CAMP formation) or PKA (see Chapter 7). In this respect, it should be noted that the influence of fluoxetine on cAMP levels is dependent on the conditions of stimulation (Edgar et al., 1999). 


\section{CONCLUSION}

Accumulating evidence suggests that major depression is associated with an upregulation of pro-inflammatory cytokines. It remains elusive whether these cytokines play a causative role in major depressive disorders, although the majority of data point to this direction. Therefore, it is warranted to examine the influence of antidepressants on cytokine production, since a causative relationship implies an inhibitory effect of antidepressants on pro-inflammatory cytokines. Reports from studies comparing cytokine levels and/or ex-vivo cytokine production before and after pharmacotherapy in depressed patients, present divergent and sometimes conflicting results. Nevertheless, we carefully conclude that antidepressant treatment may normalize cytokine production in depressed patients. As mentioned before, differences in methodology and heterogeneity of the study population may underlie these discrepancies. The need to use more standardized and immunological relevant methods in the investigation of cytokine homeostasis in psychiatric patients is put forward. When examining ex-vivo cytokine production, the use of diluted, stimulated whole blood cultures is preferred. Circulating cytokine levels in serum or plasma should be determined with specific, sensitive and well-standardized immuno-assays (e.g. ELISA). Further, it is possible that not all patients suffering form major depression display a hypersecretion of cytokines. It may therefore be warranted to differentiate patients into individuals with elevated cytokine levels and those who have not. The examination of cytokine alterations during treatment and the comparison of different antidepressants in this effect, may give more insight into both the pathophysiology of major depression and the mechanism of action of antidepressant drugs. Concerning in-vitro studies, it is clear that antidepressants of different classes have negative immunoregulatory effects. These data indicate that antidepressants may downregulate pro- and upregulate anti-inflammatory cytokines. However, it should be noted that they reflect acute effects on cytokine production. In view of the delayed clinical onset of antidepressants, one should keep in mind that only studies dealing with chronic exposure to antidepressants may be relevant. Yet, it is conceivable that acute effects on cytokine production, which are maintained during prolonged treatment, is reflected in improved depressive symptomatology only after the biological processes related to the behavioural effects of cytokines are restored. The use of animal models may be a suitable tool to examine the influence of antidepressants on cytokine production. Chronic treatment with TCAs seems to inhibit pro-inflammatory cytokine secretion and entances the production of $1 \mathrm{~L}-10$. Whether the same is true for other antidepressants remains to be determined. Animal models may also serve 
as an efficient tool to study cytokine expression in the brain and the influence of antidepressants on it. Until now, no studies have really dealt with this issue.

More research is obviously needed to establish the exact influence of anticlepressants on cytokine production and the mechanisms underlying these effects. Undoubtedly, clarification of these questions will provide more insight into the pathophysiology of major depression and could contribute to the search for more efficient antidepressant drugs.

\section{REFERENCES}

Abbas AK, Murphy KM, Sher A, (1996) Functional diversity of helper T lymphocytes. Noture 383: 787-793.

Alvarez JC, Gluck N, Fallet A, Gregoire A, Chevalier JF, Advenier C Spreux-Varoquaux $O$, (1999) Plasma serotonin level after I day of fluoxetine treatment: a biological predictor for antidepressant response? Psychopharmacology (Berl) 143: 97-101

Anisman $H$, Ravindran AV, Griffiths J, Merali $Z$, (1999) Interleukin-I beta production in dysthymia before and after pharmacotherapy. Biol Psychiatry 46:1649-1655.

Arzt $E$, Costas M, Finkielman $S$, Nahmod VE, (1991) Serotonin inhibition of tumot necrosis factor-alpha synthesis by human monocytes. Life Sci $48: 2557-2562$.

Arzt ES, Fernandez-Castelo S, Finocchiaro LM, Criscuolo ME, Diaz A, Finkielman S , Nahmod VE, (1988) Immunomodulation by indoleamines: serotonin and melatonin action on DNA and interferon-gamma synthesis by human peripheral blood mononuclear cells. $I$ Cin Inmunol 8: 513-520.

Aune TM, Golden HW, McGrath KM, (1994) Inhibitors of serotonin synthesis and antagonists of serotonin $1 \mathrm{~A}$ receptors inhibit $\mathrm{T}$ lymphocyte function in vitro and cell-mediated immunity in vivo. J Immunol 153:489-498.

Aune TM, McGrath KM, Sarr T, Bombara MP, Kelley KA, (1993) Expression of 5HTla receptors on activated human $T$ cells. Regulation of cyclic AMP levels and $T$ cell proliferation by 5-hydroxytryptamine. J Immunol 151:1175-1183.

Benbemou N, Esnault S. Shin HC, Fekkar H, Guenounou M, (1997) Differential regulation of IFN-gamma, $\mathbb{L}-10$ and inducible nitric oxide synthase in human $\mathrm{T}$ cells by cyclic AMPdependent signal transduction pathway. Immmology 91: 361-368.

Brideau C, Van Staden C, Styluler A, Rodger IW, Chan CC, (1999) The effects of phosphodiesterase type 4 inhibitors on tumour necrosis factor $\alpha$ and leukotriene $B 4$ in a novel human whole blood assay. Br.J Pharmacol 126: 979-988.

Castanon N, Blwthe RM, Dantzer R, (2001) Chronic treatment with the atypical antidepressant tianeptine attenuates sickness behaviour induced by peripheral but not central lipopolysaccharide and interleukin-I beta in the rat. Psychophormacology (Berl) 154: 50 60 .

Connor TJ, Harkin A, Kelly JP, Leonard BE, (2000) Olfactory bulbectomy provokes a Suppression of interleukin-1 beta and tumour necrosis factor-alpha production in response to an in vivo challenge with lipopolysaccharide: effect of chronic desipramine treatment. Neuroimmunomodulation 7: 27-35.

Connor TJ, Leonard BE, (1998) Depression, stress and immunological activation: the role of cytokines in depressive disorders. Life Sci 62: 583-606. 
Dantzer $R$, Bluthe RM, Gheusi G, Cremona S, Laye S, Parnet P. Kelley KW, (1998a) Molecular basis of sickness behaviour. Ann N Y Acad Sci 856:132-138.

Deintzer R, Bluthe RM, Laye S, Bret-Dibat JL, Pamet. P, Kelley KW, (1998b) Cytokines and sickness behaviour. Am N Y Acad Sc 840: 586-590.

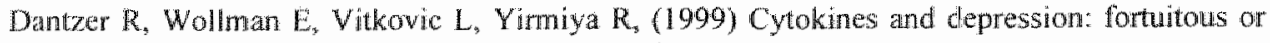
causative association? Mol Psphictry 4: 328-332.

De Groote D, Gewaert $Y$, Lopez M, Gathy R, Fauchet F, Dehart 1, Jadoul M, Radoux D, Franchimont $P_{4}$ (1993) Novel method for the measurement of cytokine production by a onestage procedure. I Immunol Methods $163: 259-267$.

De Groote D, Zangerle PF. Gevaert Y, Fassotte MF, Beguin Y, Noizat-Pireme F, Pirenne J, Gathy $R$, Lopez $M$, Dehart I, Igot D, Baudrihaye M, Delacroix D, Franchimont P: (1992) Dinect stimulation of cytokines (LL- $1 \beta$, TNF- $\alpha, 1 L-6, \pi L-2$, IFN- $\gamma$ and GM-CSF) in whole blood. 1. Comparison with isolated PBMC stimulation. Cyokine 4: 239-248.

Edgar VA, Sterin-Borda $\mathbb{L}_{,}$Cremaschi GA, Genaro AM, (1999) Role of protein kinase $C$ and CAMP in fluoxetine effects on human T*cell proliferation, Eur J Pharmacol 372:65-73.

Eigler A, Siegmund B, Emmerich U, Baumann KH, Hartmana G, Endres $\mathrm{S}$, (1998) Antiinflanmatory activities of cAMP-elevating agents: erihancement of $1 \mathrm{~L}-10$ synthesis and concuremt suppression of TNF procuction. J Lewkoc Biol 63: 101-107.

Fekkes D, Timmerman L, Pepplinkhuizen L, (1997) Effects of clomipramine on plasma amino acids and serotonergic parameters in panic disorder and depression. Eur Neuropsychopharmacol 7:235-239.

Ferjan 1 . Fravec $\mathrm{F},(1996)$ Changes in histamine and serotonin secretion from rat peritoneal mast cells caused by antidepressants. Inflamm Res 45: 141-144.

Finocchiaro LM, Ant ES, Fernandez-Castelo S, Criscuolo M, Finkielman S, Nahmod VE, (1988) Serotonin and melatonin synthesis in peripheral blood mononuclear cells: stimulation by interferon-gamma as part of an immunomodulatory pathway. Jnterferon Res 8: 705-716.

Frommberger UH, Bauer J, Haselbauer P, Fraulin A, Riemann D, Berger M, (1997) Interleukin6-(IL-6) plasma levels in depression and schizophrenia: comparison between the acute state and after remission. Eur Arch Psychiatry Clin Neunasci 247: 228-233.

Hellstrand K, Czerkinsky C, Ricksten A, Jansson B, Asea A, Kylejord H, Hermodsson S, (1993) Role of serotonin in the regulation of interferon-gamma production by human natural killer cells. J Intevferon Res 13:33-38.

Hinze-Selch D, Schuld A, Kraus T, Kuhn M, Uhr M, Haack M, Pollmacher T, (2000) Effects of antidepressants on weight and on the plasma levels of leptin, TWF-alpha and soluble TNF receptors: A longitudinal study in patients treated with amitriptyline or paroxetine. Newropsychophamacology $23: 13-19$.

Ignatowski TA, Noble BK, Wright JR, Gorfien JL, Heffner RR, Spengler RN, (1997) Neuronalassociated tumor necrosis factor (TNF alpha): its role in noradrenergic functioning and nodification of its expression following antidepressant drug administration. J Neuroimmunol $79: 84-90$.

Ignatowski TA, Spengler RN, (1994) Tumor necrosis factor-alpha: presynaptic sensitivity is modilied after antidepressant drug administration. Brain Res 665: 293-299.

Karage F, Widmer J. Bovien P, Gaillard IM. (1994) Platelet serotonin and plasma tryptophan in depressed patients: elfect of drug treatment and clinical outcome. Neuropsychophamacology. 10:207-214.

Katsikis PD, Coluen S, Londei, Feldmann M, (1995) Are CD4+ THI cells pro-inflammatory or anti-inflammatory? The ratio of $\| \mathrm{L}-10$ to $\mathrm{VFN}$-gamma or $1 \mathrm{~L}-2$ determines their function. $/ m$ t immunot 7: $1287-1294$. 
Kenis $\mathrm{O}$, Steinbusch H, De Baets M, Maes M, (2003) Influence of antidepressants on intracellular levels of cyclic adenosine monophosphate in human peripheral blood mononuclear oells. Eur Neuropsychopharmacol 13:53-56.

Kelly JP, Wrym AS, Leonard BE, (1997) The offactory bultectomized rat as an model of depression: an update. Pharmacol Ther $74: 299-316$.

Kleineman ES, Knowles RD, Blick MB, Zwelling LA, (1989) Lithim chtoride stimulates human monocytes to secrete tumor necrosis factor/cachectin. J Le 4 hoc Bio/ $46: 484-492$.

Kronfol $Z$, Remick DG, (2000) Cytokines and the brain: implications for clinical psychiatry. Am JPsychiary 157: 683-694.

Kubera M, Basta-Kaim A, Papp M, (1995) The effect of chronic treatment with imipramine on the immunoreactivity of animals subjected to a chronic mild stress model of depression. Immonophamacology $30: 225-230$.

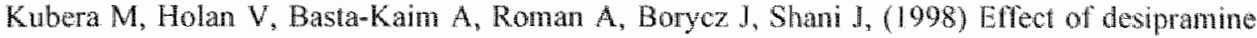
on immunological parameters in mice, and their reversal by stress. int I fmmunophormacol 20: $429-438$

Kubera M, Holan V, Mathison R, Maes M: (2000a) The effect of repeated amitriptyline and desipramine administration on cytokine release in $\mathrm{C} 57 \mathrm{BL} / 6$ mice. $P_{s y c h o n e w r o e n d o c t i n o l o g y}$ 25: 785-797.

Kubera M, Kenis G, Bosmans E, Scharpe , Maes M, (2000b) Effects of serolonin and serotonergic agonists and antagonists on the production of interferon-gamma and interleukin10. Neuropsychophamnacology 23: 89-98.

Kubera M, Lin A-H, Kenis G, Bosmans E, Van Bockstaele D, Maes M, (2001a) Antiinflammatory effects of antidepressants through suppression of the Interferon-y/laterleukin-10 production ratio. I of Clin Psychopharmacal 21 : 199-206.

Kubera M, Maes M, Holan V, Basta-Kaim A, Roman A, Shani J, (2001 b) Prolonged desipramine treatment increases the production of interleukm- 10, an anti-inflammatory cytokine, in C57BL/6 mice subjected to the chronic mild stress model of depression. I Affect Disord 63 : $171-178$.

Kubera M, Simbirtsev $A$, Mathison $\mathbb{R}$, Maes $M$, (2000c) Effects of repeated fluoxetine and citalopram administration on cytokine release in C57BL/6 mice. Psychiamy Res 96:255-266.

Kubera M, Symbirtsev A, Basta-Kaim A, Borycz J, Roman A. Papp M, Claesson M, (1996) Effect of chronic treatment with imipramine on interleukin 1 and interleukin 2 production by splenocytes obtained from rats subjected to a chronic mild stress model of depression. Pol J Pharmacol 48: 503-506.

Kucharz EJ, Sierakowski SJ, Goodwin JS, (1993) Lithium in vitro enthances interleukin-2 production by $T$ cells from patients with systemic lupus erythematosus. Immowopharmacof Immunotoxicol 15: 515-523.

Landmann R, Schaub B, Link S, Wacker HR, (1997) Unaltered monocyte function in patients with major depression before and after three months of antidepressive therapy. Biol Psychiatry 41: 675-681.

Lanquillon S, Krieg JC, Bening-Abu-Sach UHV, (2000) Cytokine production and treatment response in major depressive disorder. Neuropsychopharmacologv 22: 370-379.

Licinio J, Wong M-L, (1999) The role of inflammatory mediators in the biology of major depression: central nervous system cytokines modulate the biological substrate of depressive symptoms, regulate stress-responsive systems, and contribute to neurotoxicity and neuroprotecion. Mol Psychiary 4: $317-327$.

Lin A-h, Song C, Kenis G, Bosmans E, De Jongl R, Scharpe S, Maes M, (2000) The in vitro immunosuppressive effects of modlobemide in healthy volunters. Affect Disord 58: 69-74. 
Maes M (1999) Major depression and activation of the inlammatory response system. In: Dantzer, R. (Eds.). Cyrokines, Stress and Depression (pp. 25-46) New York: Klnwer Academic / Plenum Publishers.

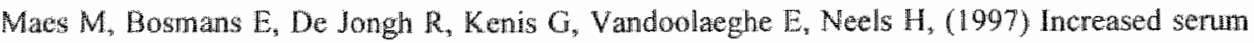
IL -6 and IL-I receptor antagonist concentrations in major depression and treatment resistant depression. Cylokine 9: $853-858$.

Maes M, Mellzer HY, Eugene B, Bergmans R, Vandoolaeghe E, Ranjan R, Desnyder R, (1995) Increased concentrations of interleukin 6 , soluble interleukin-6, soluble interleukin-2 and transferrin receptor in major depression. $J$ Affect Disord 34: 301-309.

Maes $M_{*}$ Song $C$, Lin A-h, Bonaccorso S, Kenis G, De Jongh R, Bosmans E, Scharpe S, (1999a) Negative immunoregulatory effects of antidepressants: inhibition of interferon- $\gamma$ and stimulation of interleukin 10 secretion. Neuropsychopharmacology $20: 370-379$.

Maes $M$, Song C, Lin AH, Ploli $\mathbb{R}$, Kenis $G$, Kubera , Bosmans E, (1999b) In vitro immunoregulatory effects of lithium in healthy volunteers. Psychopharmocology (Beri) 143: $401-407$.

Merendino RA, Arena A, Gangemi S, Ruello A, Losi E, Bene A, D'Ambrosio FP, (2000) In vitro interleukin 8 production by monocytes treated with lithium chloride from breast cancer patients. Tumori 86: 149-152.

Muller N, Riedel M, Gruber R, Ackenheil M, Schwarz MJ, (2000) The immune system and schizophrenia. An integrative view. Anw $N Y$ Acad Sci 917:456-467.

Nickola T,, Ignatowski TA, Reynolds JL, Spengler RN, (2001) Antidepressant drug-induced alterations in neuron-localized tumor necrosis factor-alpha mRNA and alpha(2)-adrenergic receptor sensitivity. I Phamacol Exp Ther 297: 680-687.

Peters M, Muller AM, Rose-John S, (1998) Interleukin-6 and soluble interleukin-6 receptor: direct stimulation of gp 130 and hematopoiesis. Btood 92: 3495-3504.

Platzer C, Fritsch E Elsner T, Lehmann MH, Volk HD, Prosch S, (1999) Cyclic adenosine monophosphate-responsive elements are involved in the transcriptional activation of the human \L-10 gene in monocytic cells. Eur J Immwhol 29: 3098-3104.

Platzer C, Meisel C, Vogt K, Platzer M, Volk HD, (1995) Up-regulation of monocytic IL-10 by tumor necrosis factor-alpha and CAMP elevating drugs. Int Immumol 7: 517-523.

Rapaport MH, Guylai , Whybrow $\mathrm{P},(1999)$ Immune parameters in rapid cycling bipolar patients before and after lithium treatment. J Psychiatr Res 33: 335-340.

Rapaport MH, Manji HK, (2001) The effects of lithium on ex vivo cytokine production. Biol Psychiary 50: $217-224$.

Rothermundi M, Arolt V, Fenker J, Gutbrodt H., Peters M, Kirchner H, (2001a) Different imumune pattems in melancholic and non-melancholic major depression. Eur Arch Psychiary Clin Nesrosci 251: 90-97.

Rothermundt M, Arolt V, Peters M, Gutbrodt $H$, Fenker J, Kersting A, Kirchner H, (2001b) Inflammatory markers in major depression and melancholia. J Affect Disord 63: 93-102.

Seidel A, Arolt V, Hunstiger M, Rink L, Behnisch A, Kirchner H, (1995) Cytokine production and serum proteins in depression. Scand J Immumol $41: 534-538$.

Seidel A, Arolt V. Huntstiger $M_{*}$ Rink L, Belnnisch A, Kirchner H, (1996) Increased CDS6. natural killer cells and related cytokines in major depression. Clin Immmnol Immunopahol $78: 83-85$.

Shen Y, Connor TJ, Nolan Y, Kelly JP, Leonard BE, (1999) Differential effect of chronic antidepressant treatments on lipopolysaccharide-induced depressive-like behavioural symptoms in the rat. Life Sci 65 : 1773-1786. 
Sluzewska A, Rybakowski JK. Laciak M, Mackiewicz A, Sobieska M. Wiktorowicz K, (1995) Interleukin-6 serum levels in depressed patients before and after treatment with tuoxetine. Am N Y Acad Sci $762: 474-476$.

Sluzewska A, Sobieska M, Rybakowski $\mathbb{K}$, (1997). Changes in acute-phase proteins during lithium potentiation of antidepressants in refractory depression. Neuropsychobiology $35: 123$ m 127.

Stefulj J, Jemej B, Cicin-Sain L. Rinner I, Schauenstein K, (2000) mRNA expression of serotonin receptors in cells of the immume tissues of the rat. Brain Behav Wmm 14:219-224.

Suzuki E, Shintani F, Kanba $S_{*}$ Asai M, Nakaki T, (1996) Induction of interleukin- 1 beta and. interleukin-1 receptor antagonist mRNA by chronic treatmont with various psychotropics in widespread area of rat brain. Newasci Let 215:201-204.

Vitkovic L, Bockaert J, Jacque C, (2000) "Inflammatory" cytokines: netromodulators in nomal brain? I Neurochem 74: 457-471.

Weizman R, Laor N, Podliszewski E, Notti I, Djaldetti M, Bessler H, (1994) Cytokine production in major depressed patients before and after clomipramine treatment. Biol Psychiary $35: 42$. 47.

Wilson R, Fraser WD, Mckillop JH, Smith J, OReilly DS, Thonuson JA, (1989) The "in vitro" effects of lithium on the immune system. Aufoimmunity 4: 109-114.

Wu YY, Yang XH, (1991) Enhancement of interleukin 2 production in human and Giblon T cells after in vitro treatment with lithium. Proc Soc Exp Biol Med 198: 620-624.

Xia Z, DePierre JW, Nassberger L, (1996) Tricyclic antidepressants inhibit $1 \mathrm{~L}-6, \mathrm{LL}-1 \beta$ and TNF$\alpha$ relerse in human blood monocytes and $\mathrm{IL}-2$ and interferon-y in $T$ calls. Immunopharmacology 34: $27-37$.

Yaqoob P, Newsholme EA, Calder PC, (1999) Comparison of cytokine production in cultures of whole luman blood and purified mononuclear cells. Cytokine 11:600-605.

Yirmiya R, (1996) Endotoxin produces a depressive-like episode in rats. Brain Res 71::163-174.

Yirmiya R, Pollak $Y$, Barak O, Avitsur R, Ovadia $H$, Bette M, Weihe E, Weidenfeld I, (2001) Effects of antidepressant drugs on the behavioural and physiological responses to lipopolysaccharide (LPS) in rodents. Neuropsychophammacology 24: $531-544$.

Young MR, Kut JL, Coogan MP, Wright MA, Young ME, Matthews J, (1993) Stinulation of splenic T-lymphocyte function by endogenous serotonin and by low-dose exogenous serotonin. Tmmonology 80:395-400.

Young MR, Mathews JP. (1995) Serotonin regulation of T-cell subpopulations and of macrophage accessory function. Immunology $84: 148-152$.

Zangerle PF, De Groote D, Lopez M, Meuleman RJ, Vrindts Y, Fauchet F, Dehart I, Jadoul M, Radoux D, Franchimont P, (1992) Ditect stimulation of cytokines (L-1 beta, TNF-alpha, IL6, 1L-2, IFN-ganma and GM-CSF) in whole blood: II. Application to the umatoid arthritis and osteoarthritis. Cyrokine 4: 568-575.

Zidek Z, (1999) Adenosine-cyclic AMP pathways and cytokine expression. Eur Cytokine Netw 10:319-328. 
Stability of interleukin-6, soluble interleukin-6 receptor, interleukin-10 and CC16 in human serum

Gunter Kenis, Charlotte Teunissen, Raf De Jongh, Eugène Bosmans, Harry Steinbusch, Michael Maes

Cytokine (2002), 19. pp. 228-235 


\begin{abstract}
The stability of interleukin 6 (IL-6), its soluble receptor (sIL-6R), IL-10 and $\mathrm{CCl} 6$ or uteroglobin (an endogenous cytokine inhibitor) in human serum was examined using an accelerated stability testing protocol according the Arrhenius equation. Further, the effect of time delay between blood sampling and sample processing, clotting temperature and repeated freeze-thaw cycles on serum levels of these proteins were determined. Paired serum samples were stored at $4{ }^{\circ} \mathrm{C}, 20^{\circ} \mathrm{C}, 30^{\circ} \mathrm{C}$ and $40^{\circ} \mathrm{C}$ for 1 to 21 days. We found that $\mathrm{IL}-6$ and $\mathrm{CC} 16$ concentrations did not change at $4^{\circ} \mathrm{C}, 20^{\circ} \mathrm{C}$ and $30^{\circ} \mathrm{C}$. IL-6 concentrations significantly declined after 11 days at $40^{\circ} \mathrm{C}$. The concentrations of sIL-6R and IL-10 did not change at $4^{\circ} \mathrm{C}$ but significantly decreased at $20^{\circ} \mathrm{C}$ (after 21 and 14 days respectively), $30^{\circ} \mathrm{C}$ and $40^{\circ} \mathrm{C}$ (after 1 day at both temperatures for both cytokines). Arrhenius-plots indicated that $\mathrm{sIL}-6 \mathrm{R}$ and $\mathrm{IL}-10$ are stable for at least several years at $-20^{\circ} \mathrm{C}$ and $-70^{\circ} \mathrm{C}$, respectively. Since their relative stability, no Arrhenius-plot could be calculated for IL-6 and CC16. The concentrations of the proteins examined were not significantly altered by repeated freeze-thaw cycles, nor by extended clotting times at $4^{\circ} \mathrm{C}$ or $20^{\circ} \mathrm{C}$. We conclude that serum samples for the determination of IL-6, sIL-6R and CC16 can be stored at $-20^{\circ} \mathrm{C}$ for several years, but for [L-10 determinations, storage at $-70^{\circ} \mathrm{C}$ is recommended.
\end{abstract}




\section{INTRODUCTION}

During the past decade, cytokines and other inflammatory mediators have been extensively investigated in various diseases, including autoimmune diseases, psychiatric disorders (major depression, schizophrenia, anxiety and eating disorders) (Lin et al., 1998; Maes et al., 1999) and neurodegenerative diseases (e.g. Alzheimer's disease) (Bonaccorso et al., 1998). To study the role of cytokines in these human diseases, samples of biological fluid (serum, plasma, cerebrospinal fluid, synovial fluid, etc.) are collected, processed and concentrations of the respective cytokines determined by immuno-assays, e.g. radio immuno-assays (RIA's) or enzyme immuno-assays (EIA). However, two types of bias can interfere with study results, i.e. the biological and preanalytical variability. Biological variability comprises all fluctuations in analyte concentrations due to natural conditions, such as seasonal and diurnal variability, age, gender, the menstrual cycle and other conditions that change the analyte concentration in-vivo (Fraser, 1986; Maes et al., 1995). Pre-analytical variability can be described as the variation in the analyte concentrations due to pre-analytical conditions such as blood sampling, storage etc. The present study focuses on the pre-analytical variability as a possible source of error in studies concerning cytokines or other serum proteins.

When collecting serum or plasma for cytokine determinations, attention should be paid to the processing of the samples, since it is known that anti-coagulants and time before centrifugation may influence cytokine concentrations (Thavasu et al., 1992; De Jongh et al., 1997; Flower et al., 2000). Cytokines have short half lives in-vivo and may be further degradated ex-vivo. On the other hand, exvivo induction of cytokines or other inflammatory mediators during blood processing can occur (Riches et al., 1992; Thavasu et al., 1992). This is especially important when blood samples are collected and later transported to the laboratory for processing (centrifugation, separation of plasma or serum and storage). Moreover, in longitudinal studies, samples are collected over time, stored at $-20^{\circ} \mathrm{C}$ or $-70^{\circ} \mathrm{C}$, and then simultaneously analysed in order to minimize inter-assay variability. However, it has remained unknown whether inflammatory mediators like cytokines are degradated during long-term storage or denatured by the freezing and thawing process. Thus, it is of great importance to know how long samples can be stored before measurement of the respective protein by immuno-assay is affected.

Therefore, we examined the stability of several inflammatory mediators using an accelerated stability testing protocol. This procedure is based on the Arrhenius equation, which describes a linear relationship between the logarithm of the reaction rate constant (e.g. the degradation rate) and the inverse of the absolute temperature (Kirkwood, 1977; Anderson and Scott, 199]; Ruiz et al., 
1996). The degradation rate constant $k$ at different temperatures is determined. The logarithm of $k$ is plotted versus the inverse of the absolute temperature, which gives the so called Arrhenius-plot. Using the equation of the best-fit line, one can calculate the degradation rate constant at every desirable temperature.

The specific aims of this study were 1) to examine the stability of interleukin 6 (IL-6), soluble IL-6 Receptor (sIL-6R), IL-10 and Clara Cell Protein 16 (CC16, an endogenous cytokine inhibitor) in serum using an accelerated stability testing protocol according to Arrhenius; 2) to examine the influence of clotting time (e.g. the time delay between blood sampling and sample processing) on protein concentration measurement by ELISA; and 3) to examine the effects of repeated freeze-thaw cycles on the measured protein concentration.

\section{METHODS}

\section{Samples}

Since serum concentrations of IL-6 and IL-10 are very low in healthy humans, the stability of these cytokines was examined in serum of five post-surgical patients admitted on an Intensive Care Unit. The stability of SIL-6R and CC16 was investigated in serum of the same patients and in that of three healthy volunteers. Blood of the patients was drawn from the first stopcock of an arterial line system (Pressure Monitoring Kit, Baxter BV, Utrecht, The Netherlands) after initial elimination of $10 \mathrm{ml}$ of blood. Then blood was collected in three $10 \mathrm{ml}$ and eight $5 \mathrm{ml}$ vacuumed serum tubes (SST Vacutainer@ Hemoguard, Becton Dickinson, Meylan, France). Blood from the healthy volunteers was drawn using Vacutainer Systems (Becton Dickinson, Mcylan, France). The collected blood was then processed as described below.

\section{Accelerated stability testing protocol}

The blood in the three $10 \mathrm{ml}$ serum tubes was allowed to clot for 30 minutes at room temperature and subsequently centrifuged for 15 minutes at $1600 \mathrm{xg}$. The serum from each subject was pooled in a sterile tube $(50 \mathrm{ml}$, Falcon $\otimes$, Becton Dickinson) and subsequently fractionated in sterile $1.5 \mathrm{ml}$ eppendorf tubes, 0.3 $\mathrm{ml}$ per tube. Then, the tubes were stored at the different stress temperatures. Eleven tubes were put at each stress temperature: $4^{\circ} \mathrm{C}, 20^{\circ} \mathrm{C}, 30^{\circ} \mathrm{C}$ and $40^{\circ} \mathrm{C}$. Three tubes were immediately frozen at $-20^{\circ} \mathrm{C}$ and served as controls.

For up to 21 days, at regular time points, one tube from each temperature was frozen at $-20^{\circ} \mathrm{C}$. At the end, all samples were kept at $-20^{\circ} \mathrm{C}$ until analysis. 


\section{Influence of clotting time}

To check the influence of the time delay between blood sampling and centrifugation, and the influence of clotting temperature, serum tubes were processed as follows.

Immediately after blood collection, four tubes per subject were put at $4^{\circ} \mathrm{C}$ and four were kept at room temperature. After 30 minutes, one tube at each temperature was taken and centrifuged for 15 minutes at $1600 \mathrm{xg}$. Serum was immediately collected and frozen at $-20^{\circ} \mathrm{C}$. The same procedure was repeated after 24, 48 and 96 hours. Samples were kept frozen until cytokine analysis.

\section{Cytokine analysis}

Cytokines were determined by enzyme linked immunosorbent assays (ELISA) from Eurogenetics (Tessenderlo, Belgium). Analysis was performed according manufacturer instructions. As stated by the manufacturer, the inter- and intraassay variability was lower then $10 \%$ for all assays used.

\section{Calculations and statistics}

We assumed that the concentration of the proteins in the samples that were kept frozen during the 21 -day stress period remained constant. The concentrations of the proteins in the stressed samples were compared to these control samples and the percentage recovery was calculated. After checking for normality using the Kolmogorov-Smirnov test, student t-test was used to compare the recovery after each time point (at each temperature) with the control samples. Further, the recovery was plotted versus days of heat stress and the slope of the best-fit line was determined. For IL-10 and sIL-6R, only the first three time points were used to calculate the best fit of the $40^{\circ} \mathrm{C}$ line because the concentration of both cytokines decreased to less than $20 \%$ after five days.

Then, the degradation rate was plotted versus the inverse of the absolute temperature times 1000 . The equation of the best-fit line was used to calculate the degradation constant at $-20^{\circ} \mathrm{C}$ and $-70^{\circ} \mathrm{C}$.

The kinetics of protein denaturation are comparable with that of a first order reaction (Kirkwood, 1977; Ruiz et al., 1996), which means that the degradation rate is proportional to the concentration of the respective analyte.

The equation is:

$$
-\mathrm{d}[\mathrm{C}] / \mathrm{dt}=\mathrm{k}[\mathrm{C}]
$$

or

$$
\log \left([\mathrm{C}] /[\mathrm{C}]_{0}\right)=-\mathrm{kt} / 2.303
$$


where $[\mathrm{C}]_{0}$ is the initial concentration and $[\mathrm{C}]$ is the concentration after time $t$. We additionally calculated the time after which $90 \%$ of the respective cytokine can be recovered, by substituting $[\mathrm{C}] /[\mathrm{C}]_{0}=0,90$ in the last equation.

\section{RESULTS}

\section{Stability}

The stability in serum of sIL-6R and CC 16 was investigated in 5 patients and 3 healthy controls, while the stability of $I L-6$ and $\mathbb{L L}-10$ in serum was investigated in patients only. The concentration of sterile samples of the subjects stored during 21 days at $4^{\circ} \mathrm{C}, 20^{\circ} \mathrm{C}, 30^{\circ} \mathrm{C}$ and $40^{\circ} \mathrm{C}$ were compared to triplicate samples of the same person frozen at $-20^{\circ} \mathrm{C}$. The mean concentrations of the serum proteins in patients and controls of the frozen samples are summarized in Table 1. The data depicted in Figure $\mathbb{I}(\mathrm{A})$ show that the IL-6 concentration in the serum samples stored at $4^{\circ} \mathrm{C}, 20^{\circ} \mathrm{C}$ and $30^{\circ} \mathrm{C}$ remained similar to the concentration in the frozen samples over 21 days. The relative stability of IL- 6 in serum at these three temperatures yielded to few data to calculate an Arrhenius-plot. The samples stored at $40^{\circ} \mathrm{C}$ showed a decline down to $88 \%$ from the concentration measured starting from day 11 , via the significant lower recovery of $66 \%$ at day $18(t=-4.00, p<0.05)$ down to $59 \%$ of the concentration of the frozen samples at day 21 .

The data in Figure 2(A) show the concentration of sIL-6R in serum at the different temperatures. The sIL-6R concentration in serum samples stored at $4^{\circ} \mathrm{C}$ remained similar to that in the frozen samples over the whole duration of the experiment. A significant, apparently linear, decline in the mean concentration of slL-6R in serum stored at $20^{\circ} \mathrm{C}$ was observed down to $87 \%$ of the concentration of the frozen samples after 21 days $(t=-2.30, p<0.05)$. After one day of storage at $30^{\circ} \mathrm{C}$ the concentration declined down to $91 \%(t=-1.93$, $\mathrm{p}<0.1$ ) of the frozen samples, down to the significant lower recovery of $85 \%$ at day $2(t=-3.08, p<0.01)$. The concentration of sIL-6R in serum stored at this temperature of $30^{\circ} \mathrm{C}$ further declined gradually over time down to $63 \%$ at day $21(t=-7.45, p<0.0001)$. The concentration of sIL-6R in the serum samples stored at $40^{\circ} \mathrm{C}$ showed a $50 \%$ decline after one day $(\mathrm{t}-12.00, \mathrm{p}<0.0001)$ and declined to undetectable concentrations at day 12 . The values of the degradation rate constant at each temperature are shown in Table 2. After calculation of the Arrhenius-plot, the graph and formula shown in Figure 2(B) were obtained for sIL-6R. Using this equation, we determined the $k$-value at $-20^{\circ} \mathrm{C}$ and calculated the storage period after which $90 \%$ of sIL-6R can still be recovered at this 
temperature. The projected $k$-value is $6.398 \times 10^{-6}$ and the predicted storage time is thus approximately 45 years at $-20^{\circ} \mathrm{C}$.

\section{Table 1}

Serum concentrations of the examined inflammatory markers.

\begin{tabular}{llllll}
\hline Patient & $n$ & $\begin{array}{l}\text { IL-6 } \\
\text { Mean (SD) }\end{array}$ & $\begin{array}{l}\text { SL-6R } \\
\text { Mean (SD) }\end{array}$ & $\begin{array}{l}\text { IL-10 } \\
\text { Mean (SD) }\end{array}$ & $\begin{array}{l}\text { CC16 } \\
\text { Mean (SD) }\end{array}$ \\
\hline HV-1 & 2 & $5.9(0.0)$ & $131.6(6.4)$ & $1.7(0.1)$ & $26.4(0.8)$ \\
HV-2 & 3 & $0.7(0.6)$ & $207.0(40.4)$ & $1.2(0.5)$ & $61.4(8.7)$ \\
HV-3 & 3 & $2.9(1.2)$ & $204.0(19.9)$ & $2.0(1.3)$ & $22.3(1.8)$ \\
P1 & 3 & $187.6(8.4)$ & $184.1(30.3)$ & $26.5(1.3)$ & $22.4(1.5)$ \\
P2 & 3 & $50.7(2.4)$ & $131.4(10.4)$ & $12.1(3.1)$ & $37.2(43.2)$ \\
P3 & 3 & $33.3(2.3)$ & $245.9(22.2)$ & $13.7(2.1)$ & $73.1(43.9)$ \\
P4 & 3 & $2617.5(77.7)$ & $79.9(9.8)$ & $121.8(9.2)$ & $16.6(4.4)$ \\
P5 & 2 & $141.3(11.7)$ & $212.5(5.5)$ & $38.8(5.7)$ & $26.8(20.1)$ \\
\hline
\end{tabular}

Concentrations of the examined proteins in the control samples (samples that were immediately stored at $-20^{\circ} \mathrm{C}$, and not subjected to heat stress). $\mathrm{HV}=$ Healthy Volunteer; $\mathrm{P}=\mathbb{P}$ atient.

\section{Table 2}

$k$-values for $\$ 1 L-6 \mathrm{R}$ and $\mathrm{LL}-10$.

\begin{tabular}{lll}
\hline Temperature $(\mathrm{C})$ & sIL-6R & $1 \mathrm{~L}-10$ \\
\hline 4 & 0.0802 & -0.0715 \\
20 & 0.8017 & 2.9556 \\
30 & 1.4755 & 4.3875 \\
40 & 32.191 & 11.901 \\
\hline
\end{tabular}

Percentage recovery was plotted versus days of heat stress at each temperature. Values of the degradation rate constant $h$ for sL-6R and $1 \mathrm{~L}-10$ at these different stress temperatures were determined as the slope of the best fit line. 
(A) Interleukin 6

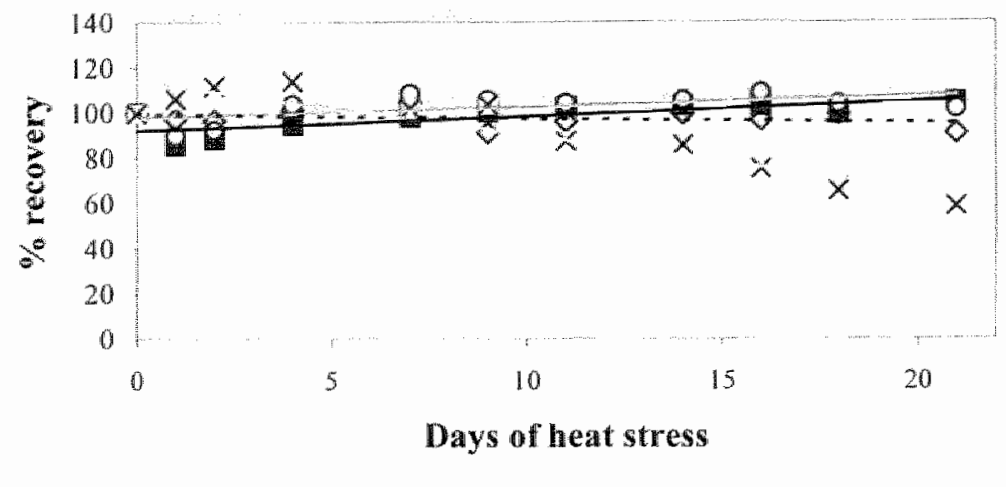

(B) $\mathrm{CC} 16$

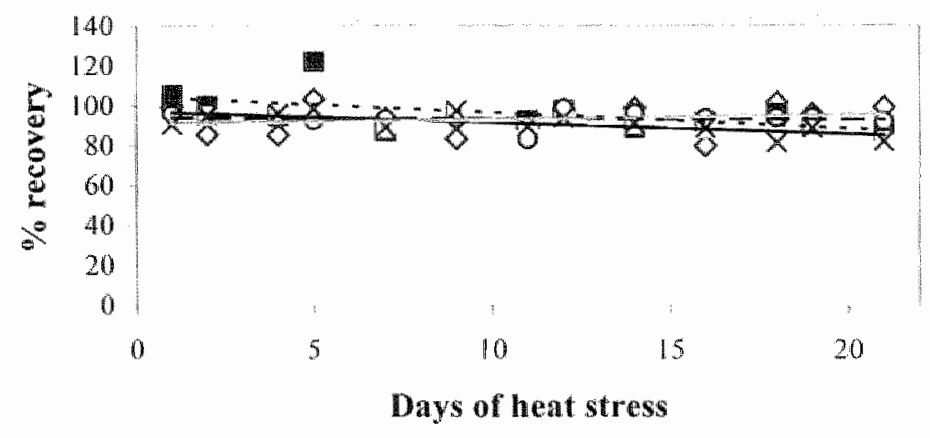

\section{Figure 1}

Recovery of (A) IL-6 and (B) CCI6 versus days of heat stress. Sample aliquots were stored for up 1021 days at $4^{\circ} \mathrm{C}(0), 20^{\circ} \mathrm{C}(\mathrm{W}), 30^{\circ} \mathrm{C}(\mathrm{O})$ or $40^{\circ} \mathrm{C}(\mathrm{X})$. The recovery was calculated as percentage of control samples (e.g. sample aliquots that were immediately stored at $-20^{\circ} \mathrm{C}$ ), One point represents the mean recovery in aliquots of serum samples from five patients for IL-6, and from five patients and three healthy volunteers for CCI6. 


\section{(A) Soluble Interleukin 6 Receptor}
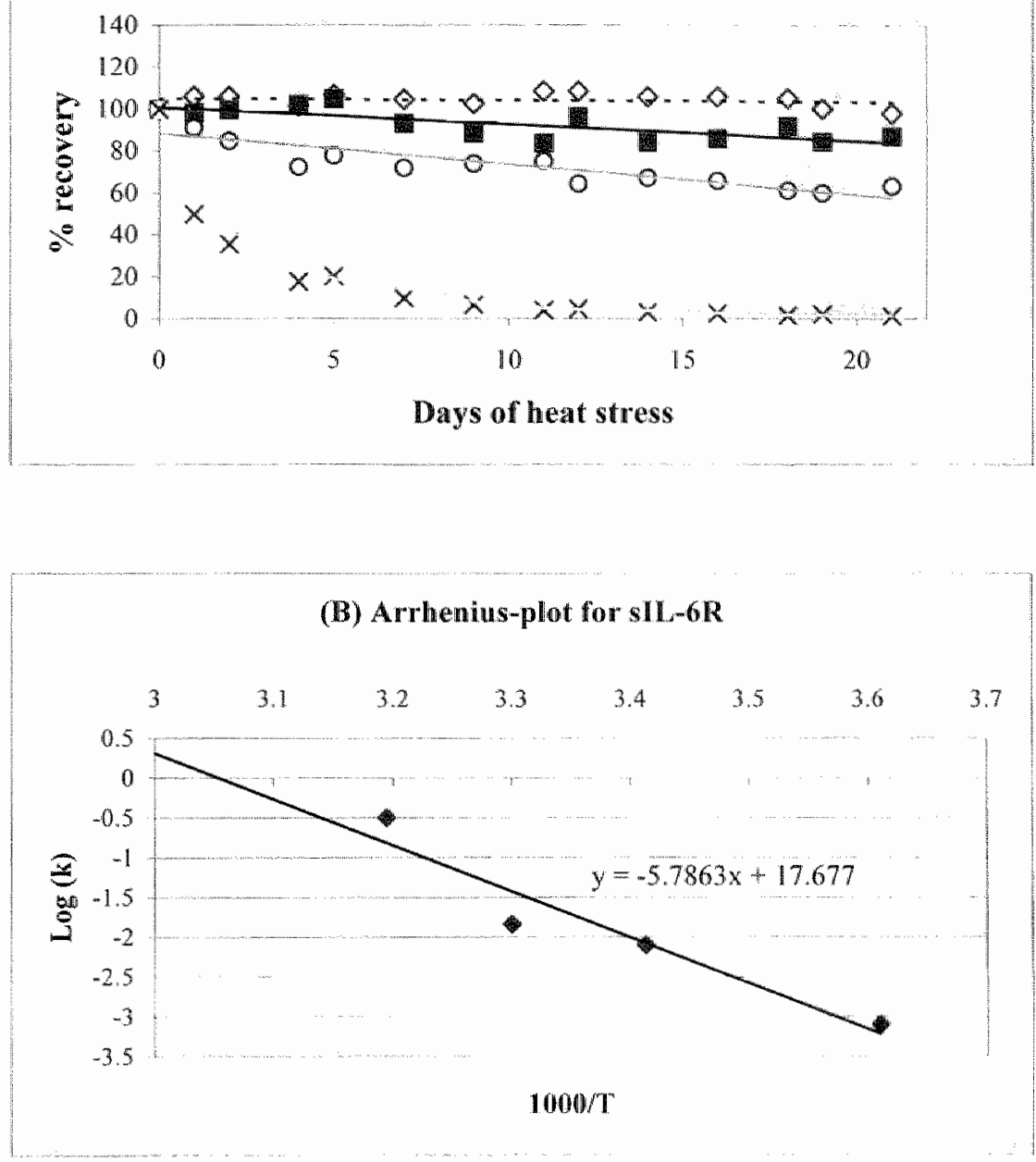

Figure 2

(A) Recovery of $\$ L-6 R$ versus days of heat stress. Sample aliquots were stored for up to 21 days at $4^{\circ} \mathrm{C}(0), 20^{\circ} \mathrm{C}\left(30^{\circ} \mathrm{C}(\mathrm{O})\right.$ or $40^{\circ} \mathrm{C}(\mathrm{X})$. The recovery was calculated as percentage of control samples (e.g. sample aliquots that were immediately stored at $-20^{\circ} \mathrm{C}$. One point represents the mean recovery in aliquots of serum samples from five patients and three healthy controls.

(B) Arrhenius-plot for s L-6R. The logarithm of the degradation rate constant $k$ is plotted versus $1000^{*}(1 / \mathrm{T})$ (where $\mathrm{T}=$ temperature, expressed as ${ }^{\circ} \mathrm{K}$ ).

The equation of the best-fil line is: $\log (k)=-5.7863^{*} 1 / T+17.677$. 


\section{(A) Interleukin 10}

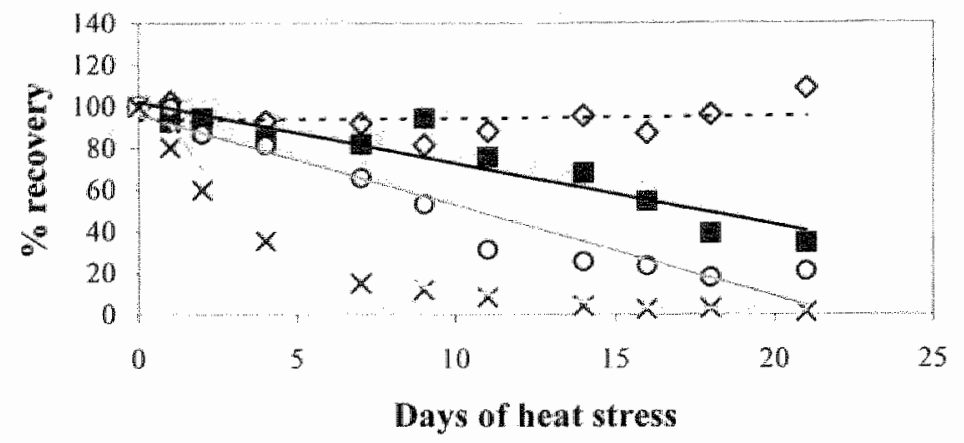

(B) Arrhenius-plot for IL-10

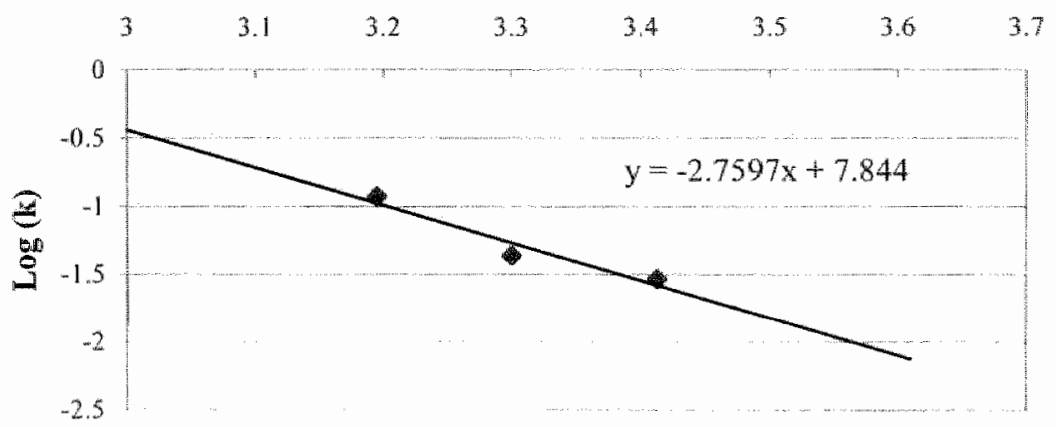

$1000 / \mathrm{T}$

\section{Figure 3}

(A) Recovery of $1 \mathrm{~L}-10$ versus days of heat stress. Sample aliquots were stored for up to 21 days at $4^{\circ} \mathrm{C}(0), 20^{\circ} \mathrm{C}\left(30^{\circ} \mathrm{C}(\mathrm{O})\right.$ or $40^{\circ} \mathrm{C}(\mathrm{X})$. The recovery was calculated as percentage of control samples (e.g. sample aliguots that were immediately stored at $-20^{\circ} \mathrm{C}$ ). One point represents the mean recovery in aliquots of serum samples from five patients.

(B) Arrhenius-plot for IL-10. The logarithm of the degradation rate constant $k$ is plotted versus $1000 *(1 / \mathrm{T})$ (where $\mathrm{T}=$ temperature, expressed as ${ }^{\circ} \mathrm{K}$ )

The equation of the best-fit line is: $\log (k)=-2.7597 * 1 / T+7.844$. 
The concentrations of IL-10 in serum samples at the different temperatures during 21 days are shown in Figure 3(A). No significant decline in $\mathrm{IL}-10$ concentrations in serum stored at $4^{\circ} \mathrm{C}$ was observed during the period of the experiment. The samples stored at $20^{\circ} \mathrm{C}$ showed a decline in $1 \mathrm{~L}-10$ concentration to $63 \%$ from on day $14(t=-3.54, p<0.001)$ and to $35 \%$ after 21 days. The IL-10 concentrations in the samples stored at $30^{\circ} \mathrm{C}$ declined from day 7 on $(t=-4.40, p<0.0001)$. The serum concentration of IL- 10 in the samples at $40^{\circ} \mathrm{C}$ was already decreased to $70 \%(t=-2.91, \mathrm{p}<0.01)$ after one day of storage. Further decrease during the following days resulted in levels indistinguishable from background at day 14 . The $k$-values for the degradation at these temperatures are shown in Table 2. Calculation of the Arrhenius-plot yielded the graph and formula demonstrated in Figure 3(B) for IL-10. The projected $k$ values at $-20^{\circ} \mathrm{C}$ and $-70^{\circ} \mathrm{C}$ are $8.63 \times 10^{-4}$ and $1.776 \times 10^{-6}$ respectively. The corresponding storage times at which $90 \%$ of the initial IL- 10 concentration can be recovered are 122 days at $-20^{\circ} \mathrm{C}$ and approximately 162 years at $-70^{\circ} \mathrm{C}$.

The concentration of $\mathrm{CC} 16$ in the serum samples remained comparable to the frozen samples at all temperatures as shown in Figure 1(B). Therefore, no Arrhenius-plot could be calculated.

\section{Clotting time}

The data depicted in Table 3 show that the serum concentration of IL-6, sIL-6R, IL-10 and CC16 are not significantly different, at room temperature, between 30 minutes clotting time and a 4-day clotting, when stored at room temperature. In addition, no differences in concentration of the proteins are observed when clotting at room temperature was compared with clotting at $4^{\circ} \mathrm{C}$ for up to four days.

\section{Influence of freeze-thaw cycles}

The data summarized in Table 4 show that no significant decline in the concentrations of IL-6, sIL-6R, IL- 10 or CC16 is observed after 2,3 and 4 times repeated freeze-thaw cycles. 
Table 3

Influence of cloting time and temperature on recovery of $1 \mathrm{~L}-6,5 / L-6 \mathrm{R}, \mathrm{LL}-10$ and $\mathrm{CC} 16$ in serum.

\begin{tabular}{lll}
\hline & $\begin{array}{l}\text { Temperature } \\
\left({ }^{\circ} \mathrm{C}\right)\end{array}$ & $\begin{array}{l}\text { \% recovery (S.D.) } \\
\text { after } 4 \text { day cloting }\end{array}$ \\
\hline $1 \mathrm{~L}-6(\mathrm{n}=5)$ & 4 & $96.9(18.5)$ \\
SIL-6R $(\mathrm{n}=8)$ & 20 & $84.1(10.8)$ \\
& 4 & $97.6(17.9)$ \\
$1 \mathrm{~L}-10(\mathrm{n}=5)$ & 20 & $103.1(13.1)$ \\
& 4 & $106.2(35.6)$ \\
$\mathrm{CC} 16(\mathrm{n}=8)$ & 20 & $109.9(63.3)$ \\
& 4 & $105.0(13.8)$ \\
\hline
\end{tabular}

$\%$ recovery of the cytokines after 4 days clotting at $4{ }^{\circ} \mathrm{C}$ and $20^{\circ} \mathrm{C}$. Concentrations were compared with a standardized clotting time of 30 minutes and \% recovery calculated. This experiment was performed on samples of patients only for $I L-6$ and $I L-10$, and on samples of patients and controls for $\$ L-6 R$ and $C C 16$.

\section{Table 4}

Influence of freeze-thaw cycles on recovery of IL-6, sIL-6R, IL-10 and CCI6 in serum.

\begin{tabular}{ll}
\hline $\operatorname{Lin}(n=3)$ & $\begin{array}{l}\text { \%o necovery (S.D.) } \\
\text { after } 4 \text { freeze-thaw cycles }\end{array}$ \\
$\operatorname{siL}-6 R(n=3)$ & $117.4(2.9)$ \\
$\operatorname{IL}-10(n=3)$ & $76.5(37.9)$ \\
$\operatorname{CC} 16(n=3)$ & $102.5(2.0)$
\end{tabular}

\% tecowery of the cylokines after 4 freaze-thaw cycles. Concentrations were compared with samples that were frozen only once.

\section{DISCUSSION}

To the best of our knowledge, this study is the first to report on the stability of several inflammatory markers in human serum, examined by means of an accelerated stability testing protocol. This method allows predicting stability for 
longer storage periods at any temperature. We found that the recovery of LL-6 and $\mathrm{CC} 16$ did not decrease for up to 21 days at $4^{\circ} \mathrm{C}, 20^{\circ} \mathrm{C}$ and $30^{\circ} \mathrm{C}$, and that CC16 concentrations even did not change at $40^{\circ} \mathrm{C}$, whereas IL-6 concentrations decreased only after 21 days at this temperature. Soluble IL-6R and IL-10 were less stable, e.g. both protein concentrations did not change at $4^{\circ} \mathrm{C}$ but the recovery decreased gradually at $20^{\circ} \mathrm{C}$ and $30^{\circ} \mathrm{C}$. The predicted storage time after which $90 \%$ of the initial concentration can be recovered is 45 years for SIL-6R at $-20^{\circ} \mathrm{C}$ and 122 days and 162 years for $1 \mathrm{~L}-10$ at $-20^{\circ} \mathrm{C}$ and $-70^{\circ} \mathrm{C}$, respectively.

The only report to our knowledge that describes an accelerated stability testing protocol with cytokines, is that of Ruiz et al. (Ruiz et al., 1996). These authors examined the stability of tumor necrosis factor $\alpha$ (TNF- $\alpha$ ) in cerebrospinal fluid (CSF) samples, and found it to be stable for at least 5 years at $-70^{\circ} \mathrm{C}$. They specifically used a pathological CSF-pool (with high TNF- $\alpha$ concentration) diluted with a normal CSF-pool to retain any degrading enzymes, and added sodium azide as preservative. In our study, undiluted serum samples were used for the test protocol and care was taken that to keep all samples sterile during the stress period.

In our study, the IL-6 concentrations did not significantly decline at $4^{\circ} \mathrm{C}, 20^{\circ} \mathrm{C}$ and $30^{\circ} \mathrm{C}$. Therefore, it was not possible to calculate the degradation rate constant at those temperatures, and, hence, no Arrhenius-plot or projected stability time could be calculated. We conclude that IL-6 is very stable and that samples for IL-6 determination can be stored frozen for very long periods before recovery is significantly decreased. These results do not corroborate those from Spong et al., who found that IL-6 concentrations in frozen amniotic fluid samples decreased over time (Spong et al., 1998). A panel of amniotic fluid samples was measured two times with a one-year interval. The median IL6 concentration from the second determination was significantly $(20 \%)$ lower compared to those of one year earlier. However, several factors may explain the discrepancy between these and our findings. First, the higher protein concentration of serum may stabilize the IL-6 molecules. Moreover, high concentrations of slL-6R are present in serum as compared to amniotic fluid (Opsjon et al., 1995). These molecules may bind IL-6 and protect it from proteolytic or thermal degradation. Second, detection of proteins in ELISAsystems is dependent on the binding of the antibodies with their respective epitopes on the protein. In some cases, these epitopes are conformational structures, which may change due to denaturation or proteolytic cleavage. The antibody then no longer binds its epitope and, hence, recovery in the ELISA decreases. We assume that the antibodies in our ELISA are able to detect partly denatured IL-6. In the study of Spong et al., a decrease in IL-6 concentrations was observed between two independent measurements (Spong et al, 1998). The 
authors do not specify whether the same batch of ELISA was used; thus, interassay variation might be an interfering factor. To overcome this problem, we used an accelerated stability testing, so that all samples could be tested in one run with the same batch of reagents.

Another major finding of this study was that the concentrations of IL-6, sIL-6R, IL -10 and $\mathrm{CC} 16$ did not change when incubated at $4^{\circ} \mathrm{C}$ or $20^{\circ} \mathrm{C}$ for up to 4 days before centrifugation. De Jongh et al. (1997) also reported no change in IL-6 or SIl $6 \mathrm{R}$ concentrations when blood was incubated at $4 \% \mathrm{C}$ for $24 \mathrm{~h}$ before centrifugation (De Jongh et al., 1997). Others showed that IL-6 and IL-1 plasma levels were unchanged when stored for up to 3 hours at $37^{\circ} \mathrm{C}$ before centrifugation (Riches et al., 1992). Some studies, however, have shown a decrease in IL-6 recovery when blood samples were left unseparated for 24 hours at both $4^{\circ} \mathrm{C}$ and room temperature (Thavasu et al., 1992), and even after 4 hours at room temperature (Flower et al., 2000). Discrepancies between these studies are difficult to explain. In the study of Thavasu et al., IL-6 spiked blood samples were used (Thavasu et al., 1992). White blood cells or thrombocytes may take up the spiked IL-6, whereas in-wivo generated IL-6 may represent equilibrium between IL-6 production and uptake. Further, comparison between studies might be difficult due to differences in study design and/or immunoassays (e.g. radio-versus enzyme immuno-assays, the antibodies used, etc.).

Finally, we showed that up to four repeated freeze-thaw cycles did thot influence the recovery of $1 L-6$, sIL $-6 R, \pi L-10$ and $C C 16$. This confirms the findings of other studies which demonstrated the resistance of IL, $-6, T N F-\alpha, 1 L-1 \alpha, I L-1 \beta$, interferon-y and other serum proteins (Leptin, Apolipoprotein E) to repeated freeze-thaw cycles (Thavasu et al., 1992; Flower et al., 2000; Schiele et al., 2000).

It is concluded that serum samples for the determination of IL-6, SIL-6R and CC 16 can be stored at $-20^{\circ} \mathrm{C}$ for several years, but for the determination of IL10 , serum samples should be stored at $-70^{\circ} \mathrm{C}$ when longer storage periods (longer then three months) are required. Further, neither a time delay between blood sampling and serum separation, nor repeated freeze-thaw cycles have a negative influence on the recovery of these proteins. Thus, we showed that practical aspects of longitudinal and clinical studies (such as long term storage, extended clotting times and repeated freeze-thawing) do not influence the measurement of the proteins examined, including cytokines. 


\section{REFERENCES}

Anderson G, Scott M, (1991) Determination of product shelf life and activation energy for five drugs of abuse. Clin Chem 37: 398-402.

Bonaccorso S, Lin A, Song C, Verkerk. R, Kenis G, Bosmans E, Scharpe S, Vandewoude $M$. Dossche A, Maes $M$, (1998) Serotonin-immune interactions in elderly volunteers and in patients with Alzheimer's disease (DAT): lower plasma tryptophan avalability to the brain in the elderly and increased serum interleukin-6 in DAT. Aging (Milano) 10:316-323.

De Jongh $R$, Vranken $J$, Vundelinckx $G$, Bosmans $E$, Maes M, Heylen $R$, (1997) The effects of anticoagulation and processing on assays of $1 \mathrm{~L}-6$, sIL-6R, sIL-2R and soluble transferrin receptor. Cytokine 9: 696-701.

Flower L, Ahuja RH, Humphries SE, Mohamed-Ali V, (2000) Effects of sample handling on the stability of interleukin 6, tumor necrosis factor alpha and leptin. Cyokine 12:1712-1716.

Fraser CG (1986) Biological variation. Interpretation of clinical chemistry laboratory data. (pp. 111-135) Oxford: Blackwell Scientific Publications.

Kirkwood TBL, (1977) Predicting the stability of biological standards and products. Biometrics 33: $736-742$.

Lin A, Kenis $G$, Bignotti $S$, Tura GJB, De Jongh $\mathbb{R}$, Bosmans E, Pioli $R$, Altamura $C$, Scharpe $S_{\text {v }}$ Maes M, (1998) The inflammatory response system in treatmentresistant schizophrenia: increased serum interleukin-6. Schizophr Res 32:9-15.

Maes $M$, Cooreman $W$, Delanghe J, Scharpe $S$, Wauters A, Neels $H$, DHondt P, Peeters $D$, Cosyns P, Ranjan R, Bosmans E, DeMeyer F, Elkis H, Desnyder R, (1995) Components of biological variation in plasma haptoglobin: relationships to plasma fibrinogen and immune variables, including interleukin-6 and its receptor. Clin Chim Acta 239:23-35.

Maes $M$, Ombelet $W$, Libbrecht 1 , Stevens $K$, Kenis $G$, De Jongh $R$, Lin A-h, Cox J, Bosmans $\mathbb{E}_{\text {x }}$ (1999) Effects of pregnancy and delivery on serum concentrations of Clara Cell Protein (CC 16), an endogenous anticytokine: lower serum $\mathrm{CCl} 6$ is related to postpartum depression. Psychiatry Res 87: 117-127.

Opsjon S-L, Novick D, Wathen NC, Cope AP, Wallach D, Aderka D, (1995) Soluble tumor necrosis factor receptors and soluble interlleukin-6 receptor in retal and maternal sera, coelomic and amnotic fluids in normal and pre-eclampsia pregnancies. I Reprod Immunol 29:119-134.

Riches P, Gooding R, Millar BC, Rowbottom AW, (1992) Influence of collection and separation of blood samples on plasma IL-1, IL-6 and TNF- $\alpha$ concentrations. I Immunol Methods 153 ; $125-131$

Ruiz MC, Quijano FR, Cortes LL, Duvison MH, Rubio RV, (1996) Determination of shelf life and activation energy for tumor necrosis factor alpha in cerebrospinal fluid samples. Chin Chem 42: 670-674.

Schiele F, Vincent-Viry M, Herbeth B, Visvikis A, Siest G, (2000) Effect of short- and long-term storage on human serum and recombinant apolipoprotein $\mathrm{E}$ concentration. Clin Chem Lab Med 38: 525-528.

Spong CY, Ghidini A, Ossandon M, Walker CN, Pezzullo JC, (1998) Are the cylokines interleukin-6 and angiogenin stable in frozen ammiotic luid? Am J Obster Gynecol 178: 783786.

Thavasu PW, Longhurst S, Joel SP, Slevin ML, Balkwill FR, (1992) Measuring cytokine levels in blood. J immunol Methods 153: 115-124. 


\section{Cllispter}

Anti-inflammatory effects of antidepressants through suppression of the interferon-rinterleukin-10 production ratio

Marta Kubera, Ai-Hua Lin, Gunter Kenis, Eugène Bosmans, Dirk van Bockstaele, Michael Maes

Journal of Clinical Psychopharmacology (2001), 21, pp. 199-206 


\section{ABSTRACT}

There is some evidence that major depression and, in particular, treatment resistant depression (TRD) is accompanied by activation of the inflammatory response system and that pro-inflammatory cytokines may play a role in the aetiology of depression. This study was carried out to examine the effects of antidepressive agents, i.e. imipramine, venlafaxine, L-5-hydroxytryptophan (L5-HTP) and fluoxetine on the production of interferon- $\gamma$ (IFN- $\gamma$ ), a proinflammatory cytokine, and IL-10, a negative immunoregulatory cytokine.

Diluted whole blood of fluoxetine-treated TRD patients (mean age $=50.6 \pm 3.9$ years) and age-matched normal controls (mean age $=51.6 \pm 1.7$ years) and younger normal volunteers (mean age $=35.4 \pm 9.6$ years) was stimulated with phytohaemagglutinin (PHA, $1 \mu \mathrm{g} / \mathrm{ml}$ ) and lipopolysaccharide (LPS, $5 \mu \mathrm{g} / \mathrm{ml}$ ) for 48 hours with and without incubation with the antidepressants at $10^{-6} \mathrm{M}$ and $10^{-5}$ M. IFN- $\gamma$ and IL- 10 were quantified by means of ELISA. The ratio of IFN- $\gamma$ to IL-10 production by immunocytes was computed because this ratio is of critical importance in determining the capacity of immunocytes to activate or inhibit monocytic and T-lymphocytic functions.

All four antidepressive drugs significantly increased the production of IL-10. Fluoxetine significantly decreased the production of IFN- $\gamma$. All four antidepressants significantly reduced the IFN- $\gamma / \mathrm{LL}-10$ ratio. There were no significant differences in the antidepressant-induced changes in IFN- $\gamma$ or IL-10 between younger and older normal volunteers and TRD patients.

Tricyclic antidepressants, selective serotonin reuptake inhibitors, serotoninnoradrenaline reuptake inhibitors as well as the immediate precursor of serotonin have a common, negative immunoregulatory effect by suppressing the IFN- $\gamma /$ IL-10 production ratio. It is suggested that the therapeutic efficacy of antidepressants may be related to their negative immunoregulatory effects. 


\section{INTRODUCTION}

Recently, it has been demonstrated that major depression is related to activation of the inflammatory response system (IRS) (Maes, 1999). The evidence includes, amongst other things, an enhanced production of pro-inflammatory cytokines, such as interleukin-1 $\beta$ (IL-1 $\beta$ ), IL-6 and interferon- $\gamma$ (IFN- $\gamma$ ) (Seidel et al., 1995; Maes, 1999). An increased production of IL-1 and IL-2 has been observed in culture supernatant of mitogen-stimulated splenocytes in the mild, chronic stress rat and mice models of depression (Kubera et al., 1996, 1998a). It has been suggested that the increased production of pro-inflammatory cytokines may play a role in the aetiology of depression (Yirmiya, 1996; Maes, 1999). Indeed, IL-1, IL-6 and IFNs given to experimental animals and humans may produce behavioural alterations and symptoms similar to those observed in major depression, such as anhedonia, anorexia, weight loss, social withdrawal, psychomotor retardation, anergy, irritability and sleep disturbances (Maes, 1999).

If pro-inflammatory cytokines are involved in the aetiology of depression one would expect that antidepressive agents have negative immunoregulatory effects. Prolonged treatment with antidepressants suppresses the acute phase response in major depressed patients (Maes et al., 1997), and in the olfactory bulbectomized and chronic mild stress models of depression in rats (Sluzewska et al., 1994; Song and Leonard, 1994). A single as well as repeated injection of desipramine to naive mice increases the capacity of splenocytes to produce the negative immunoregulatory cytokine, IL-10 (Kubera et al., 1998b). Ex-vivo studies show that antidepressants inhibit the secretion of $1 \mathrm{~L}-1 \beta, \mathrm{LL}-2$, tumor necrosis factor- $\alpha$ (TNF- $\alpha$ ), IFN- $\gamma$ and inhibit the proliferative activity of T-cells and the cytotoxic activity of natural killer cells (Xia et al., 1996; Maes, 1999). Co-incubation of whole blood of normal humans with clomipramine, a tricyclic antidepressant (TCA) or sertraline, a selective serotonin reuptake inhibitor (SSRI), decreases IFN- $\gamma$ production and increases $1 \mathrm{~L}-10$ production (Maes et al., 1999b). IFN- $\gamma$ is a T-helper $\mathbb{1}$ (Th1)-like, pro-inflammatory cytokine produced by activated T lymphocytes and natural killer cells, which boosts the production of IL-1 and IL-6 (Cavaillon, 1996). Interleukin-10 is produced by Th2-like lymphocytes, B-lymphocytes and monocytes, and has important antiinflammatory and immunosuppressive properties through suppression of IFN- $\gamma$ and other pro-inflammatory cytokines (Cavaillon, 1996). Therefore, the ratio of IFN- $\gamma$ to IL-10 produced by immunocytes is of critical importance in determining their capacity to activate or inhibit monocylic and T-lymphocytic functions (Katsikis et al., 1995).

The aim of the present study is to examine the effects of antidepressive agents, i.e. imipramine (TCA), fluoxetine (SSRI), venlafaxine (serotonin-noradrenaline 
reuptake inhibitor, SNRI) and the immediate precursor of serotonin, L-5hydroxytryptophan (L-5-HTP) on the production of IL-10 and IFN- $\gamma$ (and their ratio) by diluted whole blood of normal volunteers and patients with treatment resistant depression.

\section{METHODS}

\section{Subjects}

Blood samples for the determination of cytokine secretion were collected from 7 patients with TRD (mean age $=50.6 \pm 3.9$ years; male/female ratio: $2 / 5$ ) and 7 age-sex-matched normal controls (i.e. $>45$ years; mean age $=51.6 \pm 1.7$ years; male/female ratio: $2 / 5$ ) and 12 younger nomal volunteers (i.e. $<45$ years; mean age $=35.4 \pm 9.6$ years; male/female ratio: $5 / 7$ ). All subjects gave written informed consent after the study design was fully explained. The depressed inpatients were included if they met the DSM-IV diagnostic criteria for major depression. Diagnoses were made with the Structured Clinical Interview for DSM-III-R, Patient Version (SCID) (Spitzer el al., 1990). The depressed patients were resistant to one treatment trial with fluoxetine, $20-60 \mathrm{mg}$ daily, administered daily for 6 weeks. They were taking fluoxetine when blood was sampled. The Hamilton Rating Scale for Depression (HDRS) score was used to measure severity of illness (Hamilton, 1960). The mean HDRS score in the depressed patients was $25.1( \pm 3.2)$. The nomal volunteers had a negative history of past and present axis-I psychiatric illnesses. None was a regular drinker and none had ever been taking antidepressant or antipsychotic agents. Normal volunteers and depressed subjects were free of any chronic medical illness. All subjects were free of acute infections or allergic reactions as well as drugs known to modify the immune or endocrine functions for at least one month before blood sampling. The subjects abstained from calfeine, nicotine and alcohol for at least $12 \mathrm{hr}$ before blood sampling.

\section{Whole blood stimulation}

After an overnight fast, blood for the assays of IFN- $\gamma$ and IL-10 was taken at 9 a.m. ( 130 minutes). The effects of antidepressants on cytokine secretion were studied by stimulating $1 / 10$ diluted whole blood with PHA ( $1 \mu \mathrm{g} / \mathrm{ml}$; Murex Diagnostics Lid, Dartford, England) and LPS (5 $\mu \mathrm{g} / \mathrm{m} /$; E. coli 026:B6; lyophylized and sterilized by gamma-irradiation; Sigma, Belgium). $1.8 \mathrm{ml}$ of RPMI-1640 medium with L-glutamine (Gibco BRL), $100 \pi \mathrm{U} / \mathrm{mL}$ penicillin (Sigma) and $100 \mu \mathrm{g} / \mathrm{mL}$ streptonycin (Sigma) with PHA + LPS were placed into 24 well cell culture plates (Falcone 3047, Becton Dickinsen). Diluted 
whole blood stimulated with PHA + LPS offers the most appropriate and reproducible culture condition in order to measure cytokines, such as IFN- $\gamma$ (De Groote et al., 1992; Maes et al., 1.999b). Diluted whole blood cultures reflect the in-vivo immune cellular and humoral interactions and may be employed to examine the effects of drugs on cytokine secretion (De Groote et al., 1992; Maes et al., 1999b). The production of cytokines, such as IFN- $\gamma$, IL-6 and IL10 , under these culture conditions is related to in-vivo markers of cell-mediated immunity, such as serum concentrations of acute phase reactants and number of peripheral blood mononuclear cells, e.g. activated T-cells (De Groote et al., 1992; Maes et al., 1999a). The antidepressants were dissolved in sterile water, whereas sterile water alone served as the corresponding control. Twenty microliter of each antidepressant solution was added to the wells and gently mixed with the medium. A total of $0.2 \mathrm{ml}$ of whole blood from each of 26 subjects were cultured with two concentrations, i.e. $10^{-5} \mathrm{M}$ and $10^{-6} \mathrm{M}$, of imipramine hydrochloride (Ciba Geigy, Basel, Switzerland), venlafaxine hydrochloride (Wyeth, USA), L-5-hydroxytryptophan (Acros Organics) or fluoxetine hydrochloride (Eli-Lilly, Belgium). Viability of cells was checked by ethidium-bromide-dye exclusion. The samples were incubated for 24 hours in a humidified atmosphere at $37^{\circ} \mathrm{C}, 5 \% \mathrm{CO}_{2}$. Supernatants were taken off carefully under sterile conditions, divided into eppendorf tubes, and frozen immediately at $-75^{\circ} \mathrm{C}$. The drug concentrations employed here were chosen on the basis of literature on the therapeutic plasma concentrations of these agents. Thus, the $10^{-6} \mathrm{M}$ concentrations employed here are in therapeutic range of plasma concentrations obtained during clinical treatment, whereas the higher concentrations correspond to the concentrations usually employed by other researchers in ex-vivo experiments which aim to examine the effect of drugs on isolated immunocytes. However, blood cells of patients are exposed to the antidepressants for longer periods of time and the intracellular loading of the drugs during in-vivo conditions may be much higher than the serum concentrations obtained during treatment with these drugs. IFN- $\gamma$ and IL-10 were quantified by means of ELISA methods (Eurogenetics, Tessenderlo, Belgium) based on appropriate and validated sets of monoclonal antibodies as described by us previously (Maes et al., 1999b). All assays were carried out in one run on one and the same day. The intra-assay $\mathrm{CV}$ values for both analytes were less than $8 \%$.

\section{Statistics}

Repeated measure design analysis of variance (RM design ANOVAs) was used to examine the i) within-subject variability with the effects of antidepressant drugs as temporal condition, i.e. positive control, and each of the four different 
drugs at two concentrations; and ii) between-subject variability with the three study groups (younger controls, elderly controls and depressed patients) and gender as factors. Results of RM design ANOVAs were corrected for sphericity. Differences among treatment means were ascertained by means of the Dunn test. Tests on simple effects were employed to clarify main effects or significant interactions; a simple effect is defined as the effect of one variable at one level of the other variable. The IFN- $\gamma /$ IL-10 ratio was computed as: $z$ transformed IFN- $\gamma-z$ transformed IL-10 (Maes et al., 1999b). IFN- $\gamma$ and IL-10 and their ratio were processed in Box-Cox transformation.

\section{RESULTS}

Figure 1 shows that there were no significant effects of imipramine $(F=0.2$, $\mathrm{df}=2 / 46, \mathrm{p}=0.8)$, venlafaxine $(\mathrm{F}=2.7, \mathrm{df}=2 / 40, \mathrm{p}=0.08)$ or $\mathrm{L}-5-\mathrm{HTP} \quad(\mathrm{F}=2.1$, $\mathrm{d} f=2 / 36, p=0.1$ ) on IFN- $\gamma$ production (all results of RM design ANOVAs). There is a significant effect of fluoxetine on IFN- $\gamma$ production $(\mathrm{F}=14.8, \mathrm{df}=2 / 42$, $\mathrm{p}=0.00007)$. IFN- $\gamma$ production is significantly lowered by $10^{-6} \mathrm{M}(t=2.75, \mathrm{p}=0.008)$ and $10^{-5} \mathrm{M}(\mathrm{t}=5.44, \mathrm{p}=0.00003)$ fluoxetine. IFN- $\gamma$ production is significantly lower $(t=2.69, \mathrm{p}=0.009)$ after $10^{-5} \mathrm{M}$ than after $10^{-6} \mathrm{M}$ fluoxetine. There are no significant drug $X$ group interactions. There are significant differences in IFN- $\gamma$ between the three study groups $(\mathrm{F}=7.4, \mathrm{df}=2 / 23, \mathrm{p}=0.003$ ). Analyses of simple effects show that there are significant inter-group differences in IFN- $\gamma$ production in the positive control $(\mathrm{F}=6.7, \mathrm{~d} f=2 / 69, \mathrm{p}=0.003)$ and the imipramine $10^{-6} \mathrm{M}(\mathrm{F}=7.0, \mathrm{df}=2 / 69$, $\mathrm{p}=0.002)$ and $10^{-5} \mathrm{M}(\mathrm{F}=6.4, \mathrm{df}=2 / 69, \mathrm{p}=0.003)$ conditions. Dunn tests show significantly lower IFN- $\gamma$ production in elderly volunteers than in younger volunteers $(t=3.79, p=0.001)$ and depressed patients $(t=2.79, p=0.01)$. There are no significant gender differences in $I F N-\gamma(F=0.3, d f=1 / 20, p=0.6)$ and no significant drug $X$ gender or drug $X$ gender $X$ group interactions.

Figure 2 shows that imipramine $\left(\mathrm{F}=28.3, \mathrm{df}=2 / 44, \mathrm{p}<10^{-4}\right)$, venlafaxine $(\mathrm{F}=18.1$, $\mathrm{df}=1 / 30, \mathrm{p}=0.0004), \mathrm{L}-5-\mathrm{HTP}(\mathrm{F}=5.5, \mathrm{df}=2 / 44, \mathrm{p}=0.008)$ and fluoxetine $(\mathrm{F}=12.6$, $\mathrm{df}=2 / 42, \mathrm{p}=0.0001$ ) have significant enhancing effects on IL-10. Dunn tests show that i) $1 \mathrm{~L}-10$ is significantly higher in the $10^{-5} \mathrm{M}$ imipramine condition than in the control $\left(t=7.13, \mathrm{p}<10^{-4}\right)$ and $10^{-6} \mathrm{M}\left(t=5.64, \mathrm{p}<10^{-4}\right)$ conditions; ii) $1 \mathrm{~L}-10$ is significantly higher in the $10^{-6} \mathrm{M}(t=3.32, \mathrm{p}=0.002)$ and $10^{-5} \mathrm{M}\left(\mathrm{t}=6.00, \mathrm{p}<10^{-4}\right)$ venlafaxine condition than in the normal condition, and significantly higher in the $10^{-5} \mathrm{M}$ than in the $10^{-6} \mathrm{M}$ venlafaxine condition $(t=2.68, \mathrm{p}=0.009)$; iii) IL-10 is significantly higher in $10^{-5} \mathrm{M} \mathrm{L-5-HTP}$ condition than in the control condition $(t=3.12, \mathrm{p}=0.003)$; and iv) $\mathrm{LL}-10$ is significantly higher in the fluoxetine $10^{-5} \mathrm{M}$ condition than in the control $\left(t=5.03, \mathrm{p}<10^{-4}\right)$ and $10^{-6} \mathrm{M}(\mathrm{t}=2.50, \mathrm{p}=0.012)$ fluoxetine conditions. There are no significant interactions between drug and 
groups for any of the four antidepressants. There are no significant differences in IL-10 production between the three study groups. There are no significant gender differences in IL-10 ( F =1.7, $\mathrm{df}=1 / 20, \mathrm{p}=0.2)$ and no significant drug $\mathrm{X}$ gender or drug $\mathrm{X}$ gender $\mathrm{X}$ group interactions.
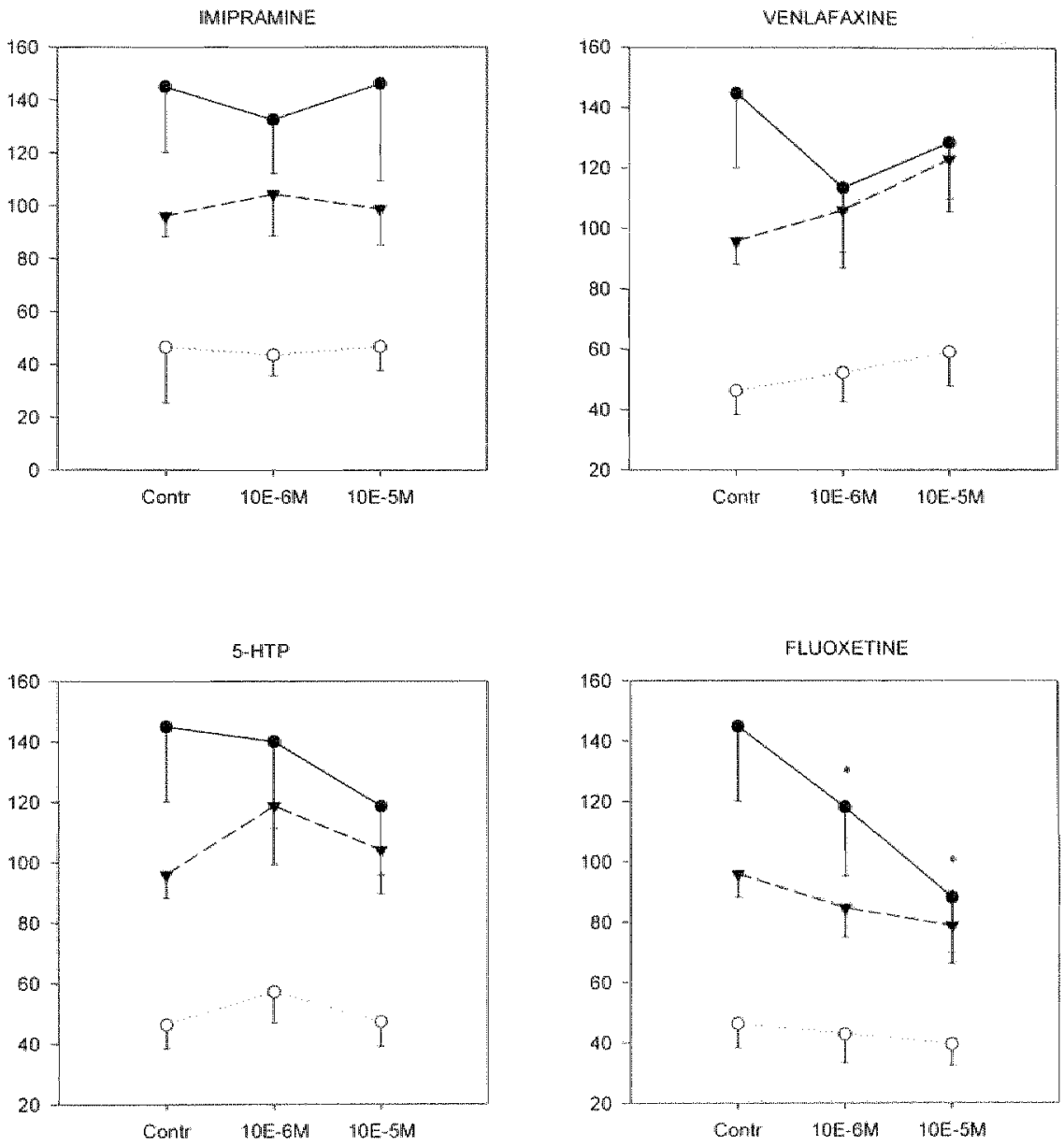

\section{Figure 1}

Effects of antidepressants on the stimulated production of IFN-y (expressed in $\mathrm{U} / \mathrm{mL}$ ). Younger normal vollunteers $(\bullet)$, older normal volunteers $(O)$, patients with treatment resistant major depression ( $\mathbf{v})$.

* Significantly different from the control condition. 

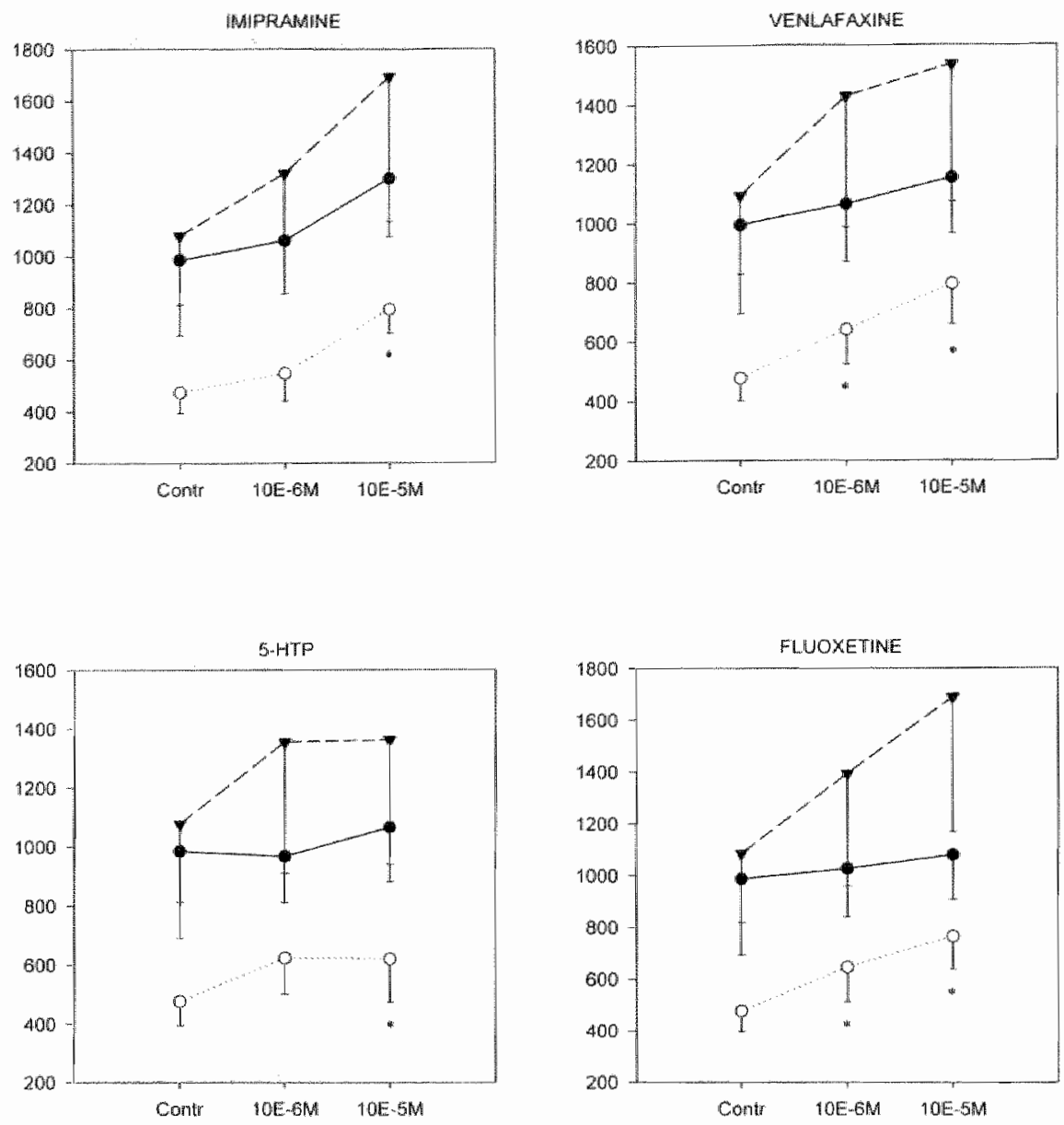

\section{Figure 2}

Effects of antidepressants on the stimulated production of IL-10 (expressed in $\mathrm{pg} / \mathrm{ml}$ ). Younger normal voluntecrs $(\bullet)$, older nomal volunteers $(0)$, patients with treatment resistant major depression $(\mathbf{v})$.

* Significantly diferent from the control condition. 

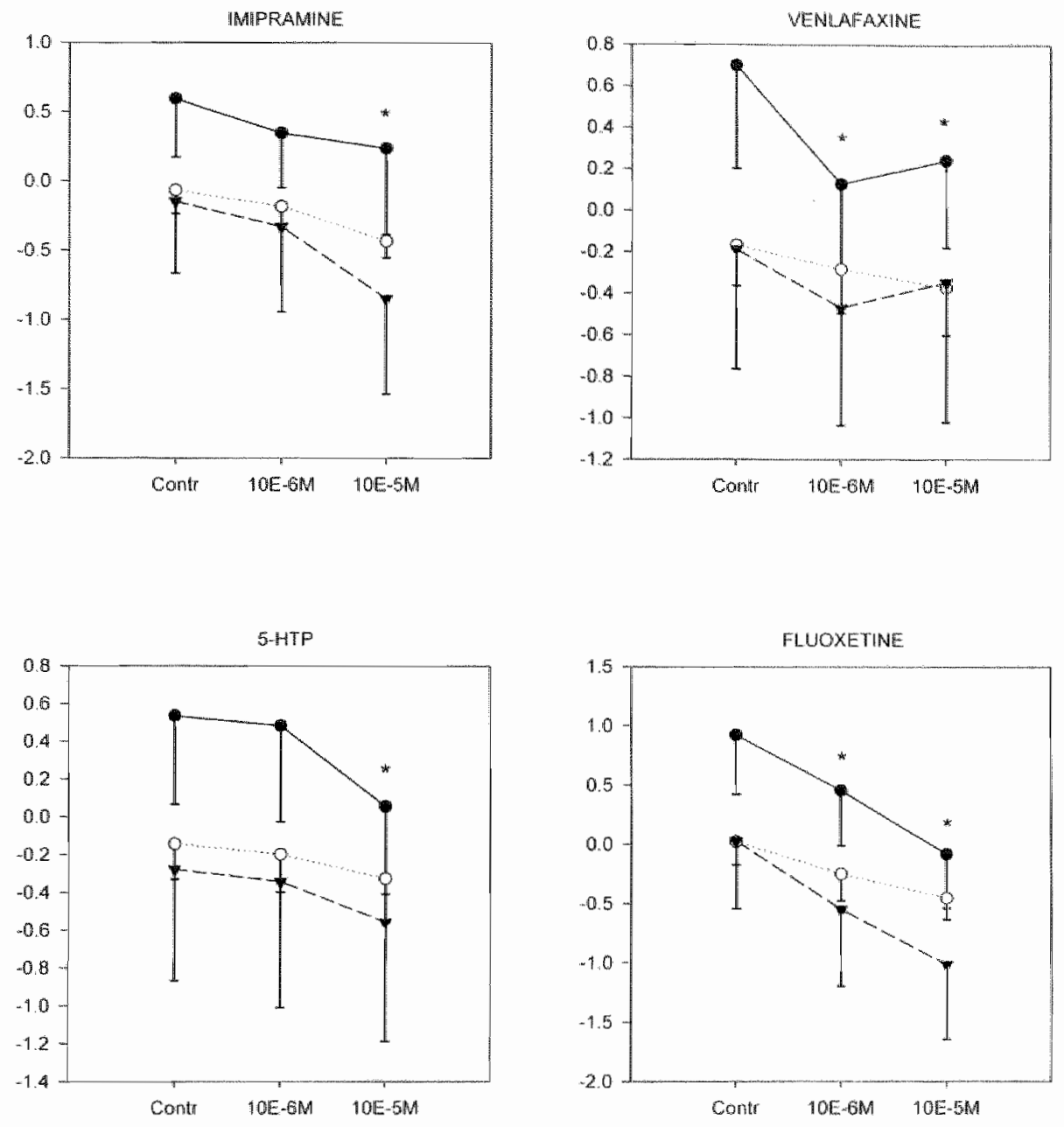

\section{Figure 3}

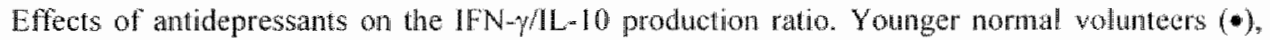
older normal volunteers (O), patients with treatment resistant major depression ( ).

* Significantly different from the control condition. 
Figure 3 shows that imipramine $(F=8.33, d f=1 / 32, p=0.006)$, venlafaxine $(F=8.7$, $\mathrm{df}=2 / 45, \mathrm{p}=0.0009), \mathrm{L}-5-\mathrm{HTP}(\mathrm{F}=5.8, \mathrm{df}=2 / 35, \mathrm{p}=0.007)$ and fluoxetine $(\mathrm{F}=27.5$, $\left.d f=2 / 38, p<10^{-4}\right)$ significantly suppress the IFN- $y /$ IL- 10 ratio. Dunn tests show i) a significantly lower IFN- $\gamma / \mathrm{L}-10$ ratio in the $10^{-5} \mathrm{M}$ imipramine $(t=4.06, \mathrm{p}=0.0004)$ than in the control condition; ii) a lower ratio following venlafaxine $10^{-5} \mathrm{M}(t=3.88$, $\mathrm{p}=0.0006)$ and $10^{-6} \mathrm{M}(\mathrm{t}=3.24, \mathrm{p}=0.002)$ than in control condition; iii) a lower ratio in the L-5-HTP $10^{-5} \mathrm{M}$ condition than in the L-5-HTP $10^{-6} \mathrm{M}$ and the control conditions; and iv) a lower IFN- $\gamma / \mathrm{IL}-10$ ratio in the fluoxetine $10^{-6} \mathrm{M}(\mathrm{t}=3.76$, $\mathrm{p}=0.0007)$ and $10^{-5} \mathrm{M}\left(\mathrm{t}=7.41, \mathrm{p}<10^{-4}\right)$ conditions than in the control condition; and a lower ratio in the fluoxetine $10^{-5} \mathrm{M}$ than in the $10^{-6} \mathrm{M}$ condition $(\mathrm{t}=3.65, \mathrm{p}=$ 0.0009 ). There were no significant differences in the IFN- $\gamma / 1 L-10$ ratio between the study groups.

\section{DISCUSSION}

The main findings of this study are that imipramine, venlafaxine, L-5-HTP and fluoxetine significantly enhance $1 \mathrm{~L}-10$ production and significantly suppress the IFN- $\gamma /$ IL-10 ratio. These results extend those of (Xia et al., 1996) who found a trend toward a significant suppression of IFN- $\gamma$ secretion and a significant inhibition of IL-1 $\beta, I L-2$ and TNF- $\alpha$ secretion by activated T-cells or monocytes pre-incubated with TCAs or SSRIs. Sertraline, clomipramine and trazodone, a heterocyclic antidepressant (HCA), significantly reduced the IFN- $\gamma / \mathrm{L}-10$ ratio (Maes et al., 1999b). The results of the above studies suggest that various types of antidepressive drugs, including TCAs, SSRIs, SNRIs, HCAs and L-5-HTP may have negative immunoregulatory effects. The effect of fluoxetine on the IFN- $\gamma / \mathrm{IL}-$ 10 ratio in the patient group may be a large one. This effect may represent a priming effect by the oral dose on the cells prior to exposure to the ex-vivo dose. However, without a group of depressed untreated patients, it cannot be concluded whether the results of the patient group represent effects of depression or fluoxetine orally or both. Moreover, the results of the present study are laboratory (ex-vivo) observations only. Therefore, there is no evidence whether the findings are of clinical relevance. Nevertheless, prolonged treatment of depressed patients with antidepressants, including fluoxetine, is accompanied by a normalization of the initially increased production of $[\mathrm{L}-6, \mathrm{IFN}-\gamma$ and positive acute phase proteins, suggesting that antidepressants have in-vivo anti-inflammatory effects (Seidel et al., 1995; Sluzewska et al., 1995; Maes et al., 1997; Maes, 1999). However, many drugs are known to alter cytokine production and in many cases these effects have no relationship to the primary function of these drugs. Systemic injection of LPS, which is a potent activator of the immune system, induced a depressive behavioural pattern in fluid-deprived rats, whille chronic treatment with imipramine 
reduces or blocks the suppressive effects of LPS on food consumption, body weight, social interaction and activity in the open-field test (Yirmiya, 1996). Bluthé et al. (1999) found that IL-10 antagonizes behavioural defects, such as depressed social behaviour, induced by LPS.

The mechanisms by which antidepressants modulate immune functions have remained elusive. Nahas et al. (1979) suggest that the immunological effects of TCAs are correlated with their liposolubility. Audus and Gordon (1982) hypothesized that TCAs may modulate immunocyte functions by binding to TCA binding sites. It is, however, unlikely that the immunological effects of these drugs are mediated through these binding sites, because TCAs are active in-vitro in the $10^{-4}-10^{-6} \mathrm{M}$ range, whereas the binding constant for this receptor is $4 \times 10^{-8} \mathrm{M}$. The existence of receptors for noradrenaline and serotonin on human immunocytes provides another potential mechanism for the immune activity of antidepressants (Kubera et al., 2000). Stimulation of $\alpha_{1}-, \alpha_{2}$-adrenergic as well as 5HT1A or 5HT4 receptors on immunocytes by noradrenaline or serotonin increases the intracellular levels of cyclic Adenosine Monophosphate (cAMP) (Kubera et al., 2000). The latter plays a critical role in the production of $I L-10$ and IFN- $\gamma$. Thus, cAMPelevating agents inhibit IFN- $\gamma$ mRNA expression and the intracellular levels of IFN- $\gamma$, and increase the expression of $\Pi \mathrm{L}-10 \mathrm{mRNA}$ and the intracellular levels of IL-10 (Platzer et al., 1995; Benbernou et al., 1997). Xia et al. (1996) reported that TCAs as well as SSRIs significantly elevate intracellular cAMP-concentrations in T-lymphocytes and monocytes. Therefore, it is safe to hypothesize that the decrease in the IFN- $/ / \mathrm{L}-10$ ratio in immunocytes co-incubated with antidepressants results from increased cAMP-levels.

Finally, we found that the production of IFN- $\gamma$ is significantly lower in the older than the younger volunteers and that the production of IFN- $\gamma$ is significantly higher in fluoxetine-treated TRD patients than in age-matched normal volunteers. It is well known that ageing is associated with a decreased IFN- $\gamma$ production (Candore et al., 1993). The higher IFN- $\gamma$ production in depressed patients treated with fluoxetine may be explained by previous findings that IFN- $\gamma$ production is significantly increased in depressed patients and that IRS activation is more pronounced in patients with TRD despite antidepressive treatments (Maes, 1999).

\section{REFERENCES}

Audus KL, Gordon MA, (1982) Tricyclic antidepressant effects on the murine lymphocyte mitogen response. J Immunopharmacol 4: 13-27.

Benbernou N, Esnault S, Shin HC, Fekkar H, Guenounou M, (1997) Differential regulation of IFN-gamma, IL-10 and inducible nitric oxide synthase in human $T$ cells by cyclic AMPdependent signal transduction pathway. Immunology $91: 361-368$. 
Buthe RM, Castanon $N$, Pousset $F$, Bristow A, Ball C, Lestage I, Michaud B, Kelley KW, Dantzer $R,(1999)$ Central injection of $1 L-10$ antagonizes the behavioural effects of lipopolysaccharide in rats. Psychoneuroendocrinology 24:301-311.

Candore $G$, Di Lorenzo G, Melluso M, Cigna D, Colucei AT, Modica MA, Caruso C, (1993) gamma-Interferon, interleukin-4 and interleukin-6 in vitro production in old subjects. Autoimmunity 16:275-280

Cavaillon JM (1996) Les Cylokines., Masson, Paris.

De Groote D, Zangerle PF, Gevaert $Y$, Fassote MF, Beguin $Y$, Noizat-Pirenne F, Pirenne J, Gathy R, Lopez M, Dehart I, Igot D, Baudrihaye M, Delacroix D, Franchimont P, (1992) Direct stimulation of cytokines (IL- $1 \beta$, TNF- $\alpha, I L-6, I L-2$, IFN- $\gamma$ and GM-CSF) in whole Blood. I. Comparison with isolated PBMC stimulation. Cytokine 4: 239-248.

Hamilton $M_{,}$(1960) A rating scale for depression. J Neurol Newosurg $P_{\text {Sychiatry } 23: 56-62 .}$

Katsikis PD, Cohen $\mathrm{S}$, Londei M, Feldmann $\mathrm{M}$, (1995) Are CD4+ THI cells pro-inflammatory or anti-inflummatory? The ratio of $1 \mathrm{~L}-10$ to IFN-gamma or $1 \mathrm{~L}-2$ determines their function. Ini Imminal 7: $1287-1294$.

Kubera M, Basta-Kaim A, Holan V, Simbirtsev A, Roman A, Pigareva N, Prokopieva E, Sham J, (1998a) Effect of mild chronic stress, as a model of depression, on the immunoreactivity of C57BL/6 mice. In J linmunopharmacol 20: 781-789.

Kubera M, Holan V, Basta-Kaim A, Roman A, Borycz J, Shani J, (1998b) Effect of desipramine on immunological parameters in mice, and their reversal by stress. Int I Immunophamacol 20: $429-438$.

Kubera M, Kenis $\mathrm{O}$, Bosmans E, Scharpe $S_{*}$ Maes $M$, (2000) Effects of serotonin and serotonergic agonists and antagonists on the production of interferon-gamma and interjeukin10. Neuropsychopharmacology 23: 89-98.

Kubera M, Symbirtsev A, Basta-Kaim A, Borycz d, Roman A. Papp M, Claesson M, (1996) Effect of chronic treatment with imipramine on interleukin 1 and interleukin 2 production by splenocytes obtained from rats subjected to a chronic mild stress model of depression. Pol $J$ Pharmacol 48: 503-506.

Maes M, (1999) Major depression and activation of the inflammatory response system. Adv Exp Med Biol $461: 25-46$.

Maes M, Delange J, Ranjan R, Mellzer HY, Desnyder R, Cooremans W, Scharpe S, (1997) Acute phase proteins in schizophrenia, mania and major depression: modulation by psychotropic drugs Psychiary Res 66:1-11.

Maes M, Song C, Lin A (1999a) Immune and clinical correlates of psychological stress-induced production of interferon-gamma and $\mathrm{IL}-10$ in humans. In: Murgo, A. J. (Eds.), Cytokines, Siress and Immunity. (pp. 39.50) Boca Ratom: CRC-Press.

Maes M, Song $C$, Lin A-h, Bonaccorso S, Kenis $G$, De Jongh R, Bosmans E, Scharpe $S$, (1999b) Negative immunoregulatory effects of antidepressants: inhibition of interferon- $\gamma$ and stimulation of interleukin-10 secretion. Newropsychopharmacology 20:370-379.

Nahtas GG, Desoize B, Leger C, (1979) Effects of psychotropic drugs on DNA synthesis in cultured lymphocytes. Proc SoC Exp Biol Med 160:344-348.

Platzer C. Meisel C, Vogt K, Platzer M, Volk HD, (1995) Up-regulation of monocytic IL-10 by tumor necrosis factor-alpha and CAMP elevating drugs. In Immunal 7:517-523.

Seidel A, Arolt V, Hunstiger M, Rink L, Behnisch A, Kirchner H, (1995) Cytokine production and serum proteins in depression. Scand $J$ Immmol 41:534-538.

Shuzewska A, Nowakowski E, Gryska k, (1994) Haptoglobin level in a chronic stress model of depression in rats before and after treatment. Eur Neurophomacol P1-18: 302. 
Sluzewska A, Rybakowski JK, Laciak M, Mackiewicz A, Sobieska M, Wiktonowicz K, (1995) Interleukin-6 serum levels in depressed patients betore and after treatment with lluoxethe. An N Y Acad Sci 762: $474-476$

Song $\mathrm{C}_{\text {, }}$ Leonard $\mathrm{BE}$, (1994) An acute hase protein response in the olfactory bulbectomized rat: effect of sertraline treatment. Med Sci Res 19: 313-314.

Spitzer RL, Williams JBW, Gibbon M, First MB (1990) Sirwchured Clinical Interview According to DSM-III-R. American Press, New York.

Xia Z, DePierre JW, Nassberger $L_{2}$ (1996) Tricyclic antidepressants inhibit IL-6, LL-1B and TNF$\alpha$ release in human blood monocytes and $\mathrm{LL}-2$ and interferon- $\gamma$ in $\mathrm{T}$ cells. Immunopharmacology $34: 27-37$.

Yirmiya $R$, (1996) Endotoxin produces a depressivemlike episode in rats. Brain Res $711:$ : $63-174$. 


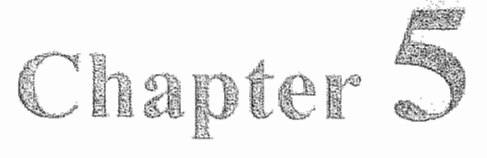

\section{Effects of serotonin and serotonergic agonists and antagonists on the production of interferon- $\gamma$ and interleukin-10}

Marta Kubera, Gunter Kenis, Eugène Bosmans, Simon Scharpé, Michael Maes

Neuropsychopharmacology, (2000), 23, pp. 89-98 


\section{ABSTRACT}

Serotonin (5-HT) is a neurotransmitter and an immune modulator. In-vitro, antidepressants with a serotonergic mode of action have, at concentrations within the therapeutical range, negative immunoregulatory effects, i.e. they increase the production rate of interleukin-10 (IL-1.0), a negative immunoregulatory cytokine. We have hypothesized that part of these effects may be explained by the serotonergic activities of antidepressants on immunocytes. This study was carried out to examine the effects of 5-HT, pchlorophenylalanine (PCPA), a 5-HT depleting agent, flesinoxan (a 5-HT1A agonist), m-chlorophenylpiperazine (mCPP; a 5-HT2A/2C agonist), and ritanserin (a 5-HT2 $\mathrm{A} / 2 \mathrm{C}$ antagonist) on the production rate of interferon- $\gamma$ (IFN$\gamma$ ), a pro-inflammatory cytokine, and $\mathrm{IL}-10$ by whole blood stimulated with polyclonal activators. The IFN- $\gamma / \mathrm{LL}-10$ production ratio was computed, since this ratio reflects the pro- versus anti-inflammatory capacity of cultured whole blood. We found that 1) $5-\mathrm{HT}, 150 \mathrm{ng} / \mathrm{mL}, 1.5 \mu \mathrm{g} / \mathrm{mL}$ and $15 \mu \mathrm{g} / \mathrm{mL}$, significantly decreased the IFN- $\gamma /[\mathrm{L}-10$ ratio; 2) PCPA $(5 \mu \mathrm{M})$ significantly suppressed the production of IFN- $\gamma$ and IL-10;3) flesinoxan $(15 \mathrm{ng} / \mathrm{mL} ; 1.5$ $\mu \mathrm{g} / \mathrm{mL}$ ) had no significant effects on the production of the above cytokines; and 4) $\mathrm{mCPP}(2.7 \mu \mathrm{g} / \mathrm{mL})$ and ritanserin $(5.0 \mu \mathrm{g} / \mathrm{mL})$ suppressed the IFN- $\gamma / \mathrm{IL}-10$ ratio. It is concluded that intracellular $5-\mathrm{HT}$ may be necessary for an optimal synthesis of IFN- $\gamma$ and IL-10, and that extracellular 5-HT concentrations at or above serum values may suppress the production of the pro-inflammatory cytokine IFN $-\gamma$. The negative immunoregulatory effects of antidepressive drugs are probably not related to their serotonergic activities. 


\section{INTRODUCTION}

Serotonin (5-hydroxytryptamine, 5-HT) is a neurotransmitter, a vasoactive amine released by platelets at sites of inflammation and an immune modulator (Roszman et al., 1985; Mossner and Lesch, 1998; Kubera and Maes, 2000). In humans, 5-HT is produced, outside the central nervous system, by enterochromaffin cells and it is stored in circulating platelets and to a lesser extent in monocytes and lymphocytes (Essmann, 1978). 5-HT is released from platelets and lymphocytes/monocytes following stimulation, by platelet activating factors or lectins/interferon- $\gamma$ (IFN- $\gamma$ ), respectively (Finocchiaro et al., 1988). Moreover, it has been demonstrated that lymphoid organs are innervated by serotonergic neurons and that 5-HT may influence the proliferation and differentiation of immunocompetent cells (Cohen, 1985; Felten et al., 1991). Pharmacological and molecular analyses have confirmed the presence of $5 \mathrm{HTIA}$ and $5 \mathrm{HT} 2 \mathrm{~A} / \mathrm{C}$ receptors on activated human immunocytes and specific 5-HT transporter sites on macrophages/lymphocytes (Aune et al., 1994).

The effect of 5-HT on cell-mediated immunity and on the inflammatory response system (IRS) is still a matter of controversy. Some studies show that 5-HT has immunosuppressive effects. Devoino et al. (1968) reported that substances, which have the property to increase 5-HT concentrations, inhibit immunogenesis and antibody production in rodents. 5-HT may suppress dellayed type hypersensitivity and transplantation immunity (Devoino and Morozova, 1988). Bonnet et al. (1984) found that 5-HT suppresses murine lymphocytic responses to phytohaemagglutinin (PHA) and/or allogeneic cells. Para-chlorophenylalanine (PCPA), an inhibitor of 5-HT synthesis, enhances the production of antibodies (Jackson et al., 1985). Other immune functions, however, may be stimulated by 5-HT. For example, cutaneous injection of 5-HT can initiate a delayed-type hypersensitivity reaction through local recruitment and activation of CD4 ${ }^{+} \mathrm{T}$-helper cells (Ptak et al., 1991). Low doses $(100 \mathrm{ng} / \mathrm{ml}$ ) of exogenously added 5-HT stimulate $T$ cell proliferation in response to interleukin-2 (IL-2) (Young et al., 1993; Young and Matthews, 1995). Enhancement of murine T-cell blastogenesis by $5-\mathrm{HT}^{\mathrm{T}}$ has been shown to occur through the 5-HT2 receptor (Young et al., 1993), whereas activation of human T-cells may occur through 5-HT1A receptors (Aune ef al., 1994). Jahnova (1994) showed immuno-activating effects of 5-HT on the production of antibodies. (Boranic et al., 1987), on the other hand, reported that 5-HT as well as PCPA suppressed antibody production.

The effects of 5-HT on the production of cytokines by human immunocytes was the subject of a few studies. Arzt et al. (1991) showed that 5-HT inhibits, in a concentration-dependent way, the LPS-induced production of tumor necrosis 
factor by human macrophages. This effect was blocked by the 5-HT2 receptor antagonist, ketanserin. In humans, 5 -HT promotes IFN- $\gamma$ production by NK cells probably through a 5 HTI A receptor mediated mechanism (Hellstrand et al., 1993).

There is now evidence that major depression is accompanied by disorders in the peripheral and central turnover of 5-HT (Maes and Meltzer, 1995). There is also evidence that the production rate of pro-inflammatory cytokines, such as IL-1, IL-6 and IFN- $\gamma$ is increased in patients with major depression (Seidel et al., 1995; Sluzewska et al., 1995; Maes, 1997; Connor and Leonard, 1998). It is hypothesized that the increased production of the above cytokines may play a role in the aetiology of depression (Maes et al., 1995; Yirmiya, 1996; Connor and Leonard, 1998). Indeed, IL-1, IL-6 and IFN- $\gamma$ given to experimental animals and humans may produce depressive symptoms or full bllown major depression (Bluthe et al., 1992; Yirmiya, 1996; Maes, 1997).

It is thought that antidepressants, such as selective 5-HT reuptake inhibitors (SSRIs), 5-HT-noradrenaline reuptake inhibitors (SNRIs) and some tricyclic antidepressants (TCAs) exert their antidepressant activity through modulation of the brain serotonergic system (Maes and Meltzer, 1995). Antidepressants have also significant negative immunoregulatory activities. In depressed patients, prolonged treatment with SSRIs normalizes the initially increased production of IL-6, IFN- $\gamma$ and positive acute phase proteins (Seidel et al., 1995; Sluzewska et al., 1995; Maes et al., 1997). In-vitro, co-incubation of human whole blood with SSRIs (fluoxetine, sertraline), an SNRI (venlafaxine), TCAs (imipramine, clomipramine), a reversible MAO-A inhibitor (RIMA; moclobemide), and L-5hydroxytryptophan (L-5-HTP), the immediate precursor of 5-HT, significantly increased the production of IL-10 and/or decreased that of IFN- $\gamma$ (Maes et al., 1999; Lin et al., 2000; Kubera et al., 2001). The results suggest that antidepressants with a serotonergic mode of action have, at concentrations within the therapeutical range, negative immunoregulatory effects. The exact mechanisms by which antidepressive drugs affect cytokine production have remained elusive. It may be hypothesized that part of these effects may be explained by the serotonergic activities of antidepressants (Maes and Meltzer, 1995), such as depletion of intracellular 5-HT stores, increased extracellular 5$\mathrm{HT}, 5-\mathrm{HT} 2 \mathrm{~A} / 2 \mathrm{C}$ receptor blockade or 5-HTlA receptor stimulation. However, to the best of our knowledge, the effects of serotonergic agonists and antagonists on the production of IFN- $\gamma$ and IL-10 have not been studied as yet.

The specific aims of the present study were to examine the effects of 5-HT, PCPA (a 5-HT depleting agent), flesinoxan (a 5-HTIA agonist), mCPP (a 5$\mathrm{HT} 2 \mathrm{~A} / 2 \mathrm{C}$ agonist), and ritanserin (a $5-\mathrm{HT} 2 \mathrm{~A} / 2 \mathrm{C}$ antagonist) on the production rate of IFN- $\gamma$ and IL- 10 by whole blood stimulated with polyclonal activators. The results of the present study provide a critical test to elucidate whether 
serotonergic mechanisms modulate the production of IFN- $\gamma$ and $\mathbb{L}-10$; and whether the effects of antidepressants on these cytokines are mediated by serotonergic mechanisms.

\section{METHODS}

\section{Subjects}

Blood samples for the assay of IL-10 and IFN- $\gamma$ were collected from 26 subjects, i.e. 19 healthy volunteers, divided into two subgroups according to age ( $<45$ years versus $\geq 45$ years) and seven major depressed patients who suffered from treatment resistant depression (TRD). The mean ages and male/female ratio of these subgroups were: 12 younger volunteers: mean age $=35.4 \pm 9.6$ years, male/female ratio: $5 / 7 ; 7$ older volunteers, mean age $=51.6 \pm 1.7$ years, male/female ratio: $2 / 5$; and TRD patients: mean age $=50.6 \pm 3.9$ years; male/female ratio: $2 / 5$. The normal volunteers had a negative past and present history of axis-I psychiatric illnesses. None was a regular drinker and none had ever been taking antidepressant or antipsychotic drugs. All subjects, i.e. normal volunteers and depressed patients, were free of medical illness. All subjects were free of acute infections, inflammatory or allergic reactions for at least two weeks prior to the study. They were free of drugs known to modify the immune or endocrine functions for at least one month before blood was sampled. All subjects abstained from caffeine, nicotine and alcohol for at least $12 \mathrm{hr}$ before blood was sampled. The depressed patients were admitted to the University Department of Psychiatry, AZ Stuivenberg, Antwerp, Belgium. Patients fulfilled with the DSM-IV diagnostic criteria for major depression (APA, 1994). We used the Structured Clinical Interview for DSM-III-R, Patient Version to make the diagnosis (Spitzer et al., 1990). The depressed patients were resistant to treatment with fluoxetine, $20-60 \mathrm{mg}$ daily, administered daily for at least 6 weeks. Patients were still taking fluoxetine when blood was sampled. The mean Hamilton Depression Rating Scale score (Hamilton, 1960) in the depressed patients was $25.1( \pm 3.2)$. All subjects gave written informed consent after the study design was fully explained.

\section{Whole blood stimulation}

After an overnight fast, blood for the assays of IFN- $\gamma$ and IL-10 was taken at 9 a.m. ( \pm 30 minutes). The effects of the serotonergic agents on these cytokines were examined by stimulating $1 / 10$ diluted whole blood with PHA $(\mathbb{\mu g} / \mathrm{ml}$; Murex Diagnostics Ltd, Dartford, England) and LPS $(5 \mu \mathrm{g} / \mathrm{ml}$; E.Coli 026; lyophylized and sterilized by gamma-irradiation; Sigma, Belgium). Diluted 
whole blood stimulated with PHA + LPS offers the most appropriate and reproducible culture condition in order to measure cytokine production (De Groote et al., 1992, 1993; Zangerie et al., 1992). Diluted whole blood cultures reflect the in-vivo immune cellular and humoral interactions and may be employed to examine the effects of drugs on cytokine secretion (De Groote et al., 1992, 1993; Zangerle et al., 1992; Maes et al., 1999). $1.8 \mathrm{ml}$ of RPMI-1640 medium with L-glutamine (Gibco BRL) and IU/mL penicillin (Sigma) and 100 $\mu \mathrm{g} / \mathrm{mL}$ streptomycin (Sigma) with PHA + LPS were placed into 24-well cell culture plates (Falcone 3047, Becton Dickinsen). The serotonergic substances were dissolved in sterile water, whereas sterile water alone served as the corresponding control. Twenty $\mu$ of each serotonergic drug solution was added to the wells and gently mixed with the medium. A total of $0.2 \mathrm{ml}$ of whole blood from each of 26 subjects were cultured with $5-\mathrm{HT}(150 \mathrm{ng} / \mathrm{mL}, 1.5$ $\mu \mathrm{g} / \mathrm{mL}$ and $15 \mu \mathrm{g} / \mathrm{mL})$, PCPA $(5 \mu \mathrm{M})$, flesinoxan $(15 \mathrm{ng} / \mathrm{mL}$ and $1.5 \mu \mathrm{g} / \mathrm{mL})$, $\mathrm{mCPP}(27 \mathrm{ng} / \mathrm{mL}$ and $2.7 \mu \mathrm{g} / \mathrm{mL})$ and ritanserin $(50 \mathrm{ng} / \mathrm{mL}$ and $5.0 \mu \mathrm{g} / \mathrm{mL})$. The viability of cells was checked by ethidium-bromide-dye exclusion. The samples were incubated for 24 hours in a humidified atmosphere at $37^{\circ} \mathrm{C}, 5 \%$ $\mathrm{CO}_{2}$. Supernatants were taken off carefully under sterile conditions, divided into eppendorf tubes, and frozen immediately at $-75^{\circ} \mathrm{C}$. IFN $\gamma$ and IL- 10 were quantified by means of ELISA methods (Eurogenetics, Tessenderlo, Belgium) based on appropriate and validated sets of monoclonal antibodies as described by us previously (Maes et al., 1999). All assays of IFN- $\gamma$ or IL-10 were carried out on the same day in one run by the same operator (AL). The intra-assay CV values for both analytes were less than $8 \%$. In our laboratory, the detection limits are $0.9 \mathrm{U} / \mathrm{mL}$ for IFN $-\gamma$ and $10 \mathrm{pg} / \mathrm{mL}$ for $\mathrm{IL}-10$.

\section{Statistics}

Repeated measure design analyses of variance (RM ANOVAs) were used to examine the 1) within-subject variability with the effects of serotonergic drugs as temporal condition, i.e. the positive control versus each of the serotonergic drugs at the different concentrations; and 2) between-subject variability with the three study groups (younger volunteers, elderly volunteers and depressed patients) and gender as factors. All results of RM design ANOVAs were corrected for sphericity. Tests on simple effects were employed to clarify main effects or significant interactions. A simple effect is the effect of one variable at one level of the other variable. Differences among treatment means were ascertained by means of the Dunn test. In order to examine the ratio of the secretion of pro-inflammatory (IFN- $\gamma$ ) versus negative immunoregulatory (IL-10) cytokines, the IFN- $\gamma / \mathrm{LL}-10$ ratio was computed as: $z$ transformed IFN $\gamma$ 
minus $\mathrm{z}$ transformed IL-10 (Maes et al., 1998). IFN- $\gamma$ and $I L-10$ and their ratio were processed in Box-Cox transformation.

\section{RESULTS}

Figure 1 shows the effects of 5-HT on the production of IFN- $\gamma$ and IL-10. RM design ANOVA showed a significant drug effect on IFN- $\gamma$ production $(\mathrm{F}=11.8$, $\mathrm{df}=3 / 85, \mathrm{p}=0.00002)$, but no significant drug $X$ group interaction $(\mathrm{F}=0.92$, $\mathrm{df}=6 / 85, \mathrm{p}=0.5$ ). Dunn tests showed significantly lower IFN- $\gamma$ production in the $5-\mathrm{HT} 1.5 \mu \mathrm{g} / \mathrm{mL}(\mathrm{t}=2.89, \mathrm{p}=0.005)$ and $15 \mu \mathrm{g} / \mathrm{mL}(\mathrm{t}=5.86, \mathrm{p}=0.000007)$, but not $150 \mathrm{ng} / \mathrm{mL}(\mathrm{t}=2.02, \mathrm{p}=0.04)$ conditions than in the control condition (tested at $\mathrm{p}=0.017$ ). RM design ANOVA showed no significant drug effects on IL-10 production ( $\mathrm{F}=2.2, \mathrm{df}=2 / 74, \mathrm{p}=0.1$ ), although there was a significant drug $\mathrm{X}$ group effect $(F=2.9, d f=5 / 74, p=0.018)$. Analyses on simple effects showed a significant drug effect in elderly volunteers $(F=5.1, d f=3 / 90, p=0.003)$, but not in younger volunteers $(F=2.2, d f=3 / 90, p=0.09)$ or major depressed patients $(\mathrm{F}=0.6, \mathrm{df}=3 / 90, \mathrm{p}=0.6)$. In elderly normal volunteers, Dunn tests showed significant suppressant effects of $5-\mathrm{HT}$ at the $1.5 \mu \mathrm{g} / \mathrm{mL}(\mathrm{t}=5.41, \mathrm{p}=0.00001)$ and $15 \mu \mathrm{g} / \mathrm{mL}(\mathrm{t}=4.23, \mathrm{p}=0.0002)$, but not at $150 \mathrm{ng} / \mathrm{mL}(\mathrm{t}=1.93, \mathrm{p}=0.05)$ (tested at $\mathrm{p}=0.01 .7$ ).

RM design ANOVA performed on the IFN- $\gamma / \mathrm{LL}-10$ ratio showed a significant drug effect $(\mathrm{F}=13.9, \mathrm{df}=2 / 74, \mathrm{p}=0.00005)$, but no significant drug $\mathrm{X}$ group interaction $(\mathrm{F}=1.8, \mathrm{df}=5 / 74, \mathrm{p}=0.1)$. Dunn tests showed that the $\mathrm{IFN}-\gamma / \mathrm{IL}-10$ ratio was significantly lower at the $5-\mathrm{HT} 150 \mathrm{ng} / \mathrm{mL}(\mathrm{t}=4.27, \mathrm{p}=0.0002), 1.5$ $\mu \mathrm{g} / \mathrm{mL}(\mathrm{t}=2.64, \mathrm{p}=0.009)$ and $15 \mu \mathrm{g} / \mathrm{mL}(\mathrm{t}=6.24, \mathrm{p}=0.000003)$ conditions than in the control condition.

Figure 1 shows the effects of PCPA on the production of IFN-y and IL-10. RM design ANOVAs showed significant drug effects on IFN $(F=110$, df $=1 / 31$, $\left.\mathrm{p}<10^{-5}\right)$ and $\mathrm{IL}-10\left(\mathrm{~F}=95.5, \mathrm{df}=1 / 30, \mathrm{p}<10^{-5}\right)$, but no significant drug $\mathrm{X}$ group interactions for IFN- $\gamma(\mathrm{F}=2.1, \mathrm{df}=2 / 31, \mathrm{p}=0.1)$ or $\mathrm{IL}-10(\mathrm{~F}=1.6, \mathrm{df}=2 / 30, \mathrm{p}=0.2)$. There were no significant effects of PCPA on the IFN//L- 10 ratio $(\mathrm{F}=0.3$, $\mathrm{d} f=1 / 30, \mathrm{p}=0.6)$ and no significant group $X$ drug interaction $(\mathrm{F}=0.4, \mathrm{~d}=2 / 30$, $\mathrm{p}=0.7$ ). 
BEROTONIN
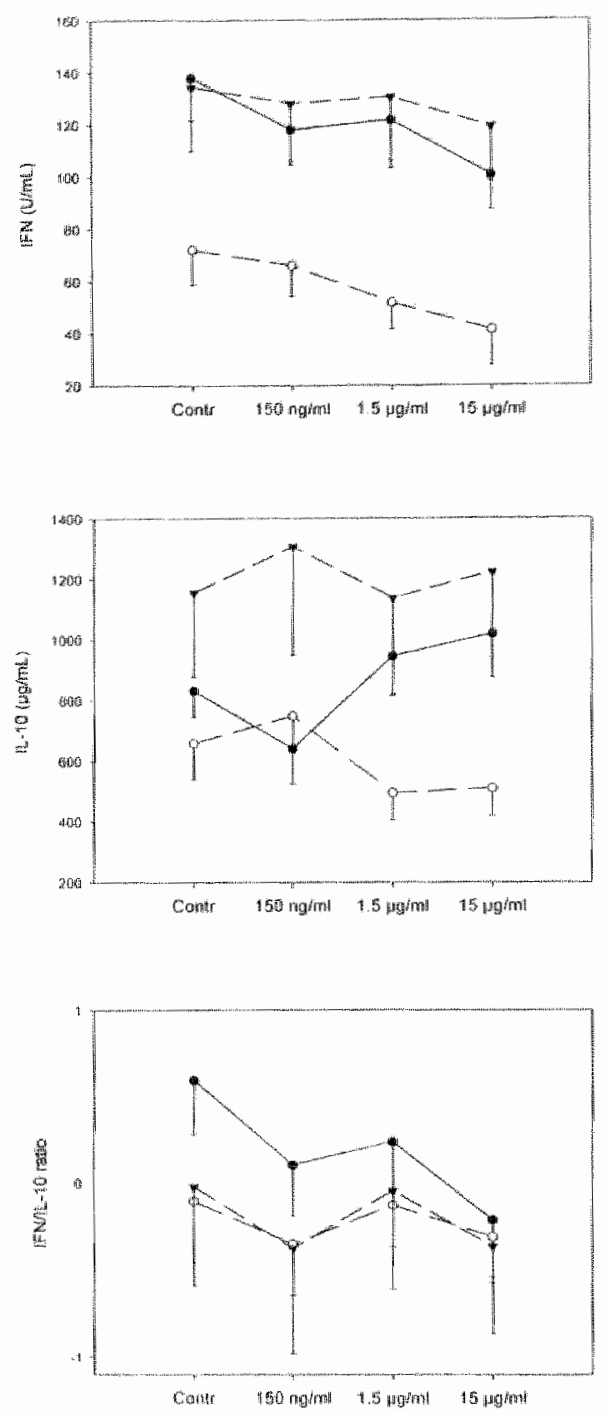

PCPA
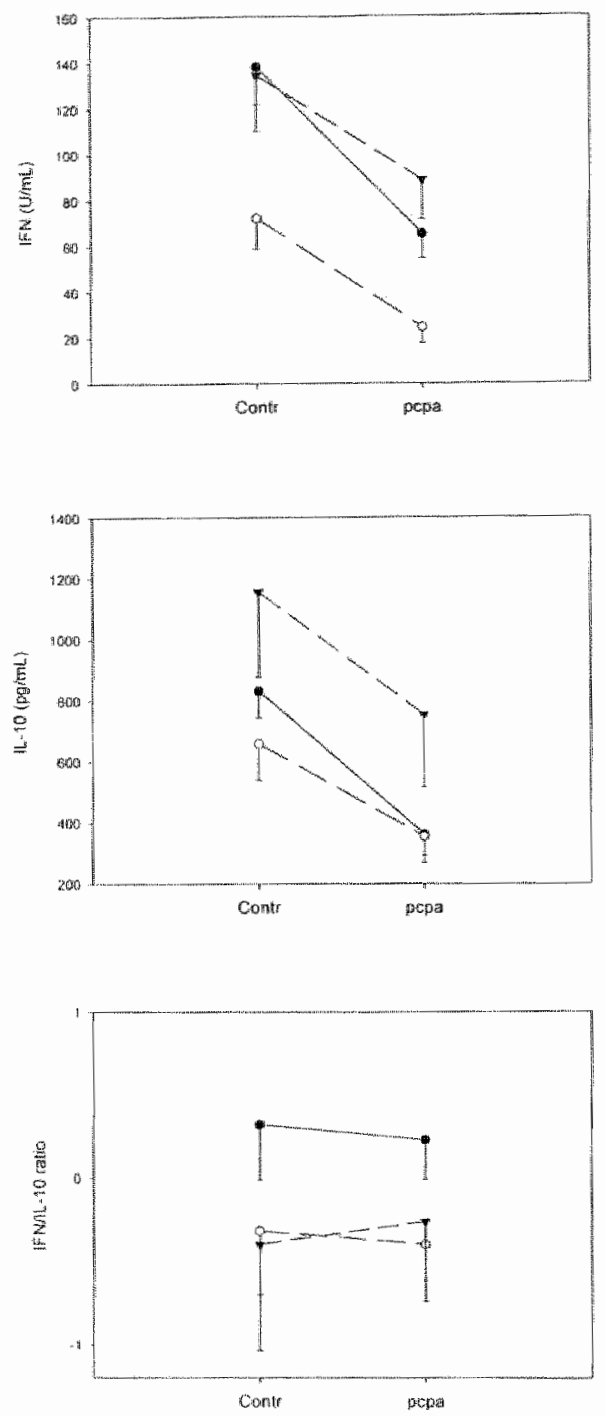

\section{Figure 1}

Effects of serotonin $(5-\mathrm{HT} ; 150 \mathrm{ng} / \mathrm{mL} ; 1.5 \mu \mathrm{g} / \mathrm{mL}$ and $15 \mu \mathrm{g} / \mathrm{mL}$ ) and p-chlorophenylajanine (PCPA, $5 \mu \mathrm{M})$ on the stimulated production of interferon- (IFN- $\gamma$ ) and interleukin-10 (IL-10) and on the IFN- $\gamma /$ IL- 10 ratio.

- Younger normal voluntees: $O$ : older normal volunteers; $\nabla$ : treatment resistant inajor depressed patients. 
RM design ANOVAs did not show any significant effects of flesinoxan (at the two concentrations) on IFN- $\gamma(\mathrm{F}=1.8, \mathrm{df}=2 / 61, \mathrm{p}=0.2), \mathrm{IL}-10(\mathrm{~F}=0.4, \mathrm{df}=2 / 51$, $\mathrm{p}=0.7$ ) or the IFN- $\gamma / \mathrm{IL}-10$ ratio $(\mathrm{F}=0.7, \mathrm{df}=1 / 41, \mathrm{p}=0.6)$ (data not shown). There were no significant group $\mathrm{X}$ drug interaction patterns for $\mathrm{IFN}-\gamma(\mathrm{F}=0.2, \mathrm{df}=4 / 61$, $\mathrm{p}=0.9), 1 L-10(\mathrm{~F}=1.4, \mathrm{~d}=3 / 51, \mathrm{p}=0.2)$ or the IFN-y/lL-10 ratio $(\mathrm{F}=0.7, \mathrm{~d} f=3 / 41$, $p=0.5)$.

Figure 2 shows the effects of mCPP and ritanserin on the production of IFN- $\gamma$ and IL-10. RM design ANOVAs showed that there were no significant effects of $\mathrm{mCPP}$ on IFN- $\gamma(\mathrm{F}=2.2, \mathrm{df}=2 / 61, \mathrm{p}=0.1)$ and $\mathrm{LL}-10(\mathrm{~F}=1.5, \mathrm{df}=2 / 51, \mathrm{p}=0.2)$. The interaction pattern group $X$ drug was not significant for IFN- $\gamma(F=1.0$, $\mathrm{df}=4 / 61, \mathrm{p}=0.4)$ and $\mathrm{IL}-10(\mathrm{~F}=1.5, \mathrm{df}=3 / 51, \mathrm{p}=0.2)$. RM design ANOVA showed that there was a significant effect of $\mathrm{mCPP}$ on the $\| \mathrm{FN}-\gamma / \mathrm{L}-10$ ratio $(F=3.7, d f=2 / 57, p=0.03)$, but no significant group $X$ drug interaction $(F=1.6$, $\mathrm{df}=4 / 57, \mathrm{p}=0.2$ ). Dunn tests (tested at $\mathrm{p}=0.025$ ) showed that the $I F N-\gamma / 1 \mathrm{~L}-10$ ratio was significantly lower in the mCPP $2.7 \mu \mathrm{g} / \mathrm{mL}$, but not $27 \mathrm{ng} / \mathrm{mL}$, condition than in the control condition.

RM design ANOVA showed a significant effect of ritanserin on the production of IFN- $\gamma(\mathrm{F}=5.2, \mathrm{df}=2 / 58, \mathrm{p}=0.008)$, but no significant group $\mathrm{X}$ drug interaction $(\mathrm{F}=1.7, \mathrm{~d} f=4 / 58, \mathrm{p}=0.2)$. Dunn tests (performed at $\mathrm{p}=0.025$ ) showed a significantly lower IFN- $\gamma$ production in the ritanserin $5.0 \mu \mathrm{g} / \mathrm{mL}(t=3.15$, $\mathrm{p}=0.003)$, but not in the $50 \mathrm{ng} / \mathrm{mL}(\mathrm{t}=0.96, \mathrm{p}=0.8)$ condition than in the control condition. RM design ANOVA did not show significant effects of ritanserin on the production of $\mathrm{IL}-10(\mathrm{~F}=1.7, \mathrm{df}=2 / 58, \mathrm{p}=0.2)$ and no significant group $\mathrm{X}$ drug interactions $(\mathrm{F}=1.3, \mathrm{df}=4 / 58, \mathrm{p}=0.3)$. RM design ANOVA showed a significant effect of ritanserin on the IFN- $\gamma / \mathrm{lL}-10$ ratio $(\mathrm{F}=5.7, \mathrm{~d} f=2 / 55$, $\mathrm{p}=0.006)$, but no significant group $\mathrm{X}$ drug interaction $(\mathrm{F}=2.1, \mathrm{~d} f=4 / 55, \mathrm{p}=0.09$ ). Dunn tests showed a significantly lower IFN- $\gamma / \mathrm{LL}-10$ ratio in the ritanserin $5.0 \mu \mathrm{g} / \mathrm{mL}(\mathrm{t}=2.98, \mathrm{p}=0.004)$, but not $50 \mathrm{ng} / \mathrm{mL}(\mathrm{t}=0.15, \mathrm{p}=0.9)$ condition than in the control condition.

RM design ANOVAs showed significant differences in culture supernatant IFN- $\gamma(\mathrm{F}=3.9, \mathrm{df}=2 / 31, \mathrm{p}=0.03)$, but not IL-10 $(\mathrm{F}=1.8, \mathrm{df}=2 / 30, \mathrm{p}=0.2)$ or the IFN- $\gamma / \mathrm{IL}-10$ ratio $(\mathrm{F}=0.4, \mathrm{~d}=2 / 30, \mathrm{p}=0.7)$ between the study groups. Dunn tests (performed at $\mathrm{p}=0.017$ ) showed significant lower IFN- $\gamma$ production in elderly than in younger volunteers $(t=2.64, p=0.012)$ and major depressed patients $(\mathrm{F}=3.14, \mathrm{p}=0.004)$. There were no significant differences in $1 \mathrm{FN}-\gamma$ production between younger volunteers and major depressed patients $(t=0.51, p=0.6)$. 
arepose
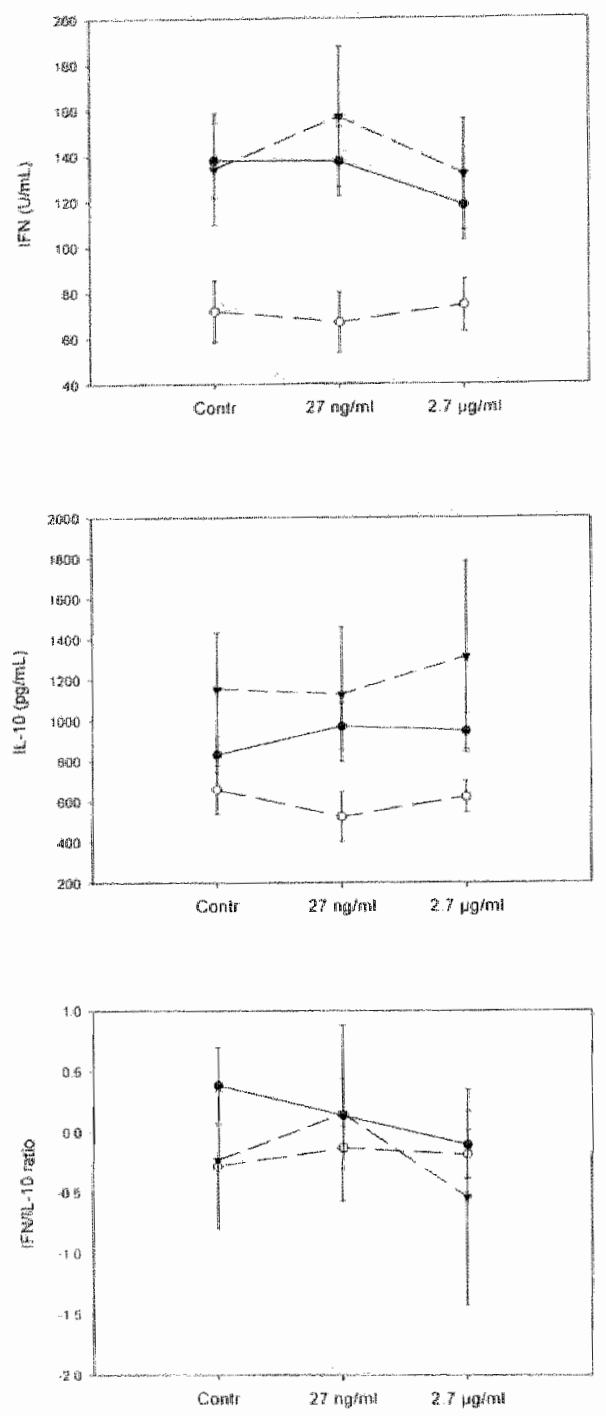

DIYASEFIN
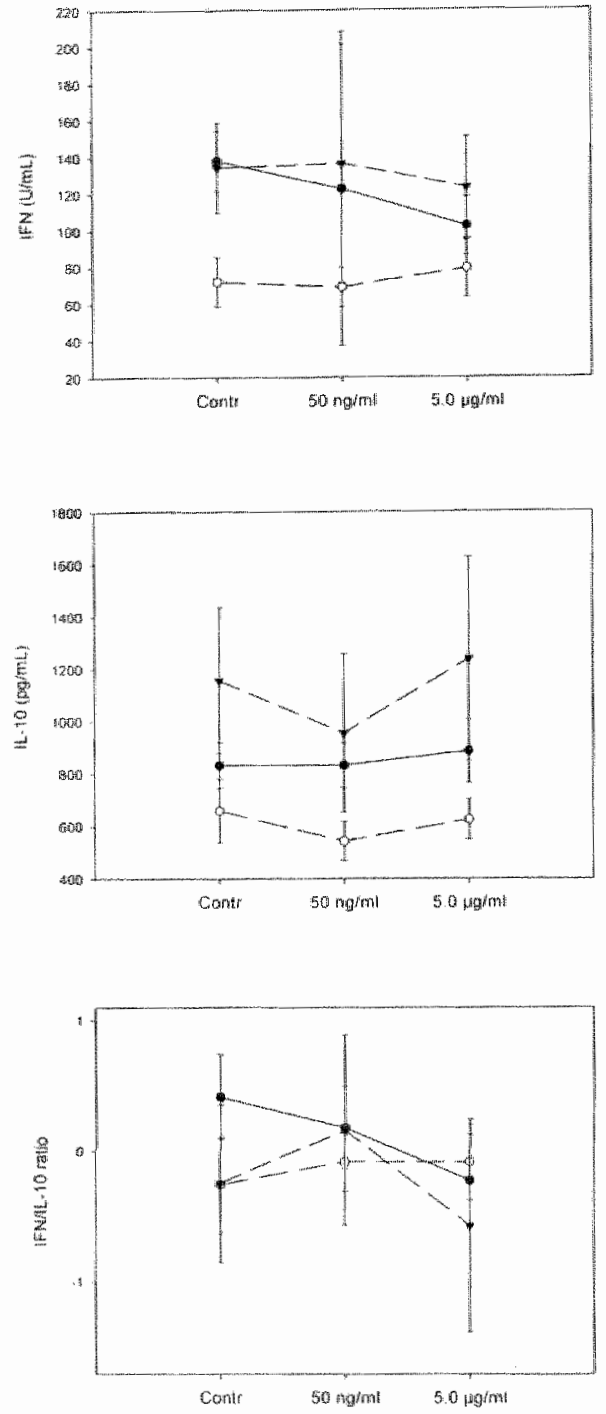

\section{Figure 2}

Efects of m-chlorophenylpuperazine (mCPP; $27 \mathrm{ng} / \mathrm{mL}$ and $2.7 \mu \mathrm{g} / \mathrm{mL}$ ), and ritanserin $(50 \mathrm{ng} / \mathrm{mL}$ and $5.0 \mu \mathrm{g} / \mathrm{mL}$ ) on the stimulated production of interferon-y (IFN- $\gamma$ ) and interlenkin-10 (IL-10) and on the IFN-y/L-10 ratio.

- Younger normal volunteers; $O$ : older normal voluntees; $\nabla$ : treatment resistant major depressed patients. 


\section{DISCUSSION}

The major findings of this study are that 1) $5-\mathrm{HT}, 150 \mathrm{ng} / \mathrm{mL}, 1.5 \mu \mathrm{g} / \mathrm{mL}$ and 15 $\mu \mathrm{g} / \mathrm{mL}$, significantly decreased the IFN- $\gamma / \mathrm{LL}-10$ ratio; 2) PCPA significantly suppressed the production of IFN- $\gamma$ and IL-1. ; 3) flesinoxan had no significant effects on the production of the above cytokines; and 4) the higher concentrations of $\mathrm{mCPP}$ and ritanserin suppressed the IFN-y/LL-10 ratio. Since IFN- $\gamma$ is a pro-inflammatory cytokine and IL- 10 an anti-inflammatory cytokine, our results suggest that $5-\mathrm{HT}, \mathrm{mCPP}$ and ritanserin may have negative immunoregulatory effects. IFN- $\gamma$ is produced by activated Th1 (T helper-1) lymphocytes and by natural killer cells. IL -10 is produced by a variety of cells, including T-lymphocytes, B-lymphocytes and monocytes. Thus, its expression is not confined to a particular T-cell subset (Th-1 like) as in the rodent (Cavaillon, 1996). IL-10 was originally characterized as a factor which inhibits the secretion of IFN- $\gamma$ by Thl-cell clones (Murray et al., 1997). Moreover, IL10 downregulates the production of monocytic cytokines (Cavaillon, 1996). The ratio of IFN- $\gamma$ to IL-10 in culture supernatants is of critical importance in determining the pro- or anti-inflammatory capacity of culture supernatants (Katsikis et al., 1995).

Previously, it has been found that 5-HT concentrations, close to the physiological concentrations, have immuno-stimulating effects, whereas higher concentrations have immunosuppressive effects (Bonnet et al., 1984; Roszman et al., 1985; Aune et al., 1994). The baseline concentrations of 5-HT in serum are between $50-200 \mathrm{ng} / \mathrm{mL}$, while under pathological conditions such as inflammation, ischemia, or trombosis, extracellular 5-HT levels may increase to $3 \mu \mathrm{M}$. Thus, in the present study we employed 5-HT at concentrations found in nornal serum and during pathological conditions. It has been reported that both $\mathrm{T}$ cells and monocytes release 5-HT in culture medium after PHA stimulation and that concentrations of $5-\mathrm{HT}$ between $10^{-8} \mathrm{M}$ to $10^{-7} \mathrm{M}$, sufficient to activate 5-HT receptors, can be reached in these cultures. We found that 5-HT at all concentrations lowered the IFN- $\gamma / \mathrm{LL}-10$ ratio, an effect which mainly could be ascribed to the suppressive effects on IFN- $\gamma$ secretion. These findings extend those of Bonnet et al. (1984) and Devoino and Morozova (1988) who reported that exogenous 5-HT may suppress various aspects of cell-mediated immunity. Devoino et al. (1968) suggested that these changes might be related to central rather than to peripheral 5-HT activities, because lesions of the serotonergic raphe nuclei promoted stimulation in immune responsivity. Nevertheless, our results show that 5 -HT has direct effects on peripheral blood immunocytes. Our results also suggest that the suppressive effects of antidepressive drugs on the IFN- $\gamma / \mathrm{LL}-10$ ratio are probably not related to direct effects of $5-\mathrm{HT}$. Indeed, the present study showed that 5-HT significantly suppressed the production of 
IFN- $\gamma$, whereas the common activity of different antidepressants, such as SSRIs, TCAs, HCAs, RIMAs and L-5-HTP is to increase IL-10 secretion, rather than decreasing that of IFN- $y$.

The second major finding of this study is that PCPA, an agent which inhibits 5HT synthesis, dramatically suppressed the production of both IFN- $\gamma$ and IL-10. Since monocytes and lymphocytes may synthesize 5-HT (Finocchiaro et al., 1988), co-incubation of whole blood with PCPA most likely imhibits 5-HT synthesis in lymphocytes and monocytes. Since we have shown that PCPA inhibits the production of IFN- $y$ and IL-10, we may hypothesize that endogenous 5-HT exerts an autocrine and necessary role in the secretion of those cytokines. In this respect, Aune et al. (1994) showed that endogenous 5HT was indispensable for human $T$ cell proliferation. PCPA at the same concentrations as employed in the present study $(5 \mu \mathrm{M})$ inhibited the proliferative responses of T cells to polyclonal activators, while the inhibition of T cell proliferation by PCPA was reversed by 5-HTP (Aune et al., 1994). Thus, intracellular 5-HT may be necessary for an optimal synthesis of IFN- $\gamma$ and IL-10, whereas extracellular 5-HT concentrations at or above serum values may suppress the production of the pro-inflammatory cytokine IFN- $\gamma$.

The third major finding of this study revolves around the immunoregulatory effects of 5-HT1A and 5-HT2 receptor agonists and antagonists. A number of 5-HT receptor subtypes have been identified on immunocytes. Serotonergic receptors on leukocytes were already demonstrated in 1982 by Eliseeva and Stefanovich (1982). Functional, pharmacological, biochemical and molecular analyses have identified the 5 HT1 A receptor on human NK cells and activated PBMC and T cells (Aune et al., 1993, 1994; Hellstrand et al., 1993). Pharmacological and molecular analyses demonstrated the presence of 5HT2C receptors on human activated $\mathrm{T}$ lymphocytes. In the present study, no significant effects of flesinoxan, a 5-HTIA agonist, on IFN- $\gamma$ or IL-10 production could be found. We found that ritanserin as well as $\mathrm{mCPP}$ significantly decrease the IFN- $/ 1 \mathrm{~L}-10$ production ratio. In the case of ritanserin it is clear that this effect is obtained through inhibition of the IFN- $\gamma$ production. $5 \mathrm{HT} 2 \mathrm{~A} / \mathrm{C}$ antagonists in the murine model inhibit the passive transfer of DTH reactions (Gershon et al., 1975; Ameisen et al,, 1989) and IFN- $\gamma$-induced murine macrophage la expression (Sternberg et al., 1987). 5-HT2A/C antagonists modulate IFN- $\gamma$-induced phagocytosis by murine macrophages (Sternberg et al,, 1987). Arzt et al. (1991) reported that 5-HT inhibits - in a concentration dependent way - the LPS-induced production of tumor necrosis factor by human macrophages, and that this effect was blocked by the 5-HT2 receptor antagonist, ketanserin. On the other hand, 5-HT2A/C receptor antagonists were not able to inhibit PHA-stimulated proliferation of $\mathrm{T}$ cells (Nordlind et al., 1992; Aune et al., 1994). Enhancement of murine T-cell 
blastogenesis by 5-HT has been shown to occur through 5-HT2 receptors (Young et al., 1993). The production of Th-1 cytokines, such as IL -2 and IFN- $\gamma$, by Ag-stimulated, immune murine spleen cells is inhibited by 5 HTIA receptor antagonists, but not by 5HT2 receptor antagonists (Aune et al., 1994).

Our observations further underscore the role of 5-HT in the production rate of pro-inflammatory (IFN- $\gamma$ ) versus negative immunoregulatory (IL-10) cytokines and may suggest an involvement of the $5 \mathrm{HT} 2 \mathrm{~A} / \mathrm{C}$, but not $5 \mathrm{HT} 1 \mathrm{~A}$, receptors in 5 -HT-mediated IFN- $\gamma$ versus IL-10 production. However, also the role of 5HT2A/C related mechanisms for the production of IFN- $\gamma$ versus IL-10 appears inconclusive since both agonists and antagonists at these receptor sites have similar effects on the IFN- $\gamma /$ IL-10 production ratio. Perhaps the effects of mCPP may in part be explained by its 5-HT reuptake inhibitory effects (Baumann et al., 1995) or its activity at other 5-HT receptors, such as the 5-HT1D sites (Schoeffter and Hoyer, 1989). Moreover, mCPP has been shown to bind to $\alpha 2-$ adrenergic receptors (Hamik and Peroutka, 1989). Stimulation of $\alpha 2$ adrenenoceptors may result in negative immunoregulatory effects (Maes et al., 2000 ). Our results that $5-\mathrm{HT} 2 \mathrm{~A} / \mathrm{C}$ receptor antagonists and agonists do not modulate the production rate of $\mathrm{IL}-10$ suggest that the negative immunoregulatory effects of SSRIs and TCAs, which may in part exert their antidepressant efficacy through their activity at $5-\mathrm{HT} 2 \mathrm{~A} / \mathrm{C}$ receptors (Maes and Meltzer, 1995), may not be ascribed to 5-HT2A/C mechanisms.

Future research should focus on the effects of antidepressants and serotonergic agents on cyclic AMP (cAMP). Xia et al. (1996) reported that TCAs as well as SSRIs significantly elevate intracellular cAMP concentrations in T lymphocytes and monocytes. Elevation of the intracellular levels of cAMP differently affects the production of IL-10 and IFN- $\gamma$ (Benbernou et al., 1997). Cyclic AMPelevating agents inhibit IFN- $\gamma$ mRNA expression and IFN- $\gamma$ levels in lymphocytes, and significantly enhance IL-10 mRNA expression and the intracellular levels of IL-10 (Benbernou et al., 1997). In monocytes, cAMP elevating drugs augment the stimulated synthesis of $I L-10$ at both protein and mRNA levels (Platzer et al,, 1995). 5-HT stimulates cAMP formation in homogenates of rat hippocampus in a concentration-dependent manner; 5HT1 A, 5-HT7 and 5-HT4 receptors are involved in mediating these responses (Markstein et al., 1999).

In the present study, we found that the production of IFN- $\gamma$ was significantly lower in older than in younger volunteers and that the production of IFN- $\gamma$ was significantly higher in fluoxetine-treated TRD patients than in age-matched normal volunteers. The differences between both age-groups may be explained by the previous findings that ageing is associated with various alterations in lymphoid cell functioning, such as decreased IFN- $\gamma$ production (Candore et al., 1993). The higher IFN- $\gamma$ production in depressed patients treated with 
fluoxetine could perhaps be explained by previous findings that IFN- $\gamma$ production is significantly increased in depressed patients and that IRS activation is more pronounced in patients with TRD despite antidepressive treatment (Seidel et al., 1995; Maes, 1997). However, the data presented are for a small cohort of subjects. Moreover, the study groups do not include a spectrum of older individuals and drug-free depressed patients. Although the data suggest differences between the younger and older normal volunteers and depressed patients following fluoxetine, a larger cohort of young and old individuals and drug-free depressed patients should be studied in order to establish valid conclusions. In addition, it should be stated that this study employed diluted whole blood stimulated with PHA + LPS to study the effects of drugs on the production of cytokines. It is conceivable that comparable results will be obtained using other polyclonal activators. Nevertheless, diluted whole blood stimulated with LPS + PHA offers the most appropriate and reproducible culture condition in order to measure cytokine production and to study the effects of any drugs on the production of cytokines (De Groote et al., 1992, 1993; Zangerle et al., 1992)

\section{REFERENCES}

Ameisen JC, Meade R, Askenase PW, (1989) A new interpretation of the involvement of serotonin in delayed-type hypersensitivity. Serotonin-2 receptor antagonists inhibit contact sensitivity by an effect on T cells. J Immunol 142: $3171-3179$.

Arzt E, Costas M, Finkielman S, Nahmod VE, (1991) Serotonin inhibition of tumor necrosis factor-alpha synthesis by human monocytes. Life Sci 48: 2557-2562.

Aune TM, Golden HW, McGrath KM, (1994) Inhibitors of serotonin synthesis and antagonists of serotonin $1 \mathrm{~A}$ receptors inhibit $T$ lymphocyte function in vitro and cell-mediated inmunity in vivo. I lmwnulol $153: 489-498$.

Aune TM, McGrath KM, Sarr T, Bombara MP, Kelley KA, (1993) Expression of 5HTla receptors on activated human $T$ cells. Regulation of cyclic AMP levels and $T$ cell proliferation by 5-hydroxytryptamine. J Immunol 151: 1175-1183.

Baumann MH, Mash DC, Staley JK, (1995) The serotonin agonist m-chlorophenylpiperazine (mCPP) binds to serotonin transporter sites in human brain. Neuroreport $6: 2150-2152$.

Benbernou N, Esnault S, Shin HC, Fekkar H, Guenounou M, (1997) Differential regulation of IFN-gamma, $1 \mathrm{~L}-10$ and inducible nitric oxide synthase in human $T$ cells by cyclic AMPdependent signal transduction pathway. Immunology 9 $1: 361-368$.

Bluthe RM, Crestani F, Kelley KW, Dantzer R, (1992) Mechanisms of the behevioural effeets of interleukin I. Rolle of prostaglandins and CRF. Am N Y Acad Sci 650: 268-275.

Bonnet M, Lespinats G, Burtin C, (1984) Histamine and serotonin suppression of lymphocyte response to phytohemagglutinin and allogeneic cells. Cell Immunol 83: 280-291.

Boranic M, Pericic D, Poljak-Blazi M, Sverko V, Marolti $T$, (1987) Suppression of immune response in rats by stress and drugs interfering with metabolism of serotonin. Am NY Acad Sei $496: 485-491$. 
Candore G, Di Lorenzo G, Melluso M, Cigna D, Colmeci AT, Modica MA, Caruso C, (1993) gamma-Interferon, interleukin-4 and interleukin-6 in vitro production in old subjects. Autoimmuwity 16:275-280.

Cavaillon JM (1996) Les Cyrokines., Masson, Paris.

Cohen RA, (1985) Platelet-induced neurogenic coronary contractions due to accumulation of the false neurotransmitter, 5-hydroxytryptamine. J Clin Invest 75: 286-292.

Comnor TJ, Leonard BE, (1998) Depression, stress and immunological activation: the role of cytokines in depressive disorders. Life Sci 62: 583-606.

De Groote D, Gevaert Y, Lopez M, Gathy R, Fauchet F, Dehart I, Jadoul M, Radoux D, Franchimont $\mathrm{P}$, (1993) Novel method for the measurenent of cytokine production by a onestage procedure. Jlmmowol Methods 163: 259-267.

De Groote D, Zangerle PF, Gevaert $Y$, Fassotte MF, Beguin $Y$, Noizat-Pirenne F, Pirene $I_{\text {, }}$ Gathy R, Lopez M, Dehart I, Igot D, Baudrihaye M, Delacroix D, Franchimont P, (1992) Direct stimulation of cytokines (IL- $\|B, T N F-\alpha\| L-6,, \| L-2, \mathbb{R} N-\gamma$ and GM-CSF) in whole blood. I. Comparison with isolated PBMC stimulation. Cytakine 4:239-248.

Devoino LV, Korovina LS, Ilyutchenok RY, (1968) Influence of some drugs on the inmune response. 1. The effect of 5-hydroxytryptophan, iproniazid and reserpine on primary and secondary immune responses. Eu J Phormacol 4: 441-448.

Devoino LV, Morozova NB (1988) Serotonergic system in neuroimmunomodulation: Mechanism of inhibition. In: Novera, H. S. (Eds.), Neuroimmunomodulation, Procedings of the First International Workshop, Bethesda, 27-30 November 1984. (pp. 119-123) New York: Gordon and Breach Sciences Publishers.

Eliseeva LS, Stefanovich LE, (1982) [Specific binding of serotonin by blood leukocytes and peritoneal cells in the mouse]. Biokhinnia $47: 810-813$.

Essmann WB (1978) Serotonin distribution in tissue and fluids. In: Essmann, W. B. (Eds.), Serotonin in Health and Disease (pp. 85-91) New York: Spectrum.

Felten DL, Cohen N, Ader R, Felten SY, Carlson SL, Roszman TL (1991) Psychoneuroimmunology. In: Cohen, N. (Eds.), Psychoneuroimmmology (pp. 1-26) San Diego: Academic Press.

Finocchiaro LM, Arzt ES, Fernandez-Castelo S, Criscuolo M, Finkielman S, Nahmod VE, (1988) Serotonin and melatonin synthesis in peripheral blood mononuclear cells: stimulation by interferon-gamma as part of an immunomodulatory pathway. J Interferon Res 8: 705-716.

Gershon RK, Askenase PW, Gershon MD, (1975) Requirement for vasoactive amines for production of delayed-type hypersensitvity skin reactions. I Exp Med $142: 732-747$.

Hamik A, Peroutka SJ, (1989) 1-(m-chlorophenyl)piperazine (mCPB') interactions with neurotransmitter receptors in the human brain. Biol Psychiatry $25: 569.575$.

Hamilton M, (1960) A rating scale for depression. Neurol Newrosug Prychiary 23:56-62.

Hellstrand K, Czerkinsky C, Ricksten A, Jansson B. Asea A, Kylefjord H, Hermodsson S, (1993) Role of serotonin in the regulation of interferon-gamma production by human natural killer cells. I Interferon Res 13:33-38.

Jackson IC, Cross RJ, Walker RF, Markesbery WR, Brooks WH, Roszman TL, (1985) Influence of serotonin on the immune response. Immunology $54: 505-512$.

Jahnova $\mathrm{E},(1994)$ The effect of risperidone and ritanserin on human $\operatorname{lgG}$ and $\operatorname{lgM}$ synthesis in vitro Plysiol Res 43: 27-31.

Katsikis PD, Cohen S, Londei M, Feldmann M, (1995) Are CD4+ TH1 cells pro-inflammatory or anti-inflammatory? The ratio of $\mathbb{L L}-10$ to $I \mathbb{E N}$-gamma or $1 \mathrm{~L}-2$ determines their function. Int Immunol 7: 1287-1294. 
Kubera M, Lin A-H, Kenis $G$, Bosmans E, Van Bockstaele D, Maes M, (200]) Antiinflammatory effects of anidepressants through suppression of the Interferon- $\gamma /$ Interleukin- 10 production ratio. J Clin Psychopharmacol 21: 199-206.

Kubera M, Maes M (2000) Serotonin-Imunune Interactions in Major Depression. In: Christen (Eds), Neuro-lmmwne Interactions in Neurologic and Psychiatric Disorders (pp. 79-87) Berlin Heidelberg: Springer-Verlag.

Lin A-h, Song C, Kenis G, Bosmans E, De Jongh R, Scharpe S, Maes M, (2000) The in vitro imm unosuppressive effects of moclobemide in healthy volunteers. $J$ Affect Disord $58: 69-74$.

Macs M (1997) The immune pathophysiology of major depression. In: van Praag, H. (Eds.), Depression. Neurobiological. Psychopathological and Therapeutic Advances. (pp. 197-215) Chichester: John Wiley.

Maes M, Delange I, Ranjan R, Meltzer HY, Desnyder R, Cooremans W, Scharpe S, (1997) Acute phase proteins in schizophrenia, mania and major depression: modulation by psychotropic drugs. Psychiatry Res 66: 1-11.

Maes M, Lin A, Kenis $G$, Egyed B, Bosmans $E$, (2000) Negative immunoregulatory effects of noradrenaline through alphid2-adrenoceptor activation. Neuroendocrinol Lett $21: 375-382$.

Maes M, Melzer HYM (1995) The serotonin Hypothesis of Major Depression. In: Kupfer, D. J. (Eds.), Psychopharmacology: The Fourth Generation of Progress. (pp. 933-944) New York: Raven Press, Lid.

Maes $M$, Smith R, Scharpe S, (1995) The monocyte-T-lymphocyte hypothesis of major depression. Psychonetroendocrinology 20:111-116.

Maes M, Song C, Lin A, De Jongh R., Van Gastel A, Kenis G, Bosmans E, De Meester I, Benoy I, Neels $H$, Demedts P, Janca A, Scharpe S, Smith RS, (1998) The effects of psychological stress on humans: increased production of pro-inflammatory cytokines and a Thl-like response in stress-induced anxiety. Cyrokine 10:313-318.

Maes M, Song C, Lin A-h, Bonaccorso S, Kenis G, De Jongh R, Bosmans E, Scharpe S, (1999) Negative immunoregulatory effects of antidepressants: inhibition of interferon- $\gamma$ and stimulation of interleukin-10 secretion. Neuropsychopharmacology 20:370-379.

Markstein R, Matsumoto $M$, Kohler $C$, Togashi $H$, Yoshioka $M$, Hoyer $D$, (1999) Pharmacological characterisation of 5-HT receptors positively coupled to adenylyl cyclase in the rat hippocampus. Noumyn Schmiedebergs Arch Phammocol 359: 454-459.

Mossner R, Lesch KP, (1998) Role of serotonin in the immune system and in neuroimmune interactions. Brain Behow Immun 12: 249-271.

Murraly PJ, Wang L, Omufryk C, Tepper RI, Young RA, (1997) T cell-derived IL-10 antagonizes macrophage function in mycobacterial infection. J Immunol 158: $315-321$.

Nordlind K, Sundstrom E, Bondesson L, (1992) Inhibiting effects of serotonin antagonists on the proliferation of mercuric chloride stimulated human peripheral blood Tlymphocytes. Int Arch Alergy Immunol 97: 105-108.

Platzer C, Meisel C, Vogt K, Platzer M, Volk HD, (1995) Up-regulation of monocytic LL-10 by tumor necrosis factor-alpha and cAMP elevating drugs. Int Immunol 7: 517-523.

Plak W. Geba GP, Askenase PW, (1991) Initiation of delayed-type hypersensitivity by low doses of monoclonal IgE antibody. Mediation by serotonin and inhibition by histamine. $J$ Immunol 146: 3929-3936.

Roszman TL, lackson JC, Cross RJ, Titus MJ. Markesbery WR, Brooks WH, (1985) Neuroanatomic and neurotransmitter influences on immune function. I Immunol 135: 769s$772 \mathrm{~s}$. 
Schoeffer $\mathbb{P}$, Hoyer D, (1989) Interaction of arylpiperazines writh 5-HTIA, 5-HTI B, 5-HTIC and 5-HTID receptors: do discriminatory 5-HTIB receptor ligunds exist? Nawmys Schmiedebergs Arch Pharmacol 339: 675-683.

Seidel A, Arolt V, Hunstiger M, Rink L, Behnisch A, Kirchner H, (1995) Cytokine production. and serum proteins in depression. Scand J Immumol $41: 534.538$.

Sluzewska A, Rybakowski JK, Laciak M, Mackiewicz A. Sobieska M, Wiktorowicz K, (1995) Interleukin-6 serum levels in depressed patients before and after treatment with fluoxatine. Am N Y Acad Sci 762: 474-476.

Spitzer RL, Williams JBW, Gibbon M, First MB (1990) Structured Chinical Interview According ro DSM-III-R. American Press, New York.

Sternberg EM, Wedner HJ, Leung MK, Parker CW, (1987) Effect of serotonin (5-HT) and other monoamines on murine macrophages: modulation of interferon-gamma induced phagocytosis. $J$ lmmunol $138: 4360-4365$.

Xia Z, DePierre JW, Nassberger L, (1996) Tricyclic antidepressants inhibit $1 \mathrm{~L}-6,1 \mathrm{~L}-1 \mathrm{~B}$ and TNF$\alpha$ release in human blood monocytes and $\mathrm{L}-2$ and interferon- $\gamma$ in $T$ cells. Immunopharmacology 34:27-37.

Yirmiya R, (1996) Endotoxin produces a depressive-like episode in rats. Brain Res 7 11 : $163-174$.

Young MR, Kut JL, Coogan MP, Wright MA, Young M, Matthews J, (1993) Stimulation of splenic T-lymphocyte function by endogenous serotonin and by low-dose exogenous serotonin. Immumology 80: 395-400.

Young MR, Mathews JP, (1995) Serotonin regulation of T-cell subpopulations and of macrophage accessory function. Immunology 84: 148-152.

Zangerle PF, De Groote D, Lopez M, Meuleman RJ, Vrindts $Y$, Fauchet F, Dehart 1 , Jadoul $\mathrm{M}_{\text {, }}$ Radoux D, Franchimont P, (1992) Direct stimulation of cytokines (IL-1 beta, TNF-alpha, IL6, IL-2, IFN-gamma and GM-CSF) in whole blood: II. Application to theumatoid arthritis and osteoarthritis. Cytokine 4: 568-575. 
Chavero

Cytokine production in stimulated human

whole blood after modulation of the cAMP/PKA-pathway

Gunter Kenis, Eugène Bosmans, Marc De Baets, Harry Steinbusch, Michael Maes

Submitted 


\section{ABSTRACT}

The cyclic adenosine monophosphate dependent protein kinase A (cAMP/PKA) pathway is an important regulator of cytokine production. It has been established that pharmacological elevation of intracellular cAMP-concentrations inhibits the stimulated production of interferon- $\gamma$ (IFN- $\gamma$ ) and tumor necrosis factor- $\alpha(\mathrm{TNF}-\alpha)$, and may enhance the production of interleukin-10 (IL-10) in isolated leukocyte subsets. However, the effects of modulation of the cAMP/PKA-pathway in stimulated whole blood have never been examined. Therefore, we sought to determine the effects of adenylate cyclase, PKA and phosphodiesterase type 4 (PDE4; an enzyme that catalyzes the breakdown of CAMP) on the stimulated production of IFN- $\gamma$, TNF- $\alpha, I L-6$, IL-10 and IL- 1 Receptor Antagonist (IL-1RA) in human whole blood. Stimulation of adenylate cyclase by forskolin enhanced the secretion of IL-10 and decreased IFN- $\gamma$ production at lower concentrations, whereas it had no effect on TNF- $\alpha$, IL-6 or IL-1RA. The adenylate cyclase inhibitor SQ22536 decreased the production of IFN- $\gamma$, TNF- $\alpha$ and both IL-IRA and IL-6 at higher concentrations, but had no effect on IL-10. Direct stimulation of PKA with the CAMP- analogue Sp-8-BrcAMPS inhibited IFN- $\gamma$, TNF- $\alpha$ and IL-1 RA production, while it enhanced IL-6 secretion at the highest concentration. Rp-8-Br-cAMPS, an inhibitor of PKA, strongly enhanced the production of IL-10 at the highest concentration, and decreased IFN- $\gamma$ secretion at lower but increased it at higher concentration. PKA-inhibition enhanced TNF- $\alpha$ production (although not significant) while it had no effect on IL-6 or IL-1RA. Rolipram, an inhibitor of PDE4, dosedependently inhibited the production of IFN- $\gamma$, TNF- $\alpha$ and IL-1RA. At the highest concentration of rolipram, IL-10 secretion was inhibited, while that of IL-6 was enhanced. Rolipram also reduced the IFN-y/LL-10 ratio, an effect comparable to that of other antidepressants. Clearly, all examined cytokines are differentially affected by inhibitors and stimulators of the CAMP/PKA-pathway. Previous studies using isolated leukocyte subsets and examining only single aspects of the cAMP/PKA-pathway, could not be completely confirmed in stimulated whole blood cultures as employed in this study. 


\section{INTRODUCTION}

The second messenger cyclic 3',5'-adenosine monophosphate (cAMP) is an important regulator of gene transcription. It is produced by the enzyme adenylate cyclase upon stimulation of certain membrane bound $G$-protein coupled receptors. The major effect or CAMP is the activation of protein kinase $\mathrm{A}(\mathrm{PKA}$, which in turn phosphorylates other downstream enzymes, kinases and transcription factors such as CAMP responsive element binding protein (CREB). Receptors that stimulate adenylate cyclase upon ligand binding include $\beta 2$ adrenergic, $\mathrm{H}_{2}$-histaminergic, some serotonergic and prostaglandin $\mathrm{E} 2\left(\mathrm{PGE}_{2}\right.$ ) receptors, all of which have been described to be expressed on leucocytes. The homeostatic regulation of the intracellular cAMP-concentration is predominantly controlled by phosphodiesterase type 4 (PDE4) that catalyzes the breakdown of cAMP to AMP.

It is known that the CAMP/PKA pathway can influence cytokine expression (for review see Zidek, 1999). In general, pharmacological elevation of intracellular cAMP-concentrations inhibits the pro-inflammatory cytokines tumor necrosis factor- $\alpha$ (TNF- $\alpha$ ) and interferon- $\gamma($ IFN- $\gamma$ ), while it enhances the production of interleukin-10 (IL-10). For example, the cAMP-analogue dibutyryl-cAMP (dbCAMP) inhibits IFN- $\gamma$ secretion in human peripheral blood mononuclear cells (PBMCs), human CD4 - and CD8 ${ }^{+}-\mathrm{T}$-cells (Shin et al., 1998), and Jurkat-cells (Benbernou et al., 1997). Histamine, through interaction with $\mathrm{H}_{2}$-receptors, inhibits IFN- $\gamma$ secretion in murine splenocytes and T-helper 1 (Thl) cells (Osna et al., 2001). $\mathrm{PGE}_{2}$, via stimulation of $\mathrm{EP} 2$ receptors, inhibits IFN- $\gamma$ production in human PBMCs, CD4 ${ }^{+}$- and CD8 ${ }^{+}$-T-cells (Abe et al., 1997; Shin et al., 1998) and Jurkat cells (Benbernou et al., 1997). Rolipram, which increases CAMP through selective inhibition of PDE4, down-regulates IFN- $\gamma$ production in human PBMCs (Yoshimura et al., 1998; Jimenez et al., 2001) and in whole blood cultures. The production of TNF- $\alpha$ is also inhibited by rolipram in several culture systems, such as human PBMCs (Yoshimura et al., 1997; Eigler et al., 1998; Jimenez et al., 2001), human whole blood (Brideau et al., 1999), mouse microglia (Yoshikawa et al., 1999) and in rat alveolar epithelial cells (Haddad et al., 2002). Agonists of $\beta$-adrenergic receptors inhibit TNF- $\alpha$ secretion (Szabo et al., 1997). Direct stimulation of adenylate cyclase by forskolin also inhibits TNF- $\alpha$ production in mouse microglia (Yoshikawa et al., 1999). A number of studies examined the influence of CAMP and/or PKA-activation on IL-10 secretion. Most studies found that pharmacological increases of cAMP enhances stimulated IL-10 production in human PBMCs (Meisel et al., 1996; Eigler et al., 1998; Elenkov et al., 1998; Shin et al., 1998; Siegmund et al., 1998), human whole blood cultures (Elenkov et al., 1998; Link et al., 2000), purified human T-cell subsets (Shin et al., 1998), Jurkat-cells (Benbernou et al., 1997) and 
mouse microglia (Yoshikawa et al., 1999). However, some reports demonstrated inhibition of $1 L-10$ production by $c$ AMP elevating agents in activated T-cells (Jimenez et al, 2001; Rafiq et al., 2001) and HIV-infected PBMCs (Cole et al., 1998). Less is known about the influence of cAMP and PKA-activation on the expression of IL-1 Receptor Antagonist (IL-IRA). It seems that db-cAMP induces monocytic and neuronal IL-1RA production (Paez Pereda et al., 1995; Yasuhara et al., 1997), but inhibits lipopolysaccharide (LPS)-induced expression and secretion of IL-1RA (Yasuhara et al., 1997). The influence of activation of the CAMP/PKA-pathway on the IL-6 production is less clear and probably dependent on the cell type, stimulus and microenvironment. In leucocytes, PKA-activation seems necessary for optimall IL-6 production, whereby cAMP-accumulation can enhance LPS-induced IL-6 secretion.

Previously, we and others have shown that antidepressants of several classes may have anti-inflammatory effects in-vitro, e.g. they inhibit the production of IFN- $\gamma$ and TNF- $\alpha$, but may enhance IL-10 production (Xia et al., 1996; Maes et al., 1999; Kubera et al., 2001). The mechanism behind this effect is yet unknown, but it is probably not related to their serotonergic activities (Kubera et al., 2000). There have been some reports that antidepressants may increase intracellular cAMP-concentrations in leucocytes (Xia el al., 1996; Edgar et al., 1999). As mentioned above, pharmacological elevation of intracellular cAMPconcentrations inhibits TNF- $\alpha$ and IFN- $\gamma$ production, while it can stimulate IL10 production. We therefore hypothesize that antidepressants exert their effect on cytokine production through stimulation of the cAMP/PKA-pathway. Most studies concerning the relation between cytokine production and the CAMP/PKA-pathway have been performed on isolated PBMCs, or leukocyte subsets. In contrast, the effects of antidepressants on cytokines have mainly been studied in whole blood cultures.

Therefore, the ain of this study is to examine the influence of the CAMP/PKA pathway on the stimulated production of cytokines in human whole blood cultures. Hereto, an both inhibitor and stimulator of adenylate cyclase (SQ22536 and forskolin, respectively) and PKA (Rp-8-Br-cAMPS and Sp-8-BrCAMPS, respectively), and an inhibitor of PDE4 (rolipram) were added to the cultures, before stimulation with a mixture of LPS and phytohaemagglutinin (PHA). Cytokines in the culture supernatant were then determined by enzyme linked immunosorbent assays (ELISA). 


\section{METHODS}

\section{Reagents}

Lipopolysaccharides (E.coli $026: \mathrm{B} 6$ ) and SQ22536 were purchased from Sigma-Aldrich (Zwijndrecht, The Netherlands). Forskolin and rolipram were obtained from ICN-Biomedicals (Zoetermeer, The Netherlands), phytohaemagglutinin (PHA) came from Abbott Diagnostics (Hoofddorp, The Netherlands). Sp-8-Br-cAMPS and Rp-8-Br-cAMPS were purchased from Biolog Life Science Institute (Bremen, Germany).

\section{Subjects}

Blood was drawn from 20 healthy volunteers (at 9 a.m. $\pm 30 \mathrm{~min}$.) after an overnight fast. All subjects gave written informed consent after full explanation of the study design. The mean age of the subjects was $25.2 \pm 1$ years and the male/female ratio was $9 / 11$. Exclusion criteria for the subjects were: i) age under 18 or over 40 ; ii) a past or present history of psychiatric disorder (axis-I); iii) subjects who ever had been taken major psychotropic medication, such as antidepressants, antipsychotics and anxiolytics; iv) subjects with alcohol or any other drug of dependence abuse; v) smokers; vi) subjects with major somatic disorders, such as diabetes, autoimmune diseases, acquired immunodeficiency syndrome; vii) subjects who currently (two weeks prior to blood sampling) suffered from an infectious, allergic or inflammatory response. The subjects abstained from caffeine and alcohol for at least 10 hours prior to blood sampling.

\section{Whole blood stimulation}

The influence of substances that inhibit or stimulate the CAMP/PKA pathway, was examined using stimulated diluted human whole blood as described previously (De Groote et al., 1992; Maes et al., 1999). Briefly, blood was diluted four times in RPMI 1640 medium (Gibco, Life Technologies, Belgium) supplemented with L-Glutamine and Penicilline-Streptomycine (Gibco, Life Technologies, Belgium). This blood suspension was plated in 24well tissue culture plates pre-filled with concentrated solutions of SQ22536, forskolin, Sp8-Br-cAMPS or Rp-8-Br-cAMPS. After a pre-incubation of $30 \mathrm{~min} .\left(37^{\circ} \mathrm{C}, 5 \%\right.$ $\mathrm{CO}_{2}$ ), a concentrated solution of LPS/PHA was added to the cultures. Plates were placed on gyratory shaker for $10 \mathrm{~min}$. to mix the content of the wells, before incubation at $37^{\circ} \mathrm{C}, 5 \% \mathrm{CO}_{2}$. The final concentrations of the substances were: SQ22536 $(1 \mu \mathrm{M}-10 \mu \mathrm{M}-100 \mu \mathrm{M})$; forskolin $(0.2 \mu \mathrm{M}-2 \mu \mathrm{M}-20$ $\mu \mathrm{M})$; Sp-8-Br-cAMPS $(1 \mu \mathrm{M}-10 \mu \mathrm{M}-100 \mu \mathrm{M})$; Rp-8-Br-cAMPS $(1 \mu \mathrm{M}-$ 
$10 \mu \mathrm{M}-100 \mu \mathrm{M})$; rolipram $(0.2 \mu \mathrm{M}-2 \mu \mathrm{M}-20 \mu \mathrm{M})$. All cultures were stimulated with LPS and PHA in a final concentration of $1 \mu \mathrm{g} / \mathrm{ml}$ and $5 \mu \mathrm{g} / \mathrm{ml}$ respectively. All culture conditions were performed in duplicate. The supernatant of one set was collected after $24 \mathrm{~h}$ (for measurement of TNF- $\alpha$ ), the other after $72 \mathrm{~h}$ (for measurement of IFN- $\gamma, \mathrm{IL}-10$, IL- 6 and IL-IRA). To collect culture supernatant, the plates were gently mixed for $15 \mathrm{~min}$. and centrifuged at $1200 \mathrm{xg}$ for $15 \mathrm{~min}$. Supernatant was aspirated and stored at $-20^{\circ} \mathrm{C}$ untill analysis of cytokines.

\section{Cytokine determination}

Cytokines were determined using sandwich based enzyme-linked immunosorbent assays (ELISA; Eurogenetics, Tessenderlo, Belgium). All assays were performed according manufacturer instructions. In our laboratory, the detection limits are as follows: IFN- $\gamma: 1 \mathrm{U} / \mathrm{ml} ; 1 \mathrm{~L}-10: 3 \mathrm{pg} / \mathrm{ml} ; 1 \mathrm{~L}-6: 10$ $\mathrm{pg} / \mathrm{ml}$; IL-1RA: 0,1 ng/ml; TNF- $\alpha$ : $10 \mathrm{pg} / \mathrm{ml}$.

\section{Statistics}

Repeated measures design analysis of variance (RM design ANOVAs) was performed to examine the within-subject variability with the effect of treatment as temporal condition. Differences among treatment means were ascertained by means of the Dunn-test. The IFN- $\gamma / \mathrm{IL}-10$ ratio was computed as: $z$-transformed IFN- $\gamma$ minus $z$-transformed IL- 10 .

\section{RESULTS}

\section{Influence of adenylate cyclase activity on cytokine production}

The effect of adenylate cyclase (AC) function on cytokine production was assessed by the addition of an inhibitor (SQ22536) or an activator (forskolin) of AC. Results of RM-design ANOVAs are presented in Table 1. There was a significant effect of AC-inhibition on the production of IFN- $\gamma, T N F-\alpha$, and ILIRA (see Figure 1). There was no effect on IL-10. Post-hoc analyses indicated that SQ22536 at $10 \mu \mathrm{M}$ and $100 \mu \mathrm{M}$ significantly reduced IFN- $\gamma$ and TNF- $\alpha$ production. The IL-IRA secretion was reduced by $1 \mu \mathrm{M}$ and $100 \mu \mathrm{M}$ of SQ22536. IL-6 production was only moderately affected by AC-inhibition: 100 $\mu \mathrm{M}$ SQ22536 slightlly reduced IL-6 production.

Activation of AC by forskolin differentially affected the secretion of IFN- $\gamma$ and IL-10. Whereas $0.2 \mu \mathrm{M}$ and $2 \mu \mathrm{M}$ forskolin significantly inhibited IFN- $\gamma$ 
production, $2 \mu \mathrm{M}$ and $20 \mu \mathrm{M}$ forskolin significantly enhanced IL-10 production. There was no effect of forskolin treatment on TNF- $\alpha$, IL- 6 or IL-IRA.

Overall, inhibition of AC inhibits IFN- $\gamma$ and TNF- $\alpha$ production, and moderately reduces IL6 and IL-1RA expression. In contrast, stimulation of AC enhances IL-10 production and only marginally affects pro-inflammatory cytokines (reduction of IFN- $\gamma$ secretion).

\section{Table 1}

Results of RM design ANOVAs, showing the effects of each CAMP/PKA modulating agent on the stimulated production of cylokines.

\begin{tabular}{|c|c|c|c|c|c|c|c|c|c|c|c|c|c|c|}
\hline & \multicolumn{2}{|l|}{5022536} & \multicolumn{3}{|c|}{ Porskolin } & \multicolumn{3}{|c|}{ Spm 8 -Br-AMPS } & \multicolumn{3}{|c|}{ Rp-A-BP×CAMBS } & \multicolumn{3}{|c|}{ Roliptram } \\
\hline & $F \quad d f$ & $p$ & IF & $d r$ & $p$ & $\mathbb{F}$ & $\mathrm{df}$ & $\beta$ & f & $d i$ & $p^{x}$ & l" & $d l^{\circ}$ & $\mathrm{p}$ \\
\hline$\| F N-y$ & $67.12 / 29$ & $10^{6}$ & 12.3 & $2 / 36$ & 0.0002 & 60.7 & $2 \pi 7$ & 0.00001 & 15.6 & $2 / 46$ & 0.000004 & 108 & $1 / 22$ & $410^{3}$ \\
\hline $\mathbb{L L}-10$ & $2.62 / 46$ & 0.09 & 157 & $2 / 42$ & $0,0000 \%$ & 6.7 & $3 / 35$ & 0.004 & 66.5 & 2.45 & $<10^{\circ}$ & 46.5 & $24 \pi$ & $410^{4}$ \\
\hline$N F-a$ & 25,4231 & 0,0000 & 0.8 & 3,0 & 0.5 & 26.2 & $1 / 27$ & 0.00000 & 1.6 & $1 / 21$ & 0.2 & 495 & $1 / 23$ & 0.000001 \\
\hline $11-6$ & $3.572 / 37$ & 0.04 & 1,4 & 230 & 0.3 & 24.65 & $2 / 34$ & $0.0000 !$ & 1.4 & $2 / 30$ & 0,2 & 21.6 & 200 & 0.00002 \\
\hline IL $M R A$ & $41.02 / 37$ & $<10^{4}$ & 1.8 & $2 / 36$ & 0.2 & 34.2 & $2 / 40$ & $x 19 y^{\circ}$ & 1.74 & 236 & 0.2 & 51.3 & $1 / 28$ & 0.00001 \\
\hline
\end{tabular}

\section{Influence of PKA activity on cytokine production}

To modulate PKA-activity, two different isomers of the cAMP analogue 8-BrcAMPS were employed. The Sp-isomer stimulates PKA, whereas the Rpisomer is a cAMP antagonist that inhibits PKA-activity. These compounds were chosen for 1) their high selectivity, 2) their high membrane permeability due to the $\mathrm{Br}$ substitution, and 3) their resistance to PDEs due to the phosphorothioate group.

Stimulation of PKA by Sp-8-Br-cAMPS treatment significantly affected the production of all cytokines examined (see Table 1 and Figure 2). Post-hoc analyses revealed that $10 \mu \mathrm{M}$ and $100 \mu \mathrm{M}$ Sp-8-Br-cAMPS strongly inhibited the production of IFN- $\gamma$ and TNF- $\alpha$. IL-1 RA secretion was reduced at $100 \mu \mathrm{M}$. Sp-8-Br-cAMPS moderately enhanced IL-10 production at $10 \mu \mathrm{M}$ and stimulated IL-6 production at $100 \mu \mathrm{M}$.

There was a significant effect of PKA-inhibition on the production of IFN- $\gamma$ and IL-10, but not on the other cytokines examined. Rp-8-Br-cAMPS at $100 \mu \mathrm{M}$ strongly enhanced $\mathrm{IL}-10$ production, but $1 \mu \mathrm{M}$ and $10 \mu \mathrm{M}$ had no effect. Rp-8Br-cAMPS had a dual effect on IFN- $\gamma$ secretion. Whereas IFN-y secretion was reduced by $1 \mu \mathrm{M}$ and $10 \mu \mathrm{M}$, it was enhanced at $100 \mu \mathrm{M}$ Rp-8-Br-cAMPS. Although $\mathrm{Rp}-8$-Br-cAMPS enhanced TNF- $\alpha$ production as well (see Figure 2), this effect did not reach statistical significance. 
These results indicate that stimulation of PKA strongly inhibits IFN-y and TNFa production, whereas PKA inhibition predominantly stimulates $1 \mathrm{~L}-10$ secretion.

\section{Effect of PDE4 inhibition on cytokine production}

RM design ANOVA showed that there was a significant effect of rolipram on the secretion of IFN- $\gamma$, IL-10, TNF- $\alpha$, IL- 6 and IL-1RA (see Table 1 and Figure 3). Post-hoc analysis revealed that rolipram $0.2 \mu \mathrm{M}$ significantly decreased the secretion of IFN $-\gamma$. At a concentration of $2 \mu \mathrm{M}$, rolipram significantly reduced the production of all cytokines examined. When compared to control cultures, $20 \mu \mathrm{M}$ rolipram significantly inhibited the production of IFN- $\gamma$, IL-10, TNF- $\alpha$ and IL-IRA, but significantly increased that of IL-6.

Further, rolipram significantly reduced the IFN- $/$ /L-10 ratio at all concentrations examined $(\mathrm{F}=11.4, \mathrm{df}=2 / 35, \mathrm{p}=0.0003)$. This effect is comparable with that of other antidepressants.

\section{DISCUSSION}

We have examined the role of the CAMP/PKA-pathway on cytokine production in stimulated diluted human whole blood. The major findings are: 1) blockade of adenylate cyclase activity reduces the production of the pro-inflammatory cytokines IFN- $\gamma$, TNF- $\alpha$ and IL-6, but does not affect IL-10 production; 2) stimulation of adenylate cyclase enhances IL-10 and reduces IFN- $\gamma$ production, but does not affect secretion of TNF- $\alpha$, IL-6 or IL-1RA; 3) direct stimulation of PKA inhibits IFN- $\gamma$, TNF- $\alpha$ and IL-IRA production, while increasing IL-6 and IL-10; 4) PKA-inhibition by Rp-8-Br-cAMPS reduces IFN- $\gamma$ production at lower concentrations, but enhances IL-10 at higher concentrations, while there is no effect on the other cylokines examined; 5) inhibition of PDE4 by rolipram dose dependent decreases IFN- $\gamma$, TNF- $\alpha$, IL-10 and IL-1RA production, while I.L-6 production is decreased at lower, but strongly enhanced at higher concentrations. 

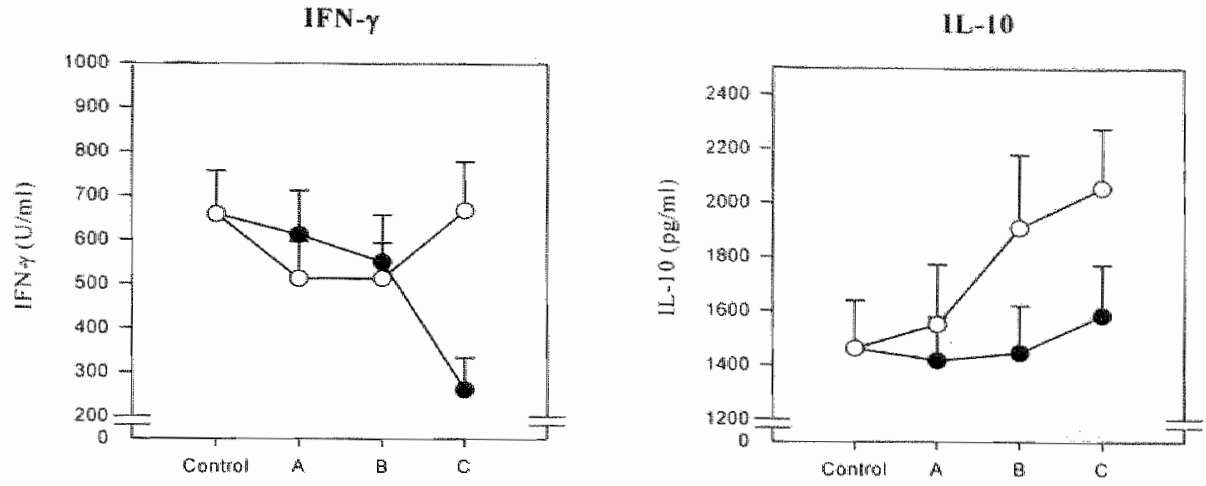

TNF- $\alpha$

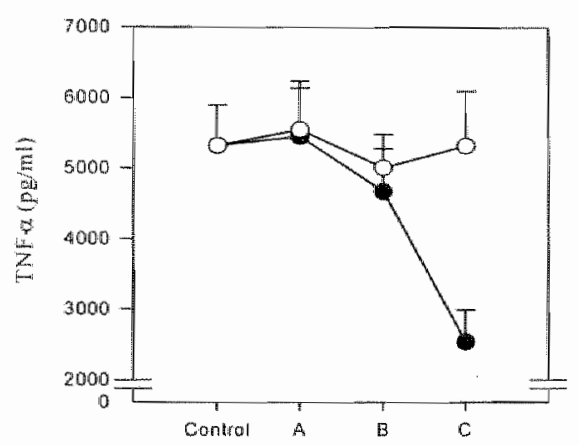

$\| L-6$

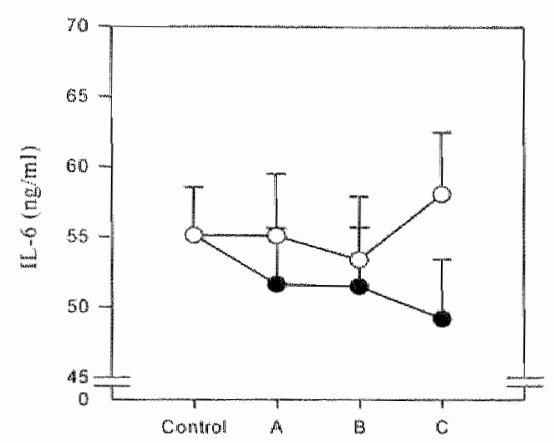

IL-I RA
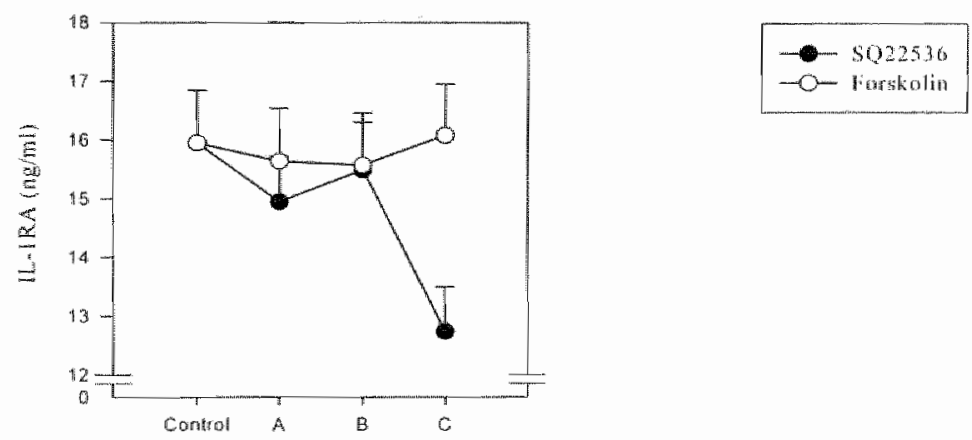

Figure 1

Influence of SQ22536 and forskolin on stimulated production of cytokines in whole blood. Concentrations employed were: $1 \mu \mathrm{M}(\mathrm{A}), 10 \mu \mathrm{M}(\mathrm{B})$ and $100 \mu \mathrm{M}(\mathrm{C})$ for $\mathrm{SQ22536}$; and $0.2 \mu \mathrm{M}$ (A), $2 \mu \mathrm{M}(\mathrm{B})$ and $20 \mu \mathrm{M}$ (C) for forskolin. 

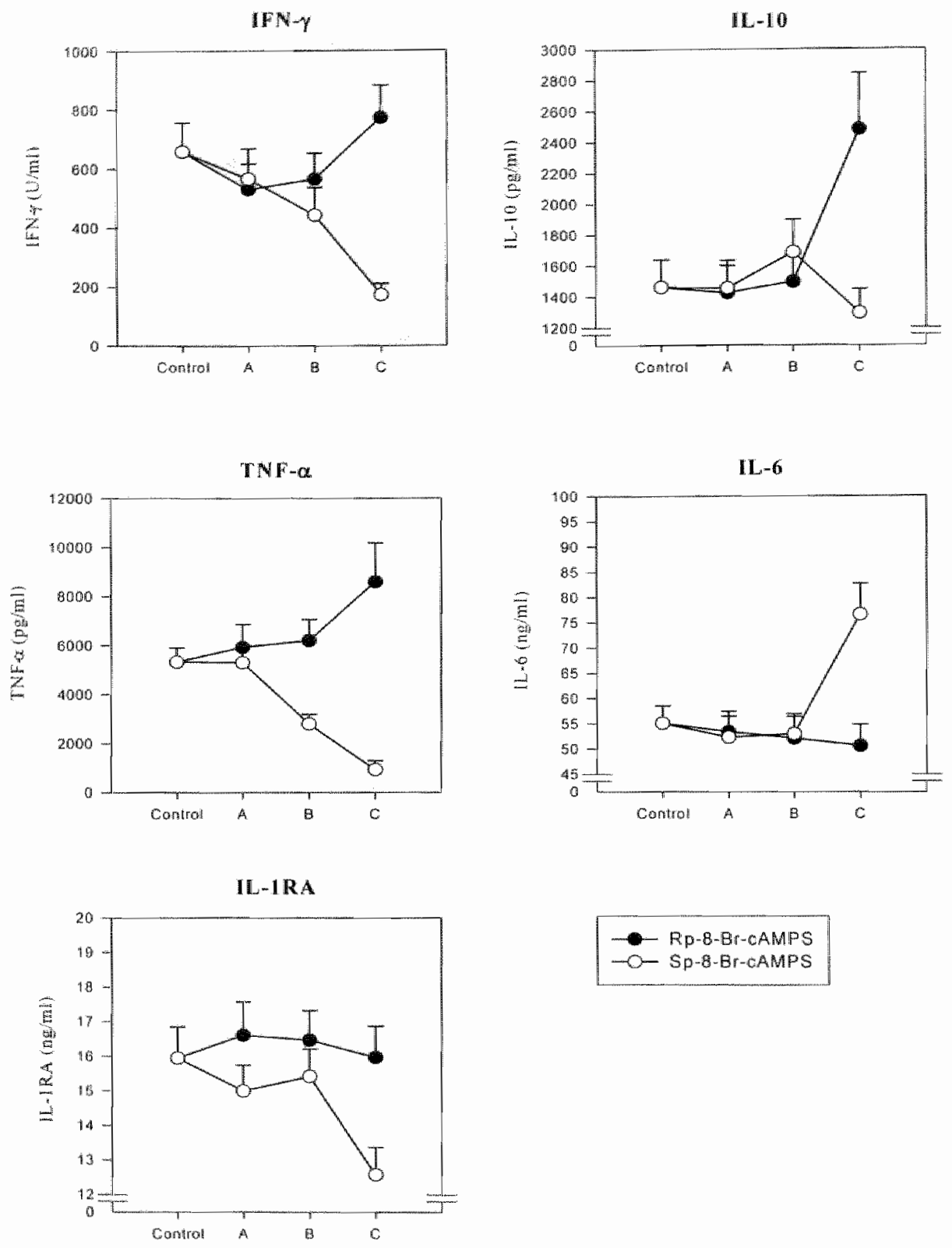

Figure 2

Intluence of Sp-8-Br-cAMPS and Rp-8-Br-cAMPS on stimulated cytokine production in whole blood. Concentrations employed were: $1 \mu \mathrm{M}(\mathrm{A}), 10 \mu \mathrm{M}(\mathrm{B})$ and $100 \mu \mathrm{M}(\mathrm{C})$ for both substances. 
IFN-y

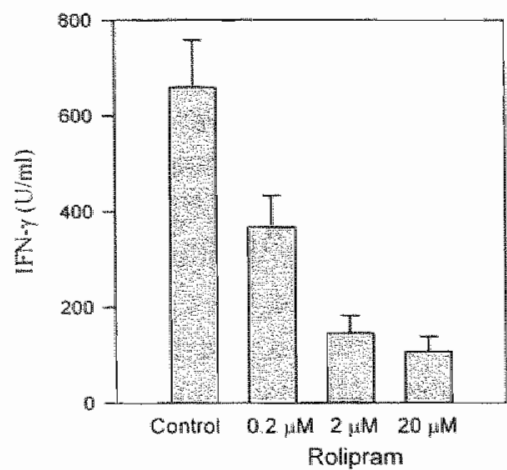

TNF- $\alpha$

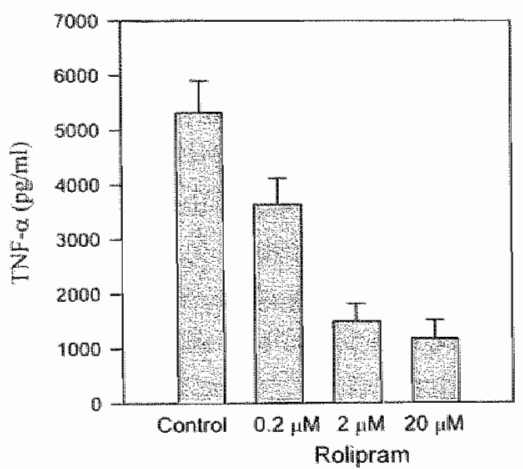

IL-6

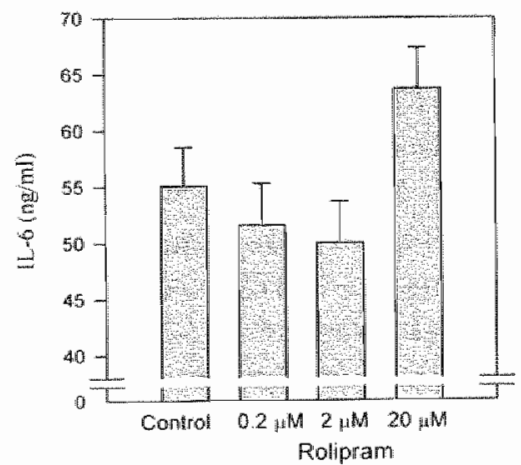

11- 10

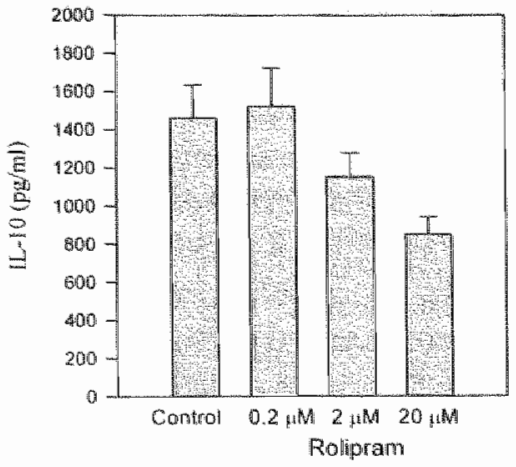

IL-I RA

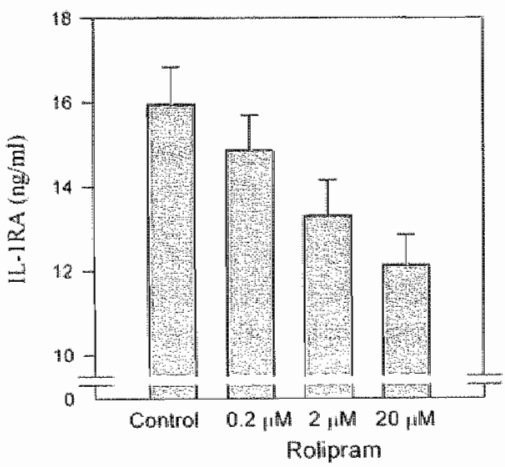

IFN- $/$ IL-10

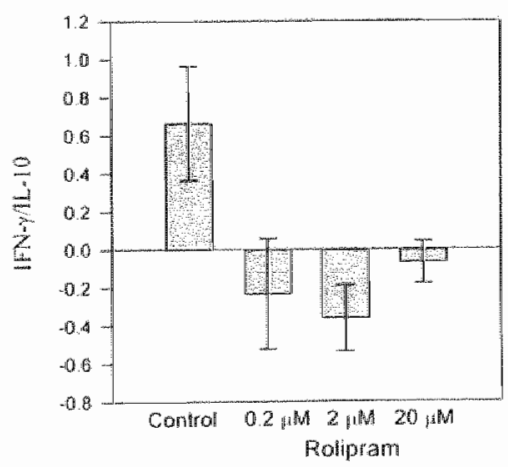

Figure 3

Influence of rolipram on stimulated cytokine production in whole blood. 
To the best of our knowledge, the effects of adenylate cyclase inhibition on stimulated cytokine production, have never been examined before. We found that the adlenylate cyclase inhibitor SQ22536 dose-dependently inhibited the production of IFN $-\gamma$ and TNF- $\alpha$, and reduced IL-6 production at the highest concentration used. This indicates that cAMP-formation is indispensable for optimal pro-inflammatory cytokine production after stimulation with LPS/PHA. Indeed, intracellular CAMP-concentrations are increased in white blood cells after stimulation with LPS/PHA or other immunological stimuli (Wang et al., 1978; Shenker and Gray, 1979; Oksenberg et al., 1989; Kenis et al., 2003), and is required for optimal T-cell activation (Wang et al., 1978). Apparently, blocking of this initial cAMP-increase megatively influences the proinflammatory cytokines IFN- $\gamma$, TNF- $\alpha$ and IL-6, while production of the antiinflammatory cytokine $1 \mathrm{~L}-10$ is not affected.

To study the influence of adenylate cyclase (AC) activity on cytokine production, we used a well-known stimulator of $\mathrm{AC}$, forskolin. This substance directly stimulates $\mathrm{AC}$ to form $\mathrm{CAMP}$ out of ATP, resulting in increased intracellular CAMP concentrations. Since forskolin was pre-incubated for 30 min. before stimulation with LPS/PHA, the cultures with forskolin have higher cAMP-levels at the time of stimulation. We found that forskolin enhanced IL-10 and IL-6 production but did not affect TNF- $\alpha$, nor IL-IRA production in stimulated human whole blood. Forskolin-enhanced IL-10 production has been shown previously in human monocytes (Shames et al., 2001), and is probably related to increased intracellular cAMP-concentrations. Others found that forskolin inhibits TNF- $\alpha$ expression and release in purified human T-cells (Sottile et al., 1996) and monocytes (Ollivier et al., 1996; Sottile et al., 1996; Chong et al., 2002), also probably related to a forskolin-induced cAMPincrease. In our whole blood model, however, there was no effect of forsholin on TNF- $\alpha$. In contrast, the whole blood production of IFN- $\gamma$ was moderately inhibited only at the lower concentrations of forskolin tested $(0,2-2 \mu \mathrm{M})$. Indeed, it has been shown that forskolin inhibits IFN- $\gamma$ expression and secretion in human T-cells (Snijdewint et al., 1993; Sottile et al., 1996; Bodor et al., 2001). Our finding that $20 \mu \mathrm{M}$ forskolin does not inhibit IFN- $\gamma$ production is difficult to explain. Furthermore, forskolin did not affect IL-6 production in stimulated whole blood. Zubiaga et al. also found no effect of forskolin on stimulated IL -6 production in murine Th-2 cells (Zubiaga et al., 1990), while others showed that forskolin up-regulated IL-6 production in pokeweed mitogen stimulated human T-cells (Sottile et al., 1996). To the best of our knowledge, there have been no other reports on the effects of forskolin on IL-1RA production.

It is generally accepted that the downstream effects of cAMP are mediated by PKA. Therefore, we tested the influence of direct activation or inhibition of 
PKA on the stimulated production of cytokines. Direct stimulation of PKA with Sp-8-Br-cAMPS dose-dependently inhibited the production of IFN- $\gamma$ and TNF$\alpha$, which could be expected since pharmacological increases in intracellular CAMP or the addition of cAMP-analogues (like $8-\mathrm{Br}-\mathrm{CAMP}$ or dibutyrylCAMP) inhibits IFN- $\gamma$ (Benbernou et al., 1997; Cole et al., 1998; Shin et al., 1998) and TNF- $\alpha$ (Yoshimura et al., 1997; Wordemann et al., 1998) secretion in several cell culture systems. $I L-10$ production was significantly enluanced at $10 \mu \mathrm{M}$, but not at $100 \mu \mathrm{M} \mathrm{Sp-8-Br-cAMPS}$. An increase in IL-10 production could be expected, since direct stimulation of PKA enhances IL-10 expression and secretion (Platzer et al., 1995; Eigler et al., 1998; Shin et al., 1998). However, it has been shown that IL-10 production is induced by TNF- $\alpha$ (Platzer et al., 1995). This may explain the fact that IL-10 was not further increased after stimulation with $100 \mu \mathrm{M} \mathrm{Sp-8-Br-cAMPS} \mathrm{(as} \mathrm{compared} \mathrm{to} 10 \mu \mathrm{M}$ of the PKAstimulator), because TNF- $\alpha$ production was inhibited by more then $80 \%$ at this concentration. IL-6 production was moderately enhanced at $100 \mu \mathrm{M} \mathrm{Sp}-8-\mathrm{Br}-$ cAMPS in our whole blood model. Zubiaga et al. did not find an effect of $\mathrm{db}$ cAMP on IL-6 production in murine Th-cells (Zubiaga et al., 1990). To the best of our knowledge, this is the first report on the influence of PKA-stimulation on IL-1RA. IL-1RA production was inhibited only at $100 \mu \mathrm{M}$ Sp-8-Br-cAMPS.

To the best of our knowledge, this is the first report on the effects of direct PKA-inhibition on LPS/PHA-stimulated cytokine production. Blockade of PKA had a concentration dependent effect on IFN- $\gamma$ production. Rp-8-Br-cAMPS at 1 $\mu \mathrm{M}$ and $10 \mu \mathrm{M}$ moderately decreased IFN- $\gamma$, whereas $100 \mu \mathrm{M}$ increased IFN- $\gamma$ production. It is known that activation of PKA inhibits T-cell proliferation, immune cell activation and pro-inflammatory cytokine secretion (including IFN- $\gamma$ and TNF- $\alpha$ ) (Bryce et al., 1999; Zidek, 1999). Prolonged inactivation of PKA will therefore result in increased production of these cytokines upon stimulation. Although not significant, TNF- $\alpha$ production was also increased by $61 \%$ at $100 \mu \mathrm{M}$ Rp-8-Br-cAMPS. The decreased production of IFN- $\gamma$ at the lower concentrations of Rp-8-BR-cAMPS are difficult to explain. As mentioned before, increases in intracellular cAMP-concentrations and subsequent PKAactivation are indispensable for normal activation of immune cells.

Surprisingly, $\mathbb{L} \mathrm{L}-10$ production was strongly enhanced at $100 \mu \mathrm{M}$ of $\mathrm{Rp}-8-\mathrm{Br}-$ CAMPS. Since it has been shown that CAMP-increases and PKA-activation stimulate IL-10 production (Platzer et al., 1995; Meisel et al., 1996; Benbernou et al., 1997; Eigler et al., 1998; Elenkov et al., 1998; Woiciechowsky et al., 1998), one would expect a down-regulation of $1 \mathrm{~L}-10$ at high concentrations of the inhibitor. Two recently described phenomena may explain this finding. First, the regulation of IL-10 production by CAMP/PKA is cell-type specific. Thus, it has been reported that the regulation of IL-10 gene expression in human monocytes differs from that in T-cells (Riese et al., 2000). Second, IL-10 
production in response to endotoxin, is to a great extend mediated by the initial TNF- $\alpha$ release (Platzer et al., 1995). Thus, it may be speculated that $100 \mu \mathrm{M}$ $\mathrm{Rp}-8-\mathrm{Br}-\mathrm{CAMPS}$ increased TNF- $\alpha$ production (by $61 \%$, resulting in an enhanced production of IL-10. It is important to realize that the concentration of cytokines in the supernatant of stimulated whole blood, is the net effect of cytokine production by all the different cell types present in the blood (i.e. monocytes, T- and B-lymphocytes, neutrophils, Natural Killer cells, mast cells, eosinophils, basophils, etc.). Moreover, these cells also release inflammatory mediators that can influence cytokine production by other cell types. Modulation of adenylate cyclase or PKA-activity may result in an altered release of these mediators or in a different cellular response to these mediators and, hence, resulting in an altered secretion pattern of cytokines. In whole blood, all the natural in-vivo occurring cell types (and in their natural occurring ratios) are present. The results obtained from experiments using whole blood although they reflect better the in-vivo situation and display the netto effect of drugs on cytokine production, cannot be readily compared with other culture systems that use purified or isolated cell types.

We found that rolipram dose-dependently inhibited the production of IFN- $\gamma$ and TNF- $\alpha$ at all concentrations examined. These results corroborate those of others, who reported inhibitory effects of rolipram on the production of TNF- $\alpha$ (Gantner et al., 1997; Eigler et al., 1998; Brideau et al., 1999; Yoshikawa et al., 1999). It has also been reported that rolipram reduces the production of IFN- $\gamma$ in T-cells (Sommer et al., 1995; Essayan et al., 1997; Pette et al., 1999). Our results extend these findings to stimulated whole blood. Interestingly, rolipram, at $2 \mu \mathrm{M}$ and $20 \mu \mathrm{M}$, inhibited the secretion of IL-10. The effects of rolipram on in-vitro IL-J0 production are not clear. In T-cells, rolipram inhibits IL-10 secretion (Crocker et al., 1998; Pette et al., 1999; Jimenez et al., 2001). In contrast, LPS-induced IL-10 production is augmented by rolipram in human PBMCs (Eigler et al., 1998), peritoneal macrophages (Kambayashi et al., 1995) and microglia (Yoshikawa et al., 1999). In all these studies, rolipram was used in the same concentration range as in our experiments. The different effects of rolipram on various culture systems, may be related to a differential regulation of IL-10 expression in different cell types. Activation of the CAMP/PKApathway can activate the promoter of the $\mathrm{IL}-10$ gene in monocytes (Platzer et all, 2000), but to a lesser extent in T-cells (Riese et al., 2000). Thus, IL-10 gene expression is differentially regulated in monocytes and T-cells by CAMP elevation. In our whole blood stimulation assay, many $1 \mathrm{~L}-10$ producing cell types are present. The concentration of IL-10 (and of other cytokines) measured in the culture supernatant, reflects the net effect of rolipram on the stimulated production of cytokines by all these cells. 
Another major finding is that rolipram reduces the IFN- $\gamma / \mathrm{LL}-10$ production ratio. Previously, we have shown that antidepressants like imipramine, fluoxetine, venlafaxine, clomipramine, sertraline and trazodone also decrease the IFN- $\gamma / \mathrm{IL}$ 10 ratio in stimulated whole blood (Maes et al., 1999; Kubera et al., 2001). Thus, antidepressants of various classes have negative immunoregulatory effects. These effects may be of clinical relevance, since several proinflammatory cytokines are up-regulated in patients with major depression (Connor and Leonard, 1998; Maes, 1999). Experiments in animals indicate that pro-inflammatory cytokines have profound behavioural effects (such as anhedonia, decreased locomotor activity, sleepdisturbances) (Dantzer et al, 1998), and clinical trials in humans show that cytokine therapy can induce depressive symptoms (Maes et al., 2001). Therefore, we hypothesize that antidepressants exert their effect at least in part by their negative immunoregulatory capacity. This is underscored by the fact that rolipram does not display effects on the central serotonergic system as compared to other antidepressants, e.g. selective serotonin reuptake inhibitors. Thus, rolipram has no effect on serotonin release, the firing rate of serotonergic neurons, does not block serotonin reuptake and reduces serotonin metabolism in several brain regions (Kehr et al., 1985; Schoffelmeer et al., 1985; Scuvee-Moreau et al., 1987). It has been suggested that the antidepressant capacity of rolipram is related to a facilitated neurotransmission at the postsynaptic level due to increased signaling of cAMP-linked noradrenaline and/or serotonin receptors (Kehr et al., 1985; Wachtel and Schneider, 1986).

\section{REFERENCES}

Abe $\mathbb{N}$, Katamura $K$, Shintaku $N$, Fuktui $T$, Kiyomasu $T$, lio J, Ueno $H$, Tai G, Mayumi $M$, Furusho $\mathrm{K}$, (1997) Prostaglandin $\mathrm{E} 2$ and $\mathrm{LL} 4$ provide naive $\mathrm{CD} 4+\mathrm{T}$ cells with distinct inhibitory signals for the priming of IFN-gamma production. Cel/ Immunol 181: 86-92.

Benbernou N, Esnaulit S, Shin HC, Fekkar H, Guenounou M, (1997) Differential regulation of IFN-gamma, IL-10 and inducible nitric oxide synthase in human $T$ cells by cyclic AMPdependent signal transduction pathway. Immunology $91: 361-368$.

Bodor J, Feigenbaum L, Bodorowa J, Bare C, Reitz MS, Jr., Gress RE, (2001) Suppression of Tcell responsiveness by inducible cAMP early repressor (ICER). J Lewkoc Biol 69: 1053-1050.

Brideau C, Van Staden C, Styluer A, Rodger IW, Chan CC, (1999) The effects of phosphodiesterase type 4 inhibitors on tumour necrosis factor-a and leukotriene B4 in a novel human whole blood assay. Br I Pharmacol 126: 979-988.

Bryce PJ, Dascombe MJ, Hutchinson IV, (1999) Immunomodulatory effects of pharmacological elevation of cyclic AMP in T lymphocytes proceed via a protein kinase $\mathrm{A}$ independent mechanism. Imwnuophormacology $41: 139-146$.

Chong YH, Shin SA, Lee HJ, Kang JH, Subl YH, (2002) Molecular mechanisms underlyng cyclic AMP inhibition of macrophage dependent TNF-alpha production and metrotoxicity in 
response to anyloidogenic C-lerminal fragment of Alzheimer's amyloid precursor protein. $J$ Neuroimmumal 133: 160-174.

Cole SW, Korin YD, Fahey JL, Zack JA, (1998) Norepinephrine accelerates HIV replication via protein kinase A-dependent effects on cytokine production. $J \mathrm{Im} m u$ mo $161: 610-616$.

Connor TI, Leonard BE, (1998) Depression, stress and immunological activation: the role of cytokines in depressive disorders. Life Sci $62: 583-606$.

Crocken IC, Ohia SE, Church MK, Townley RG, (1998) Phosphodiesterase type 4 inhibitors, but not glucocorticoids, are more potent in suppression of cytokine secretion by mononuclear cells from atopic than nonatopic donors. J Allergy and Chin Immunol 102: 797-804.

Dantzer R, Bluthe RM, Gheusi G, Cremona S, Laye S, Parnet P, Kelley KW, (1998) Molecular basis of sickness behavion. Amn N Y Acad Sci 856:132-138.

De Groote D, Zangerle PF, Gewaert $Y$, Fassotte MF, Beguin $Y$, Noizat-Pirenne IF, Pirenne J, Gathy R, Lopez $M$, Dehart I, Igot D, Baudrihaye M, Delacroix D, Franchimont P, (1992)

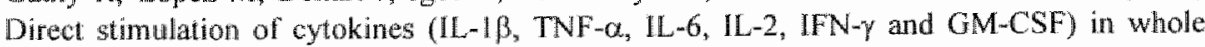
blood. 1. Comparison with isolated PBMC stimalation. Cytokine 4:239-248.

Edgar VA, Sterin-Borda L, Cremaschi GA, Genaro AM, (1999) Role of protein kinase C and CAMP in fluoxetine effects on human T-cell prolliferation. Eur J Pharmacol 372: 65-73.

Eigler A, Siegmund B, Emmerich U, Baumann KH, Hartmann G, Endres S, (1998) Antiinflammatory activities of CAMP-elevating agents: enhancement of IL- 10 synthesis and concurrent suppression of TNF" procuction. J Lewkoc Biol 63: 101-107.

Elenkor IJ, Webster E, Papanicolaou DA, Fleisher TA, Chrousos GP, Wilder RL, (1998) Histamine potently suppresses human $\mathrm{LL}-12$ and stimulates IL-10 production via $\mathrm{H}_{2}$ receptors. J Immwnol $161: 2586-2593$.

Essayan DM, Kagey-Sobotka A, Lichtenstein LM, Huang S-K, (1997) Differential regulation of human antigen specific Th1 and Th2 lymphocyte responses by isozyme selective cyclic nucleotide phosphodiesterase inhibitors. J Phamacol Exp Ther 282: 505-512.

Gantner F, Kupferschmidt R, Schudt C, Wendel A, Hatzelmann A, (1997) In witro differentiation of human monocytes to macrophages: change of PDE profile and its relationschip to suppression of tumour necrosis factor- $\alpha$ release by PDE inhibitors. Br J Pharmacol 121: 22, I$23 \%$.

Haddad J, Land SC, Tamow-Mordi WO, Zembala M, Kowalczyk D, Lauterbach R, (2002) Inmunopharmacological potential of selective phosphodiesterase inhibition. II. Evidence for the involvement of an inhibitory-kappaB/nuclear factor-kappaB-sensitive pathway in alveolar cpithelial cells. J Pharmacol Exp Ther 300: 567-576.

Jimenez JL, Punzon C. Navaro J, Munoz-Femandez MA, Fresno M, (2001) Phosphodiesterase 4 inhibitors prewent cytokine secretion by $t$ lymphocytes by inhibiting nuclear factor-kappab and nuclear factor of activated t cells activation. I Phormacol Exp Ther 299: 753-759.

Kambayashi $T$, Jacob C, Zhou D, Mazurek $N$, Fong $M$, Strassmann $G$, (1995) Cyclic nucleotide phosphodiesterase type IV participates in the regulation of $1 \mathrm{~L}-10$ and in the subsequent inhibition of TNF $\mathrm{O}$ and $1 \mathrm{~L}-6$ release by endotoxin-stimulated macrophages. I Immunol 155: 4909-4916.

Kehr W, Debus $G$, Neumeister $R$, (1985) Effects of Rolipram, a novel antidepressant, on monoamine metabolism in rat brain. I Nenral Tronsm 63:1-12

Kenis G, Steinbusch H, De Baets M, Maes M, (2003) Influence of antidepressants on intracellular levels of cyclic adenosine monophosphate in human peripheral blood mononuclear cells. Eu Neuropsychopharmaco/ 13:53-56. 
Kubera $M$, Kenis $G_{3}$ Bosmans $E$, Scharpe $S$, Maes $M_{\text {, }}$ (2000) Effects of serotonin and serotonergic agonists and amtagonists on the production of interferon-gamma and interleukin10. Neuropsychopharmacology $23: 89-98$.

Kubera M, Lin A-H, Kenis G, Bosmans E, Van Bockstaele D, Maes M, (2001) Antiinflammatory effects of antidepressants through suppression of the Interferon- $/$ /nterteukin-10 production ratio. J Clin Psychopharmacol 21: 199-206.

Link AA, Kino T, Worth JA, McGuire JL, Crane ML, Chrousos GP, Wilder RL, Elenkov IJ, (2000) Ligand-activation of the adenosine A2a receptors inhibits $1 L-12$ production by human monocytes. I Immunol 164: 436-442.

Maes M, (1999) Major depression and activation of the inflammatory response system. Ad Exp Med Biol $461: 25-46$.

Maes M, Bonaccorso S, Marino V, Puzelia A, Pasquini M, Biondi M, Artini M, Amerighi $C_{\text {, }}$ Meltzer H, (2001) Treatment with interferon-alpha (IFN alpha) of hepatitis C patients induces lower serum dipeptidyl peptidase IV activity, which is related to IFN alpha-induced depressive and anxiety symptoms and immune activation. Mol Psychiotry 6:475-480.

Maes M, Song C, Lin A-h, Bonaccorso S, Kenis G, De Jongh R, Bosmans E, Scharpe S, (1999) Negative immunoregulatory effects of antidepressants: inhibition of interferon- $\gamma$ and stimulation of interleukin-10 secretion. Neuropsychopharnacology $20: 370-379$.

Meisel C, Vogt K, Platzer C, Randow F, Liebenthal C, Volk HD, (1996) Differential regulation of monocytic tumor necrosis factor-alpha and interleukin-10 expression. Ew I Immonol 26: $1580-1586$.

Oksenberg D, Oksenberg JR, Sakai K, Peroutka SJ, Steinman L, (1989) Cychic adenosine 3:,5'monophosphate metabolism in activated T-cell clones. Immunology 67: 484-488.

Ollivier V, Parry GC, Cobb RR, de Prost D, Mackman N, (1996) Elevated cyclic AMP inhibits NF-kappaB-mediated transcription in human monocytic cells and endothelial cells. J Biol Chem 271: 20828-20835.

Osna N, Elliott K, Khan MM, (2001) The effects of histamine on interferon gamma production are dependent on the stimulatory signals. Int Immunophamacol 1: 135-145.

Paez Pereda M, Sauer J, Perez Castro C, Finkielman S, Stalla GK, Holsboer F, Arzt E, (1995) Corticotropin-releasing hormone differentially modulates the interleukin-I system according to the level of monocyte activation by endotoxin. Endocrinology $136: 5504-5510$.

Pette M, Muraro PA, Pette DF, Dinter H, McFarland HF, Martin R, (1999) Differential effects of phosphodiesterase type 4-specific inhibition on human autoreactive myelin-specific $T$ cell clones. J Newroimmunot 98: 147-156.

Platzer C, Docke W, Volk H, Prosch S, (2000) Catecholamines trigger $1 L-10$ release in acute systemic stress reaction by direct stimulation of its promoter/enhancer activity in nonocytic cells. J Neuroimmunol 105: 31-38.

Platzer C, Meisel C, Vogt K, Platzer M。 Volk HD, (1995) Up-regulation of monocytic $1 \mathrm{~L}$ - 10 by tumor necrosis factor-alpha and CAMP elevating drugs. Int Immunol 7:517-523.

Rafiq K, Charitidou L, Bullens DM, Kasran A, Lorre K, Ceuppens I, van Gool SW, (2001) Regulation of the IL-10 production by human T cells. Scand.J Immunol 53: 139-147.

Riese U, Brenner $\mathrm{S}$, Docke WD, Prosch S, Reinke P, Oppert M, Volk HD, Platzer C, (2000) Catecholamines induce $1 \mathrm{~L}-10$ release in patients suffering from acute myocardial infarction by transactivating its promoter in monocytic but not in "l-cells. Mol Cell Biochem 212:45-50.

Schoffelmeer AN, Wardeh G, Mulder AH, (1985) Cyclic AMP facilitates the electrically ewoked release of radiolabelled noradrenaline, dopamine and 5-hydroxytryptamine from rat brain slices. Naunyn Schmiedebergs Arch Pharmacol 330: 74-76. 
Scuwe-Moreau J, Giesbers 1, Dresse A, (1987) Effect of rolipram, a phosphodiesterase inhibitor and potential antidepressant, on the firing rate of central monoaminergic neurons in the rat. Arch th Pharmacodym Ther 288: $43-49$.

Shames BD, McIntyre RC, Jr., Bensard DD, Pulido El, Selzman CH, Reznikov LL, Harken AH, Meng $X, 2001)$ Suppression of tumor necrosis factor alpha production by cAMP in human monocytes: dissociation with mRNA level and independent of interleukin-10. J SuFg Res 99: 187-193.

Shenker BJ, Gray 1, (1979) Cyclic nucleotide metabolism during lymphocyte transformation. I. Enzymatic mechanisms in changes in CAMP and cGMP concentration in Balb/c mice. Cell Imwmunol $43: 11-22$.

Shin HC, Benbernou N, Fekkar H, Esnault S, Guenounou M, (1998) Regulation of IL-17, IFNgamma and $\mathrm{LL}-10$ in human CD8( $+\mathrm{T}$ cells by cyclic AMP-dependent signal transduction pathway. Cytokine 10: 841-850.

Siegmund B, Eigler A, Hartmann G, Hacker U, Endres S, (1998) Adrenaline enhances LPSinduced IL-10 synthesis: evidence for protein kinase A-mediated pathway. Int J inmunopharmacol 20: 57-69.

Snijdewint FG, Kalinski P, Wierenga EA, Bos JD, Kapsenberg ML, (1993) Prostaglandin E2 differentially modulates cytokine secretion profiles of human $\mathrm{T}$ helper lymphocytes. $J$ Imwunol 150: $5321-5329$.

Sommer $N$, Loschmann PA, Northoff GH, Weller M, Steinbrecher A, Steinbach JP, Lichtenfels $R$, Meyermann R, Riethmuller A, Fontana A, Dichgans J, Martin R, (1995) The antidepressant rolipram suppresses cytokine production and prevents autoimmune encephalomyelitis. Nature Medicine 1: 244-248.

Soltile A, Venza I, Venza M, Valenti A, Teti D, (1996) PGE2-induced immunoregulation mediated by cytokine production from cultures of human peripheral $T$ lymphocytes. Innmunophomacol Imwnunoxicol 18: 27-36.

Szabo C, Hasko G, Zingarelli B, Nemeth ZH, Salzman AL, Kvetan V, Pastores SM Vizi ES, (1997) Isoproterenol regulates tumour necrosis factor, interleukin-10, interleukin-6 and nitric oxide production and protects against the development of vascular hyporeactivity in endotoxaemia. Immumology 90: 95-100.

Wachtel H, Schneider $H_{*}$ (1986) Rolipran, a novel antidepressant drug, reverses the bypothermia and hypokinesia of monoamine-depleted mice by an action beyond postsynaptic monoamine receptors. Neuropharmacology $25: 1119-1126$.

Wang T, Sheppard JR, Foker JE, (1978) Rise and fall of cyclic AMP required for onset of lymphocyte DNA synthesis. Science 201: 155-157.

Woiciechowsky C, Asadullah K, Nestler D, Eberhardi B, Platzer C, Schoning B, Glockner F, Lanksch WR, Volk HD, Docke WD, (1998) Sympathetic activation triggers systemic interleukin-10 release in immunodepression induced by brain injury. Nat Med 4:808-813.

Wordemann M, Fandrey I, Jelkmann W, (1998) Tumor necrosis factor-alpha production by human hepatoma cell lines is resistant to drugs that are inhibitory to macrophages. $J$ Interferon Cytokine Res 18: 1069-1075.

Xia 2. DePierre JW, Nassberger L, (1996) Tricyclic antidepressants inhibit IL-6, IL-1B and TNF$\alpha$ release in human blood monocytes and $\mathrm{IL}-2$ and interferon- $\gamma$ in $\mathrm{T}$ cells. Imomunopharmacology 34: $27-37$.

Yastuhara O, Matsuo A, Terai $K$, Walker DG, Berger AE, Akiguchi I, Kimura J, McGeer PL, (1997) Expression of interleukin- 1 receptor antagonist protein in post-mortem human brain tissues of Alzheimer's disease and control cases. Acta Neuropathol (Berl) 93: 414-420. 


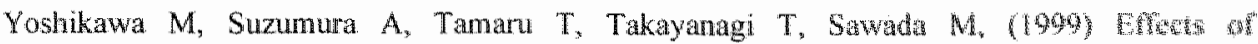
phosphodiesterase inhibitors on cytokine production by moroglia. Multiple so 9 erosis $5: 126=$ 133.

Yoshimura T, Kurita C, Nagao T, Usami $\mathrm{E}_{n}$ Nakao T, Watanabe $\mathrm{S}$, Kobayashi d, Yamazaka $\mathrm{F}_{*}$ Tanaka H, Nagai H, (1997) Effects of CAMP-phosphodiesterase isozyme inhibitor on cytokine production by lipopolysaccharide-stimulated human peripheral blood mononuclear cells. Gen Pharmacol 29:633-638.

Yoshimura T, Nagao T, Nakao T, Watanabe S, Usami E, Kobayashi J, Yanazaki F, Tanaka $\mathrm{H}_{\text {, }}$ Inagaki $N$, Nagai $H_{1}$, (1998) Modulation of Thl- and Th2-like cytokine production from mitogen-stimulated human peripheral blood mononuclear cells by phosphodiesterase inhibitors. Gen Pharmacol 30: 175-180.

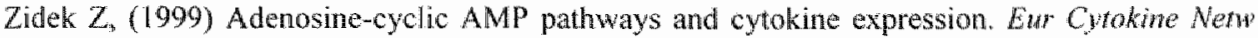
10: $319-328$.

Zubiaga AM, Munoz E, Merrow M. Huber BT, (1990) Regulation of interleukin 6 production in Thelper cells. Int Inmmot 2: 1047-1054. 
Role of the CAMP/PKA-pathway in the antiinflammatory effects of paroxetine and imipramine in human whole blood and peripheral blood mononuclear cells

Gunter Kenis, Marta Kubera, Eugène Bosmans, Belinda Egyed, Marc De Baets, Harry Steinbusch and Michael Maes 


\section{ABSTRACT}

Antidepressants have negative immunoregulatory effects in-vitro by decreasing the production of interferon- $\gamma$ (IFN- $\gamma$, a pro-inflammatory cytokine), and/or increasing that of interleukin-10 ( $1 \mathrm{~L}-10$, an anti-inflammatory cytokine). The mechanism behind this effect is yet not known, but it may be mediated by the cyclic adenosine monophosphate (cAMP) dependent protein kinase A (PKA) pathway. Indeed, pharmacological elevation of intracellular CAMPconcentrations inhibits the production of pro-inflammatory cytokines and enhances that of IL-10. The present study examines the effects of paroxetine and imipramine on the stimulated production of tumor necrosis factor- $\alpha$ (TNF- $\alpha$ ), IFN- $\gamma$, IL-10 and IL-6, in diluted human whole blood and in human peripheral blood mononuclear cells (PBMCs). Further, the role of the CAMP/PKA-pathway in the effects of antidepressants on cytokine production was examined by the addition of an adenylate cyclase inhibitor (SQ22536) or an inhibitor of PKA (Rp-8-Br-cAMPS). Paroxetine and imipramine significantly reduced the production of TNF- $\alpha$, IFN- $\gamma$ and IL- 10 but not IL- 6 in whole blood cultures. Rp-8-Br-cAMPS, but not SQ22536, blocked the suppressant effect of paroxetine on TNF- $\alpha$ production. Neither substance could reverse the effects of both anticlepressants on IFN- $\gamma$ or IL-10. In PBMC-cultures, paroxetine and imipramine decreased TNF- $\alpha$ production, which could be reversed by $\mathrm{Rp}-8-\mathrm{Br}$ cAMPS but not by SQ22536. Imipramine, but not paroxetine, inhibited IFN- $\gamma$ and IL-10 secretion by PBMCs. There was no influence of SQ22536 or Rp-8Br-cAMPS in this effect. It is concluded that the suppressant effect of paroxetine and imipramine on TNF- $\alpha$ production is mediated by PKA, whereas the inhibitory effects on IFN- $\gamma$ and IL- 10 are probably not related to the CAMP/PKA-pathway. 


\section{INTRODUCTION}

Accumulating evidence suggests that pro-inflammatory cytokines, e.g. interleukin-1 $\beta$ (IL-1 $\beta), I L-6$, interferon- $\gamma($ IFN- $\gamma)$ and tumor necrosis factor $\alpha$ (TNF- $\alpha$ ), play a role in the aetiology and pathophysiology of major depression (Connor and Leonard, 1998; Maes, 1999). Indeed, major depressed patients have increased levels of circulating IL-6, IL-1 $\beta$ and TNF $\alpha$ (Maes, 1999; Mikova et al., 2001; Owen et al., 2001). These cytokines are thought to mediate "sickness behaviour" induced by the administration of $I L-1 \beta$ or lipopolysaccharides (LPS) to animals (Bluthé et al., 2000a, 200b; Dantzer, 2001). Sickness behaviour is a syndrome that resembles the clinical symptoms of major depression (Maes et al., 1993), and is characterized by anhedonia, psychomotor retardation, sleep disturbances and decreased social activity and exploration (Yirmiya, 1996; Dantzer, 2001). In humans, immunotherapy with cytokines such as IFN- $\alpha$ induces depressive symptoms and full-blown major depression in psychiatric healthy subjects (Zdilar et al., 2000; Bonaccorso et al., 2001; Schaefer et al., 2002).

If pro-inflammatory cytokines are involved in the pathophysiology of major depression, one may expect that antidepressants reduce these cytokines or counteract their actions. In this respect, it has been shown that antidepressants have negative immunoregulatory effects in-vitro. For example, tricyclic antidepressants (TCAs) decrease the production of IL-1 $\beta$, TNF- $\alpha$ and IL-6 in purified human monocytes and that of IFN- $\gamma$ and IL-2 in human T-lymphocytes (Xia et al., 1996). In our laboratory, we demonstrated that TCAs (i.e. imipramine), Selective Serotonin Reuptake Inhibitors (SSRIs, i.e. tluoxetine and sertraline), Serotonin/Noradrenaline Reuptake inhibitors (SNRIs, i.e. venlafaxine), Reversible Inhibitors of Mono-amine Oxidase-A (i.e. moclobemide), the heterocyclic antidepressant trazodone, 5-hydroxy-tryptophan (5-HTP) and lithium, all decrease the production of IFN- $\gamma$ and/or increase that of IL-10 in stimulated human whole blood (Maes et al., 1999b, 1999a; Kubera et al., 2000, 2001; Lin et al., 2000). IL-10 is an anti-inflammatory cytokine that imhibits activated immune cells and decreases pro-inflammatory cylokine production. Thus, the antidepressant induced decrease in IFN- $\gamma$ production relative to that of $\mathrm{IL}-10$, indicates that antidepressants have negative immunoregulatory effects in-vitro. Moreover, it has been shown that antidepressants may have anti-inflammatory effects in-wivo (Kenis and Maes, 2002). For example, antidepressant treatment normalizes increased IL-6 plasma levels in depressed patients (Sluzewska et al., 1996).

The mechanism behind the effects of antidepressants on cytokine production remains unknown. Although serotonin $(5-\mathrm{HT})$ has anti-inflammatory properties and modulates the cytokine network (Kubera and Maes, 2000), the effects of 
antidepressants on cytokine production are probably not related to their serotonergic actions (Kubera et al., 2000). We suggest that antidepressants modulate the activity of intracellular transduction pathways that are involved in cytokine regulation.

One of these pathways may be the cyclic adenosine monophosphate dependent protein kinase A (CAMP/PKA) pathway. Cyclic AMP is formed out of ATP by the enzyme adenylate cyclase. Adenylate cyclase activity is positively or negatively regulated by several G-protein coupled receptors (including serotonergic and adrenergic receptors). The major effect of cAMP is the activation of PKA. This kinase, in turn, regulates the activity of other kinases, enzymes and transcription factors. Activation of the CAMP/PKA-pathway inhibits the production of several pro-inflammatory cytokines (including IFN- $\gamma$ and TNF $-\alpha$ ) and stimulates that of IL-10 (Platzer et al., 1995; Benbernou et al., 1997; Eigler et al., 1998). Furthermore, it has been shown that TCAs and fluoxetine may increase intracellular concentrations of cAMP in human white blood cells (Xia et al., 1996; Edgar et al., 1999). Thus, since activation of the cAMP/PKA-pathway and exposure to antidepressants have comparable effects on cytokine production, and since antidepressants may increase cAMP in white blood celis, it is hypothesized that antidepressants modulate cytokine production trough activation of the CAMP/PKA-pathway.

Recently, Musselman et al. demonstrated that paroxetine pretreatment is effective in the prevention of IFN- $\alpha$ induced depression (Musselman et al., 2001). It has been shown that IFN- $\alpha$ treatment activates the cytokine network (Brassard et al., 2002), leading to psychiatric disturbances, including major depression (Bonaccorso et al., 2001). We hypothesize that paroxetine inhibits pro-inflammatory cytokine production and, hence, prevents cytokine-induced depressive symptoms.

The purpose of this study is to examine the effect of paroxetine and imipramine on cytokine production, and whether these effects are mediated by CAMP/PKA. Therefore, the specific aims of this study are 1) to examine the effect of paroxetine and imipramine on the stimulated production of TNF- $\alpha$, IFN- $\gamma$, IL10 and $\mathrm{IL}-6$ in diluted human whole blood and in human peripheral blood mononuclear cells (PBMCs);2) to examine the role of the CAMP/PKA pathway in this effect by pretreatment of the cultures with SQ22536 (an adenylate cyclase inhibitor) or Rp-8-Br-cAMPS (an inhibitor of PKA). 


\section{METHODS}

\section{Reagents}

Imipramine, SQ22536 and LPS (E. coli 026:B6) were purchased from SigmaAldrich (Bornem, Belgium). Phytohaemagglutinin was purchased from BioTrading (Bierbeek, Belgium). Paroxetine was a kind gift of GlaxoSmithKline (The Netherlands). Rp-8-Br-cAMPS was acquired from BIOLOG Life Science Institute (Bremen, Germany).

\section{Subjects}

After an overnight fast, blood was drawn from 20 healthy volunteers ( 10 males and 10 females) between $8: 30$ and 9:30 a.m. All subjects gave written informed consent after full explanation of the study design. This study was approved by the Medical Ethical Committee of the Academic Hospital of Maastricht. The mean age of the subjects was $27.0 \pm 5.3$ years. Exclusion criteria for the subjects were: i) age under 18 or over 40 ; ii) a past or present history of psychiatric disorder (axis-I); iii) subjects who ever had been taken major psychotropic medication, such as antidepressants, antipsychotics and anxiolytics; iv) subjects with alcohol or any other drug of dependence abuse; v) smokers; vi) subjects with major somatic disorders, such as diabetes, autoimmune diseases, acquired immunodeficiency syndrome; vii) subjects who currently (two weeks prior to blood sampling) suffered from an infectious, allergic or inflammatory response. The subjects abstained from caffeine and alcohol for at least 12 hours prior to blood sampling.

\section{Culture and stimulation of whole blood}

Blood was diluted four times in RPMI 1640 culture medium (Bio Whittaker, Verviers, Belgium) supplemented with L-glutamine and antibiotics $(100 \mathrm{U} / \mathrm{ml}$ penicilline and $100 \mu \mathrm{g} / \mathrm{ml}$ streptomycine). The suspension was homogenized and plated in a 24-well tissue culture plate (Costar, The Netherlands) at 1 $\mathrm{ml} /$ well. The wells were pre-filled with concentrated solutions of $\mathrm{SQ} 22536$ or $\mathrm{Rp}-8-\mathrm{Br}-\mathrm{c} A \mathrm{MP}$. The final concentration of both substances was $1 \mu \mathrm{M}$. After the addition of the blood suspension, the plates were incubated for $30 \mathrm{~min}$ at $37^{\circ} \mathrm{C}$ and $5 \% \mathrm{CO}_{2}$. Subsequently, concentrated solutions of the antidepressants were added to the respective wells. For paroxetine, the final concentrations were 0.01 $\mu \mathrm{M}, 0.1 \mu \mathrm{M}$ and $1 \mu \mathrm{M}$, whereas for imipramine $1 \mu \mathrm{M}$ and $10 \mu \mathrm{M}$ was used. The plates were placed on a gyratory shaker for $10 \mathrm{~min}$. to mix to contents of the wells, and afterwards incubated for $20 \mathrm{~min}$. at $37^{\circ} \mathrm{C}$ and $5 \% \mathrm{CO}_{2}$. Then, the cultures were stimulated with LPS and PHA (final concentrations of $10 \mu \mathrm{g} / \mathrm{ml}$ 
and $1 \mu \mathrm{g} / \mathrm{ml}$, respectively). Plates were mixed for $10 \mathrm{~min}$. and transferred to the incubator. Two sets of cultures were performed: one set for the determination of TNF $-\alpha$ (supernatant collected after $24 \mathrm{~h}$ ) and one set for the measurement of

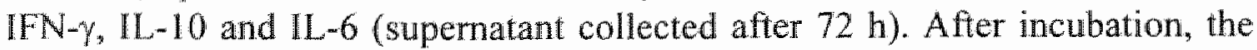
plates were mixed for $10 \mathrm{~min}$. before centrifugation at $800 \mathrm{xg}$ and $4^{\circ} \mathrm{C}$ for 15 min. Supernatant was carefully aspirated and transferred to labeled eppendorf tubes. Samples were stored at $-20^{\circ} \mathrm{C}$ until cytokine analysis.

\section{Purification and culturing of PBMCs}

Heparinized human whole blood was layered on top of a separation gradient (Histopaque-1077 ${ }^{\text {क }}$, Sigma, Bomem, Belgium) and centrifuged according the manufacturers instructions. The PBMC-layer was removed and washed once in culture medium (RPMI-1640, Life Technologies, Ghent, Belgium), and an additional two times in culture medium supplemented with $10 \%$ autologous plasma. Cells were counted and the cell suspension was adjusted to $2 \times 10^{6}$ cells $/ \mathrm{ml}$. The cells were plated in a 96 -well tissue culture plate at $50 \mu 1\left(1 \times 10^{5}\right.$ cells) per well. Concentrated solutions of the adenylate cyclase inhibitor (SQ22536) and the PKA-inhibitor (Rp-8-Br-cAMPS) were added. The plates were incubated at $37^{\circ} \mathrm{C}$ and $5 \%, \mathrm{CO}_{2}$ for $30 \mathrm{~min}$. before the addition of concentrated solutions of paroxetine and imipramine. Plates were pre-incubated for an additional 30 min. before stimulation with LPS/PHA. The final culture volume was $100 \mu \mathrm{l}$ and the final concentrations of LPS and PHA were $10 \mu \mathrm{g} / \mathrm{ml}$ and $1 \mu \mathrm{g} / \mathrm{ml}$, respectively. After an incubation period of $48 \mathrm{~h}$, the plates were centrifuged for $10 \mathrm{~min}$. at $800 \mathrm{xg}$ and $4^{\circ} \mathrm{C}$. Supernatants were carefully aspirated and transferred to Eppendorf tubes. The samples were stored at $-20^{\circ} \mathrm{C}$ until cytokine determination.

\section{Cytokine determinations}

Cytokines were determined using commercially available enzyme linked immunosorbent assays (ELISA) from DiaMed-Eurogen (Turnhout, Belgium). All assalys were performed according manufacturer instructions. Determinations were performed in a single run by the same operator. The intra-assay variations were lower than $8 \%$ for all assays.

\section{Statistics}

Repeated Measures (RM) design analyses of variance (ANOVAs) were used to examine the within-subject variability with the effects of paroxetine or imipramine and SQ22536 and Rp-8-Br-cAMPS alone or together versus the positive control as temporal (treatment) condition, and between-subject 
variability with gender as factor. The results of all RM design ANOVAs were corrected for sphericity. Post-hoc analysis was performed using Fisher's Least Significant Difference (LSD) test to check for significant differences between treatment conditions.

\section{RESULTS}

\section{Effects of paroxetine on cytokine production in whole blood}

Figure 1 shows the effects of paroxetine with and without SQ22536 or $\mathrm{Rp}-8-\mathrm{Br}-$ cAMPS on the production of TNF- $\alpha$, IFN- $\gamma$, IL-10 and IL-6. RM design ANOVA showed a significant effect of paroxetine on the production of TNF- $\alpha$ $(\mathrm{F}=4.5, \mathrm{df}=2 / 35, \mathrm{p}=0.02)$. Fisher's LSD test showed suppressant effects of paroxetine at $0.01 \mu \mathrm{M}$ and $0.1 \mu \mathrm{M}$. RM design ANOVA showed that treatment with paroxetine alone, and together with SQ22536 or Rp-8-Br-cAMPS, significantly affected the stimulated production of $\mathrm{TNF}-\alpha(\mathrm{F}=3.6, \mathrm{df}=4 / 61$, $\mathrm{p}=0.013)$. Fisher's LSD test showed that $\mathrm{Rp}-8-\mathrm{Br}-\mathrm{cAMPS}$ significantly reversed the inhibitory effect of all tested paroxetine concentrations on TNF- $\alpha$ production. Pre-incubation with SQ22536 did not significantly increase TNF- $\alpha$ production in the paroxetine treated cultures, although the significant reduction of TNF- $\alpha$ by $0.01 \mu \mathrm{M}$ paroxetine, was lost by the addition of SQ22536.

Paroxetine significantly affected the production of $\operatorname{IFN}-\gamma(\mathrm{F}=5.0, \mathrm{df}=3 / 45$, $\mathrm{p}=0.007)$. Fisher's LSD test showed suppressant effects of paroxetine at 0.01 . $\mu \mathrm{M}, 0.1 \mu \mathrm{M}$ and $1 \mu \mathrm{M}$. RM design ANOVA showed a significant effect of paroxetine alone, or together with SQ22536 or Rp-8-Br-cAMPS on the stimulated production of IFN $\gamma(\mathrm{F}=3.2, \mathrm{df}=3 / 54, \mathrm{p}=0.03)$. Fisher's LSD test showed that neither pre-incubation with SQ22536 or Rp-8-Br-cAMPS reversed the suppressant effects of paroxetine.

There was a significant effect of paroxetine on the production of $\mathrm{IL}-10(\mathrm{~F}=5.7$, $\mathrm{df}=2 / 31, \mathrm{p}=0.01$ ). Fisher's LSD test showed suppressant effects of paroxetine at $0.01 \mu \mathrm{M}, 0.1 \mu \mathrm{M}$ and $1 \mu \mathrm{M}$. However, there was no significant effect of paroxetine with SQ22536 or Rp-8-Br-cAMPS on the stimulated production of $\mathrm{IL}-10(\mathbb{F}=2.3, \mathrm{df}=2 / 27, \mathrm{p}=0.1)$.

Although paroxetine inhibited the production of both IFN- $\gamma$ and IL-10, RM design ANOVA showed that $0.1 \mu \mathrm{M}$ and $1 \mu \mathrm{M}$ paroxetine decreased the IFN- $\gamma /$ LL- 10 ratio $(F=3.4, d f=2 / 44, p=0.034$; data not shown).

There were no significant effects of paroxetine $(F=0.9, \mathrm{df}=2 / 30, \mathrm{p}=0.4)$ or paroxetine with SQ22536 or $\mathrm{Rp}-8-\mathrm{Br}-\mathrm{c}$ AMPS $(\mathrm{F}=2.0, \mathrm{df}=2 / 35, \mathrm{p}=0.1)$ on the stimulated production of IL-6. 
The above results indicate that the inhibitory effect of paroxetine on TNF- $\alpha$ production is probably mediated by PKA, independent of cAMP formation. There is no evidence that CAMP/PKA is involved in the inhibitory effects of paroxetine on IFN- $\gamma$ or IL-10 production.
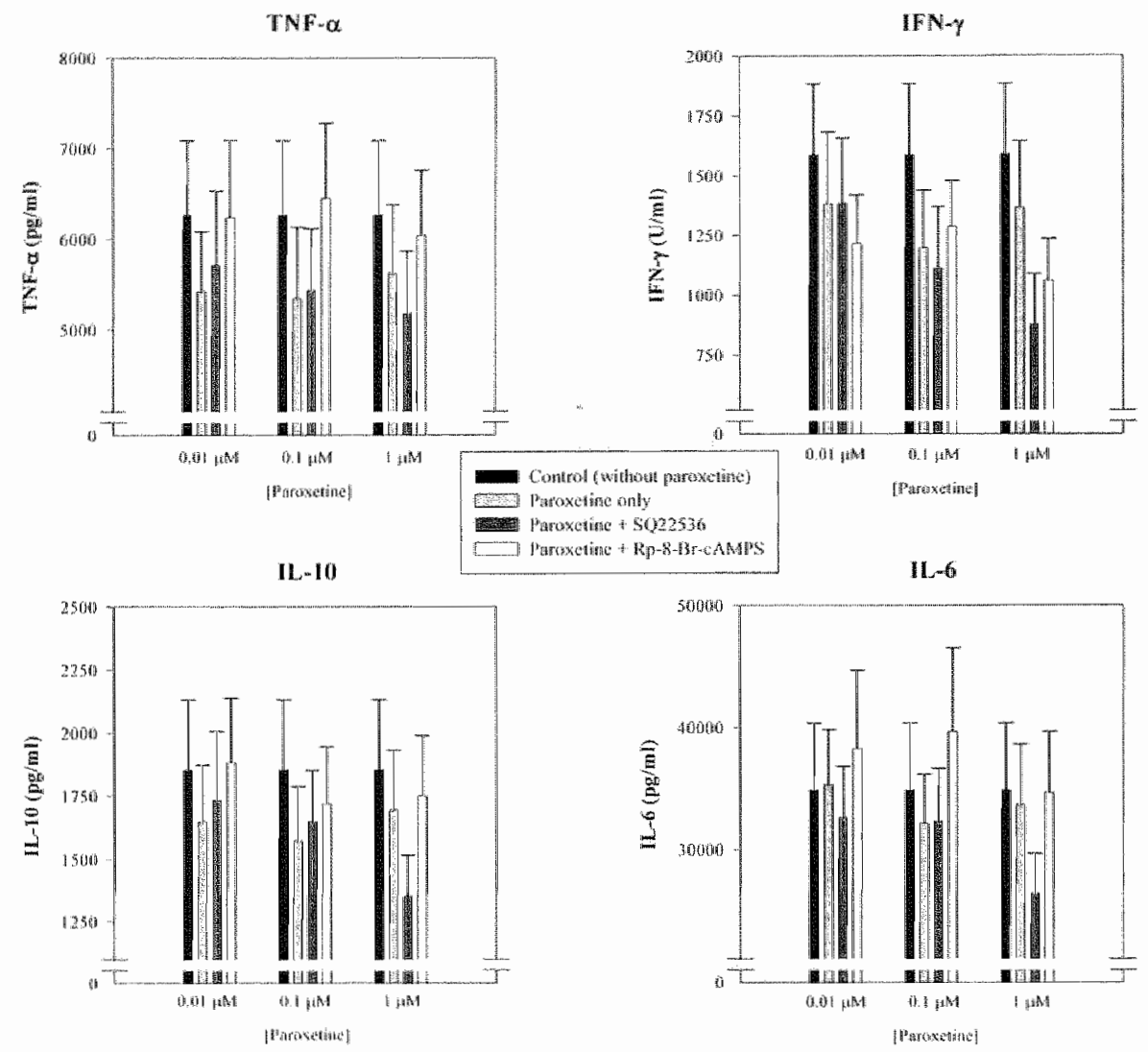

\section{Figure}

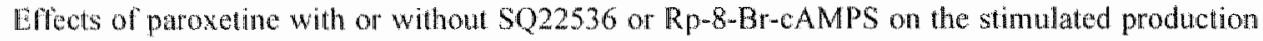

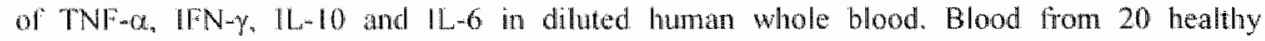
volunteers was diluted and stimulated with LPS $(10 \mu \mathrm{g} / \mathrm{ml})$ and PHA (I $\mu \mathrm{g} / \mathrm{ml})$, in the presence or absence of paroxetine $0.01 \mu \mathrm{M}, 0.1 \mu \mathrm{M}$ or $1 \mu \mathrm{M}$. SQ22536 and Rp-8-Br-cAMPS, both used at $1 \mu \mathrm{M}$, were pre-incubated for $30 \mathrm{~min}$. After addition of antidepressants, the cultures were incubated for $30 \mathrm{~min}$. before stimulation with LPS/PHA. Supernatant was collected after $24 \mathrm{~h}$ (for TNF- of determination) or $72 \mathrm{~h}$ (for determination of IFN- $\gamma$, IL-10 or IL-6). Bars represent means, error bars SEM. 


\section{Effects of imipramine on cytokine production in whole blood}

Figure 2 shows the effects of imipramine with and without SQ22536 or Rp-8Br-cAMPS on the production of TNF- $\alpha$, IFN- $\gamma$, IL-10 and IL-6. Imipramine significantly reduced the production of TNF- $\alpha$ at both $1 \mu \mathrm{M}$ and $10 \mu \mathrm{M}(\mathrm{F}=6.5$, $\mathrm{df}=2 / 28, \mathrm{p}=0.005)$. RM design ANOVA showed a significant effect of treatment with imipramine with or without SQ22536 and Rp-8-Br-cAMPS on the production of TNF $-\alpha(F=5.6, d f=3 / 53, p=0.002)$. Fisher's LSD test showed that SQ22536 did not reverse the decrease in TNF- $\alpha$ production, but pre-incubation with Rp-8-Br-cAMPS significantly reversed the imipramine-induced inhibition of TNF- $\alpha$ production.

The secretion of IFN- $\gamma$ was significantly decreased by imipramine $1 \mu \mathrm{M}$ and $10 \mu \mathrm{M}(\mathrm{F}=5.5, \mathrm{df}=2 / 33, \mathrm{p}=0.008)$. RM design ANOVA showed a trend towards significant effects of imipramine with or without SQ22536 or Rp-8-Br-cAMPS on IFN- $\gamma$ production $(F=2.4, \mathrm{df}=3 / 51, \mathrm{p}=0.076)$.

RM design ANOVA showed a significant effect of imipramine on IL-10 production $(F=5.5, \mathrm{df}=2 / 30, \mathrm{p}=0.008)$. Fisher's LSD-test showed that imipramine $1 \mu \mathrm{M}$ and $10 \mu \mathrm{M}$ significantly suppressed the production of $1 \mathrm{~L}-10$. Imipramine did not change the IFN- $\gamma /$ IL-10 production ratio (data not shown).

There was a significant effect of treatment with imipramine with or without SQ22536 or Rp-8-Br-cAMPS on the production $\mathrm{IL}-10 \quad(\mathrm{~F}=3.4, \mathrm{df}=4 / 60$, $\mathrm{p}=0.015$ ). Fisher's LSD test showed that this significant effect is attributable to the imipramine-induced suppression of $1 \mathrm{~L}-10$ production.

There was no effect of imipramine $(\mathrm{F}=2.8, \mathrm{df}=1 / 25, \mathrm{p}=0.1)$ or imipramine with or without SQ22536 and Rp-8-Br-cAMPS $(F=1.4, \mathrm{df}=2 / 38, \mathrm{p}=0.3)$ on the production of IL-6.

The above results indicate that a) PKA may play a role in the inhibition of the production of TNF- $\alpha$ by imipramine; b) adenylate cyclase activity seems to have no influence in this effect; and c) the effects of imipramine on IFN- $\gamma$ and $1 \mathrm{~L}-10$ are probably independent of CAMP and PKA. 
$\operatorname{Tn} x^{2}-\alpha$

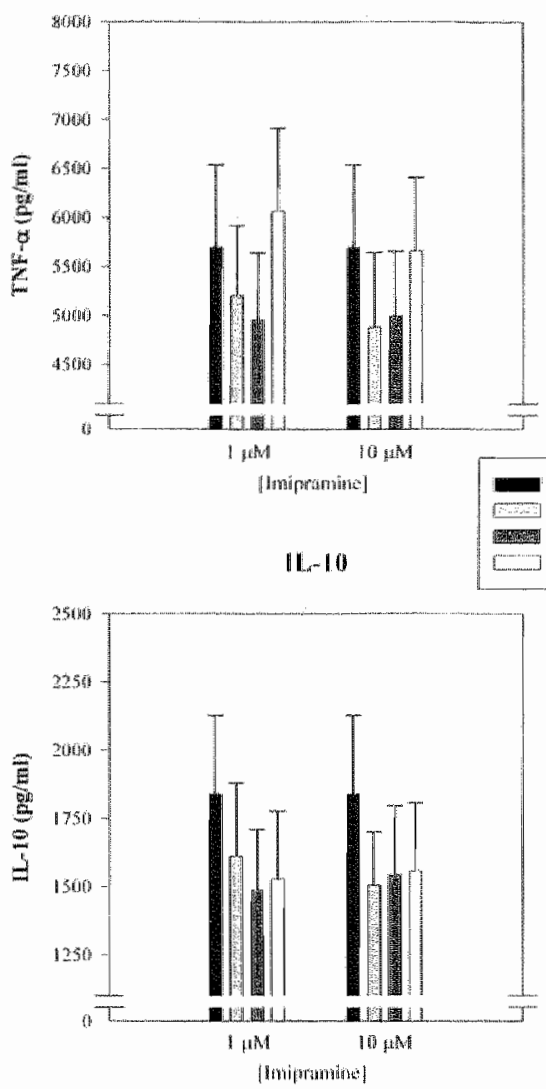

IFN-Y

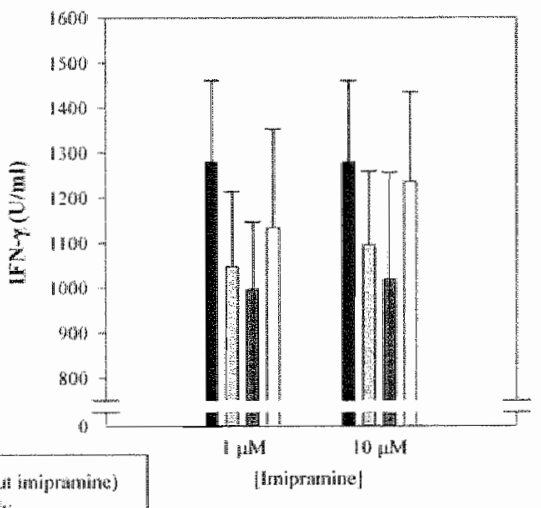

$\| L-6$

\section{Figure 2}

Effect of imipramine with or without 5 Q22536 or Rp-8-Br-CAMPS on the stimulated production of TNF $-\mathbb{G}, \mathbb{F N}-\gamma_{*}, \mathbb{L},-10$ and $\mathbb{L}-6$ in diluted human whole blood. Blood from 20 healthy volunteers was diluted and stimulated with LPS $(10 \mu \mathrm{g} / \mathrm{ml})$ and PHA $(\mathrm{l} \mu \mathrm{g} / \mathrm{ml})$, in the presence or absence of imipramine $1 \mu \mathrm{M}$ or $10 \mu \mathrm{M}$. SQ22536 and Rp-8-Br-cAMPS, both used at $1 \mu \mathrm{M}$, were pre-incubated for $30 \mathrm{~min}$. Alter addition of antidepressants, the cultures were incubated for 30 min. before stimulation with LPSPHA. Supernatant was collected after $24 \mathrm{~h}$ (for TNF-a determination) or $72 \mathrm{~h}$ (for determination of IFN-y, $L \mathrm{~L}-10$ or $\mathrm{LL}-6$ ). Bars represent mean, error bars SEM. 


\section{Influence of paroxetine and imipramine on the production of cytokines in human PBMCs}

The effects of paroxetine (with or without SQ22536 or Rp-8-Br-cAMPS) on the stimulated production of TNF- $\alpha$, IL-10 and IFN- $\gamma$ are shown in Figure 3. First, the effect of paroxetine alone was analysed with RM design ANOVA. Paroxetine significantly affected the stimulated production of TNF- $\alpha(\mathrm{F}=3.8$, $\mathrm{df}=2 / 26, \mathrm{p}=0.038)$, but not that of IL-10 ( $\mathrm{F}=2.5, \mathrm{df}=3 / 35, \mathrm{p}=0.082)$ or $\mathrm{IFN}-\gamma$ $(\mathrm{F}=0.5, \mathrm{df}=2 / 27, \mathrm{p}=0.598)$. Fisher's $\mathrm{LSD}$ test showed that $1 \mu \mathrm{M}$ paroxetine significantly decreased the production of TNF- $\alpha$. Addition of SQ22536 or Rp8-Br-cAMPS did not affect cytokine production.

On the other hand, as shown in Figure 4, there was a marked effect of imipramine on the production of all cytokines examined (TNF- $\alpha$ : $F=19.1$, $\mathrm{df}=2 / 30, \mathrm{p}<10^{-3} ; \quad \mathrm{IL}-10: \mathrm{F}=20.9, \mathrm{df}=1 / 21, \mathrm{p}<10^{-3} ; \mathrm{IFN}-\gamma: \mathrm{F}=25.7, \mathrm{df}=2 / 28$, $\mathrm{p}<10^{-3}$ ). Post-hoc analysis showed that this was entirely due to the highly suppressant effect of imipramine $10 \mu \mathrm{M}$, whereas there was no effect of imipramine $1 \mu \mathrm{M}$ on either cytokine examined. Remarkably, as shown in Figure 4 , the production of IL-10 and IFN- $\gamma$ was completely inhibited by co-incubation with $10 \mu \mathrm{M}$ imipramine. Pre-incubation with SQ22536 or Rp-8-Br-cAMPS did not change the inhibitory effect of imipramine on either cytokine examined.

\section{DISCUSSION}

The major findings of this study are that paroxetine decreases the stimulated secretion of TNF- $\alpha$ in human whole blood at $0.01 \mu \mathrm{M}$ and $0.1 \mu \mathrm{M}$, and of IFN- $\gamma$ and $\mathrm{LL}-10$ at $0.01 \mu \mathrm{M}, 0.1 \mu \mathrm{M}$ and $1 \mu \mathrm{M}$. Imipramine significantly reduces the production of TNF- $\alpha$, IFN- $\gamma$ and $\| \mathrm{L}-10$ at $1 \mu \mathrm{M}$ and $10 \mu \mathrm{M}$. Both antidepressants do not influence the secretion of IL-6. The inhibitory effect of both antidepressants on TNF- $\alpha$ production is probably mediated by PKA, since addition of the selective PKA-inhibitor Rp-8-Br-cAMPS restored TNF- $\alpha$ production. On the other hand, no significant role of cAMP and/or PKA in the effect of paroxetine or imipramine on IFN- $\gamma$ and $I L-10$ production could be found. In human PBMC-cultures, $1 \mu \mathrm{M}$ of paroxetine decreased the production of TNF- $\alpha$, whereas there was no effect on IFN- $\gamma$ or IL-10. Imipramine at $10 \mu \mathrm{M}$ strongly inhibited the production of TNF- $\alpha$, IFN- $\gamma$ and IL-10 in PBMC-cultures. These effects could not be reversed by inhibition of adenylate cyclase or PKA. 
TNF $-\alpha$

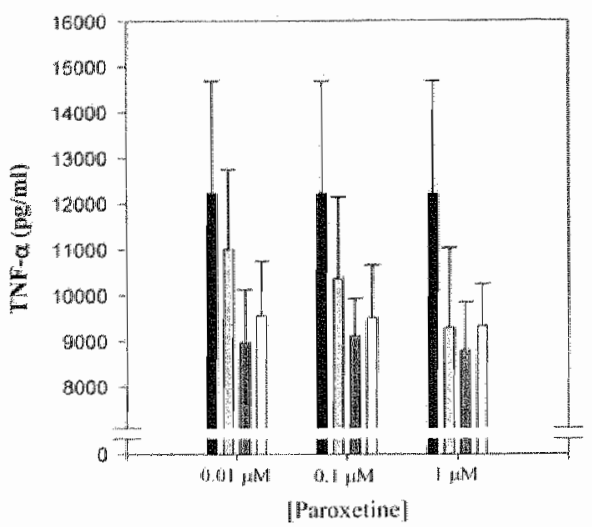

$\| F N-y$

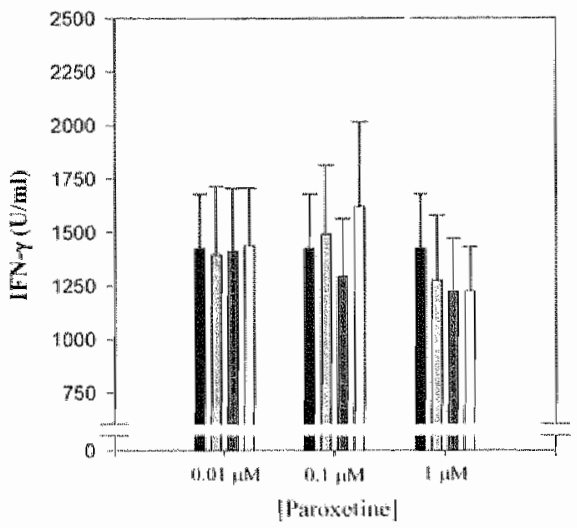

IL-10

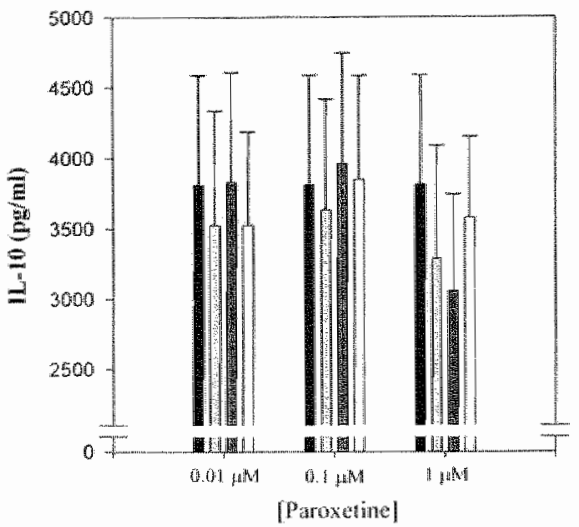

Conirol (wathoul Panosetire) Parometime

Parotetine +5022536

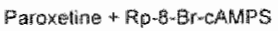

\section{Vigure 3}

Effects of paroxetine alone or together with $\mathrm{SQ22536}$ or $\mathrm{Rp}-8-\mathrm{Br}$-CAMPS on the stimulated production of TNF- $\alpha$, IFN-y and IL-10 in human PBMCs. PBMCs from 20 healthy volunteers were plated at $1 \times 10^{5}$ cells/well and stimulated with LPS $(10 \mu \mathrm{g} / \mathrm{ml})$ and PHA $(1 \mu \mathrm{g} / \mathrm{ml})$, in the presence or absence of paroxetine $0.01 \mu \mathrm{M}, 0.1 \mu \mathrm{M}$ or $1 \mu \mathrm{M}$. $\$ 022536$ and $\mathrm{Rp}-8-\mathrm{Br}-\mathrm{CAMPS}$, both used at $1 \mu \mathrm{M}$, were pre-incubated for $30 \mathrm{~min}$. After addition of antidepressants, the cultures were incubated for 30 min. before stimulation with LPS/PHA. Supenatant was collected after 48 and frozen for cytokine deternination. Bars represent mean, error bars SEM. 
TNF- $\alpha$

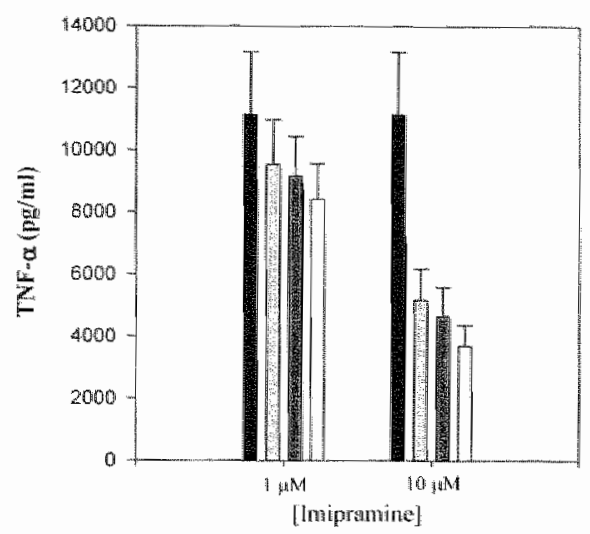

IFN- $\gamma$

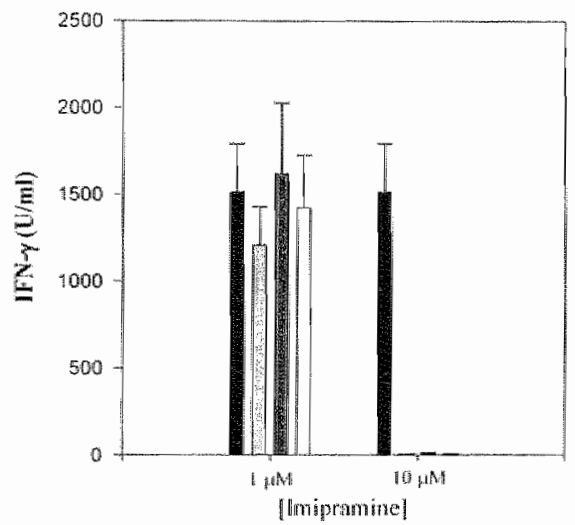

IL-10

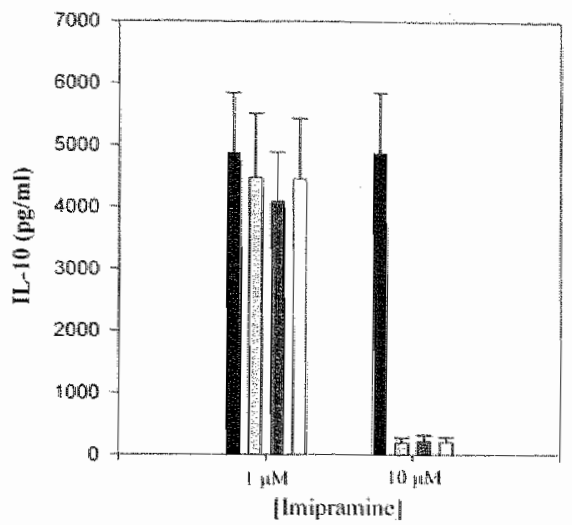

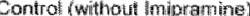
itsipramine

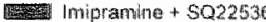

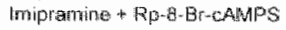

\section{Figure 4}

Effects of impramine alone or together with $5 Q 22536$ or Rp-8-Br-CAMPS on the stimulated production of TNF $a$, IFN- $\gamma$ and IL-10 in human PBMCs. PBMCs from 20 healthy volunteers were plated at $1 \times 10^{5}$ cells/well and stimulated with LPS $(10 \mu \mathrm{g} / \mathrm{ml})$ and PHA $(1 \mu \mathrm{g} / \mathrm{ml})$, in tho presence or absence of imipramine $1 \mu \mathrm{M}$ or $10 \mu \mathrm{M}$. $\$$ Q22536 and Rp-8-Br-cAMPS, both used at I. $\mu \mathrm{M}$, were pre-incubated for $30 \mathrm{~min}$. After addition of antidepressants, the cultures were incubated for 30 min. before stimulation with LPS/PHA. Supernatant was collected after 48 and frozen for eytokine determination. Bars represent mean, error bars SEM. 
The modulation of the cytokine network is best studied in diluted whole blood (De Groote et al., 1992; Zangerle et al., 1992; Yaqoob et al., 1999). Whole blood cultures are more reproducible and have lower intra-assay variations when compared to cultures of purified PBMCs. Moreover, diluted whole blood reflects better the in-vivo conditions, contain the humoral immunoregulatory factors present in plasma and preserve the normal monocyte/lymphocyte ratio. However, when examining the influence of pharmacological agents on cytokine secretion, it may be warranted to use PBMC-cultures, since red blood cells may act as scavengers for the agents, and the purified white blood cells are less influenced by other immunomodulatory mediators. Therefore, in this study we compared whole blood and PBMC-cultures to examine the effects of antidepressants on cytokine production.

This is the first report on the effects of antidepressants on the stimulated production of TNF- $\alpha$ in diluted human whole blood. We found that paroxetine at $0.01 \mu \mathrm{M}$ and $0.1 \mu \mathrm{M}$ inhibits TNF- $\alpha$ secretion in stimulated diluted whole blood. In PBMC-cultures, paroxetine reduces $\mathrm{TNF}-\alpha$ secretion at all concentrations, reaching significance at $1 \mu \mathrm{M}$. Imipramine suppressed TNF- $\alpha$ production in whole blood cultures at $1 \mu \mathrm{M}$ and $10 \mu \mathrm{M}$, and in PBMC-cultures only at $10 \mu \mathrm{M}$. Although these results suggest that paroxetine inhibits TNF- $\alpha$. secretion in-vitro, they also indicate that it is not a marked effect. Others failed to show an effect of paroxetine on the LPS-induced TNE- $\alpha$ release in-vivo (Shen et al., 1999). Fluoxetine, another SSRI, did not change splenic TNF- $\alpha$ expression after LPS administration (Yirmiya et al., 2001). On the other hand, the inhibition of TNF- $\alpha$ by imipramine $10 \mu \mathrm{M}$ was more pronounced. This is in agreement with previous studies, which showed that various TCAs, including imipramine at $5 \mu \mathrm{M}$, inhibit the secretion of TNF- $\alpha$ and other pro-inflammatory cytokines in human monocytes (Xia et al., 1996). In addition, also some in-vivo studies show inhibitory effects of imipramine and other TCAs on TNF- $\alpha$. For example, treatment with amitryptiline significantly decreased the ex-vivo TNFa secretion in depressed patients (Lanquillon et al., 2000). Chronic treatment with amitryptiline or nortryptiline, significantly increased the p75 subunit of the soluble TNF- $\alpha$ receptor (Hinze-Selch et al., 2000), an endogenous TNF- $\alpha$ antagonist. Chronic administration of desipramine (a TCA) attenuated the invivo production of TNF $\alpha$ after an LPS-challenge (Shen et al., 1999; Connor et al., 2000). Thus, TCAs inhibit the production of TNF- $\alpha$, both in-vivo and invitro, whereas the effect of SSRIs has remained unclear. We found that both paroxetine and imipramine decrease the stimulated TNF- $\alpha$ secretion in-vitro. Another finding of this study is that paroxetine and imipramine, at all concentrations examined, decrease the production of IFN- $\gamma$ and IL-10. We previously showed that antidepressants of several classes inhibit the production of IFN- $\gamma$ in stimulated human whole blood (Maes et al., 1999a; Kubera et al., 
2001). In these studies, antidepressants had either no effect or even enhanced IL-10 production, but also decreased the production of IFN- $\gamma$ relative to that of IL-10 (Maes et al., 1999a; Kubera et al., 2001). Here, both paroxetine and imipramine decreased the stimulated production of IL-10. However, paroxetine reduced the IFN- $\gamma / \mathrm{LL}-10$ production ratio.

A second major finding of this study is that the effects of paroxetine and imipramine on TNF- $\alpha$ production could be mediated by PKA. It is known that, pharmacological elevation of intracellular CAMP-concentrations and the subsequent activation of PKA inhibits TNF- $\alpha$ expression (Platzer et al., 1995; Eigler et al., 1998; Zidek, 1999). We found that blockade of cAMP-formation by the adenylate cyclase inhibitor SQ22536 had no effect on the inhibition of TNF- $\alpha$ by both imipramine and paroxetine. However, inhibition of PKA by Rp8-Br-cAMPS did reverse this reduction. Thus, the antidepressant-induced inhibition of TNF- $\alpha$ could be mediated by an up-regulation of PKA-activity. Inactive PKA is a tetrameric complex composed of two catalytic subunits bound with two regulatory subunits. Upon binding of CAMP with the regulatory units, these are released from the catalytic subunits rendering the latter free to phosphorylate several target proteins, including other kinases and transcription factors (Shaywitz and Greenberg, 1999). Since blockade of cAMP-formation does not reverse the effect of the antidepressants on TNF- $\alpha$ production, the upregulation of PKA-activity is probably not mediated by an increase in cAMP. Therefore, it is suggested that antidepressants - being lipophilic molecules that can readily cross the plasma-membrane - interfere with either the catalytic or the regulatory subunit of PKA in such a way that PKA activation is facilitated, resulting in a down-regulation of TNF- $\alpha$ expression.

Increases in CAMP are known to inhibit IFN- $\gamma$ secretion (Benbernou et al., 1997). However, in the present study, inhibitors of adenylate cyclase or PKA could not reverse the inhibitory effect of the antidepressants on IFN- $\gamma$ production, indicating that this effect is not mediated by cAMP or PKA. Therefore, other intracellular signal transduction proteins may be involved. Interestingly, it has been reported that fluoxetine may reduce Protein Kinase $\mathrm{C}$ (PKC) activity in lymphocytes (Edgar et al, 1998, 1999), an effect that is probably mediated by calcium mobilization. PKC-activation is an important step in pro-inflammatory cytokine production (Kontny et al., 1999). Thus, it may be suggested that down-regulation of PKC mediates the inhibitory effect of antidepressants on IFN- $y$ and/or TNF- $\alpha$ production.

Another finding of this study is that the effect of antidepressants on whole blood cytokine production differs from that in PBMC-cultures. Although there is an inhibitory effect of paroxetine and imipramine on TNF- $\alpha$ production in both cultures, it could not be reversed by SQ22536 or Rp-8-Br-cAMPS in PBMCcultures. Only imipramine $10 \mu \mathrm{M}$ inhibited the secretion of IFN- $\gamma$ and IL-10 in 
PBMC-cultures, whereas all examined paroxetine and imipramine concentrations inhibited this in whole blood cultures. Other cells present in whole blood cultures (including neutrophils, granulocytes and platelets) can produce cytokines and release immunomodulatory mediators that influence cytokine production by other cell types. Thus, the inhibitory effect of paroxetine and imipramine on cytokine production in whole blood may be related to the influence of these drugs on cells not present in PBMC-cultures. Further, the ratio between lymphocytes and monocytes is preserved in whole blood cultures, whereas purification of PBMCs alters this ratio. Both cell types influence one another, and changing the ratio between them will result in a different cytokine response. Since whole blood cultures reflect better the in-vivo environment, are more reproducible and have a lower variability, the use of diluted whole blood instead of PBMC-cultures is advised.

It is concluded that paroxetine and imipramine decrease the production of TNF$\alpha$, IFN- $\gamma$ and IL- 10 , but not that of IL-6, in stimulated, diluted whole blood. The inhibitory effect on TNF- $\alpha$ is probably related to PKA-activation, whereas no role of $\mathrm{CAMP} / \mathrm{PKA}$ in the effect on $I F N-\gamma$ or $1 \mathrm{~L}-1.0$ could be demonstrated. In PBMC-cultures, the highest concentration of paroxetine and imipramine inhibits TNF- $\alpha$ production, but this effect is not mediated by the cAMP/PKA-pathway. IFN- $\gamma$ and IL-10 production in PBMCs is strongly inhibited by $10 \mu \mathrm{M}$ imipramine, which cannot be reversed by inhibitors of adenylate cyclase or PKA.

These data are important because negative immunoregulatory effects of antidepressants may play a role in the effectiveness of paroxetine in the prevention of depressive side effects related to IFN- $\alpha$ therapy in Hepatitis C patients (Musselman et al., 2001). IFN- $\alpha$ therapy induces the production of other cytokines including TNF- $\alpha$ and IFN- $\gamma$ (Bonaccorso et al., 2001; Brassard et al., 2002), two pro-inflammatory cytokines that are implicated in the pathophysiology of major depression (Connor and Leonard, 1998). It is suggested that paroxetine, through lowering the induction of pro-inflammatory cytokines, attenuates the effects of these cytokines on the development of depressive symptomatology. Further research should focus on intracellular transduction cascades that mediate the effects of antidepressants on cytokine production. This may help to clarify the mechanism of action of antidepressants and to elucidate the biology of mood disorders.

\section{Acknowledgement}

We greatly thank GlaxoSmithKline for providing paroxetine and financial support. The work of Dr. M. Kubera is partly supported by the grant 
6P05A07620 from the State Committee for Scientific Research, Warszawa, Poland.

\section{REFERENCES}

Benbernou N, Esnault S, Shin HC, Fekkar H, Guenounou M, (1997) Differential regulation of IFN-ganma, $\mathbb{L}-10$ and inducible nitric oxide synthase in human $T$ cells by cychic AMP. dependent signal transduction pathway. Immwnology $91: 361-368$.

Bluthe RM, Laye S, Michaud B, Combe C, Dantzer R, Parnet P, (2000a) Role of interleukinI beta and tumour necrosis factor-alpha in lipopolysaccharide-induced sickness behaviour: a study with interletukin-1 type I receptor-deficient mice. Eur I Neurasci 12:4447-4456.

Bluthé RM, Michaud B, Poli V, Dantzer R, (2000b) Role of IL-6 in cytokine-induced sickness. behaviour: a study with IL-6 deficient mice. Physiol Behav 70: 367-373.

Bonaccorso S, Puzella A, Marino V, Pasquini M, Biondi M, Artini M, Amerighi C, Levrero M. Egyed B, Bosmans E, Meltzer HY, Maes M, (2001) Immunotherapy with interferon-alloha in patients affected by chronic hepatitis $C$ induces an intercortelated stimulation of the cytokine network and an increase in depressive and anxiety symptoms. Psychiary Res 105: 45-55.

Brassard DL, Grace MJ, Bordens RW, (2002) Interferon-alpha as an inmunotherapeutic protein. J Leukoc Biol 71: 565-581.

Connor TJ, Harkin A, Kelly JP, Leonard BE, (2000) Olfactory bulbectomy provokes a suppression of interleukin-lbeta and tumour necrosis factor-alpha production in response to an in vivo challenge with lipopolysaccharide: effect of chronic desiptamine treatment. Neuroimmmomodulation 7:27-35.

Connor TJ, Leonard BE, (1998) Depression, stress and immunological activation: the role of cytokines in depressive disorders. Life $\$$ C $62: 583-606$.

Dantzer R, (2001) Cytokine-induced sickness behaviour: where do we stand? Brain Behav Immun 15: 7-24.

De Groote D, Zangerle PF, Grevaert $Y$, Fassotte MF, Beguin Y, Noizat-Pirenne F, Pirenne J, Gathy R, Lopez M, Dehart I, Igot D, Baudrihaye M, Delacroix D, Franchimont P, (1992) Direct stimulation of cytokines (IL-1B, TNF- $\alpha,[L-6,1 L-2,1 F N-\gamma$ and $G M-C S F$ ) in whole blood. 1. Comparison with isolated PBMC stimulation. Cyrokine 4: 239-248,

Edgar VA, Genaro AM, Cremaschi G, Sterin-Borda L, (1998) Fluoxetine action on murine "Tlymphocyte proliferation participation of $\mathrm{PKC}$ activation and calcium mobilisation. $C \mathrm{C} / \mathrm{l}$ Signal 10: 721-726.

Edgar VA, Sterin-Borda L, Cremaschi GA, Genaro AM, (1999) Role of protein kinase C and cAMP in fluoxetine effects on human T-cell proliferation. Eur J Pharmocol 372: 65-73.

Eigler A, Siegmund B, Emmerich U, Baumann KH, Hartmann G, Endres S, (1998) Anti. inflammatory activities of cAMP-elevating agents: enhancement of $1 \mathrm{~L}-10$ synthesis and concurrent suppression of TNF procuction. J Leukoc Biol 63: 101-107.

Hinze-Selch D, Schuld A, Kraus T, Kuhn M, Uhr M, Haack M, Pollmacher T, (2000) Effects of antidepressants on weight and on the plasma levels of leptin, TNF-alpha and soluble TNF receptors: A longitudinal study in patients treated with amitriptyline or paroxetine. Neuropsychopharmacology 23: 13-19.

Kenis G, Maes M. (2002) Effects of antidepressants on the production of cylokines. Int I Nenropwychophamacol $5: 401-412$. 
Kontny E, Ziolkowska M, Ryzewska A, Maslinski W, (1999) Protein Kinase C-dependent pathway is critical for the production of pro-inflanmatory cytokines (TNE- $\alpha, L L-1 \beta, I L-6)$. Cytakine 11: 839.848 .

Kubera M, Kenis $G$, Bosmans $E$, Scharpe $S_{\text {n }}$ Maes $M$, (2000) Effects of serotonin and serobonergic agonists and antagonists on the production of interferon-gamma and interleukin10. Neuropsychopharmacology 23: 89-98.

Kubera $M$, Lin A-H, Kenis G, Bosmans E, Van Bockstaele D, Maes M. (2001) Antiinflammatory eflects of antidepressants through suppression of the Interferon-g/Interleukin10 production ratio. $J$ Clin Pychopharmacol 21: 199-206.

Kubera M, Maes M (2000) Serotonin-Inwmime Interactions in Major Depression. In: Patterson, Kordon and Christen (Eds.), Neuro-lmmune Interactions in Neurologic and Psychiatric Disorders (pp. 79-87) Berlin Heidelberg: Springer-Verlag.

Lanquillon $\mathrm{S}$, Krieg JC, Bening-Abu-Sach UH V, (2000) Cytokine production and treatment response in major depressive disorder. Neuropsychopharnacology 22: $370 m 379$.

Lin A-h, Song C, Kenis $G$, Basmans E, De Jongh R, Scharpe $S$, Maes M, (2000) The in vitro immunosuppressive effects of modtobemide in healthy volunteers. I Affect Disord 58: 69-74.

Maes M, (1999) Major depression and activation of the inflammatory response system. Adv Exp Med Biol 461: $25-46$.

Maes M, Meltzer $\mathbb{H} Y$, Scharpe S, Cooreman W, Uyttenbroeck W, Suy E, Vandervorst C, Calabrese J, Raus J, Cosyns P, (1993) Psychonotor retardation, anorexia, weight loss, sleep disturbances, and loss of energy: psychopathological correlates of hyperhaptoglobinemia during major depression. Psychiary Res $47: 229-241$

Maes M, Song C, Lin A-h, Bonaccorso S, Kenis $G$, De Jongh R, Bosmans E, Scharpe S, (1999a) Negative immunoregulatory effects of antidepressants: inhibition of interferon-y and stimulation of interleukin-10 secretion. Nerropsychopharmacology 20:370-379.

Maes $M$, Song $C$, Lin AH, Pioli $R$, Kenis $G$, Kubera $M_{*}$ Bosmans $E$, (1999b) In vitro immunoregulatory effects of lithium in healthy volunteers. Psychophamacology (Berl) 143 : $401-407$.

Mikova O, Yakimova R, Bosmans $\mathbb{E}$, Kenis G, Maes M, (2001) Increased tumor necrosis factor alpha concentrations in major depression and multiple sclerosis. European Neuropsychopharmacology 11:203-208.

Musselman DL, Lawson DH. Gumnick JF, Manatunga AK, Penna $S$, Goodkin RS, Greiner K, Memeroff $\mathrm{CB}_{3}$ Miller AH, (2001) Paroxetine for the prevention of depression induced by high-dose interferon alfa. $N$ Lngl / Med 344: 96!-966.

Owen BM, Eccleston D, ferrier IN, Young AH, (2001) Raised levels of plasma interleukin-1 beta in major and postviral depression. Acta Psychiatr Scand 103: 226-228.

Platzer C, Meisel C, Vogt K, Platzer M, Volk HD, (1995) Up-regulation of monocytic L-10 by tumor necrosis factor-alpha and CAMP elevating dnigs. In Inmmol 7: 517-523.

Schaefer M, Engelbrecht MA, Gut O, Fiebich BL, Bauer J, Schmidt F, Ginnze H, Lieb K, (2002) Interferon alpha (IFN- $\alpha$ ) and psychiatric syndrones. A review. Prog NeuroPsichopharnacol Biol Psychiatry 26: 731-746.

Shaywitz AI, Greenberg ME, (1999) CREB: a stimulus-induced transcription factor activated by "diverse array of extracellular signals. Anm Rev Biochem 68: $821-861$.

Shen Y, Connor TJ, Nolan Y, Kelly JP, Leonard BE, (1999) Differential effect of chronic antidepressant treatments on lipopolysaccharide-induced depressive-like behavioural symptoms in the rat. Life Sci 65: 1773-1786. 
Sluzewska A, Rybakowski JK, Laciak M, Mackiewicz A, Sobieska M, Wiktorowicz K, (1996) Interleukin-6 serum levels in depressed patients before and after treatment with fluoxetine. Ann $N$ Y Acad Sci $762 ; 474-476$.

Xia $Z$, DePierre JW, Nassberger $L_{*}$ (1996) Tricyclic antidepressants inhibit IL-6, IL-I b and TNF. a release in human blood monocytes and $\mathrm{CL}-2$ and interferon- $\gamma$ in $T$ cells. Imununopharmacology $34: 27-37$.

Yaqoob P, Newsholme EA, Calder PC, (1999) Comparison of cytokine production in cultures of whole human blood and purified mononuclear cells. Cytokine il 1: 600-605.

Yimiya R, (1996) Endotoxin produces a depressive-like episode in rats. Brain Res 711: 163-174.

Yirmiya R, Pollak Y, Barak O, Avitsur R, Ovadia H, Bette $M_{n}$ Weihe $E_{*}$ Weidenteld J, (2001) Effects of antidepressant drugs on the behavioural and physiological responses 10 lipopolysaccharide (LPS) in rodents. Newropsychophamacology 24: $531-544$.

Zangerle PF, De Groote D, Lopez M, Meuleman RJ, Vrindts Y, Fauchet F, Dehart I, Jadoul M, Radoux D, Franchimont P, (1992) Direct stimulation of cytokines (IL-1 beta, TNF-alpha, IL. 6, IL-2, IFN-gamma and GM-CSF) in whole blood: II. Application to rheumatoid arthritis and osteoarthritis. Cytokine 4:568-575.

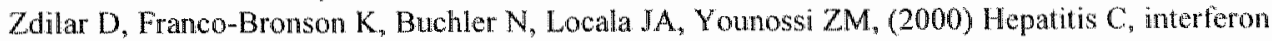
alfa, and depression. Hepatology 31: 1207-1211.

Zidek Z, (1999) Adenosine-cyclic AMP pathways and cytokine expression. Eur Cyrokine Nenw $10: 319-328$. 
Influence of antidepressants on intracellular levels of cyclic adenosine monophosphate in human peripheral blood mononuclear cells

Gunter Kenis, Harry Steinbusch, Mare De Baets, Michael Maes

European Neuropsychopharmacology (2003), 13, pp. 53-56 


\begin{abstract}
This study examines the effects of paroxetine and imipramine on intracellular concentrations of cyclic adenosine monophosphate (cAMP) in human peripheral blood mononuclear cells. It was found that imipramine and paroxetine had no effect on basal cAMP-levels. Stimulation with lipopolysaccharides and phytohaemagglutinin increased intracellular cAMP-concentrations. However, pre-incubation with imipramine or paroxetine did not influence this increase. These data do not support the hypothesis that cAMP may be related to the invitro anti-inflammatory effects of antidepressants.
\end{abstract}




\section{INTRODUCTION}

Antidepressants have in-vitro anti-inflammatory effects. It was found that tricyclic antidepressants decrease the stimulated production of interleukin- $1 \beta$ (IL-1 $\beta$ ), IL-6 and tumor necrosis factor $\alpha$ (TNF- $\alpha$ ) in human monocytes and that of IL-2 and interferon- $\gamma$ (IFN- $\gamma$ ) in human T-lymphocytes (Xia et al., 1996). These cytokines enhance inflammatory reactions and stimulate T-cell proliferation and, hence, are termed pro-inflammatory cytokines. Some antidepressants enhance the production of IL-10 (Maes et al., 1999), a potent anti-inflammatory cytokine. In stimulated whole blood, antidepressants of several classes have negative immunoregulatory effects as shown by a reduction of the IFN- $\gamma / \mathrm{IL}-10$ production ratio (Maes et al., 1999; Kubera et al., 2001). The mechanism whereby antidepressant drugs modulate cytokine expression is yet not known. One explanation may revolve around the second messenger cyclic adenosine monophosphate (CAMP). Indeed, antidepressants can increase intracellular cAMP-concentrations in purified human monocytes and lymphocytes (stimulated with lipopolysaccharides (LPS) and phytohaemagglutinin (PHA) respectively) and in concanavalin-A stimulated human peripheral blood mononuclear cells (PBMCs) (Xia et al, 1996; Edgar et al., 1999). Further, pharmacological elevation of cAMP inhibits the production of various pro-inflammatory cytokines, including IFN- $\gamma$ and TNF- $\alpha$, and stimulates the expression of IL-10 (Platzer et al., 1995; Benbernou et al., 1997; Zidek, 1999). Thus, it is suggested that antidepressants may enhance cAMPresponses in white blood cells, leading to changes in cytokine expression profiles. The effects of antidepressants on cytokine production have been studied in diluted whole blood stimulated with LPS and PHA. However, the effects of antidepressants on CAMP-concentrations in leukocytes after stimulation with LPS/PHA have not yet been examined.

Therefore, the aim of this study was to determine the influence of the antidepressants imipramine and paroxetine on intracellular cAMP-levels in human PBMCs, with or without LPS/PHA-stimulation.

\section{METHODS}

\section{Reagents}

Imipramine and LPS (E. coli 026:B6) were purchased from Sigma-Aldrich (Bornem, Belgium). PHA was purchased from BioTrading (Bierbeek, Belgium). Paroxetine was a kind gift of Smith-Kline Beecham (The Netherlands). 


\section{Blood collection}

After an overnight fast, venous blood was drawn from seven healthy volunteers using Vacutainer ${ }^{\text {in }}$-systems (BD, Erembodegem, Belgium). Subjects abstained from alcohol and caffeine at least $12 \mathrm{~h}$ prior to blood sampling.

\section{PBMC Isolation}

Heparinized human whole blood was layered on top of a separation gradient (Histopaque-1077 ${ }^{7}$, Sigma, Bornem, Belgium) and centrifuged according to manufacturer"s instructions. The PBMC-layer was removed and washed once in culture medium (RPMI1640, Life Technologies, Ghent, Belgium), and an additional two times in culture medium supplemented with $5 \%$ autologous plasma. Cells were counted and the cell suspension was adjusted to $2 \times 10^{7}$ cells $/ \mathrm{m})$. The cells were plated in a 96-well tissue culture plate at $50 \mu \mathrm{l}\left(1 \times 10^{6}\right.$ cells) per well. Concentrated solutions of the antidepressants and/or stimulants were then added to a final culture volume of $100 \mu$. The plates were incubated at $37^{\circ} \mathrm{C}$ and $5 \% \mathrm{CO}_{2}$ for $30 \mathrm{~min}$. before the addition of the antidepressants.

\section{Culture conditions}

All culture conditions were performed in triplicate. lmipramine was used at final concentrations of $1 \mu \mathrm{M}$ and $10 \mu \mathrm{M}$, paroxetine at $0.01 \mu \mathrm{M}, 0.1 \mu \mathrm{M}$ and $1 \mu \mathrm{M}$. These concentrations were chosen since the therapeutic plasma level of imipramine is around $1 \mu \mathrm{M}$ and that of paroxetine around $0.1 \mu \mathrm{M}$. Both antidepressants were dissolved in PBS and further diluted in culture medium. The antidepressants were pre-incubated for $30 \mathrm{~min}$. before stimulation with LPS/PHA. The final concentration of LPS and PHA was $10 \mu \mathrm{g} / \mathrm{ml}$ and $1 \mu \mathrm{g} / \mathrm{ml}$ respectively.

\section{Intracellular CAMP determination}

After the addition of LPS/PHA, the plates were incubated for $30 \mathrm{~min}$. at $37^{\circ} \mathrm{C}$ and $5 \% \mathrm{CO}_{2}$. After incubation, the plates were put on ice and $100 \mu \mathrm{l}$ of an icecold solution of $10 \%$ trichloro-acetic acid (TCA) was added to each well. The suspension in each well was transferred to eppendorf tubes. Subsequently, each well was rinsed with $200 \mu \mathrm{l}$ of an ice-cold 5\% TCA-solution and this suspension was added to the corresponding eppendorf tube. The tubes were centrifuged at $14000 \mathrm{rpm}$ in an Eppendorf centrifuge for $10 \mathrm{~min}$. The lysates were transferred to glass tubes, and TCA in the samples was extracted using diethyl ether. One $\mathrm{ml}$ of $\mathrm{H}_{2} \mathrm{O}$-saturated diethyl ether was added to each sample, thoroughly mixed for 20 seconds, and, after separation, the upper ether-phase was aspirated. This procedure was repeated 4 times. Finally, the samples were 
put at $50^{\circ} \mathrm{C}$ for $30 \mathrm{~min}$. to evaporate remaining ether. Samples were stored at $-20^{\circ} \mathrm{C}$ until analysis of cAMP.

Cyclic AMP-concentrations were determined with a radio-immunoassay (RIA) according the method of Brooker et al. (1979), using antibodies as described by Steiner et al. (1972).

\section{Statistics}

Repeated Measures (RM) design analysis of variance (ANOVA) was used to examine the effect of treatment. Dunn-tests were performed to check for significant differences between culture conditions. The results of the RM design ANOVA were corrected for sphericity.

\section{RESULTS AND DISCUSSION}

The intracellular CAMP-concentrations are depicted in Figure 1. RM design ANOVA showed that there was a significant effect of culture treatment $(\mathrm{F}=$ 19.2; $\left.\mathrm{df}=11 / 245 ; \mathrm{p}<10^{-5}\right)$. Stimulation with LPS/PHA significantly increased intracellular cAMP-concentrations (Dunn-test: $t=5.11, \mathrm{p}=0.00002$ ). However, there was no effect of the antidepressants on cAMP-concentrations. Moreover, pre-exposure of the LPS/PHA-stimulated cultures to the antidepressants does not have an additional effect on intracellular $\mathrm{CAMP}$-concentrations.

We found that stimulation of human PBMCs with LPS/PHA increases intracellular cAMP-concentrations. This is in agreement with previous studies which describe an increase in intracellular cAMP-concentrations in lymphocytes following exposure to various immunological stimulants (Wang et al., 1978; Shenker and Gray, 1979; Oksenberg et al., 1989). An increased adenylate cyclase activity, followed by an increase in CAMP, seems to be an important step in T-cell activation (Oksenberg et al., 1989). We hypothesized that antidepressants may further enhance the stimulation-induced CAMP increase, which could lead to altered gene expression (e.g. cytokine production). However, in contrast to the results of Xia et al. (1996), we were not able to show that antidepressants of two different classes enhanced intracellular CAMPlevels. Several differences in cultures conditions may explain these discrepancies. In the study of Xia et al. (1996), separated monocytes and lymphocytes were pre-incubated for $24 \mathrm{~h}$ with tricyclic antidepressants before stimulation with $10 \mu \mathrm{g} / \mathrm{ml}$ LPS and $5 \mu \mathrm{g} / \mathrm{ml}$ PHA respectively, both for $15 \mathrm{~min}$. 


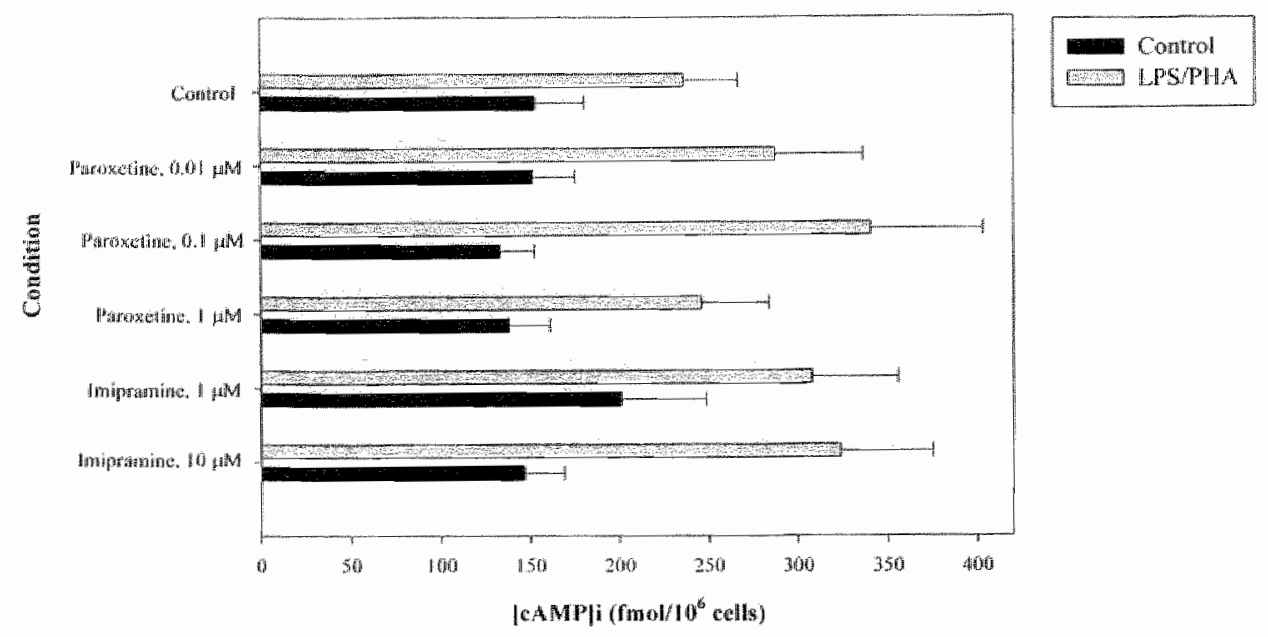

\section{Figure 1}

Intracellular CAMP-concentrations in human PBMCs after exposure to imipramine and paroxetine, with (light bars) or without (dark bars) stimulation with LPS/PHA. Antidepressants were added 30 min. before stimulation with LPS/PHA. Cells were lysed and CAMP-levels determined 30 min. after the addlition of LPS/PHA.

In the present study, PBMCs (containing both monocytes and lymphocytes) were pre-incubated for $30 \mathrm{~min}$. before stimulation with LPS and PHA $(10 \mu \mathrm{g} / \mathrm{ml}$ and $1 \mu \mathrm{g} / \mathrm{ml}$ respectively) for $30 \mathrm{~min}$. These culture conditions were chosen since the same conditions were employed in our studies concerning cytokine production in human whole blood. After stimulation, intracellular cAMPconcentrations reach maximum after $30 \mathrm{~min}$. (Wang et al., 1978; Oksenberg et al., 1989) and, hence, intracellular CAMP-concentrations were measured at this time point. Recently, it has been shown that the influence of antidepressants on cAMP may be dependent on the concentration of the mitogenic stimulant (Edgar et al., 1999). Together with the differences in culture conditions, this may explain the differences between the study of Xia et al. (1996) and ours.

Cyclic AMP is formed by adenylate cyclase, an enzyme that is stimulated by several G-protein coupled receptors, including $\beta$-adrenergic and some serotonergic receptors (i.e. 5-HT4, 5-HT6 and 5-HT7). The intracellular cAMPconcentration is controlled through its breakdown by phosphodiestereases (PDEs). A possible mechanism by which antidepressants may alter cAMPconcentrations is therefore a direct interaction of antidepressants with adenylate cyclase or PDEs. However, indirect mechanisms should be considered. For 
example, increased serotonin concentrations in the culture medium (through inhibition of serotonin reuptake) may stimulate serotonergic receptors that are positively coupled to adenylate cyclase. In this case, longer incubation times are required to detect the $\mathrm{cAMP}$ increase. However, we have shown previously that the effects of antidepressants on cytokine production are not related to their serotonergic action (Kubera et al., 2000). This possibility was therefore excluded and we measured intracellular cAMP after $30 \mathrm{~min}$., which is sufficient to detect pharmacological elevation of cAMP-concentrations. Further, it may be hypothesized that the anti-inflammatory effects of antidepressants in diluted whole blood, results from mediators released by other cell types that are not present in PBMCs. However, the anti-inflammatory effects of antidepressants have also been shown in PBMC-cultures (Xia et al., 1996). Thus, antidepressants influence cytokine production by a direct effect on PBMCs.

It is concluded that stimulation with LPS/PHA increase intracellular concentrations of CAMP in human PBMCs. Paroxetine and imipramine do not influence basal cAMP-concentrations. Moreover, pre-exposure of PBMCs with antidepressants does not enhance the cAMP response to LPS/PHA stimulation. Our data do not support the hypothesis that an increase in intracellular cAMPconcentrations is related to alterations in white blood cell cytokine production after exposure to antidepressants in-vitro.

It has recently been demonstrated that fluoxetine may inhibit the activity of Protein Kinase C (PKC) in human T-cells (Edgar et al., 1999). Inhibition of $\mathrm{PKC}$ may result in a decreased production of pro-inflammatory cytokines (Kontny et al., 1999). Therefore, it may be hypothesized that inhibition of PKC by antidepressants results in an inhibition of pro-inflammatory cytokine production in whole blood. The possible role of PKC in the antidepressant altered cytokine production is subject of future research.

\section{REFERENCES}

Benbernou N, Esnault $S_{*}$ Shin HC, Fekkar H, Guenounou M, (1997) Differential regulation of IFN-gamma, IL-10 and inducible nitric oxide synthase in human $T$ cells by cyclic AMP. dependent signal transduction pathway. Immunology $91: 361-368$.

Brooker G, Harper MF, Terasaki WL, Moytan RD, (1979) Radioimmunoassay of cyclic AMP and cyclic GMP. Adv Cyclic Nucleotide Res 10: 1-33.

Edgar VA, Sterin-Borda L, Cremaschi GA, Genaro AM, (1999) Role of protein kinase C and CAMP in thoxetine effects on human T-cell proliferation. Eur J Pharmaco/ $372 ; 65-73$.

Kontny E, Ziolkowska M, Ryzewska A, Maslinski W, (1999) Protein Kinase C-dependent pathway is criticall for the production of prominflammatory cytokines (TNF-a, $I L-1 B, \| L-6)$. Cytokine 11:839-848. 
Kubera M, Kenis $G$, Bosmans E, Scharpe $S$, Maes $M$, (2000) Effects of serotonin and serotonergic agonists and antagonists on the production of interferon-gamma and interleukin10. Neuropuychophasmacology $23: 89-98$.

Kubera $M$, Lin A-H, Kenis $G$, Bosmans $E$, Van Bockstaele D, Maes M, (2001) Antiinflammatory effects of antidepressants through suppression of the Interferon- $\gamma /$ Interleukin- 10 production ratio. J Clin Psychophasmacol 21: 199-206.

Maes M, Song C, Lin A-h, Bonaccorso $S$, Kenis $G$, De Jongh $R$, Bosmans E, Scharpe S, (1999) Negative immunoregulatory effects of antidepressants: inhibition of interferon- $\gamma$ and stimulation of interleukin-10 secretion. Newropsychopharmacology 20:370-379.

Oksenberg D, Oksenberg JR, Sakai K, Peroutka SJ, Steinman L, (1989) Cyclic adenosine 3',5monophosphate metabolism in activated $T$-cell clones. Immnnology $67: 484-488$.

Platzer C, Meisel C, Vogt K, Platzer M, Volk HD, (1995) Up-regulation of monocytic LL-10 by tumor necrosis factor-alpha and CAMP elevating drugs. Int Immunol 7:517-523.

Shenker BJ, Gray I, (1979) Cyclic nucleotide metabolism during lymphocyte transformation. 1.Enzymatic mechanisms in changes in $\mathrm{cAMP}$ and $\mathrm{cGMP}$ concentration in Balb/c mice. Cell Immusnol 43: 11-22.

Steiner AL, Parker CW, Kipnis DM, (1972) Radioimmunoassay for cyclic nucleotides. 1.Preparation of antibodies and iodinated cyclic nucleotides. J Biol Chem 247: 1106-1113.

Wang $T$, Sheppard JR, Foker $\sqrt{ } E_{3},(1978)$ Rise and fall of cyclic AMP required for onset of lymphocyte DNA synthesis. Science 201: 155-157.

Xia Z, DePierre IW, Nassberger L, (1996) Tricyclic antidepressants inhibit IL-6, IL-1B and TNFa release in human blood monocytes and $1 \mathrm{~L}-2$ and interferon-y in $T$ cells. Immunopharmacology $34: 27-37$.

Zidek Z, (1999) Adenosine-cyclic AMP pathways and cytokine expression. Eur Cytokine Netw 10: $319-328$. 


\section{Imipramine inhibits interleukin-6 and tumor necrosis factor- $\alpha$ production in primary rat whole brain cell cultures}

Gunter Kenis, Harry Steinbusch, Marjanne Markerink, Charlotte Teunissen, Marc De Baets, Ives Moesen, Michael Maes 


\section{ABSTRACT}

Antidepressants of several classes influence cytokine production by human blood cells. They inhibit Interferon- $\gamma$ (IFN- $\gamma$ ) and Tumor Necrosis Factor- $\alpha$ $(\mathrm{TNF}-\alpha)$, two important pro-inflammatory cytokines, and/or stimulate Interleukin-10 (IL-10), an anti-inflammatory cytokine. We have used reaggregating whole brain cell cultures to asses the effects of antidepressants (imipramine) on the production of cytokines by brain cells. After stimulation with $1 \mu \mathrm{g} / \mathrm{ml}$ or $10 \mu \mathrm{g} / \mathrm{ml}$ of lipopolysaccharides (LPS), high concentrations of TNF- $\alpha, I L-10$ and IL- 6 were found in the culture supernatant of the whole brain spheroids. IFN- $\gamma$ could not be detected. Imipramine at $30 \mu \mathrm{M}$ significantly decreased the production of IL-6, but did not affect IL-10 production. TNF- $\alpha$ production was significantly reduced by imipramine $30 \mu \mathrm{M}$ after stimulation with $10 \mu \mathrm{g} / \mathrm{ml}$ LPS. There was no effect of $10 \mu \mathrm{M}$ imipramine on the cytokines examined. This is the first study to show that antidepressants may influence stimulated cytokine production in a multi-cellular culture system of brain cells. It is concluded that imipramine inhibits the production of IL-6 and to a lesser extend that of TNF- $\alpha$. We hypothesize that antidepressants exert part of their effect through modulation of central cytokine production. 


\section{INTRODUCTION}

There is accumulating evidence that pro-inflammatory cytokines may play a role in the aetiology and/or pathophysiology of mood disorders. Proinflammatory cytokines are mainly produced by activated monocytes,

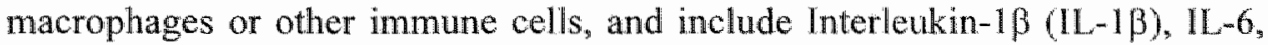
Tumor Necrosis Factor- $\alpha$ (TNF- $\alpha$ ) and Interferon- $\gamma($ IFN- $\gamma)$. Evidence for their potential role in psychiatric disorders recently emerged from both human studies and animal experiments. Depressed patients have higher circulating levels of pro-inflammatory cytokines as compared to healthy controls (Sluzewska et al., 1996; Berk et al., 1997; Maes, 1999; Mikova et al., 2001; Owen et al., 2001). Hypersecretion of these cytokines has profound behavioural effects and may contribute to the pathophysiology of major depression (Connor and Leonard, 1998). The potential impact of cytokines on the aetiology of major depression is highlighted by the fact that psychiatric healthy patients treated with cytokines (for example Hepatitis $C$ patients treated with IFN- $\alpha$ ) can suffer from mood-disturbances and even full-blown major depression (Capuron et al., 2000; Zdilar et al., 2000; Bonaccorso et al., 2002). In animals, administration of pro-inflammatory cytokines or lipopolysaccharides (LPS) induces "sickness behaviour", a syndrome that resembles some key features of clinical depression like anhedonia, reduced social exploration, reduced food intake and sleep disturbances (Yirmiya, 1996; Dantzer, 2001). The molecular mechanisms underlying the behavioural effects of cytokines are yet not known, but may involve stimulation of the afferent vagal nerve and induction of cytokine production in several brain structures (Konsman et al., 1999; Dantzer, 2001).

Indeed, it is known that cytokines can be produced by virtual all brain cells in both normal and pathological conditions (Szelenyi, 2001). Neurons constitutively produce TNF- $\alpha$ (Ignatowski et al., 1997) and IL-6 (Gadient and Otten, 1997; Lemke et al., 1999), which can also be expressed by astrocytes and microglia and are up-regulated under insulting conditions (Munoz-Fernandez and Fresno, 1998; Orzylowska et al., 1999; De Simoni et al., 2000). Brain IL-10 expression has also been found, mainly by astrocytes (Jander et al., 1998; Hulshof et al., 2002). It has even been proposed that some cytokines play a physiological role in the normal brain (Vitkovic et al., 2000).

If hypersecretion of pro-inflammatory cytokines is involved in the pathophysiology of major depression then antidepressants should inhibit the production or counteract the actions of these cytokines. In this respect, it has been shown that antidepressants inhibit pro-inflammatory cytokine and may stimulate anti-inflammatory cytokine production (for review see Kenis and Maes, 2002). This has been demonstrated in-vitro using cultures of whole blood or purified peripheral blood mononuclear cells (Xia et al., 1996; Maes et al., 
1999; Lin et al., 2000; Kubera et al., 2001), and in animal models (Shen et al., 1999; Connor et a1., 2000; Kubera et al., 2000a, 2000b). However, the effects of antidepressants on cytokine production by brain cells have, to the best of our knowledge, not yet been examined.

Re-aggregating whole brain cel】 cultures have been used in toxicological and neurodevelopmental studies (Honegger and Schilter, 1995; Teunissen et al., 2000, 2002). Brain cells, obtained by dispersion of fetal rat whole brains, are cultured while continuously rotating on a gyratory shaker. This procedure allows the cells to re-aggregate and form spherical structures. These so-called spheroid cell cultures consist of a three-dimensional network of several functional cell types including neurons, astrocytes, microglia and oligodendrocytes (Teunissen et al., 2000). Since cytokines secreted by one cell can influence the functioning of surrounding cells, it is better to study the cytokine network in a culture system comprising all cells present in the brain. Therefore, we used whole brain spheroids to examine the effects of antidepressants on cytokine production by brain cells. The specific aims of the study were to examine the production of IL-6, TNF- $\alpha$, IL-10 and IFN- $\gamma$ in rat whole brain spheroids stimulated with LPS, and to investigate the influence of the tricyclic antidepressant imipramine on the production of these cytokines.

\section{METHODS}

\section{Animals}

Time pregnant Lewis rats were bred in the animal centre of the University of Maastricht. Experiments were approved by the local committee for animal wellare at the university, according the guidelines of the European Communities Council Directive (86/609/EEC).

\section{Re-aggregating brain cell cultures}

Whole brain spheroids were prepared as follows. Whole brains from 12-10 foetuses (gestation day 15) from two rats were isolated and transferred to a nylon gauze bag (Nytal ${ }^{2}, 200 \mu \mathrm{m}$, Merck, The Netherlands) in ice-cold Hank's D2 solution (5.5 mM D-glucose, $41.32 \mathrm{mM}$ sucrose, $138 \mathrm{mM} \mathrm{NaCl}, 5.4 \mathrm{mM}$ $\mathrm{KCl}, 0.17 \mathrm{mM} \mathrm{Na} \mathrm{HPO}_{4}, 14 \mu \mathrm{M}$ phenol red, $1.8 \mathrm{mM} \mathrm{CaCl}, 0.8 \mathrm{mM} \mathrm{MgCl} 2$ ). Subsequently, the brains were washed three times in Hank's D1 solution (5.5 $\mathrm{mM}$ D-glucose, $46.52 \mathrm{mM}$ sucrose, $138 \mathrm{mM} \mathrm{NaCl}, 5.4 \mathrm{mM} \mathrm{KCl}, 0.17 \mathrm{mM}$ $\mathrm{Na}_{2} \mathrm{HPO}_{4}, 0.22 \mathrm{mM} \mathrm{KH}_{2} \mathrm{PO}_{4}, 14 \mu \mathrm{M}$ phenol red), and thereafter gently extruded through the nylon gauze. The cell suspension was then filtered through a nylon mesh ( $\mathrm{Nytal}^{\mathrm{si}}, 150 \mu \mathrm{m}$, Merck, The Netherlands) and washed three times by 
centrifugation at $170 \mathrm{xg}$ for $5 \mathrm{~min}$. in Hank's DI solution. Finally, cells were plated out in $25 \mathrm{ml}$ Delong flasks (Bellco Glass) at a density of $1 \times 10^{7}$ cells/ml (3.5 ml/flask) in DMEM supplemented with $1 \% \mathrm{~L}$-ghutamine and $10 \%$ foetal calf serum. The flasks were placed on a gyratory shaker $(85 \mathrm{rpm}$, Innova 2000 , New Brunswick, USA) in an incubator at $37^{\circ} \mathrm{C}, 9 \% \mathrm{CO}_{2}$ in humidified air. After 2 days, macroscopic spherical cell aggregates have formed. The cultures were then transferred to $50-\mathrm{ml}$ DeLong flasks and $5 \mathrm{ml}$ of medium was added. Thereafter, medium was changed three times a week. After 1 week of culture, D,L- $\alpha$-tocopherol $(0.1 \mathrm{mM}$, ICN Biomedical, Aurora, USA) was added to the medium.

\section{Culture maintenance and experiments}

After 18 days in culture, the spheroids were plated in 6-well tissue culture plates. Fifty microliter of a concentrated solution of imipramine (SigmaAldrich, Zwijndrecht, The Netherlands) was added. The final concentrations of imipramine were $10 \mu \mathrm{M}$ and $30 \mu \mathrm{M}$. Medium served as the corresponding control. The plates were then incubated for 4 hours while continuously shaking at $37^{\circ} \mathrm{C}$ and $9 \% \mathrm{CO}_{2}$ in a humidified atmosphere. Afterwards, concentrated solutions of LPS (E.coli strain 026:B6; Sigma-Aldrich, Zwijndrecht, The Netherlands), or medium as control, were added to the cultures. Final concentrations of LPS were $1 \mu \mathrm{g} / \mathrm{ml}$ and $10 \mu \mathrm{g} / \mathrm{ml}$. The plates were then incubated for 72 hours. After incubation, culture supernatants were harvested and stored at $-20^{\circ} \mathrm{C}$ until cytokine analysis.

\section{Cytokine determinations}

Cytokines in the culture supernatant were determined by enzyme-linked immunosorbent assays (ELISA) using specific and validated sets of monoclonal or polyclonal antibodies. Antibodies and standard solutions for the development of TNF- $\alpha$ and IFN- $\gamma$ ELISAs were obtained from U-CyTech (Utrecht, The Netherlands), those for IL-10 and IL-6 from BD-Biosciences (Erembodegem, Belgium). Capture antibodies were diluted in coating buffer (for IL-6, TNF$\alpha$ and IFN- $\gamma$ : $50 \mathrm{mM}$ citric acid, $100 \mathrm{mM}$ phosphate buffer, $\mathrm{pH} 7.2$; for 11-10: $50 \mathrm{mM}$ carbonate buffer, $\mathrm{pH} 9.6$ ) to $2 \mu \mathrm{g} / \mathrm{ml}(\mathrm{IL}-6$, TNF- $\alpha$ and IFN- $\gamma$ ) or 1 $\mu \mathrm{g} / \mathrm{ml}$ (IL-10). Diluted antibodies were transferred to 96-well ELISA microtiterplates (Greiner, Germany) at $100 \mu \mathrm{l}$ per well, and incubated overnight at $4^{\circ} \mathrm{C}$. Plates were washed twice in phosphate buffered saline (PBS) with $0.1 \%$ Tween- 80 (PBS/T-80) and blocked by adding $150 \mu \mathrm{l}$ of $3 \%$ bovine serum albumine (BSA) in PBS to each well. After 1 hour incubation at $37^{\circ} \mathrm{C}$, plates were washed twice with PBS/T-80. Then, $100 \mu$ of the samples or standards were added to the wells, and the plates were subsequently incubated for 2 hours 
as follows: IL-6 and IFN- $\gamma$ plates at $37^{\circ} \mathrm{C} ;$ IL-10 and TNF- $\alpha$ plates at room temperature (RT), while shaking at $500 \mathrm{rpm}$ on a microtiterplate-shaker. After incubation, plates were washed five times, followed by the addition of biotinylated detection antibodies $(100 \mu \mathrm{l} / \mathrm{well})$ diluted in Tris-buffered saline with $0.05 \%$ Tween-20 (TBS-T) and 2.5\% BSA (TBS-T/BSA). Again, IL-6 and IFN $-\gamma$ plates were incubated at $37^{\circ} \mathrm{C}$; IL-10 and TNF- $\alpha$ plates at RT while shaking ( 1 hour for all plates). Then, plates were washed 5 times and incubated at $100 \mu \mathrm{l} /$ well with streptavidin conjugated Horse Radish Peroxidase (DiaMedEurogen, Turnhout, Belgium) for $20 \mathrm{~min}$. at $37^{\circ} \mathrm{C}$. After washing 5 times, 100 $\mu \mathrm{l}$ of a mixture of $\mathrm{H}_{2} \mathrm{O}_{2}$ and tetramethylbenzidine (DiaMed-Eurogen, Turnhout, Belgium) was added to the wells and incubated for $20 \mathrm{~min}$. at RT in the dark. Reaction was stopped after $20 \mathrm{~min}$. by the addition of $2 \mathrm{~N} \mathrm{H}_{2} \mathrm{SO}_{4}$. Absorption (at $450 / 600 \mathrm{~nm}$ ) was determined using a microtiterplate reader. Standard curve was constructed and cytokine concentrations in the samples calculated using accompanying software.

Using the above described protocol, detection limits were $10 \mathrm{pg} / \mathrm{ml}$ for IL-10 and TNF- $\alpha$, and $200 \mathrm{pg} / \mathrm{ml}$ for IL-6. In our laboratory, inter-assay variation was below $10 \%$. All assays were performed on the same day (for each cytokine) by a single operator using the same batch of reagents.

\section{Statistics}

Repeated measures design analyses of variance (RM-ANOVAs) were used to evaluate the effect of imipramine on cytokine production. Data were normalized where necessary, and adjusted for sphericity violation using GreenhouseGeisser corrections. Post-hoc analyses were performed with Least Significant Difference tests (LSD). All analyses were performed using the statistical software package SPSS version 10.0 .

\section{RESULTS}

Spheroid cultures stimulated with $1 \mu \mathrm{g} / \mathrm{ml}$ or $10 \mu \mathrm{g} / \mathrm{ml}$ LPS produced high levels of TNF- $\alpha$, IL-10 and IL-6 (see Figure 1). IFN- $\gamma$ could not be detected after stimulation with LPS (data not shown). Additional experiments indicated that neither phorbol-myristate acetate (PMA), Concanavalin A (ConA) or phytohaemagglutinin (PHA) were able to induce IFN- $\gamma$ production in these cultures (data not shown). In cultures stimulated with $1 \mu \mathrm{g} / \mathrm{ml}$, imipramine significantly affected the production of IL-6 $(\mathrm{F}=8.9, \mathrm{df}=1 / 4, \mathrm{p}=0.04)$, but not that of $\mathrm{lL}-10(\mathrm{~F}=3.7, \mathrm{df}=2 / 5, \mathrm{p}=0.101)$. There was a trend towards a significant effect on TNF- $\alpha$ production $(F=7.3, d f=1 / 3, p=0.07)$. Post-hoc analysis 
indicated that imipramine at $30 \mu \mathrm{M}$ significantly reduced the production of IL6 , but there was no significant effect of $10 \mu \mathrm{M}$ imipramine. Although RMANOVA did not show an effect of imipramine treatment on TNF $-\alpha$, post-hoc comparison indicated that $30 \mu \mathrm{M}$ imipramine significantly reduced TNF-ot production.

Similar results were found when spheroids were stimulated with $10 \mu \mathrm{g} / \mathrm{ml}$ LPS. There was a significant effect of imipramine on the production of TNF- $\alpha$ $(\mathrm{F}=10.4, \mathrm{df}=2 / 5, \mathrm{p}=0.02)$ and $\mathrm{IL}-6(\mathrm{~F}=46.1, \mathrm{df}=1 / 3, \mathrm{p}=0.005)$, but not on that of IL-10 $(\mathrm{F}=2.6, \mathrm{df}=2 / 5, \mathrm{p}=0.178)$. Post-hoc analysis showed that $30 \mu \mathrm{M}$ imipramine significantly reduced the production of TNF- $\alpha$ and $I L-6$. There was no effect of imipramine $10 \mu \mathrm{M}$ on any of the cytokines examined.

In view of the limited number of experiments, non-parametric statistical analyses were concomitantly performed. However, Friedman-tests to asses the effects of imipramine on cytokine production in cultures with either $1 \mu \mathrm{g} / \mathrm{ml}$ or $10 \mu \mathrm{g} / \mathrm{ml}$ LPS, showed the same results as with RM-ANOVAs.

\section{DISCUSSION}

The present study shows that whole brain spheroids can be stimulated with LPS to produce cytokines. TNF- $\alpha$, IL-10 and IL- 6 were found in high concentrations in the culture supernatant, while IFN- $\gamma$ could not be detected. Imipramine, a widely used tricyclic antidepressant, inhibited the stimulated production of IL-6 and to a lesser extend that of TNF- $\alpha$ in these whole brain spheroids. IL-10 production was not affected by imipramine.

We found that whole brain spheroids are capable of producing cytokines upon stimulation with LPS. It is known that LPS can stimulate various brain cells to produce cytokines. For example, LPS induces TNF- $\alpha$ production in rat astrocytes (Lieberman et al., 1989; Chung and Benveniste, 1990; Forloni et al., 1997) and microglia (Nakamura et al., 1999; Puffenbarger et al., 2000; Facchinetti et al., 2003). IL-6 is produced upon LPS-stimulation by rat astrocytes (Lieberman et al., 1989; Benveniste et al., 1990; Gottschall et al., 1994; Fischer et al., 1997; Forloni et al., 1997) and microglia (Loughlin and Woodroofe, 1996; Forloni et al., 1997; Nakamura et al., 1999). Recently, Ledeboer and colleagues have demonstrated the production of $1 \mathrm{~L}-10$ in astrocyte-microglia co-cultures and in enriched astrocyte and microglia cultures, upon stimulation with LPS (Ledeboer et al., 2000, 2002). The effects of LPS are probably mediated by CD 14 and Toll-like receptor 4 , both of which have found to be expressed in the rat brain (Lallamme and Rivest, 2001). In view of the above, it is likely that the major source of TNF- $\alpha$, IL-10 and IL-6 in our spheroid cultures are LPS-activated astrocytes and microglia. 
TNF $\propto \alpha$

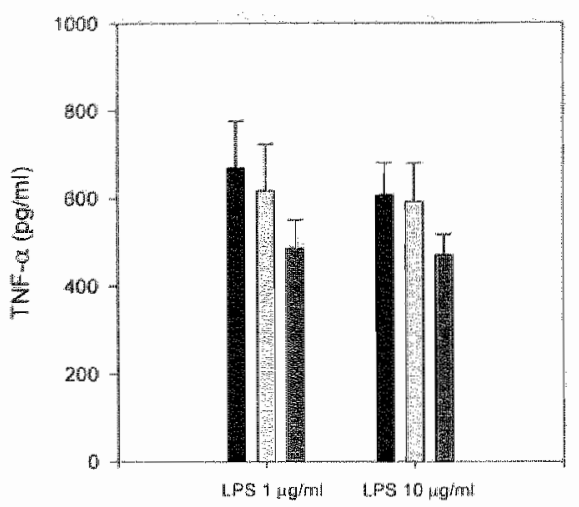

IL-6

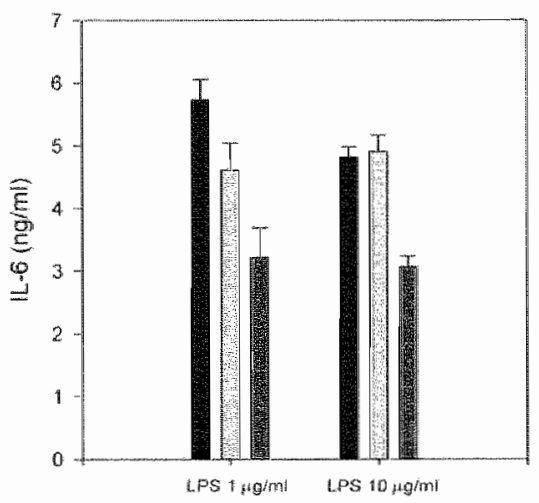

IL-10

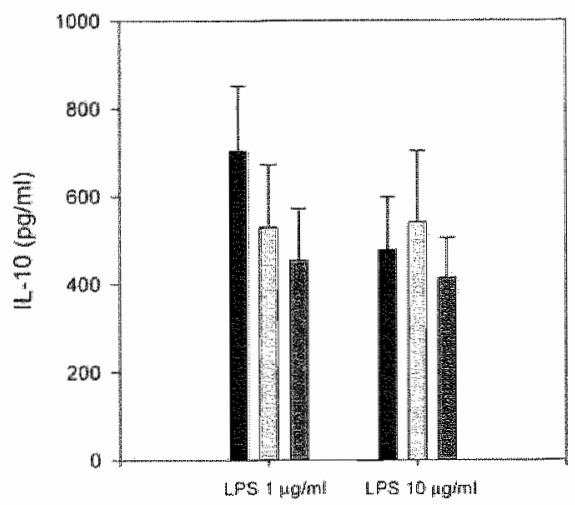

Figure 1

Concentrations of TNFa, $I \mathrm{~L}-10$ and $\mathrm{LL}-6$ in culture supernatant of LPS (I $\mu \mathrm{g} / \mathrm{ml}$ and $10 \mu \mathrm{g} / \mathrm{ml})$ stimulated whole brain spheroid culures, in the absence or presence of $10 \mu \mathrm{M}$ or $30 \mu \mathrm{M}$ imipranine. Bars represent means of 4 independent experiments; error-bars represent S.E.M.

A second major finding is that the antidepressant imipramine inhibits TNF- $\alpha$ and IL-6 production, but has no effect on IL-10. Interestingly, TNF- $\alpha$ and IL-6 have been implicated in the pathophysiology of major depression. Both cytokines have profound behavioural effects. For example, intra-peritoneal administration of TNF- $\alpha$ in rats reduced the consumption of a palatable solution, an indication of anhedonia (Hayley et al., 1999; Brebner et al., 2000), and intracerebroventricular administration induces anxiogenic-like effects 
(Connor et al., 1998). IL-6 seems to have less potent effects on behaviour (Connor et al., 1998; Lenczowski et al., 1999; Brebner et al., 2000), although prolonged elevation of IL-6 may reduce food and water intake (Sakic et al., 2001). Further, IL-6 may act synergistically or enhance the behavioural effects of other cytokines implicated in sickness behaviour (Lenczowski et al., 1999). Another biological feature of major depression in which TNF- $\alpha$ and $1 \mathrm{~L}-6$ have been implicated, is the hyperactivity of the hypothalamic-pituitary-adrenal (HPA) axis. Indeed, both cytokines are potent activators of the HPA-axis (Hayley et al., 1999; Brebner et al., 2000; Dunn, 2000). Moreover, TNF- $\alpha$ and IL-6 can modulate brain functioning by altering monoamine metabolism in various brain regions (Zalcman et al., 1994, 1998; Connor et al., 1998; Brebner et al., 2000). Disturbances in monoaminergic systems have often been implicated in major depression (Maes and Meltzer, 1995). In our model, imipramine inhibited the production of TNF- $\alpha$ and IL- 6 , and may thus alleviate the behavioural, neurochemical and neuroendocrine effects associated with these cytokines.

Current research on the mechanism of action of antidepressant drugs focuses on their possible neurogenic and/or neuroprotective properties (Malberg et al., 2000; Coyle and Duman, 2003). TNF- $\alpha$ and IL-6 have been implicated in both neurodegeneration and neuroprotection. It seems that while they support neuronal functioning and have proliferating effects in normal physiological conditions, they can induce neuronal cell death at higher concentrations, for example during inflammation or other major insults such as ischaemia (MunozFernandez and Fresno, 1998). On the other hand, the anti-inflammatory cytokine IL-10 seems to have opposing effects to TNF- $\alpha$ and IL-6. First, while the pro-inflammatory cytokines can be neurotoxic and lead to neurodegenereation, IL-10 is neuroprotective and improves the survival and proliferation of neurons and microglia (Strle et al., 2001). Second, IL-10 inhibits peripheral and central pro-inflammatory cytokine production by microglia (Di Santo et al., 1997; Heyen et al, 2000). Third, the behavioural effects of systemic or central administration of LPS are prevented by $1 L-10$ (Bluthe et al., 1999). Our results indicate that the antidepressant imipramine may change the balance between potential neurotoxic and neuroprotective cytokines, and may thus prevent neurodegeneration and/or enhance neurogenesis.

The relevance of our data is underscored by the fact that the effects of imipramine occur in clinical relevant concentrations. Indeed, while steady state serum and plasma concentrations of imipramine reach $0.5-1 \mu \mathrm{M}$ (Vandel et al., 1992; Levitt et al., 1999), brain concentrations reach much higher levels (Fisar et al., 1996). Moreover, accumulation of antidepressants in brain tissue is not limited to imipramine (Karson et al., 1993; Bolo et al., 2000). Further, while the 
presence and effects of cytokines in the brain have mainly been studied in animals, it is known that also human brain cells can produce a broad range of cytokines and express several cytokine receptors (Lee et al., 2002).

This study shows that imipramine - in pharmacological concentrations reduces the LPS-induced production of IL-6 and TNF- $\alpha$ in a stable multicellular culture system of brain cells. In view of the possible role of IL-6 and TNF- $\alpha$ in the pathophysiology of major depression, we hypothesize that imipramine exert its antidepressant effect, at least in part, by modulating the brain cytokine network.

\section{REFERENCES}

Benveniste EN, Sparacio SM, Norris JG, Grenett HE, Fuller GM, (1990) Induction and regulation of interleukin-6 gene expression in rat astrocytes. J Neuroimmunol 30: 201-212.

Berk M, Wadee AA, Kusclike RH, O'Neill-Kert A, (1997) Acute phase proteins in major depression. I Psychosom Res 43: 529-534.

Bluthe $\mathbb{R M}$, Castanon N, Pousset F, Bristow A, Ball C, Lestage J, Michaud B, Kelley KW, Dantzer R, (1999) Central injection of IL-10 antagonizes the behavioural effects of lipopolysaccharide in rats. Pychoneuroendocrinology $24: 301-311$.

Bolo NR, Hode $Y$, Nedelec JF, Laine E, Wagner G, Macher JP, (2000) Brain pharmacokinetics and tissue distribution in vivo of fluvoxamine and fluoxetine by fluorine magnetic resonance spectroscopy. Neuropsychophammacology 23: 428-438.

Bonaccorso S, Marino V, Puzella A, Pasquini M, Biondi M, Artini M, Almerighi C, Verkerk $\mathrm{R}$, Meltzer $H$, Maes M, (2002) Increased depressive ratings in patients with hepatitis $C$ receiving interferon-alpha-based immunotherapy are related to interferon-alpha-induced changes in the serotonergic system. J Clin Psychopharmacol 22: 86-90.

Brebner $K$, Hayley $S$, Zacharko $\mathbb{R}$, Merali $Z$, Anisman H, (2000) Synergistic effects of interlakin-1beta, interleukin-6, and tumor necrosis factor-alpha: central monoamine, corticosterone, and behavioral variations. Neturopsychopharmacology $22: 566-580$.

Capuron L, Ravaud A, Dantzer R, (2000) Early depressive symptoms in cancer patients receiving interleukin 2 and/or interferon alla-2b therapy. J Clin Oncol 18:2143-2151.

Chung IY, Benveniste EN, (1990) Tumor necrosis factor-alpha production by astrocytes. Induction by lipopolysaccharide." IFN-gamma, and IL-1 beta. J Immunol 144:" 2999-3007.

Connor TI, Harkin A, Kelly JP, Leonard BE, (2000) Olfactory bulbectony prowokes a suppression of interleukin-llbeta and tumour necrosis factor-alpha production in response to an in vivo challenge with lipopolysaccharide: effect of chronic desipramine treatment. Neuredmumamodulation $7: 27-35$.

Connor TH, Leonard BE, (1998) Depression, stress and immunological activation: the role of cytokines in depressive disorders. Life Sci 62: 583-606.

Connor TJ, Song C, Leonard BE, Merali $Z$, Anisman $H$, (1998) An assessment of the effects of central interleukin-lbeta, $-2,-6$, and tumor necrosis factor-alpha administration on some behavioural, neurochemical, endocrine and immune parameters in the rat. Newroscience 84: $923-933$.

Coyle JT, Duman RS, (2003) Finding the intracellular signaling pathways affected by mood disorder treatments. Neuron 38: 157-160. 
Dantzer $\mathbb{R}_{,}$(2001) Cytokine-induced sickness behavior: where do we stand? Brain Beliow Immun 15: 7-24.

De Simoni MG, Perego C, Ravizza T, Moneta D, Conti M, Marchesi F, De Luigi A, Garatini S. Vezzani A, (2000) Inflammatory cytokines and related genes are induced in the rat hippocampus by limbic status epilepticus. Eu J Neturosci 12: 2623-2633.

Di Santo E, Adami M, Bertorelli R, Ghezzi P, (1997) Systemic interleukin 10 administration inhibits brain tumor necrosis factor production in mice. EuF J Phamacol 336: 197-202.

Dumn AJ, (2000) Cytokine activation of the HPA axis. Ann N Y Acad Sci 917: 608-617.

Facchineti $F$, Del Giudice E, Furegato S, Passarotto M, Leon A, (2003) Cannabinoids ablate release of TNFalpha in rat microglial cells stimulated with lypopolysaccharide. Ghia 41: 161. 168.

Fisar Z, Krulik R, Fuksova K, Sikora $J_{0}$ (1996) Imipramine distribution among red blood cells, plasma and brain tissue. Gen Physio Biophys 15: $51-64$.

Fischer HG, Nitzgen B, Reichmann G, Hadding U, (1997) Cytokine responses induced by Toxoplasma gondii in astrocytes and microglial cells. Eur J Immunol 27: 1539-1548.

Forloni $G$, Mangiarotti $F$, Angeretti $N$, Lucca E, De Simoni MO, (1997) Beta-amyloid fragment potentiates $\| \mathrm{L}-6$ and TNF-alpha secretion by LPS in astrocytes but not in microglia. Cyokine 9: $759-762$.

Gadient RA, Otten UH, (1997) Interleukin-6 (IL-6) - a molecule with both beneficial and destructive potentials. Prog Neurobiol 52: 379-390.

Gottschall PE, Tatsuno 1, Arimura A, (1994) Regulation of interleukin-6 (IL-6) secretion in primary cultured rat astrocytes: synergism of interleukin-1 (IL-1) and pituitary adenylate cyclase activating polypeptide (PACAP). Brain Res 637: 197-203.

Hayley S, Brebner K, Lacosta S, Merali Z, Anisman H, (1999) Sensitization to the effects of tumor necrosis factor-alpha: neuroendocrine, central monoamine, and behavioral variations. $J$ Neurosci 19: 5654-5665.

Heyen JR, Ye S, Finck BN, Johnson RW, (2000) Interleukin (IL)-10 inhibits IL 6 production in microglia by preventing activation of NF-kappaB. Brain Res Mol Brain Res 77: 138-147.

Honegger $\mathrm{P}$, Schilter B (1995) The use of serum-free aggregating brain cell cultures in neurotoxicology. In: W, C. L. and W, S. (Eds.), Neurotoxicology: Approaches and merhods. (pp. 507-516) New York: Academic Press.

Hulshof S, Montagne L, Do Groot CJ, Van Der Valk P, (2002) Cellular localization and expression patterns of interleukin-10, interleukinm 4 , and their receptors in multiple sclerosis lesions. Glia 38: 24-35.

Ignatowski TA, Noble BK, Wright.JR, Gorfien JL, Hefther RR, Spengler RN, (1997) Neuronalassociated tumor necrosis factor (TNF alpha): its role in noradrenergic functioning and modification of its expression following antidepressant drug administration. J Newroimmumol 79: $84-90$.

Jander S, Pohl J, DUrso D, Gillen C, Stoll G, (1998) Time course and cellular localization of interleukin-10 mRNA and protein expression in autoimmune inflammation of the rat central nervous system. Am J Pathol 152: $975-982$.

Karson $\mathrm{CN}$, Newton JE, Livingston R, Jolly JB, Cooper TB, Sprigg J, Komoroski RA, (I993) Human brain fluoxetine concentrations. J Newropsychiatry Chin Neurosci $5: 322-329$.

Kenis G. Maes M, (2002) Effects of antidepressants on the production of cytokines. Int I Neuropsychopharmacol $5: 401-412$.

Konsman JP. Kelley K. Dantzer R, (1999) Temporal and spatial relationships between lipopolysaccharide-induced expression of Fos, interleukin- 1 beta and inducible nitric oxide synthase in rat brain. Neuroscience $89: 535-548$. 
Kubera M, Holan V, Mathison R, Maes M, (2000a) The effect of repeated amitriptyline and desipramine administration on cytokine release in C57BL/6 mice. Psychoneuroendocrinology 25:785-797.

Kubera $M$, Lin A-H, Kenis G, Bosmans E, Van Bockstaele D, Maes M, (2001) Antiinflammatory effects of antidepressants through suppression of the Interferon $y /$ Interleukin-10 production ratio. J Clin Psychopharmacol 21:199-206.

Kubera M, Simbirtsev A, Mathison R, Maes M, (2000b) Effects of repeated fluoxetine and citalopram administration on cytokine release in C57BL/6 mice. Psychiatry Res 96: 255-266.

Laflamme N, Rivest $\mathrm{S},(2001)$ Toll-like receptor 4 : the missing link of the cerebral innate inmune response triggered by circulating gram-negative bacterial cell wall components. Faseb $J 15$ : 155-163.

Ledeboer A, Breve JJ, Poole S, Tilders FJ, Van Dam AM, (2000) Interleukin-10, interleukin-4, and transforming growth factor-beta differentially regulate lipopolysaccharide-induced production of pro-inflammatory cytokines and nitric oxide in co-cultures of rat astroglial and microglial cells. Glia 30: 134-142.

Ledeboer A, Breve JJ, Wierinckx A, wan der Jagt $\mathrm{S}$, Bristow AF, Leysen JE, Tilders FJ, Van Dam $A M,(2002)$ Expression and regulation of interleukin- 10 and interleukin- 10 receptor in rat astroglial and microglial cells. Eur J Neurosei 16: 1175-118.8.

Lee YB, Nagai A, Kim SU, (2002) Cytokines, chemokines, and cytokine receptors in human microglia. INeurosci Res 69: 94-103.

Lemke R, Hartlage-Rubsamen M, Schliebs R, (1999) Differential injury-dependent glial expression of interleukins-I alpha, beta, and interleukin-6 in rat brain. Glia $27: 75-87$.

Lenczowski MJ, Bluthe RM, Roth J, Rees GS, Rushforth DA, wan Dam AM, Tilders FJ, Dantzer" $R$, Rothwell NJ, Luheshi GN, (1999) Central administration of rat $1 \mathrm{~L}-6$ induces HPA activation and fever but not sickness behavior in rats. Am I Physiol 276: R652-658.

Levitt AJ, Joffe RT, Kamil R, McIntyre R, (1999) Do depressed subjects who have failed both fluoxetine and a tricyclic antidepressant respond to the combination? $J \mathrm{Clin}$ Psychiary 60 : $613-616$.

Lieberman AP, Pitha PM, Shin HS, Shin ML, (1989) Production of tumor necrosis factor and other cytokines by astrocytes stimulated with lipopolysaccharide or a neurotropic virus. Proc Nat Acad Sci U S A 86: 6348-6352.

Lin A-h, Song C, Kenis G, Bosmans. E, De Jongh $R$, Scharpe S, Maes M, (2000) The in vitro immunosuppressive effects of moclobemide in healthy volumeers. I Afect Disord 58: 69-74.

Loughlin AJ, Woodroofe MN, (1996) Inhibitory effect of interferon-gamma on LPS-induced interleukin 1 beta production by isolated adula rat brain microglia. Neurochem in 29: 77-82.

Maes M. (1999) Major depression and activation of the inflammatory response system. Adv Exp Med Biol 461: $25-46$.

Maes M, Melizer HYM (1995) The serotonin hypothesis of major depression. In: Honig, A and van Prage, H. (Eds.), Depression: Neurobiological, Psychopathological and Therapeutic Adwances. (pp. 197-215) Chichester: John Wiley.

Maes M, Song C, Lin A-h, Bonaccorso S, Kenis G, De Jongh $\mathbb{R}$, Bosmans E, Scharpe S, (1999) Negative immunoregulatory effects of antidepressants: inhibition of interferon- $\gamma$ and stimulation of interleukin-10 secretion. Neuropsychophasmacology $20: 370-379$.

Malberg JE, Eisch AJ, Nestler EJ Duman RS, (2000) Chronic antidepressant treatment increases neurogenesis in adult rat hippocampus. $J$ Neurosei 20: $9104-9110$.

Mikova O, Yakimova R, Bosmans E, Kenis G, Maes M, (2001) Increased tumor necrosis factor alpha concentrations in major depression and multiple sclerosis. European Kewopsychophamacology 11:203-208. 
Munoz-Fermandez MA. Fresno M, (1998) The role of tumour necrosis factor, interleukin 6 , interferon-gamma and inducible nitric oxide synthase in the development and pathology of the nervous system. Prog Neurobiol 56: 307-340.

Nakamura Y, Si QS, Kataoka K. (1999) Lipopolysaccharide-induced microglial activation in culture: temporal profiles of morphological change and release of cytokines and nitric oxide. Neurosci Res: 35: 95-100.

Orzylowska O, Oderfeld-Nowak B, Zaremba M, Januszewski S, Mossakowski M, (1999) Prolonged and concomitant induction of astroglial immunoreactivity of interleukin- 1 beta and interleukin-6 in the rat hippocampus after transient global ischemia. Neurosci Lett 263: 72-76.

Owen BM, Eccleston D, Ferrier IN, Young AH, (2001) Raised levels of plasma interleukin-lbeta in major and postviral depression. Acta Psychiatr Scand 103: 226-228.

Puffenbarger RA, Boothe AC, Cabral GA, (2000) Cannabinoids inhibit LPS-inducible cytokine mRNA expression in rat microglial cells. Gha 29:58-69.

Sakic B, Gauldie J, Denburg IA, Szechtman H, (2001) Behavioral effects of infection with IL-6 adenovector. Broin Behav Immun 15:25-42.

Shen $Y$, Connor TJ, Nolan $Y$, Kelly JP, Leonard BE, (1999) Differential effect of chronic antidepressant treatments on lipopolysaccharide-induced depressive-like behavioural symptoms in the rat. Liffe Sci 65: 1773-1786.

Sluzewska A, Rybakowski JK., Laciak M, Mackiewicz A, Sobieska M, Wiktorowicz K. (1996) Interleukin- 6 serum levels in depressed patients before and after treatment with flwoxetine. Am N Y Acad Sci 762: 474-476.

Strle $K$, Zhou JH, Shen WH, Broussard SR, Johnson RW, Freund GG, Dantzer R, Kelley KW, (2001) Interleukin-10 in the brain. Crit Rev Imwnunol 21: 427-449.

Szelenyi I, (2001) Cytokines and the central nervous system. Brain Res Bull 54:329-338.

Teunissen CE, Markerink-van Ittersum M, de Bruijn C, Steinbusch HW, de Vente J, (2002) Evaluation of 3-nitrotyrosine as a marker for 3-nitropropionic acid-induced oxidative stress in Lewis and Wistar rats and strain-specific whole brain spheroid cultures. Brain Res 931: 5-20.

Teunissen CE, Steinbusch HW, Markerink-van Ittersum M, De Bruijn C, Axer H, De Vente J, (2000) Whole brain spheroid cultures as a nodel to study the development of nitric oxide synthase-guanylate cyclase signal transduction. Brain Res Dev Brain Res 125:99-115.

Vandel S, Bertschy G, Bonin B, Nezelof S, Francois TH, Vandel B, Sechter D, Bizouard P, (1992) Tricyclic anticlepressant plasma levels after fuoxetine addition. Neuropsychobiology 25: 202-207.

Vitkovic L, Bockaert ل, Jacque C, (2000) "Inflammatory" cytokines: neuromodulators in normal brain? I Neurochem 74: 457-471.

Xia Z, DePierre IW, Nassberger $L,(1996)$ Tricyclic antidepressants inhibit $1 L-6,1 L-1 \beta$ and TNF$\alpha$ release in human blood monocytes and $\mathrm{LL}-2$ and interferon-y in $\mathrm{T}$ cells. Immunopharmacology $34: 27-37$.

Yirmiya $R$, (1996) Endotoxin produces a depressive-like episode in rats. Brain Res 711: 163-174. Zalcman S, Green-Johnson JM, Murray $L$, Nance DM, Dyck D, Anisman H, Greenberg AH, (1994) Cytokine-specific central monoamine alterations induced by interleukin- $1,-2$ and -6 . Brain Res 643: 40-49.

Zalcman S, Murray L, Dyck DG, Greenberg AH, Nance DM, (1998) Interleukin-2 and -6 induce behavioral-activating effects in mice. Brain Res 811: 111-121.

Zdilar D, Franco-Bronson K, Buchler N. Locala JA, Younossi ZM, (2000) Hepatitis C, interferon alfa, and depression. Hepotology $31: 1207-1211$. 
Cllopter

1

General discussion 


\section{EFFECTS OF ANTIDEPRESSANTS ON CYTOKINE PRODUCTION}

Although it was long thought that depression was associated with a state of immunosuppression, Maes et al. (1990) and Smith (1991) were the first to propose that chronic activation of some aspects of the immune system (i.e. macrophages) and the concurrent excessive secretion of pro-inflammatory cytokines underlies the pathophysiology of major depression. Since then, evidence has accumulated to confirm a possible role of cytokines in major depression. This evidence includes:

- increased concentrations of circulating cytokines in depressed patients

- administration of pro-inflammatory cytokines to animals induces sickness behaviour - a syndrome that resembles several clinical features of major depression

- human cytokine therapy can induce major depression in psychiatric healthy subjects

Moreover, it is now clear that cytokines have a dramatic effect on neurotransmitter function and on neuro-endocrine homeostasis. Several possible pathways by which cytokines modulate brain function have been revealed. These include:

- passive or active transfer of cytokines across the blood-brain barrier

- induction of cytokine synthesis in the brain through stimulation of endothelial cells and peri-vascular macrophages

- cytokine stimulation of the afferent vagus nerve

Hence, several possible mechanisms of how cytokines can precipitate depression have been described. These include:

- alterations in neurotransmission and neurotransmitter turn-over

- cytokine-induced catabolism of tryptophan

- induction of HPA-axis hyperactivity

- induction of "gllucocorticoid resistance", resulting in sustained HPAaxis hyperactivity and cytokine secretion

If pro-inflammatory cytokines play a role in the aetiology and pathophysiology of major depression, then antidepressants should interfere in their synthesis and/or function. This intriguing hypothesis provides alternative research possibilities to verify the theory of cytokine-induced depression. To study the effect of antidepressants on cytokine production, one can measure circulating cytokine concentrations in depressed patients before and after treatment with antidepressants. As reviewed in Chapter 2, many studies on this topic report inconsistent findings. Several methodological issues may underlie this inconsistency. Due to the limited sample size in most studies, it is not possible to differentiate subgroups of depressed patients (i.e. patients with different 
phenotypes of depression). It has been shown that cytokine patterns may differ between patients with melancholic or non-melancholic depression. Differences were also found in patients with dysthymia versus major depression. Furthermore, patients were sometimes treated with different kinds of antidepressants, and medication status at baseline is not always clear. The latter, together with other possible confounding factors (such as smoking), may contribute to the divergent study results. In addition, it is conceivable that not all depressed patients have increased levels of cytokines. Depression is a syndrome with a multi-causal aetiology including genetic, environmental and somatic factors. Patients should therefore be divided in groups with or without elevated cytokine levels. Sluzewska et al. (1996) showed that in patients with elevated IL-6 levels before treatment, these levels returned to control after six weeks of fluoxetine treatment. Besides the heterogeneity of the study population, methodological differences in cytokine measurement may contribute to inconsistency of studies. Cytokine concentrations in serum or plasma should be measured using specific, high-sensitive and well-standardized immuno-assays (e.g. ELISA). Standardization helps to compare results between different studies, while the use of high-sensitive assays is a prerequisite to accurately detect the low concentration of circulating cytokines.

Animal models may be another suitable tool to examine the influence of antidepressants on cytokines. Chronic treatment with TCAs inhibits proinflammatory cytokines and enhances IL-10 production (reviewed in Chapter 2). While the effects of other antidepressants on cytokine secretion is not so clear, all antidepressants do counteract the behavioural responses associated with pro-inflammatory cytokines, as do the anti-inflammatory cytokines $1 \mathrm{~L}-10$ and IL-1RA.

Concerning the effects of antidepressants on cytokine production in-vitro, Xia et al. (1996) found that TCAs inhibit monocytic pro-inflammatory cytokines and Th1-derived cytokines. In that study, purified monocytes or lymphocytes were used. However, when examining the effects of pharmacotherapeutics on cytokines, the use of diluted whole blood offers a reliable and more reproducible method (De Groote et al., 1992; Zangerle et al., 1992; Yaqoob et al., 1999). Whole blood cultures contain all cells and immunoregulatory factors that are normally present in plasma and thus reflect better the in-vivo environment then purified cells. Further, immune cells are present in their natural occurring ratios. This is important because secretion of cytokines is influenced by cellular contact with other cells and by soluble factors secreted by these cells. Changing the ratio between the different cell types may result in altered cytokine patterns. Stimulated diluted whole blood thus better reflects the in-vivo situation, and by addition of a drug to these cultures, one can examine the net effect of this substance on cytokine secretion. Moreover, whole blood 
cultures are more reproducible and exhibit smaller inter- and intra-assay variability (De Groote et al., 1992; Yaqoob et al., 1999). Using this model, it was shown that clomipramine, sertraline and trazodone significantly reduce IFN-y secretion (Maes et al., 1999). Clomipramine also increased that of IL-10. That study was extended to other antidepressants in this thesis (Chapter 4). Imipramine, venlafaxine, 5-hydroxytryptophan (5-HTP, the immediate precursor of serotonin) and fluoxetine all significantly enhanced IL-10 secretion. Fluoxetine also decreased the production of IFN- $\gamma$. Another study, using similar whole blood cultures, reported that moclobemide increased stimulated IL-10 production (Lin et al., 2000). Thus, antidepressants of different classes have anti-inflammatory effects in-vitro by reducing the secretion of IFN$\gamma$ and/or by increasing that of $1 \mathrm{~L}-10$. The question arises whether these findings are relevant for the in-vivo antidepressant properties of these drugs. It is obvious that anti-inflammatory properties of antidepressants are in accordance with the hypothesis that pro-inflammatory cytokines are involved in depression pathology, and with the hypothesis formulated in this thesis. As explained in detail before, peripherally produced cytokines can have dramatic effects on central nervous system function (Dunn et al., 1999; Dunn, 2000), and these peripheral cytokines may precipitate major depression (Connor and Leonard, 1998; Maier and Watkins, 1998j. Consequently, it is likely that a reduction in peripherally produced cytokines would contribute to the relief of depressive symptomatology. The reduction of IFN- $\gamma$ secretion indicates that antidepressants temper a Thl-like immune response, which is associated with activation of monocytes/macrophages and the accompanying production of proinflammatory cytokines. On the other hand, $1 \mathrm{~L}-10$ is an important de-activator of both Th1-lymphocytes and monocytes/macrophages, and inhibits proinflammatory cytokine secretion. Antidepressant-induced increases in IL-10 could thus normalize activated immune cells and reduce hypersecretion of proinflammatory cytokines. Another emerging question deals with the fact that the whole blood cultures reflect acute effects of antidepressants on cytokine production. In view of the delayed clinical onset of antidepressants, one could argue that only studies dealing with chronic antidepressant exposure are relevant. However, it is conceivable that acute effects on cytokine production, that are maintained during prolonged treatment, are reflected in clinical improvement only after the biological processes related to the behavioural effects of cytokines are restored.

Although circulating pro-inflammatory cytokines may precipitate major depression, it is possible that their effects on emotion and behaviour are mediated by induction of central pro-inflammatory cytokine secretion (Dantzer, 2001). Further, cytokines like $\mathbb{L}-\mathbb{1} \beta$ and TNF- $\alpha$ may have physiological roles in the normal brain (Vitkovic et al., 2000). In addition, antidepressants occur in 
higher concentrations in the brain than in blood. Therefore, the effects of antidepressants on cytokine production by brain cells were explored in Chapter 9. Hereto, re-aggregating whole brain cell cultures were used. These so-called spheroid cultures are based on the capacity of foetal cells to form macroscopic three-dimensional networks (spheres) of differentiated cells, provided that they are cultured under continuous shaking. Brain-spheroid cultures contain mature and functional neurons, astrocytes, microglia and oligodendrocytes (Teunissen et al., 2000). As such, these cultures comprise all the cell types of the normal brain and may reflect better the in-vivo micro-environment as compared to other primary cell cultures. It was found that imipramine decreased the production of IL-6 and TNF- $\alpha$ in LPS-stimulated spheroids, while IL-10 secretion was not influenced. The results indicate that antidepressants may selectively reduce proinflammatory cytokine secretion by brain cells. These results concur with the findings in human whole blood cultures. Obviously, more experiments with other antidepressants are warranted. Nevertheless, the current data are intriguing, especially in the light of an emerging new theory of depression, the so-called "neurogenesis hypothesis of major depression".

Briefly, this hypothesis states that a prolonged reduction in the generation of new-born neurons in the hippocampus of the adult brain may underlie several psychiatric disorders, including major depression (Jacobs et al., 2000; Kempermann and Kronenberg, 2003). There is indeed evidence that depression is associated with hippocampal atrophy and hippocampal volume loss. In addition, accumulating evidence suggests that chronic treatment with antidepressants increases proliferation of progenitor cells in the hippocampus and promotes neuronal survival (Malberg et al,, 2000; Duman et al., 2001; Santarelli et al., 2003). Chronic treatment with antidepressants also increases the activity of survival pathways and stimulate the secretion of several trophic factors, including brain derived neurotrophic factor (BDNF) (Nibuya et al., 1996). The underlying mechanisms of the reduction in neurogenesis has yet to be elucidated, but the negative influence of glucocorticoids on neuronal survival have been implicated (Jacobs et al., 2000). However, it may be suggested that also pro-inflammatory cytokines contribute to this phenomenon (Monje et al., 2003). Indeed, TNF- $\alpha, I L-1 \beta$ and $I L-6$ are potent neurotoxic molecules (Szelenyi, 2001). As discussed before, hypersecretion of pro-inflammatory cytokines can induce cytokines in the brain, which has deleterious effects on brain function and on neuronal viability. The findings that antidepressants selectively inhibit pro-inflammatory cytokine secretion by brain cells may thus explain part of the neuroprotective effects of these drugs.

This thesis thus provides evidence that several types of antidepressants modulate the secretion of cytokines, both in the peripheral immune system and in the central nervous system. It is suggested that the reduction of pro- 
inflammatory cytokine secretion is part of the mechanism of the antidepressant action of these drugs.

Besides antidepressants, also other psychotropic drugs can modulate the secretion of cytokines. The effect of antipsychotic drugs on cytokines has been subject of a few studies. However, the results are inconsistent and differ between the drugs examined. For example, in in-vitro experiments, haloperidol increases the secretion of IL-2, IFN- $\gamma$ (Rudolf et al., 2002) and IL-1RA (Song et al., 2000), and inhibits TNF $\alpha$ and $\amalg L-1 \beta$ (Moots et al., 1999). Clozapine enhances the secretion of IL-2, IFN- $\gamma$, IL-6, IL-1RA and sIL-2R (Hinze-Selch et al., 1998; Song et al., 2000; Rudolf et al., 2002). Chlorpromazine has no effect on the in-vitro production of TNF-o, IL-1 $\beta, I L-1$ RA or IL-10 (Bleeker et al., 1997), but in animal experiments, it decreases pro-inflammatory cytokines and enhances IL-10 secretion (for review see Pollmacher et al., 2000). The stimulatory effect of haloperidol and clozapine on Th1-cytokines (IFN- $\gamma$, and $(\mathrm{L}-2)$ is opposite to the effect of antidepressants. In patients, subchronic treatment with clozapine increases pro-inflammatory cytokines such as TNF- $\alpha$ (Pollmacher et al., 1996), sIL-2R (Maes et al., 1994), and IL-6 (Maes et al., 1997), while prolonged treatment may decrease TNF- $\alpha$ levels (Monteleone et al., 1997). Treatment with risperidone increases IL-12 (Kim et al., 2001), while haloperidol treatment decreases IL-2 levels (Kim et al., 2000). In conclusion, antidepressants and antipsychotics exert differential effects on the cytokine network, and the effect on cytokine secretion of the latter is not uniform among the different drugs.

\section{INTRACELLULAR MECHANISMS UNDERLYING ANTIDEPRESSANT ALTERED CYTOKINE EXPRESSION}

If the antidepressant altered cytokine secretion contributes to clinical recovery from depression, then uncovering the intracellular mechanisms by which antidepressants change cytokine gene expression would undoubtedly lead to a better understanding of antidepressant action and to the development of new and better drugs. It could also reinforce the cytokine hypothesis of major depression, since a direct effect of antidepressants on cytokine synthesis implies that changes in cytokine patterns during treatment are related to the action of the pharmacological agent itself, and that these changes do not merely reflect an improvement in the patient's condition.

Several mechanisms that underlie the effect of antidepressants on cytokines can be proposed. First, it is possible that the primary biochemical effect of antidepressants (i.e. reuptake inhibition of serotonin and/or noradrenaline) is responsible for a change in cytokine expression. Lymphocytes, monocytes and 
macrophages express both the receptors and transporters of several neurotransmitters (Gordon and Barnes, 2003). Moreover, serotonin and noradrenaline have profound effects on inmune cell function and cytokine secretion (Mossner and Lesch, 1998; Elenkov et al., 2000). Hence, it may be suggested that the anti-inflammatory properties of antidepressants are related to their serotonergic or noradrenergic activities. Chapter 5 presents data of a study that examined the effect of serotonin and other serotonergic agents on cytokine production in stimulated whole blood. The results point to a complex effect of serotonin on cytokine secretion. Serotonin itself decreases IFN-y production, but depletion of intracellular serotonin by PCPA inhibits both IFN- $\gamma$ and IL-10 secretion. Thus, increases in extracellular serotonin concentrations has antiinflammatory effects through inhibition of IFN- $\gamma$, but intracellular serotonin may be necessary for optimal cytokine production. It could not be determined which receptor subtype mediates the effect of serotonin on IFN- $\gamma$ production. Neither flesinoxan, a 5-HT1A agonist, nor MCPP, a 5-HT2A/2C agonist, had an effect on IFN- $\gamma$. Ritanserin, a 5-HT2A/2C antagonist, decreased IFN- $\gamma$ secretion. It is possible that other 5-HT receptor subtypes (5-HT4, 5-HT7, which are also expressed on immunocytes) are involved.

The inhibitory effect of serotonin on IFN- $\gamma$ and the concomitant reduction of the IFN-y/L-10 ratio, is comparable to the effects of antidepressants. However, it was concluded that modulation of cytokine expression by antidepressants is not mediated by serotonin, because antidepressants predominantly increase IL-10, rather then inhibiting IFN- $\gamma$. Nevertheless, the role of serotonin cannot be completely excluded. A recent study reported that serotonin inhibits the production of TNF- $\alpha$ in human PBMCs (Cloez-Tayarani et al., 2003). In Chapter 7 , it is reported that imipramine and paroxetine also reduce $\mathrm{TNF}-\alpha$ secretion in stimulated human whole blood and PBMCs. Clearly, the exact role of serotonin in the effects of antidepressants on cytokines needs further investigation.

The effects of noradrenaline on cytokine expression lave been extensively described by others (Elenkov et al., 2000, Elenkov and Chrousos, 2002). Noradrenaline inhibits pro-inflammatory cytokines ( $T N F-\alpha$ and $I F N-\gamma$ ), while it stimulates anti-inflammatory cytokine secretion (IL-10 and transforming growth factor $\beta$ ). In addition, the IFN-y/LL-10 ratio is reduced in whole blood cultures pre-incubated with noradrenaline or noradrenergic agonists (Maes et al., 2000 ). Thus, anticlepressants and noradrenaline have comparable effects on cytokine secretion, and, hence, noradrenaline may be involved in the action of antidepressants on cytokines.

Besides the abowe mentioned indirect mechanisms (through serotonin and/or noradrenline) of antidepressants altering cytokine production, more direct effects may be involved. Antidepressants are lipophilic molecules that readily 
can cross the cell membrane. It may therefore be proposed that antidepressants modulate intracellular targets, such as kinases or transcription factors, which regulate cytokine gene expression. The effects of antidepressants on cytokine production are comparable to that of drugs that stimulate the cAMP/PKAsignalling pathway. Therefore, it is hypothesized that antidepressants increase cAMP/PKA-signalling, resulting in a decrease of pro-inflammatory (IFN- $\gamma$ and TNF- $\alpha$ ) and an increase in anti-inflammatory (IL-10) cytokine secretion. In order to examine this hypothesis, inhibitors of the cAMP/PKA-pathway were co-incubated with antidepressants in stimulated whole blood (Chapter 7). If antidepressants stimulate cAMP/PKA-signalling, then these inhibitors should reverse the effects of antidepressants on cytokine production. Blockade of cAMP-formation by inhibiting adenylate cyclase did not change the effects of antidepressants (imipramine and paroxetine) on TNF- $\alpha$, IFN- $\gamma$ and IL-10. On the other hand, inhibition of PKA reversed the inhibitory effect of both antidepressants on TNF- $\alpha$ production, but not on that of IFN-y or IL-10. These results indicate that: $i)$ the effects of antidepressants on cytokine production are not mediated by an increase in CAMP (through enhanced activity of adenylate cyclase); and ii) increased PKA-activity is involved in the decrease in TNF- $\alpha$ production, but not in the effects on IFN- $\gamma$ or $1 \mathrm{~L}-10$. Further, in Chapter 8 it is shown that antidepressants do not increase intracelhular cAMP-concentrations in white blood cells. Taken together, these data indicate that increases in intracellular CAMP-concentrations are not involved in the effect of antidepressants on in-vitro cytokine secretion. Yet, the effects of antidepressants on TNF- $\alpha$ are related to enhanced PKA-activity, which is generally thought to be a consequence of increased cAMP-formation. Our data thus show that antidepressants may enhance PKA-activity, independent of increases in cAMP. It is hypothesized that antidepressants may facilitate the interaction of CAMP with the regulatory subunit of PKA, thereby increasing PKA-activity without influencing intracellular cAMP-concentrations. Alternatively, antidepressants may directly activate PKA by interacting with the regulatory subunits. Both possibilities require more detailed investigation.

Although cAMP/PKA-signalling is an important and well-known pathway in the regulation of cytokine expression, many other signalling cascades are involved. It is therefore conceivable that antidepressants target other pathways that modulate cytokine expression. For example, it has been reported that fluoxetine may reduce Protein Kinase C (PKC) activity in lymphocytes (Edgar et al., 1998, 1999). PKC-activation is an important step in pro-inflammatory cytokine production (Kontny et al., 1999). Hence, it may be suggested that down-regulation of PKC mediates the inhibitory effect of antidepressants on pro-inflammatory cytokines. Recently, research has focused on the effects of antidepressants on glucocorticoid receptor functioning. Sustained hyperactivity 
of the HPA-axis in depressed patients probably results from reduced glucocorticoid receptor function, resulting in impaired negative feed-back regulation (Holsboer, 2000; Pariante and Miller, 2001). Several antidepressants potentiate glucocorticoid receptor signalling by inducing translocation of the receptor from cytoplasm to the nucleus, independent of the presence of glucocorticoids, and by enhancing glucocorticoid-induced gene transcription (Pariante et al., 1997, 2001, 2003; Okuyama-Tamura et al., 2003). Interestingly, glucocorticoids inhibit pro-inflammatory cytokine secretion (TNF- $\alpha$ and IFN- $\gamma$ ) and stimulate the production of anti-inflammatory cytokines (IL-10) (for review see Elenkov and Chrousos, 2002). Thus, it may be suggested that antidepressants modulate cytokine secretion by enhancing glucocorticoid mediated signalling.

\section{FUTURE DIRECTIONS}

It is clear that many intracellular pathways are possible targets for antidepressants. Rather then modulating all these pathways and seeing whether they reverse or enhance the effects of antidepressants, a more target-directed approach to find the pathways involved may be preferred. Micro-array technology offers a convenient tool for the simultaneous screening of a vast number of genes that are potentially up- or down-regulated following antidepressant treatment. Both acute and long-term effects (reflecting adaptive changes) on gene expression can be examined using gene expression arrays.

Still, the question remains how antidepressants modulate gene expression. The primary target of these drugs is probably not the genome itself. Rather, antidepressants induce changes in activity of kinases or transcription factors, or modulate the function of membrane-associated and intracellular receptors. These acute changes ultimately lead to altered gene-expression. A possible approach to examine effects of antidepressants on kinase activity is the use of phospho-specific antibodies that recognize (phosphorylated) substrates of specific kinases. Later, the proteins that are primarily activated by these kinases

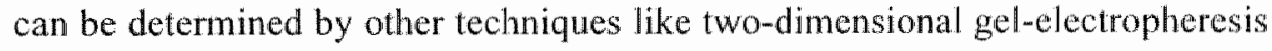
or mass-spectrometry.

These procedures offer a more appropriate tool to look for intracellular targets of antidepressants, and may give an answer to what signalling pathways are involved in the effects of antidepressants on cytokine synthesis. They will also render additional information on how other common adaptive changes that are relevant for antidepressant action, are established. Finally, the ability to modulate specific signalling pathways with more selective drugs may offer new and improved treatment approaches for major depression. 


\section{REFERENCES}

Bleeker MW, Netea MG, Kullberg BI, Van der Ven-Jongekrijg J, Van der Meer JW, (1997) The effects of dexamethasone and chlorpromazine on tumour necrosis factor-alpha, interleukin-1 beta, interleukin-1 receptor antagonist and interleukin-10 in human volunteers. Immunology 91: $548-552$.

Cloez-Tayarani I, Petit-Bertron AF, Venters HD, Cavaillon JM, (2003) Differential effect of serotonin on cytokine production in lipopolysaccharide-stimulated human peripheral blood mononuclear cells: inwolvement of 5-hydroxytryptamine2A receptors. Int Immunol 15: 233240 .

Connor TJ, Leonard BE, (1998) Depression, stress and immunological activation: the role of cytokines in depressive disorders. Life Sci 62: $583-606$.

Dantzer R, (2001) Cytokine-induced sickness behavior: where do we stand? Brain Behav Immwa $15: 7-24$.

De Groote D, Zangerle PF, Gevaert $Y$, Fassotte MF, Beguin $Y$, Noizat-Pireme F, Pirenne $J$, Gathy $R$, Lopez $M$, Dehart I, Igot D, Baudrihaye $M$, Delacroix $\mathbb{D}$, Franchimont $P,(1992)$ Direct stimulation of cytokines (IL-1b, TNF-a IL-6, IL-2, IFN-g and GM-CSF) in whole blood. 1. Comparison with isolated PBMC stimulation. Cylokine 4: 239-248.

Duman RS, Nakagawa S, Malberg J, (200 Regulation of adult neurogenesis by antidepressant treatment. Newropsychopharmacology $25: 836-844$.

Dunn Al, (2000) Cytokine activation of the HPA axis. Anr. N Y Acad Sci 917: 608-617.

Dunn AJ, Wang $J$, Ando $T$, (1999) Effects of cytokines on cerebral neurotransmission. Comparison with the effects of stress. Adv Exp Med Biol 461: $117-127$.

Edgar VA, Genaro AM, Cremaschi G, Sterin-Borda L, (1998) Fluoxetine action on murine Tlymphocyte proliferation: participation of $\mathrm{PKC}$ activation and calcium mobilisation. Cell Signal 10: 721-726.

Edgar VA, Sterin-Borda L, Cremaschi GA, Genaro AM, (1999) Role of protein kinase C and cAMP in fluoxetine effects on human T-cell proliferation. Eur J Pharmacol 372: 65-73.

Elenkov IJ, Chrousos GP, (2002) Stress hormones, proinflammatory and anti-inflammatory cytokines, and autoimmunity. Ann N Y Acad Sci 966:290-303.

Elenkov U, Wilder RL, Chrousos GP, Vizi ES, (2000) The sympathetic nerve - an integrative interface between wo supersystems: the brain and the immune system. Phamacol Rev 52: 5954638 .

Gordon J, Barnes NM, (2003) Lymphocytes transport serotonin and dopanine: agony or ecstasy? Trends lwmol 24: 438-443.

Hinze-Selch D, Becker EW, Stein GM. Berg PA, Mullington J, Holsboer F, Pollmacher T, (1998) Effects of clozapine on in vitro immune parameters: a longitudinal study in clozapine-treated schizophrenic patients. Neuropsychopharmacology 19: 114-122.

Holsboer fin, (2000) The corticosteroid receptor hypothesis of depression. Newropsychophamacology 23: 477-501.

Macobs BL, Praag H, Gage FH, (2000) Adult brain neurogenesis and psychiatry: a novel theory of depression. Mol Psychiatry 5: 262-269.

Kempermann G, Kronenberg G, (2003) Depressed new neurons--adult hippocampal neurogenesis and a cellular plasticity hypothesis of major depression. Biol Psychiatry 54: 499-503.

Kin DJ, Kim W, Yoon SJ, Go HJ, Choi BM, Jun TY, Kim YK, (2001) Effect of risperidone on serum cytokines. Im J Netrosei 11 1: 11-19.

Kim YK, Kin L, Lee MS, (2000) Relationships between interleukins, neurotransmitters and psychopathology in drug-liree male schizophrenics. Schizophr Res" 44: 165-175. 
Kontny E, Ziolkowska M, Ryzewska A, Maslinski W, (1999) Protein Kinase C-dependent pathway is critical for the production of pro-inflammatory oytokines (TNF-a, $\|L-1 b\| L-6$,$) .$ Cyokine $11: 839-848$.

Lin A-h, Song C, Kenis G, Bosmans E, De Jongh R, Scharpe S, Maes M. (2000) The in vitro immunosuppressive effects of moclobemide in healthy volunteers. Affect Disord 58: 69-74.

Maes M, Bosmans E, Kenis G, De Jong R, Smith RS, Meltzer HY, (1997) In vivo immunomodulatory effects of clozapine in schizophrenia. Schizoph" Res 26:221-225.

Maes M, Bosmans E, Suy E, Vandervorst C, De Jonckheere C. Raus $\mathbb{1}$, (1990) Immune disturbances during major depression: upregulated expression of interleukin-2 receptors. Newopsychobiology 24: 115-120.

Maes M, Lin A, Kenis G, Egyed B, Bosmans E, (2000) Negative immunoregulatory effects of noradrenaline through alpha2- adrenoceptor activation. Neuroendocrinol Let $21: 375-382$.

Maes M, Meltzer HY, Bosmans E, (1994) Immune-inflammatory markers in schizophrenia: comparison to nomal controls and effects of clozapine. Acta Psychiat Scand 89; 346-351.

Maes M, Song C, Lin A-h, Bonaccorso S, Kenis G, De Jongh R, Bosmans E, Scharpe S, (1999) Negative immunoregulatory effects of antidepressants: inhibition of interferon-g and stimulation of interleukin-10 secretion. Newropsychopharmacology 20:370-379.

Maier SF, Watkins LR, (1998) Cytokines for psychologists: implications of bidirectional immune-tom brain communication for understanding behavior, mood, and cognition. Psychol Rev 105: 83-107.

Malberg JE, Eisch AJ, Nestler EJ, Duman RS, (2000) Chronic antidepressant treatment increases neurogenesis in adult rat hippocampus. I Neurosci $20: 9104-9110$.

Monje ML, Toda H, Palmer TD, (2003) Inflammatory blockade restores adult hippocampal neurogenesis. Science 302; 1760-1765.

Monteleone P, Fabrazzo M, Tortorella A. Maj M, (1997) Plasma levels of interleukin-6 and tumor necrosis factor alpha in chronic schizophrenia: effects of clozapine treatment. Psychiatry Res $71: 11-17$.

Moots RJ, Al-Saffar Z, Hutchinson D, Golding SP, Young SP, Bacon PA, McLaughlin PJ, (1999) Old drug, new tricks: haloperidol inhibits secretion of proinflammatory cytokines. Am Rheum Dis: 58: 585-587.

Mossner $\mathbb{R}$, Lesch KP, (1998) Role of serotonin in the immune system and in neuroimmune interactions. Brain Behav Immun 12: 249-271.

Nibnya M, Nester EJ, Duman RS, (1996) Chronic antidepressant administration increascs the expression of CAMP response element binding protein (CREB) in rat hippocampus. J Neurosci 16: 2365-2372.

Okuyama-Tamura M, Mikuni M, Kojima 1, (2003) Modulation of the human glucoconticoid receptor function by antidepressive compounds. Neurosch Led 342:206-210.

Pariante CM, Kim RB, Makoff A, Kerwin RW, (2003) Antidepressant lluoxeline enhances glucocorticoid receptor function in vitro by modulating membrane steroid transporters. $\mathrm{Br} J$ Pharmacol 139:1111-1118.

Pariante CM, Makoff A, Lovestone S, Feroli S, Heyden A, Miller AH, Kerwin RW, (200\|) Antidepressiants enhance glucocorticoid receptor function in vitro by modulating the membrane steroid transporters. Br J Pharmacol 134: 1335-1343.

Pariante CM, Miller AH, (2001) Glucoconticoid receptors in major depression: relewance to pathophysiology and treatment. Biol Psychiatry 49:391-404.

Pariante CM, Pearce BD, Pisell TL, Owens MJ, Miller AH, (1997) Steroid-independent translocation of the glucocorticoid receptor by the antidepressant desipramine. Mot Pharmacol 52: $571-581$. 
Pollmacher T, Hadak M. Schuld A, Kraus T, Hinze-Selch D, (2000) Effects of antipsychotic drugs on cytokine networks. I Psychiar Res 34:369-382.

Polmacher T, Hinze-Selch D, Mullington J, (1996) Effects of clozapine on plasma cytokine and soluble cytokine receptor levels. J Ctin Psychophamacol 16:403-409.

Rudolf $S$, Peters M, Rothermundt $M$, Arolt $V$, Kirchner $H$, (2002) The influence of typical and atypical neuroleptic drugs in the production of interleukin-2 and interferon-gamma in vitro. Newropsychobiology $46: 180-185$.

Santarclli L, Saxe $M$, Gross $C$, Surget $A$, Battaglia $F$, Dulawa $S$, Weisstaub N, Lee $J$, Duman $R$, Arancio O, Belzung $\mathbb{C}$, Hen $\mathbb{R}$, (2003) Requirement of hippocampal neurogenesis for the behawioral effects of antidepressants. Science 301: 805 809.

Sluzewska A, Rybakowski JK, Laciak M, Mackiewicz A, Sobieska M, Wiktorowicz K, (1996) Interleukin-6 serum levels in depressed patients before and after treatment with fluoxetine. Anm N Y Acad Sci $762: 474-476$.

Smith RS, (1991) The macrophage theory of depression. Med Hypotheses 35: 298-306.

Song $C_{\text {, Lin }}$, Kenis $G_{3}$ Bosmans E, Maes M, (2000) Immunosuppressive effects of clozapine and balloperidol: enhanced production of the interleukin- 1 receptor antagonist. Schizophr Res 42: $157-164$.

Szelenyi J, (2001) Cytokines and the central nervous system. Brain Res Bull 54:329-338.

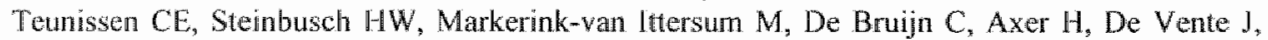
(2000) Whole brain spheroid cultures as a model to sudy the development of nitric oxide synthase-guanylate cyclase signal transduction. Brain Res Dev Brain Res 125: 99-115.

Vitkovic L, Bockaert J, Jacque C, (2000) "Inflammatory" cytokines" neuromodulators in normal brain? I Neurochem 74: 457-471.

Xia Z, DePierre JW, Nassberger L, (1996) Tricyclic antidepressants inhibit IL-6, IL-IB and TNF$\alpha$ release in human blood monocytes and $\mathrm{IL}-2$ and interferon- $\gamma$ in $T$ cells. Immunopharmacology 34:27-37.

Yaqoob P, Newsholme EA, Calder PC, (1999) Comparison of cytokine production in cultures of whole human blood and purified mononuclear cells. Cytokine 11: 600-605.

Zangerle PF, De Groote D, Lopez M, Meuleman RJ, Vrindts Y, Fauchet F, Dehart I, Jadoul M, Radoux D, Franchimont $\mathbb{P}$, (1992) Direct stimulation of cytokines (IL-1 beta, TNF-alpha, IL6, $1 \mathrm{~L}-2$, $\mathbb{F N}$-gamma and GM-CSF) in whole blood II. Application to rheumatoid arthritis and osteoarthritis. Cytokine 4: 568-575. 


\section{Summary}

Chapter 1 is a general introduction to this thesis and outlines the scientific background of the hypothesis and the presented experiments. Current views on the mechanism of action of antidepressants and the different antidepressant classes are briefly discussed. This is followed by an introduction to the following topics: cytokines and the immune system, the putative role of cytokines in the pathophysiology of major depression, and intracellular signalling through the cyclic AMP/Protein Kinase A (cAMP/PKA) pathway. The first part of the hypothesis states that antidepressants have antiinflammatory effects by inhibiting the production of pro-inflammatory cytokines and/or by stimulating that of anti-inflammatory cytokines. The second part states that these effects are mediated by the cAMP/PKA pathway.

Chapter 2 provides a review of the current literature concerning the effects of antidepressants on the production of cytokines. These effects have been examined in depressed patients before and after treatment with antidepressants, in animal models of depression, and in in-vitro experiments. The results of the human studies are not always conclusive. The methodological shortcomings underlying these inconsistencies are discussed. From animal experiments it is clear that tricyclic antidepressants have anti-inflammatory effects, while antidepressants of all classes have anti-inflammatory effects in-vitro.

In chapter 3 the stability of cytokines was examined using an accelerated stability testing protocol. We found that samples for the determination of interleukin-6 (IL-6), soluble IL-6 Receptor and CC 16 can be stored at $-20^{\circ} \mathrm{C}$ for a longer period of time (years). IL-10 is less stable at $-20^{\circ} \mathrm{C}$ and should be stored at $-70^{\circ} \mathrm{C}$.

In chapter 4 , the effects of several antidepressants (imipramine, venlafaxine and fluoxetine) and 5 hydroxytryptophan (5-HTP) on the production of interferon- $\gamma($ IFN- $\gamma)$ and IL-10 were examined. Wholle blood from healthy volunteers and treatment resistant depressed patients was stimulated with lipopolysaccharides (LPS) and phytohaemagglutinin (PHA). This stimulates white blood cells to produce cytokines. By incubating the blood in the presence or absence of antidepressants, one can examine the effects of these pharmacological agents on the cytokine network. All examined antidepressants and 5-HTP reduced the IFN- $\gamma / \mathrm{LL}-10$ production ratio, and, hence, have antiinflammatory effects.

Antidepressants clearly act on the central serotonergic system by inhibiting the reuptake of serotonin $(5-\mathrm{HT})$ or by stimulation of serotonergic receptors. White blood cells are also capable of synthesizing serotonin and express serotonergic 
receptors on their cell membrane. In order to examine whether serotonin mediates the effects of antidepressants on cytokine secretion, the effects of serotonergic agonists and antagonists on the production of cytokines in stimulated whole blood were explored in chapter 5. Stimulation of 5-HT1Areceptors (using flesinoxan) did not influence cytokine secretion. Both an agonist (m-chlorophenylpiperazine) and an antagonist (ritanserin) of 5-HT2A/C receptors reduced the IFN- $\gamma / \mathrm{IL}-10$ ratio. Serotonin itself also decreases the IFN- $\gamma /$ LL-10 ratio. Intracellular depletion of serotonin (using parachlorophenylalanine) inhibited both [FN- $\gamma$ and $\mathbb{I L}-10$ production. It is concluded that intracellular serotonin is necessary for the optimal production of IFN- $\gamma$ and IL-10 and that 5-HTIA receptors are not involved in the effects of antidepressants on cytokine production. Further, the reduction of the IFN- $\gamma / \mathrm{IL}-10$ ratio by 5 -HT was due to the inhibition of IFN- $\gamma$ secretion, while previous studies indicated that antidepressants predominantly increased the production of $1 \mathrm{~L}-10$. Therefore, it is concluded that the effects of antidepressants on cytokines are probably not mediated by serotonin.

In chapter 6, the effects of agonists and antagonists of the CAMP/PKA-pathway on in-vitro cytokine production are described. The major findings are that stimulation of adenylate cyclase decreases the production of IFN- $\gamma$, while it enhances that of IL-10. Stimulation of PKA inhibits both IFN- $\gamma$ and TNF- $\alpha$ production. Blocking of adenylate cyclase reduces the IFN- $\gamma$ and TNF- $\alpha$ secretion, while inhibition of PKA stimulates TNF- $\alpha$ and IL-10. We also examined the effects of rolipram on cytokine secretion. Rolipram is an inhibitor of phosphodiesterase type 4, and inhibits the breakdown of cAMP and, hence, increases intracellular cAMP-concentrations. Rolipram, which is also known as an antidepressant, inhibited the secretion of IFN- $\gamma$ and TNF- $\alpha$, and to a lesser extend also that of IL-10. However, rolipram reduced the IFN- $\gamma / \mathrm{LL}-10$ ratio, an effect that is comparable with that of other antidepressants. Clearly, in-vitro cytokine production is differentially affected by inhibitors and activators of the CAMP/PKA-pathway.

In chapter 7, we examined whether the effects of antidepressants on cytokine production are mediated by activation of the cAMP/PKA-pathway. Stimulated whole blood was incubated with paroxetine and imipramine in the presence or absence of SQ22536 (an inhibitor of adenylate cyclase) or Rp-8-Br-cAMPS (an inhibitor of PKA). We found that both paroxetine and imipramine reduced the secretion of TNF- $\alpha$, IFN- $\gamma$ and IL-10. Paroxetine also decreased the IFN- $\gamma / \mathrm{IL}$ 10 ratio. The effects of both antidepressants on TNF- $\alpha$ secretion was reversed by Rp-8-Br-cAMPS. Pre-incubation with SQ22536 had no effect. It is concluded that PKA mediates the effects of antidepressants on TNF- $\alpha$, but not the effects on IFN- $\gamma$ or IL-10. 
Chapter 8 presents results of the effects of antidepressants on CAMPconcentrations in white blood cells. Both antidepressants affected neither basal cAMP-concentrations nor those after stimulation with LPS and PHA.

The effects of antidepressants on the production of cytokines by brain cells has never been examined before. In chapter 9 , we used primary rat whole brain cell cultures to examine the effects imipramine on the production of IL-6, TNF- $\alpha$, and IL- 10 . The cultures consist of a three-dimensional network of differentiated neurons, astrocytes and microglia. In this way, one can examine the net effect of imipramine on cytokine secretion by all types of brain cells. Imipramine reduced the production of IL- 6 and TNF- $\alpha$. We concluded that imipramine inhibits pro-inflammatory cytokine production by brain cells, and, hence, that it may modulate cytokine expression in the brain.

In chapter 10, all the results presented in this thesis are critically discussed in the light of current views on the mechanism of action of antidepressants. 


\section{Samenvatting}

Hoofdstuk 1 is een algemene introductie en beschrijft de wetenschappelijke achtergrond van de hypothese en de uitgevoerde experimenten. Eerst wordt de huidige visie op de werkingsmechanismen van antidepressiva belicht. Daarna volgt een inleiding tot de volgende onderwerpen: cytokines en het immuunsysteem, de mogelijke rol van cytokines in de pathophysiologie van depressie, en intracellulaire signaaloverdracht via cyclisch AMP/Proteine Kinase A (cAMP/PKA). Het eerste deel van de hypothese luidt dat antidepressiva anti-inflammatoire effecten hebben door het remmen van proinflanmatoire cytokines en/of door het stimuleren van anti-inflammatoire cytokines. Het tweede deel stelt dat deze effecten gemedieerd worden door de cAMP/PKA-pathway.

Hoofdstuk 2 is een literatuuronderzoek betreffende de effecten van antidepressiva op de productie van cytokines. Deze effecten werden zowel in depressieve patiënten (voor en na behandeling met antidepressiva), in diermodellen van depressie, als in in-vitro experimenten onderzocht. De resultaten van de humane studies zijn niet eenduidig en de methodologische gebreken van deze studies worden besproken. Uit de diermodellen blijkt dat voornamelijk de tricyclische antidepressiva een anti-inflammatoir effect hebben, terwijl antidepressiva van alle klassen anti-inflammatoire eigenschappen vertonen in-vitro.

Hoofdstuk 3 beschrijft een versnelde stabiliteitsstudie van cytokines in serum. We kwamen tot de conclusie dat interleukine-6 (IL-6), de oplosbare IL-6 receptor en $\mathrm{CC} 16$ gedurende lange tijd (verschillende jaren) op $-20^{\circ} \mathrm{C}$ kunnen bewaard worden. IL-10 blijft maar enkele maanden stabiel bij $-20^{\circ} \mathrm{C}$ en wordt best bij $-70^{\circ} \mathrm{C}$ bewaard.

Met de experimenten beschreven in hoofdstuk 4 onderzochten we de effecten van verschillende antidepressiva (imipramine, venlafaxine en fluoxetine) en 5 hydroxy-tryptofaan (5-HTP) op de gestimuleerde productie van interferon- $\gamma$ (IFN- $\gamma$ ) en IL-10 in-vitro. Bloed van gezonde vrijwilligers en therapieresistente patiënten werd gestimuleerd met lipopolysacchariden (LPS) en phytohemagglutinine (PHA). Hierdoor worden de witte bloedcellen aangezet tot cytokine productie. Door het bloed zowel in aan- als afwezigheid van de antidepressiva te incuberen, krijgen we een idee van de effecten van deze farmacologische stoffen op het cytokine netwerk. Alle onderzochte antidepressiva en 5-HTP reduceren de IFN- $/$ /L-10 ratio, en hebben dus antiinflammatoire effecten. 
Antidepressiva beînvloeden het centrale serotonine systeem door het blokkeren van de heropname van serotonine of door stimulatie van serotonine receptoren. Witte bloedcellen synthetiseren serotonine en brengen serotonine receptoren tot expressie. Om na te gaan of serotonine betrokken is in het effect van antidepressiva op cytokine secretie, werd in hoofdstuk 5 gekeken naar de invloed van serotonine en agonisten/antagonisten van serotonine op de productie van cytokines. We gebruikten hiervoor gestimuleerd volbloed. Stimulatie van 5-HT1A-receptoren (met flesinoxan) heeft geen invloed op de secretie van cytokines. Zowel een agonist (m-chlorophenylpiperazine) als een antagonist (ritanserin) van $5-\mathrm{HT} 2 \mathrm{~A} / \mathrm{C}$ receptoren verlagen de $\mathrm{IFN}-\gamma / \mathrm{LL}-10$ ratio. Serotonine zelf verminderde de IFN- $\gamma /$ IL-10 ratio, net zoals antidepressiva. Intracellulaire depletie van serotonine (door incubatie met parachlorophenylalanine) onderdrukt de secretie van zowel IFN- $\gamma$ en IL-10. Uit deze experimenten besluiten we dat intracellulair serotonine noodzakelijk is voor een optimale productie van IFN- $\gamma$ en IL-10, en dat 5-HT1A receptoren niet betrokken zijn in de effecten van antidepressiva op cytokines. Verder is de reductie in de IFN- $\gamma / \mathrm{IL}-10$ ratio door serotonime voornamelijk te wijten aan een onderdrukking van de IFN- $\gamma$ productie, terwijl uit eerdere studies bleek dat antidepressiva voornamelijk de IL-10 stimuleren. Daarom werd besloten dat de effecten van antidepressiva op cytokines waarschijnlijk niet gemedieerd worden door serotonine.

Hoofdstuk 6 beschrijft de effecten van agonisten en antagonsiten van de cAMP/PKA-weg op de in-vitro cytokine productie. De belangrijkste bevindingen zijn dat stimulatie van adenylaat cyclase de secretie van IFN- $\gamma$ remt en deze van IL-10 stimuleert. PKA-activatie remt de productie van IFN- $\gamma$ en TNF $-\alpha$. Het blokkeren van adenylaat cyclase vermindert de IFN- $\gamma$ en TNF- $\alpha$ productie, terwijl inhibitie van PKA zowel TNF- $\alpha$ als IL-10 stimuleert. Bij deze experimenten werd ook het effect van de phosphodiesterase remmer rolipram onderzocht. Rolipram, wat ook een antidepressivum is, remt de afbraak van cAMP en verhoogt zo de intracellulaire cAMP-concentraties. Rolipram verminderde de secretie van IFN- $\gamma$ en TNF- $\alpha$, en in mindere mate deze van IL10. Net zoals andere antidepressiva verminderde rolipram de IFN- $\gamma / L$ L-10 ratio. Activatie of inhibitie van de CAMP/PKA-pathway heeft dus diverse effecten op de secretie van cytokines.

In hoofdstuk 7 werd nagegaan of de effecten van antidepressiva op de in-vitro cytokine secretie gerelateerd zijn aan activatie van de CAMP/PKA-pathway. Volbloed werd geîncubeerd met paroxetine of imipramine, telkens in aan- of afwezigheid van SQ22536 (een remmer van adenylaat cyclase), of Rp-8-BrcAMPS (een inhibitor van PKA). We vonden dat paroxetine en imipramine de productie van TNF- $\alpha$, IFN- $\gamma$ en IL-10 reduceerden, warbij paroxetine ook de IFN- $\gamma /$ IL-10 reduceerde. De effecten van beide antidepressiva op TNF- $\alpha$ 
secretie werd tegengegaan door pre-incubatie met Rp-8-Br-cAMPS. Dit was niet het geval met de andere cytokines. Pre-incubatie met SQ22536 had geen effect. PKA medieert dus de effecten van antidepressiva op TNF- $\alpha$, maar niet op deze van andere cytokines.

Hoofdstuk 8 geeft de resultaten weer van de effecten van antidepressiva op cAMP-concentraties in witte bloedcellen. Er was geen effect van paroxetine en imipramine op de basale en de gestimuleerde cAMP-concentraties.

De effecten van antidepressiva op cytokine productie in hersencellen werd nog nooit onderzocht. In hoofdstuk 9 maakten we gebruik van een primaire cultuur van foetale rat hersencellen om de effecten van imipramine op IL-6, TNF $-\alpha$ en IL-10 na te gaan. Het voordeel van een dergelijke cultuur is dat er macroscopische sferen, bestaande uit gedifferentieerde astrocyten, microglia en neuronen gevormd worden. Dit lat ons toe om het effect van imipramine op alle celtypen zoals ze in de hersenen voorkomen te onderzoeken. Imipramine verminderde de productie van IL-6 en TNF- $\alpha$, maar niet deze van IL-10. We besluiten hieruit dat imipramine de productie van pro-inflammatoire cytokines door hersencellen remt, en dat imipramine dusdanig de secretie van cytokines in de hersenen kan beînvloeden.

In hoofdstuk 10 worden de resultaten uit de verschillende hoofdstukken kritisch besproken. Hierbij worden de resultaten ook besproken in het licht van andere gangbare hypothesen betreffende de werkingsmechanismen van antidepressiva. 


\section{Dankwoord}

Dagelijks kom je wel mensen tegen die je, op welke manier dan ook, een steun geven in je bezigheden, zij het bij het schrijven van een proefschrift, je familiale aangelegenheden, je vrijetijdsbesteding of gewoon je mens zijn.

Zo zijn er dus ook personen die helemaal niets met dit proefschrift te maken hebben, maar die toch een enorme steun hebben gegeven. Daarom wil ik dan ook jedereen bedanken die ik de voorbije jaren heb ontmoet en me op een of andere manier de moed hebben gegeven om door te zetten.

Graag bedank ik mijn promotoren Prof. Michael Maes en Prof. Harry Steinbusch en mijn co-promotor Dr. Marc De Baets. Michael, onze samenwerking dateert al van 1996 . Ik was altijd geboeid door je onderzoek over cytokines en psychiatrische stoornissen. Dank je om me het vertrouwen te geven om dit project bij jou uit te voeren. Harry, bedankt voor je advies en sturing, en vooral voor je steun en hulp bij de afronding van dit project. Marc, bedankt voor al je suggesties i.w.m. de experimenten en de manuscripten, en om me over de eindmeet te helpen.

Verder wil ik graag alle personen bedanken die me geholpen hebben bij de experimenten, in het bijzonder Marjanne Markering voor de cAMP-metingen en sferoïde-culturen, en Belinda Egyed voor de cytokine metingen.

Eugène Bosmans ben ik zeer dankbaar voor het advies en de ondersteuning bij de cytokine bepalingen. Dank zij hem werd mijn interesse voor het wetenschappelijk onderzoek aangescherpt.

I would also like to thank Dr. Marta Kubera, Dr. Aye-Mu Myint and Prof. Brian Leonard. Marta, thanks for the fruitful collaboration over the past years.

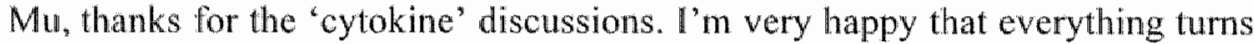
out fine for you. Good luck with your thesis! Prof. Leonard, many thanks for your support, helpful suggestions and especially the inspiring discussions.

Op de afdeling neurowetenschappen is er altijd een leuke sfeer en ik wil daarvoor alle medewerkers van harte danken. Yasin, Daniël en Cindy, (ex-)kamergenoten en collega AIO's, dank voor de leuke gesprekken en de gezelligheid. Veel succes met jullie promotie! Nicole, Hellen, Akke, Wiel, jullie staan altijd klaar om iedereen met allerlei kleine belangrijke dingetjes te helpen. Hartelijk dank! Charlotte Teunissen en Jos Prickaerts, ex-collega's, fijn om met jullie gewerkt te hebben. Charlotte, bedankt voor de sferoïden. Jos, dank voor de gestresste ratten. Ik kijk uit naar onze toekomstige samenwerking! 
Marjanne en Marieke, hartstikke leuk dat jullie mijn paranimfen wilden zijn. Marjanne, dank voor al je hulp bij de experimenten en bij de voorbereidingen van deze promotie, en zeker voor de opkrikkende babbeltjes tussendoor. Marieke, onze discussies over cytokines, depressie en alle andere dingen zijn zeer leerrijk, evenals onze gesprekken over het harde AlO leven. Dank je voor al je hulp bij de voorbereidingen van dit boekje en de promotie. Ik wens je veel succes bij het afronden van jouw promotie!

Een leuke familie is natuurlijk ook een enorme steun. Bedankt allemaal! En, ja hoor, nu is het eindelijk af

Mama en papa, dank voor jullie onvoorwaardelijke steun en begrip. Dank om me te laten studeren. Dank voor al jullie hulp. Bedankt voor alles!

Hannelore en Joachim, met jullie is onze thuis een echt gezin. Dank je om zo goed woor Ana te zorgen als ik weer eens aan dit boekje moest werken!

Leen, mijn liefste, zonder jouw steun was dit allemaal nooit gelukt. Bedankt voor je geduld en om er altijd voor me te zijn!

Ana, mijn kleine schat, je glimlach en stralende oogjes brengen oneindig veel vreugde. Als ik naar je kijk, of we lezen samen een boekje, dan geef je papa zoveel rust en voldoening. Een berg wordt dan een heuveltje. 